\title{
Thermochemical Ethanol via Indirect Gasification and Mixed Alcohol Synthesis of Lignocellulosic Biomass
}

Technical Report NREL/TP-510-41168 April 2007

S. Phillips, A. Aden, J. Jechura, and D. Dayton National Renewable Energy Laboratory

T. Eggeman

Neoterics International, Inc. 


\section{Thermochemical Ethanol via Indirect Gasification and Mixed Alcohol Synthesis of Lignocellulosic Biomass}

S. Phillips, A. Aden, J. Jechura, and D. Dayton National Renewable Energy Laboratory

T. Eggeman

Neoterics International, Inc.

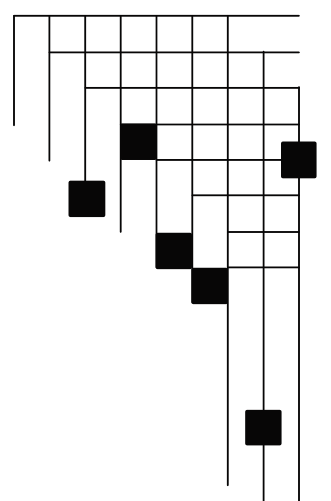

Prepared under Task No. BB07.3710 


\section{NOTICE}

This report was prepared as an account of work sponsored by an agency of the United States government. Neither the United States government nor any agency thereof, nor any of their employees, makes any warranty, express or implied, or assumes any legal liability or responsibility for the accuracy, completeness, or usefulness of any information, apparatus, product, or process disclosed, or represents that its use would not infringe privately owned rights. Reference herein to any specific commercial product, process, or service by trade name, trademark, manufacturer, or otherwise does not necessarily constitute or imply its endorsement, recommendation, or favoring by the United States government or any agency thereof. The views and opinions of authors expressed herein do not necessarily state or reflect those of the United States government or any agency thereof.

Available electronically at http://www.osti.gov/bridge

Available for a processing fee to U.S. Department of Energy and its contractors, in paper, from:

U.S. Department of Energy

Office of Scientific and Technical Information

P.O. Box 62

Oak Ridge, TN 37831-0062

phone: 865.576 .8401

fax: 865.576 .5728

email: mailto:reports@adonis.osti.gov

Available for sale to the public, in paper, from:

U.S. Department of Commerce

National Technical Information Service

5285 Port Royal Road

Springfield, VA 22161

phone: 800.553.6847

fax: 703.605.6900

email: orders@ntis.fedworld.gov

online ordering: http://www.ntis.gov/ordering.htm 


\section{Executive Summary}

This work addresses a policy initiative by the Federal Administration to apply United States Department of Energy (DOE) research to broadening the country's domestic production of economic, flexible, and secure sources of energy fuels. President Bush stated in his 2006 State of the Union Address: "America is addicted to oil." To reduce the Nation's future demand for oil, the President has proposed the Advanced Energy Initiative which outlines significant new investments and policies to change the way we fuel our vehicles and change the way we power our homes and businesses. The specific goal for biomass in the Advanced Energy Initiative is to foster the breakthrough technologies needed to make cellulosic ethanol cost-competitive with corn-based ethanol by 2012 .

In previous biomass conversion design reports by the National Renewable Energy Laboratory (NREL), a benchmark for achieving production of ethanol from cellulosic feedstocks that would be "cost competitive with corn-ethanol" has been quantified as $\$ 1.07$ per gallon ethanol minimum plant gate price.

This process design and technoeconomic evaluation addresses the conversion of biomass to ethanol via thermochemical pathways that are expected to be demonstrated at the pilot-unit level by 2012. This assessment is unique in its attempt to match up:

- Currently established and published technology.

- Technology currently under development or shortly to be under development from DOE Office of Biomass Program funding.

- Biomass resource availability in the 2012 time frame consistent with the Billion Ton Vision study.

Indirect steam gasification was chosen as the technology around which this process was developed based upon previous technoeconomic studies for the production of methanol and hydrogen from biomass. The operations for ethanol production are very similar to those for methanol production (although the specific process configuration will be different). The general process areas include: feed preparation, gasification, gas cleanup and conditioning, and alcohol synthesis \& purification.

The cost of ethanol as determined in this assessment was derived using technology that has been developed and demonstrated or is currently being developed as part of the OBP research program. Combined, all process, market, and financial targets in the design represent what must be achieved to obtain the reported $\$ 1.01$ per gallon, showing that ethanol from a thermochemical conversion process has the possibility of being produced in a manner that is "cost competitive with corn-ethanol" by 2012. This analysis has demonstrated that forest resources can be converted to ethanol in a cost competitive manner. This allows for greater flexibility in converting biomass resources to make stated volume targets by 2030 . 


\section{Table of Contents}

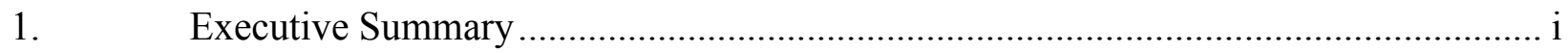

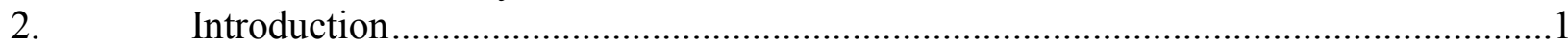

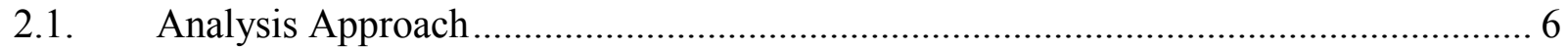

2.2. Process Design Overview …………………….............................................. 10

2.3. Feedstock and Plant Size ……….................................................................. 12

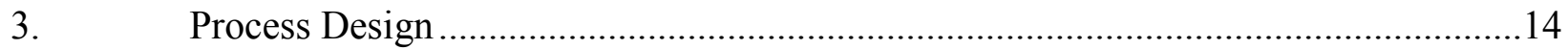

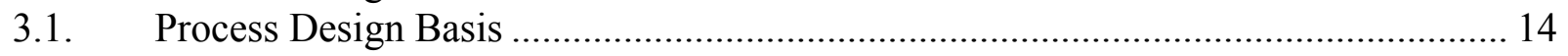

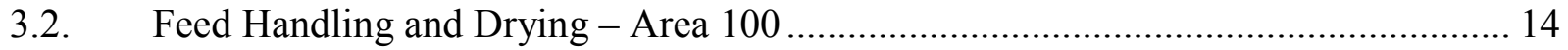

3.3. Gasification - Area 200 ..................................................................................... 15

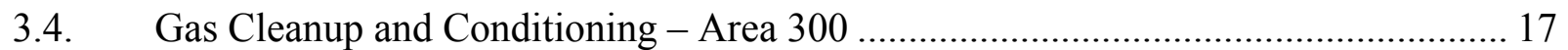

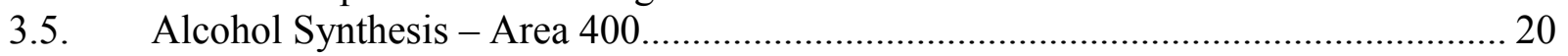

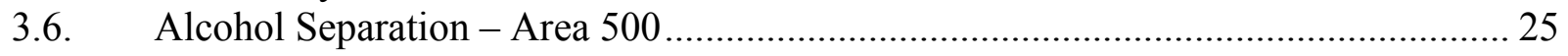

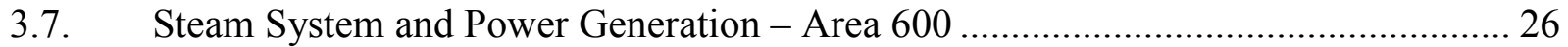

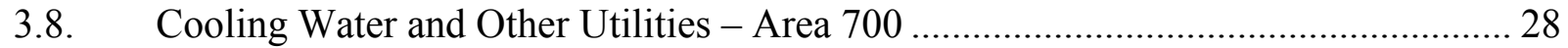

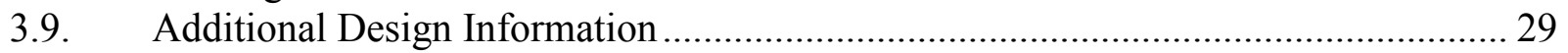

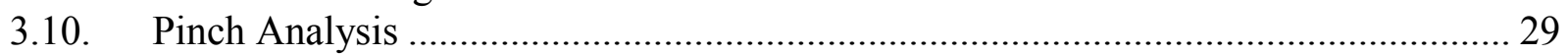

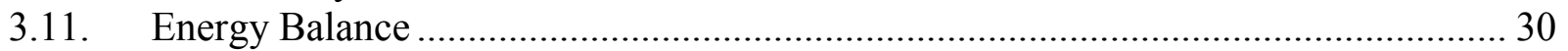

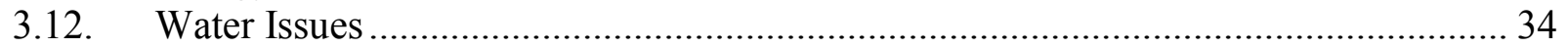

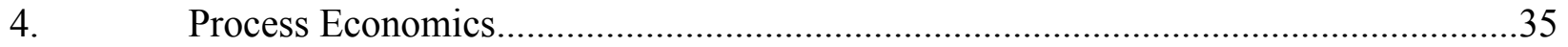

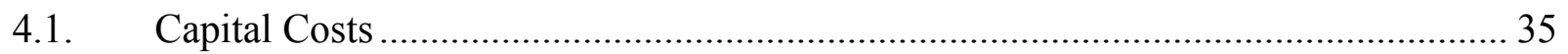

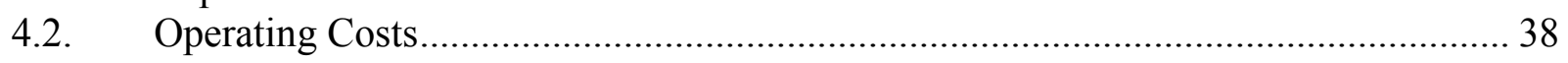

4.3. Value of Higher Alcohol Co-Products...................................................................... 41

4.4. Minimum Ethanol Plant Gate Price .......................................................................... 42

5. Process Economics, Sensitivity Analyses, and Alternate Scenarios............................43

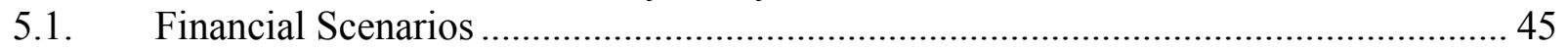

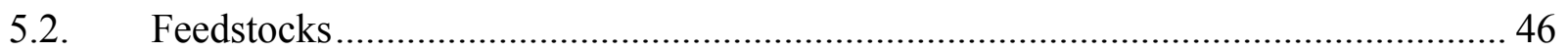

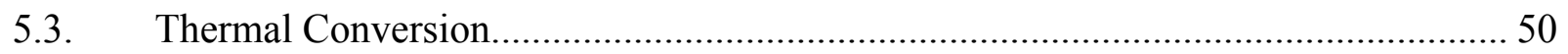

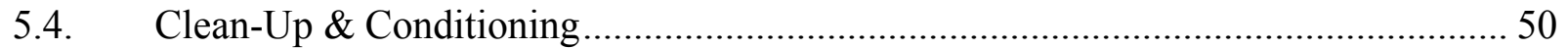

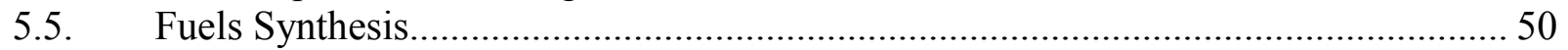

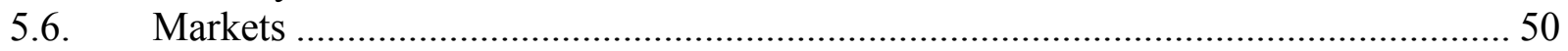

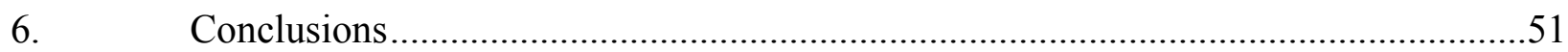

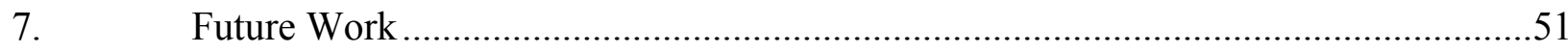

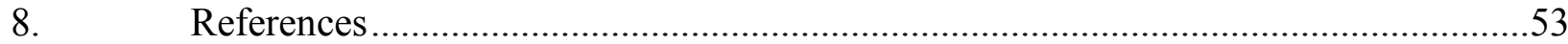




\section{List of Figures}

Figure 1. U.S. list prices for ethanol................................................................................. 2

Figure 2. Estimated capital intensities for biomass-to-methanol processes ................................. 5

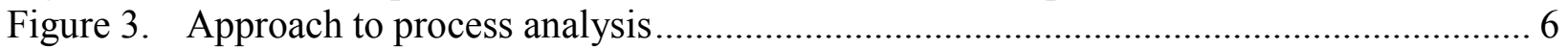

Figure 4. Chemical Engineering Magazine's plant cost indices ................................................ 9

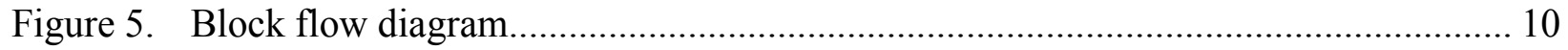

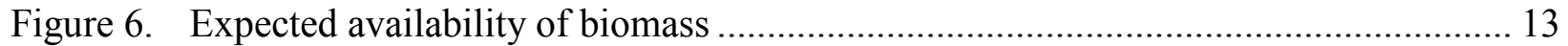

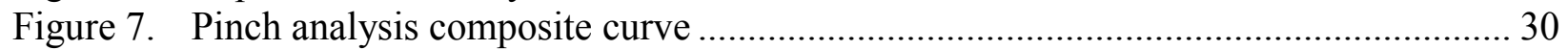

Figure 8. Cost contribution details from each process area ………………………….............. 43

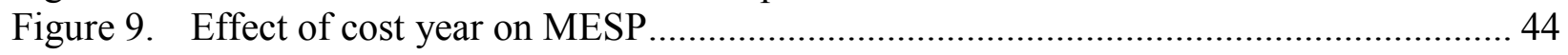

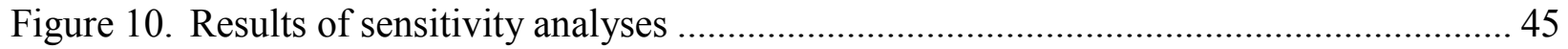

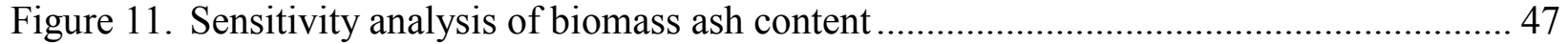

Figure 12. Sensitivity analysis of biomass moisture content ............................................... 48

Figure 13. Sensitivity analysis of raw syngas diverted for heat and power due to biomass moisture content

\section{List of Tables}

Table 1. Chemical Engineering Magazine's Plant Cost Indices............................................... 8

Table 2. Ultimate Analysis of Hybrid Poplar Feed................................................................. 13

Table 3. Gasifier Operating Parameters, Gas Compositions, and Efficiencies.......................... 16

Table 4. Current and Target Design Performance of Tar Reformer ........................................ 17

Table 5. Target Design Tar Reformer Conditions and Outlet Gas Composition........................ 18

Table 6. Process Conditions for Mixed Alcohols Synthesis ...................................................... 21

Table 7. System of Reactions for Mixed Alcohol Synthesis .................................................... 23

Table 8. $\quad$ Mixed Alcohol Reaction Performance Results .......................................................... 23

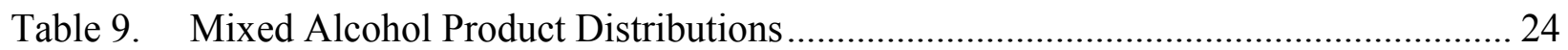

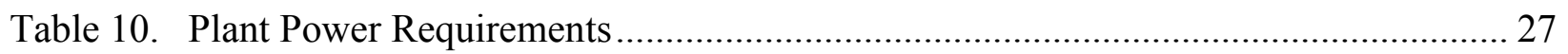

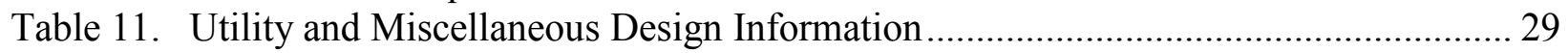

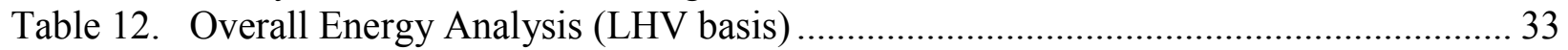

Table 13. Process Water Demands for Thermochemical Ethanol ................................................ 34

Table 14. General Cost Factors in Determining Total Installed Equipment Costs...................... 35

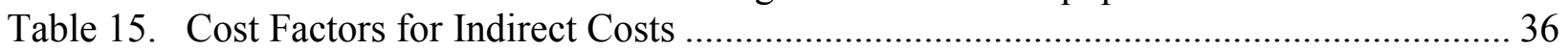

Table 16. Feed Handling \& Drying and Gasifier \& Gas Clean Up Costs from the Literature Scaled to 2,000 tonne/day plant ............................................................................. 36

Table 17. System Design Information for Gasification References ......................................... 37

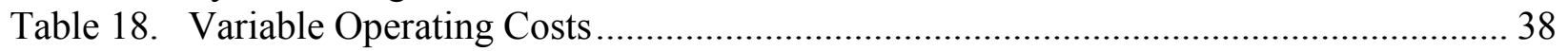

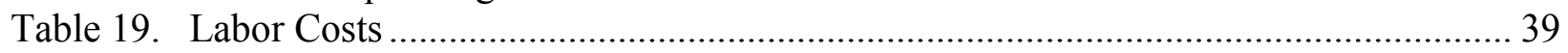

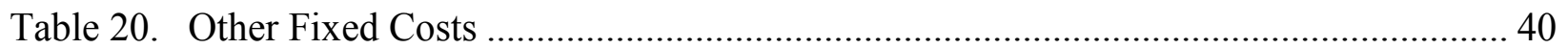

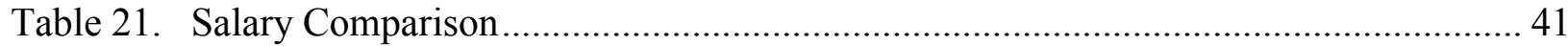

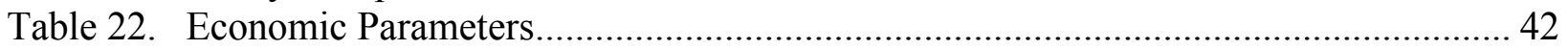




\section{Introduction}

This work addresses a policy initiative by the Federal Administration to apply United States Department of Energy (DOE) research to broadening the country's domestic production of economic, flexible, and secure sources of energy fuels. President Bush stated in his 2006 State of the Union Address: "America is addicted to oil." [1] To reduce the Nation's future demand for oil, the President has proposed the Advanced Energy Initiative [2] which outlines significant new investments and policies to change the way we fuel our vehicles and change the way we power our homes and businesses. The specific goal for biomass in the Advanced Energy Initiative is to foster the breakthrough technologies needed to make cellulosic ethanol costcompetitive with corn-based ethanol by 2012.

In previous biomass conversion design reports by the National Renewable Energy Laboratory (NREL), a benchmark for achieving production of ethanol from cellulosic feedstocks that would be "cost competitive with corn-ethanol" has been quantified as $\$ 1.07$ per gallon ethanol minimum plant gate price [3] (where none of these values have been adjusted to a common cost year). The value can be put in context with the historic ethanol price data as shown in Figure 1 [4]. The \$1.07 per gallon value represents the low side of the historical fuel ethanol prices. Given this historical price data, it is viewed that cellulosic ethanol would be commercially viable if it was able to meet a minimum return on investment selling at this price.

This is a cost target for this technology; it does not reflect NREL's assessment of where the technology is today. Throughout this report, two types of data will be shown: results which have been achieved presently in a laboratory or pilot plant, and results that are being targeted for technology improvement several years into the future. Only those targeted for the 2012 timeframe are included in this economic evaluation. Other economic analyses that attempt to reflect the current "state of technology" are not presented here. 


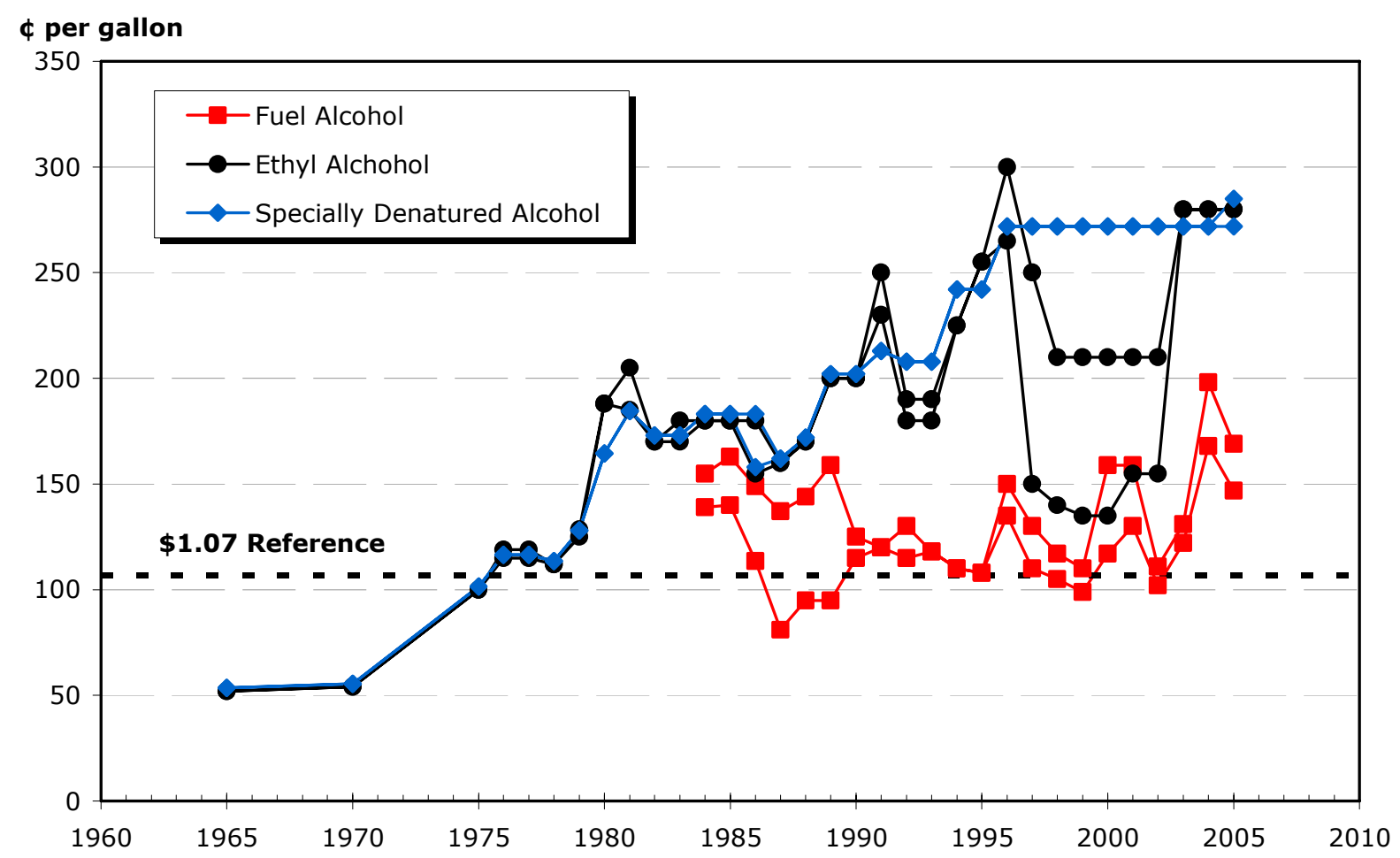

Figure 1. U.S. list prices for ethanol ${ }^{a}$

Conceptual process designs and associated design reports have previously been done by NREL for converting cellulosic biomass feedstock to ethanol via Biochemical pathways. Two types of biomass considered have been yellow poplar [5] and corn stover. [3] These design reports have been useful to NREL and DOE program management for two main reasons. First of all, they enable comparison of research and development projects. A conceptual process design helps to direct research by establishing a benchmark to which other process configurations can be compared. The anticipated results of proposed research can be translated into design changes; the economic impact of these changes can then be determined and this new design can be compared to the benchmark case. Following this procedure for several proposed research projects allows DOE to make competitive funding decisions based on which projects have the greatest potential to lower the cost of ethanol production. Complete process design and economics are required for such comparisons because changes in performance in one research area may have significant impacts in other process areas not part of that research program (e.g., impacts in product recovery or waste treatment). The impacts on the other areas may have significant and unexpected impacts on the overall economics.

Secondly, they enable comparison of ethanol production to other fuels. A cost of production has also been useful to study the potential ethanol market penetration from technologies to convert lignocellulosic biomass to ethanol. The cost estimates developed must be consistent with

\footnotetext{
a The curve marked "Ethyl Alcohol" is for 190 proof, USP, tax-free, in tanks, delivered to the East Coast. That marked "Specially Denatured Alcohol" is for SDA 29, in tanks, delivered to the East Coast, and denatured with ethyl acetate. That marked "Fuel Alcohol" is for 200 proof, fob works, bulk, and denatured with gasoline.
} 
applicable engineering, construction, and operating practices for facilities of this type. The complete process (including not only industry-standard process components but also the newly researched areas) must be designed and their costs determined.

Following the methodology of the biochemical design reports, this process design and technoeconomic evaluation addresses the conversion of biomass to ethanol via thermochemical (TC) pathways that are expected to be demonstrated at the pilot-unit level by 2012. This assessment is unique in its attempt to match up:

- Currently established and published technology.

- Technology currently under development or shortly to be under development from DOE Office of Biomass Program (OBP) funding. (See Appendix B for these research targets and values.)

- Biomass resource availability in the 2012 time frame consistent with the Billion Ton Vision study [6].

This process design and associated report provides a benchmark for the Thermochemical Platform just as the Aden et al. report [3] has been used as a benchmark for the Biochemical Platform since 2002. It is also complementary to gasification-based conversion assessments done by NREL and others. This assessment directly builds upon an initial analysis for the TC production of ethanol and other alcohol co-products [7, 8], which, in turn, was based upon a detailed design and economic analysis for the production of hydrogen from biomass.[9] This design report is also complementary to other studies being funded by the DOE OBP, including the RBAEF (Role of Biomass in America's Energy Future) study [10]. However, the RBAEF study differs in many ways from this study. For example, RBAEF is designed for a further time horizon than 2012. It is based on a different feedstock, switchgrass, and it considers a variety of thermochemical product options, including ethanol, power and Fischer-Tropsch liquids [11]. Other notable gasification studies have been completed by Larsen at Princeton University, including a study examining the bioproduct potential of Kraft mill black liquor based upon gasification [12].

Indirect steam gasification was chosen as the technology around which this process was developed based upon previous technoeconomic studies for the production of methanol and hydrogen from biomass [13]. The sub-process operations for ethanol production are very similar to those for methanol production (although the specific process configuration will be different). The general process areas include: feed preparation, gasification, gas cleanup and conditioning, and alcohol synthesis \& purification.

Gasification involves the devolatilization and conversion of biomass in an atmosphere of steam and/or oxygen to produce a medium-calorific value gas. There are two general classes of gasifiers. Partial oxidation (POX) gasifiers (directly-heated gasifiers) use the exothermic reaction between oxygen and organics to provide the heat necessary to devolatilize biomass and to convert residual carbon-rich chars. In POX gasifiers, the heat to drive the process is generated internally within the gasifier. A disadvantage of POX gasifiers is that oxygen production is expensive and typically requires large plant sizes to improve economics [14]. 
The second general class, steam gasifiers (indirectly-heated gasifiers), accomplish biomass heating and gasification through heat transfer from a hot solid or through a heat transfer surface. Either byproduct char and/or a portion of the product gas can be combusted with air (external to the gasifier itself) to provide the energy required for gasification. Steam gasifiers have the advantage of not requiring oxygen; but since most operate at low pressure they require product gas compression for downstream purification and synthesis unit operations. The erosion of refractory due to circulating hot solids in an indirect gasifier can also present some potential operational difficulties.

A number of POX and steam gasifiers are under development and have the potential to produce a synthesis gas suitable for liquid fuel synthesis. These gasifiers have been operated in the 4 to 350 ton per day scale. The decision as to which type of gasifier (POX or steam) will be the most economic depends upon the entire process, not just the cost for the gasifier itself. One indicator for comparing processes is "capital intensity," the capital cost required on a per unit product basis. Figure 2 shows the capital intensity of methanol processes $[15,16,17,18,19,20]$ based on indirect steam gasification and direct POX gasification. This figure shows that steam gasification capital intensity is comparable or lower than POX gasification. The estimates indicate that both steam gasification and POX gasification processes should be evaluated, but if the processes need to be evaluated sequentially, choosing steam gasification for the first evaluation is reasonable. 


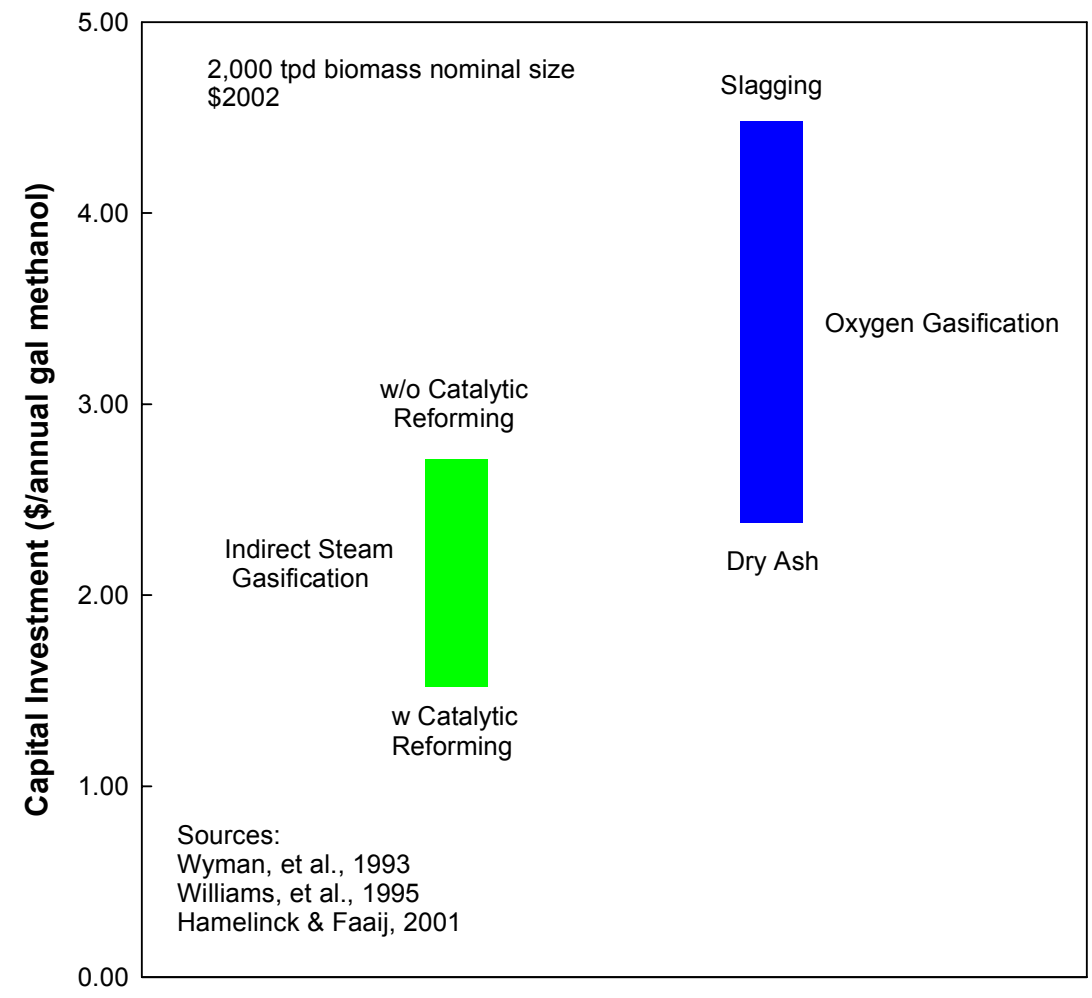

Figure 2. Estimated capital intensities for biomass-to-methanol processes

Another philosophy applied to the process development was the idea to make the process energy self-sufficient. It was recognized that the heat and power requirements of the process could not be met just with char combustion and would require additional fuel. Several options were considered. Additional biomass could be added as fuel directly to the heat and power system, however, this would increase the process beyond 2,000 tonne/day. Fossil fuels (coal or natural gas) could also be added directly to provide the additional fuel. Alternately syngas could be diverted from liquid fuel production to heat and power production. This option makes the design more energy self-sufficient, but also lowers the overall process yield of alcohols.

It was decided that (1) no additional fuel would be used for heat and power and (2) only enough syngas would be diverted so that the internal heat and power requirements would be exactly met. Thus, there would neither be electricity sales to the grid nor electricity purchases. The only exception to this would be if other operating specifications were such that syngas could no longer be backed out of the heat and power system but there is still excess electricity (that could then be sold to the grid for a co-product credit). This resulted in $28 \%$ of the unconditioned syngas being diverted to power the process. Model calculations show that if none of the syngas was diverted in this manner, and all of it was used for mixed alcohols production, the ethanol and higher alcohols yields would increase by $38 \%$. Thus, the baseline ethanol yield of $80.1 \mathrm{gal} / \mathrm{dry}$ ton could rise as high as $110.9 \mathrm{gal} /$ ton, with total production of all alcohols as high as 130.3 
gal/dry ton. However, the minimum ethanol plant gate price increases in this scenario because of the cost of the natural gas required to meet the energy demands of the process.

\subsection{Analysis Approach}

The general approach used in the development of the process design, process model, and economic analysis is depicted in Figure 3. The first step was to assemble a general process flow schematic or more detailed process flow diagrams (PFDs). (See Appendix H for the associated PFDs for this design). From this, detailed mass and energy balance calculations were performed around the process. For this design, Aspen Plus software was used. Data from this model was then used to properly size all process equipment and fully develop an estimate of capital and operating costs. These costs could have potentially been used in several types of economic analysis. For this design however, a discounted cash flow rate of return (DCFROR) analysis was used to determine the ethanol minimum plant gate price necessary to meet an $\mathrm{n}^{\text {th }}$ plant hurdle rate (IRR) of $10 \%$.

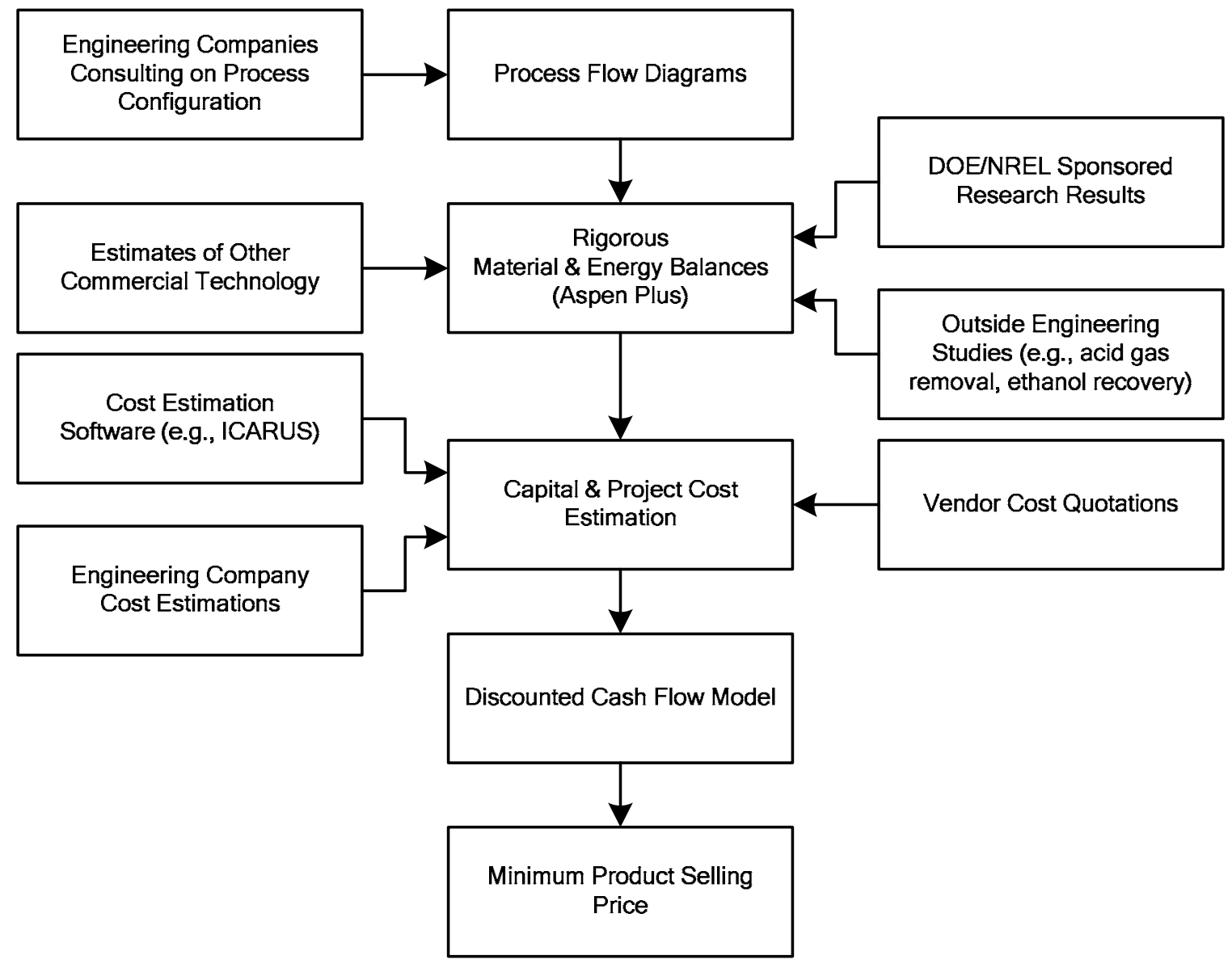

Figure 3. Approach to process analysis 
This TC conversion process was developed based upon NREL experience performing conceptual designs for biomass conversion to ethanol via biochemical means [3], biopower applications, and biomass gasification for hydrogen production.[9] Specific information for potential subprocesses were obtained as a result of a subcontract with Nexant Inc. [21, 22, 23, 24]

Aspen Plus version 2004.1 was used to determine the mass and energy balances for the process. The operations were separated into seven major HIERARCHY areas:

- Feed Handling and Drying (Area 100)

- Gasification (Area 200)

- Cleanup and Conditioning (Area 300)

- Alcohol Synthesis (Area 400)

- Alcohol Separation (Area 500)

- Steam Cycle (Area 600)

- Cooling Water (Area 700)

Overall, the Aspen simulation consists of about 300 operation blocks (such as reactors, flash separators, etc.), 780 streams (mass, heat, and work), and 65 control blocks (design specs and calculator blocks). Many of the gaseous and liquid components were described as distinct molecular species using Aspen's own component properties database. The raw biomass feedstock, ash, and char components were modeled as non-conventional components. There was more detail and rigor in some blocks (e.g., distillation columns) than others (e.g., conversion extent in the alcohol synthesis reactor). Because this design processes three different phases of matter (solid phase, gas phase, and liquid phase), no single thermodynamics package was sufficient. Instead, four thermodynamics packages were used within the Aspen simulation to give more appropriate behavior. The "RKS-BM" option was used throughout much of the process for high temperature, high pressure phase behavior. The non-random two-liquid "NRTL" option with ideal gas properties was used for alcohol separation calculations. The 1987 Steam Table properties were used for the steam cycle calculations. Finally, the ELECNRTL package was used to model the electrolyte species potentially present within the quench water system.

The process economics are based on the assumption that this is the "nth" plant, meaning that several plants using this same technology will have already been built and are operating. This means that additional costs for risk financing, longer start-ups, and other costs associated with first-of-a-kind plants are not included.

The capital costs were developed from a variety of sources. For some sub-processes that are well known technology and can be purchased as modular packages (i.e. amine treatment, acid gas removal), an overall cost for the package unit was used. Many of the common equipment items (tanks, pumps, simple heat exchangers) were costed using the Aspen Icarus Questimate costing software. Other more specific unit operations (gasifier, molecular sieve, etc) used cost estimates from other studies and/or from vendor quotes. As documented in the hydrogen design report [9], the installed capital costs were developed using general plant-wide factors. The installation costs incorporated cost contributions for not only the actual installation of the purchased equipment but also instrumentation and controls, piping, electrical systems, buildings, yard improvements, etc. These are also described in more detail in Section 3. 
The purchased component equipment costs reflect the base case for equipment size and cost year. The sizes needed in the process may actually be different than what was specifically designed. Instead of re-costing in detail, an exponential scaling expression was used to adjust the bare equipment costs:

$$
\text { New Cost }=(\text { Base Cost })\left(\frac{\text { New Size }}{\text { Base Size }}\right)^{n}
$$

where $n$ is a characteristic scaling exponent (typically in the range of 0.6 to 0.7 ). The sizing parameters are based upon some characteristic of the equipment related to production capacity, such as inlet flow or heat duty in a heat exchanger (appropriate if the log-mean temperature difference is known not to change greatly). Generally these related characteristics are easier to calculate and give nearly the same result as resizing the equipment for each scenario. The scaling exponent $n$ can be inferred from vendor quotes (if multiple quotes are given for different sizes), multiple estimates from Questimate at different sizes, or a standard reference (such as Garrett, [25] Peters and Timmerhaus, [26] or Perry et al. [27]).

Since a variety of sources were used, the bare equipment costs were derived based upon different cost years. Therefore, all capital costs were adjusted with the Chemical Engineering (CE) magazine's Plant Cost Index [28] to a common basis year of 2005:

$$
\text { New Cost }=(\text { Base Cost })\left(\frac{\text { Cost Index in New Year }}{\text { Cost Index in Base Year }}\right) \text {. }
$$

The CE indices used in this study are listed in Table 1 and depicted in Figure 4. Notice that the indices were very nearly the same for 2000 to 2002 (essentially zero inflation) but take a very sharp increase after 2003 (primarily due a run-up in worldwide steel prices).

Table 1. Chemical Engineering Magazine's Plant Cost Indices

\begin{tabular}{|c|c|c|c|}
\hline Year & Index & Year & Index \\
\hline 1990 & 357.6 & 1998 & 389.5 \\
\hline 1991 & 361.3 & 1999 & 390.6 \\
\hline 1992 & 358.2 & 2000 & 394.1 \\
\hline 1993 & 359.2 & 2001 & 394.3 \\
\hline 1994 & 368.1 & 2002 & 395.6 \\
\hline 1995 & 381.1 & 2003 & 402.0 \\
\hline 1996 & 381.7 & 2004 & 444.2 \\
\hline 1997 & 386.5 & 2005 & 468.2 \\
\hline
\end{tabular}


Chemical Engineering Plant Cost Index

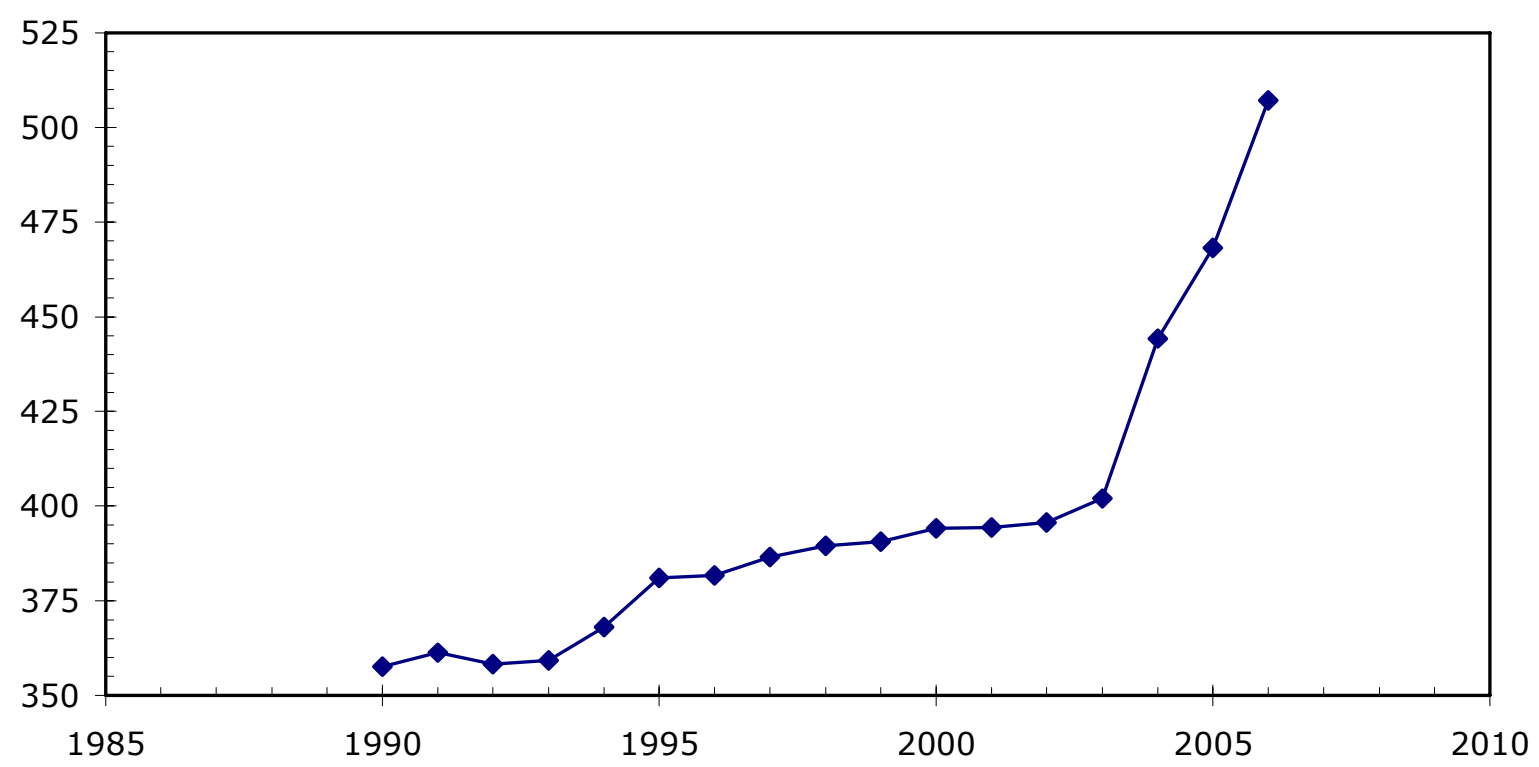

Figure 4. Chemical Engineering Magazine's plant cost indices

Once the scaled, installed equipment costs were determined, we applied overhead and contingency factors to determine a total plant investment cost. That cost, along with the plant operating expenses (generally developed from the ASPEN model's mass and energy balance results) was used in a discounted cash flow analysis to determine the ethanol plant gate price, using a specific discount rate. For the analysis done here, the ethanol minimum plant gate price is the primary value used to compare alternate designs. 


\subsection{Process Design Overview}

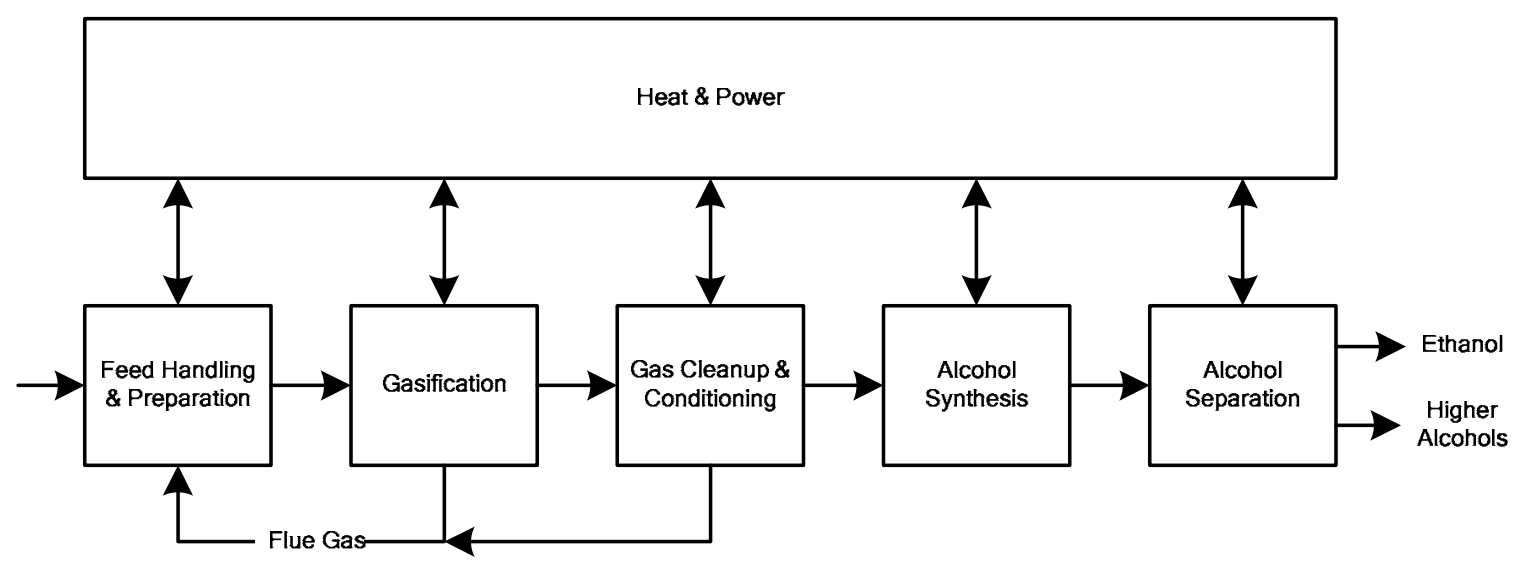

Figure 5. Block flow diagram

A simple block flow diagram of the current design is depicted in Figure 5. The detailed process flow diagrams (PFDs) are in Appendix H. The process has the following steps:

- Feed Handling \& Preparation. The biomass feedstock is dried from the as-received moisture to that required for proper feeding into the gasifier using flue gases from the char combustor and tar reformer catalyst regenerator.

- Gasification. Indirect gasification is considered in this assessment. Heat for the endothermic gasification reactions is supplied by circulating hot synthetic olivine "sand" between the gasifier and the char combustor. Conveyors and hoppers are used to feed the biomass to the low-pressure indirectly-heated entrained flow gasifier. Steam is injected into the gasifier to aid in stabilizing the entrained flow of biomass and sand through the gasifier. The biomass chemically converts to a mixture of syngas components $\left(\mathrm{CO}, \mathrm{H}_{2}\right.$, $\mathrm{CO}_{2}, \mathrm{CH}_{4}$, etc.), tars, and a solid "char" that is mainly the fixed carbon residual from the biomass plus carbon (coke) deposited on the sand. Cyclones at the exit of the gasifier separate the char and sand from the syngas. These solids flow by gravity from the cyclones into the char combustor. Air is introduced to the bottom of the reactor and serves as a carrier gas for the fluidized bed plus the oxidant for burning the char and coke. The heat of combustion heats the sand to over $1800^{\circ} \mathrm{F}$. The hot sand and residual ash from the char is carried out of the combustor by the combustion gases and separated from the hot gases using another pair of cyclones. The first cyclone is designed to capture mostly sand while the smaller ash particles remain entrained in the gas exiting the

\footnotetext{
${ }^{\mathrm{a}}$ Calcined magnesium silicate, primarily Enstatite $\left(\mathrm{MgSiO}_{3}\right)$, Forsterite $\left(\mathrm{Mg}_{2} \mathrm{SiO}_{3}\right)$, and $\mathrm{Hematite}\left(\mathrm{Fe} \mathrm{O}_{3}\right)$. This is used as a sand for various applications. A small amount of magnesium oxide $(\mathrm{MgO})$ is added to the fresh olivine to prevent the formation of glass-like bed agglomerations that would result from biomass potassium interacting with the silicate compounds.
} 
cyclone. The second cyclone is designed to capture the ash and any sand passing through the first cyclone. The hot sand captured by the first cyclone flows by gravity back into the gasifier to provide the heat for the gasification reaction. Ash and sand particles captured in the second cyclone are cooled, moistened to minimize dust and sent to a land fill for disposal.

- Gas Cleanup \& Conditioning. This consists of multiple operations: reforming of tars and other hydrocarbons to $\mathrm{CO}$ and $\mathrm{H}_{2}$; syngas cooling/quench; and acid gas $\left(\mathrm{CO}_{2}\right.$ and $\left.\mathrm{H}_{2} \mathrm{~S}\right)$ removal with subsequent reduction of $\mathrm{H}_{2} \mathrm{~S}$ to sulfur. Tar reforming is envisioned to occur in an isothermal fluidized bed reactor; de-activated reforming catalyst is separated from the effluent syngas and regenerated on-line. The hot syngas is cooled through heat exchange with the steam cycle and additional cooling via water scrubbing. The scrubber also removes impurities such as particulates and ammonia along with any residual tars. The excess scrubber water is sent off-site to a waste-water treatment facility. The cooled syngas enters an amine unit to remove the $\mathrm{CO}_{2}$ and $\mathrm{H}_{2} \mathrm{~S}$. The $\mathrm{H}_{2} \mathrm{~S}$ is reduced to elemental sulfur and stockpiled for disposal. The $\mathrm{CO}_{2}$ is vented to the atmosphere in this design.

- Alcohol Synthesis. The cleaned and conditioned syngas is converted to alcohols in a fixed bed reactor. The mixture of alcohol and unconverted syngas is cooled through heat exchange with the steam cycle and other process streams. The liquid alcohols are separated by condensing them away from the unconverted syngas. Though the unconverted syngas has the potential to be recycled back to the entrance of the alcohol synthesis reactor, this recycle is not done in this process design because $\mathrm{CO}_{2}$ concentrations in the recycle loop would increase beyond acceptable limits of the catalyst. Added cost would be incurred if this $\mathrm{CO}_{2}$ were separated. Instead the unconverted syngas is recycled to the Gas Cleanup \& Conditioning section, mostly as feed to the tar reformer.

- Alcohol Separation. The alcohol stream from the Alcohol Synthesis section is depressurized in preparation of dehydration and separation. Another rough separation is performed in a flash separator; the evolved syngas is recycled to the Gas Cleanup \& Conditioning section, mostly as feed to the tar reformer. The depressurized alcohol stream is dehydrated using vapor-phase molecular sieves. The dehydrated alcohol stream is introduced to the main alcohol separation column that splits methanol and ethanol from the higher molecular weight alcohols. The overheads are topped in a second column to remove the methanol to ASTM sales specifications. The methanol leaving in the overheads is used to flush the adsorbed water from the molecular sieves. This methanol/water mixture is recycled back to the entrance of the alcohol synthesis reactor in order to increase the yield of ethanol and higher alcohols.

- Heat \& Power. A conventional steam cycle produces heat (as steam) for the gasifier and reformer operations and electricity for internal power requirements (with the possibility of exporting excess electricity as a co-product). The steam cycle is integrated with the biomass conversion process. Pre-heaters, steam generators, and super-heaters are integrated within the process design to create the steam. The steam will run through turbines to drive compressors, generate electricity or be withdrawn at various pressure 
levels for injection into the process. The condensate will be sent back to the steam cycle, de-gassed, and combined with make-up water.

A cooling water system is also included in the Aspen Plus model to determine the requirements of each cooling water heat exchanger within the biomass conversion process as well as the requirements of the cooling tower.

Previous analyses of gasification processes have shown the importance of properly utilizing the heat from the high temperature streams. A pinch analysis was performed to analyze the energy network of this ethanol production process. The pinch concept offers a systematic approach to optimize the energy integration of the process. Details of the pinch analysis will be discussed in Section 3.10 .

\subsection{Feedstock and Plant Size}

Based upon expected availability per the Billion Ton Vision [6] study, the forest resources were chosen for the primary feedstock. The Billion Ton Vision study addressed short and long term availability issues for biomass feedstocks without giving specific time frames. The amounts are depicted in Figure 6. The upper sets of numbers (labeled "High Yield Growth With Energy Crops" and "High Yield Growth Without Energy Crops") are projections of availability that will depend upon changes to agricultural practices and the creation of a new energy crop industry. In the target year of 2012 it is most probable that the amounts labeled "Existing \& Unexploited Resources" will be the only ones that can be counted on to supply a thermochemical processing facility. Notice that the expected availability of forest resources is nearly the same as that of agricultural resources. Prior studies for biochemical processing have largely focused on using agricultural resources. It makes sense to base thermochemical processing on the forest resources. TC processing could fill an important need to provide a cost-effective technology to process this major portion of the expected biomass feedstock. 


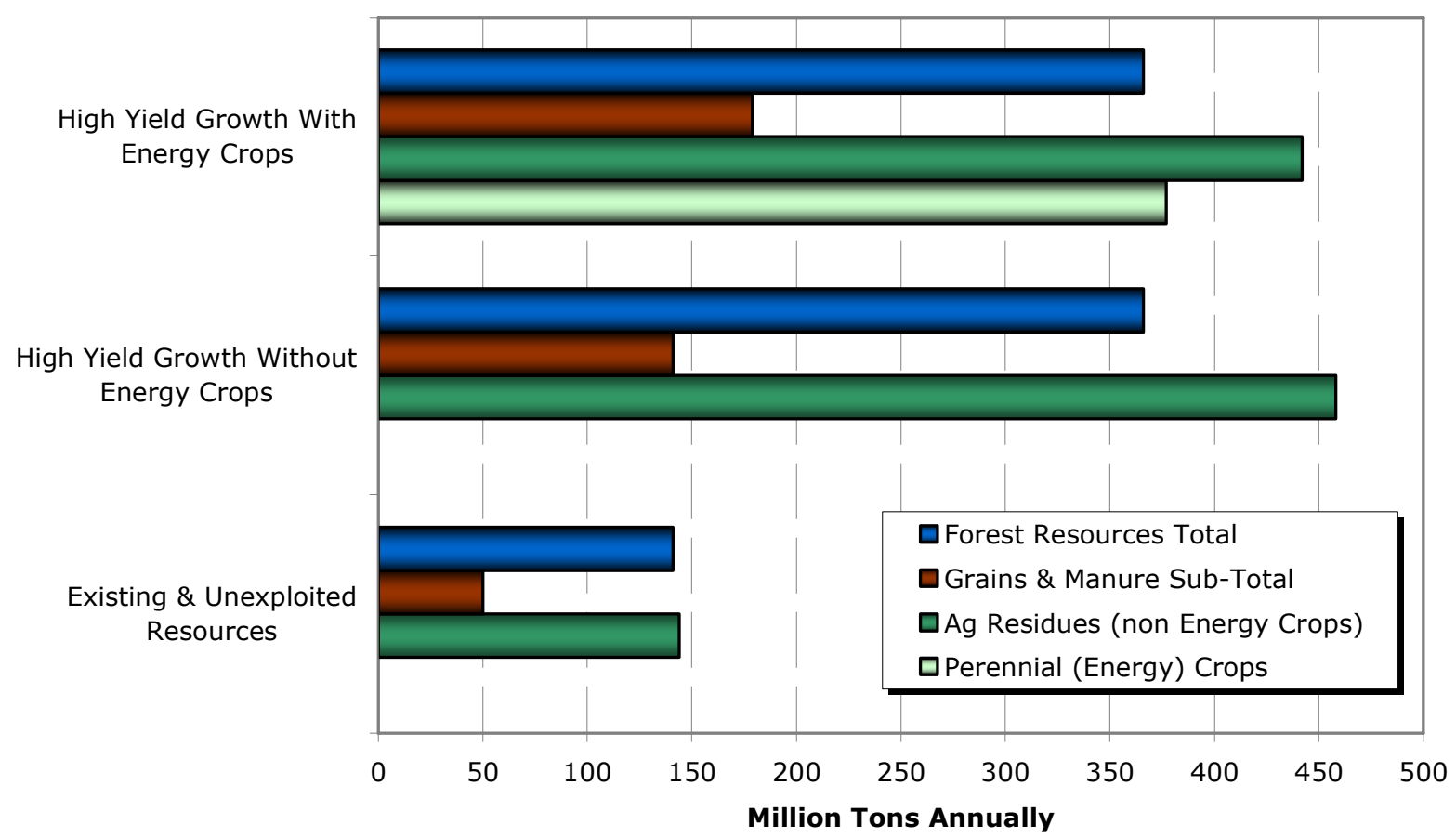

Figure 6. Expected availability of biomass

Past analyses have used hybrid poplar wood chips delivered at $50 \mathrm{wt} \%$ moisture to model forest resources [9]; the same will be done here. The ultimate analysis for the feed used in this study is given in Table 2. Performance and cost effects due to composition and moisture content were examined as part of the sensitivity analysis and alternate scenarios.

Table 2. Ultimate Analysis of Hybrid Poplar Feed

\begin{tabular}{|l|c|}
\hline Component (wt\%, dry basis 29) & \\
\hline Carbon & 50.88 \\
\hline Hydrogen & 6.04 \\
\hline Nitrogen & 0.17 \\
\hline Sulfur & 0.09 \\
\hline Oxygen & 41.90 \\
\hline Ash & 0.92 \\
\hline Heating value $^{\mathrm{c}}(\mathrm{Btu} / \mathrm{lb}):$ & $8,671 \mathrm{HHV}^{\mathrm{d}}$ \\
& $8,060 \mathrm{LHV}^{\mathrm{e}}$ \\
\hline
\end{tabular}

The design plant size for this study was chosen to match that of the Aden et al. biochemical process [3], 2,000 dry tonne/day (2,205 dry ton/day). With an expected 8,406 operating hours per year ( $96 \%$ operating factor) the annual feedstock requirement is 700,000 dry tonne/yr $(772,000$ dry ton/yr). As can be seen in Figure 6 this is a small portion of the 140 million dry ton/yr of

\footnotetext{
${ }^{\mathrm{c}}$ Calculated using the Aspen Plus Boie correlation.

${ }^{\mathrm{d}}$ Higher Heating Value

e Lower Heating Value
} 
forest resources potentially available. Cost effects due to plant size were examined as part of the sensitivity analysis.

The delivered feedstock cost was chosen to match recent analyses done at Idaho National Laboratory (INL) [30] to target $\$ 35$ per dry ton by 2012. Cost effects due to feedstock cost were also examined as part of the sensitivity analysis.

\section{Process Design}

\subsection{Process Design Basis}

The process design developed for this study is based upon the current operation and R\&D performance goals for the catalytic tar destruction and heteroatom removal work at NREL and alcohol synthesis work at NREL and PNNL. This target design shows the effect of meeting these specific research and development $(\mathrm{R} \& \mathrm{D})$ goals.

The process broadly consists of the following sections:

- Feed handling and drying

- Gasification

- Gas clean up and conditioning

- Alcohol synthesis

- Alcohol separation

- Integrated steam system and power generation cycle

- Cooling water and other utilities

\subsection{Feed Handling and Drying - Area 100}

This section of the process accommodates the delivery of biomass feedstock, short term storage on-site, and the preparation of the feedstock for processing in the gasifier. The design is based upon a woody feedstock. It is expected that a feed handling area for agricultural residues or energy crops would be very similar.

The feed handling and drying section are shown in PFD-P800-A101 and PFD-P800-A102. Wood chips are delivered to the plant primarily via trucks. However, it is envisioned that there could be some train transport. Assuming that each truck capacity is about 25 tons [31], this means that if the wood, at a moisture content of $50 \%$, was delivered to the plant via truck transport only, then 176 truck deliveries per day would be required. As the trucks enter the plant they are weighed (M-101) and the wood chips are dumped into a storage pile. From the storage pile, the wood chips are conveyed (C-102) through a magnetic separator (S-101) and screened (S-102). Particles larger than 2 inches are sent through a hammer mill (T-102/M-102) for further size reduction. Front end loaders transfer the wood chips to the dryer feed bins (T-103).

Drying is accomplished by direct contact of the biomass feed with hot flue gas. Because of the large plant size there are two identical, parallel feed handling and drying trains. The wet wood 
chips enter each rotary biomass dryer (M-104) through a dryer feed screw conveyor (C-104).

The wood is dried to a moisture content of $5 \mathrm{wt} \%$ with flue gas from the char combustor (R-202) and tar reformer's fuel combustor (R-301). The exhaust gas exiting the dryer is sent through a cyclone (S-103) and baghouse filter (S-104) to remove particulates prior to being emitted to the atmosphere. The stack temperature of the flue gas is set at $62^{\circ}$ above the dew point of the gas, $235^{\circ} \mathrm{F}\left(113^{\circ} \mathrm{C}\right)$. The stack temperature is controlled by cooling the hot flue gas from the char combustor and the tar reformer with two steam boilers (H-286B and H-311B) prior to entering the dryer. This generated steam is added to the common steam drum (T-604) (see section on Steam System and Power Generation - Area 600). The dried biomass is then conveyed to the gasifier train (T-104/C-105).

Equipment costs were derived from the biochemical design report that utilized poplar as a feedstock. [5]

\subsection{Gasification - Area 200}

This section of the process converts a mixture of dry feedstock and steam to syngas and char. Heat is provided in an indirect manner - by circulating olivine that is heated by the combustion of the char downstream of the gasifier. The steam primarily acts as a fluidizing medium in the gasifier and also participates in certain reactions when high gasifier temperatures are reached.

From the feed handling and drying section, the dried wood enters the gasifier section as shown in PFD-P800-A201. Because of the plant size, it is assumed that there are two parallel gasifier trains. The gasifier (R-201) used in this analysis is a low-pressure indirectly-heated circulating fluidized bed (CFB) gasifier. The gasifier was modeled using correlations based on run data from the Battelle Columbus Laboratory (BCL) 9 tonne/day test facility (see Appendix I).

Heat for the endothermic gasification reactions is supplied by circulating a hot medium between the gasifier vessel and the char combustor (R-202). In this case the medium is synthetic olivine, a calcined magnesium silicate, primarily Enstatite $\left(\mathrm{MgSiO}_{3}\right)$, Forsterite $\left(\mathrm{Mg}_{2} \mathrm{SiO}_{3}\right)$, and Hematite $\left(\mathrm{Fe}_{2} \mathrm{O}_{3}\right)$, used as a heat transfer solid for various applications. A small amount of $\mathrm{MgO}$ must be added to the fresh olivine to avoid the formation of glass-like bed agglomerations that would result from the biomass potassium interacting with the silicate compounds. The $\mathrm{MgO}$ titrates the potassium in the feed ash. Without $\mathrm{MgO}$ addition, the potassium will form glass, $\mathrm{K}_{2} \mathrm{SiO}_{4}$, with the silica in the system. $\mathrm{K}_{2} \mathrm{SiO}_{4}$ has a low melting point $\left(\sim 930^{\circ} \mathrm{F}, 500^{\circ} \mathrm{C}\right)$ and its formation will cause the bed media to become sticky, agglomerate, and eventually defluidize. Adding $\mathrm{MgO}$ makes the potassium form a high melting $\left(\sim 2,370^{\circ} \mathrm{F}, 1,300^{\circ} \mathrm{C}\right)$ ternary eutectic with the silica, thus sequestering it. Potassium carry-over in the gasifier/combustor cyclones is also significantly reduced. The ash content of the feed is assumed to contain $0.2 \mathrm{wt} \%$ potassium. The $\mathrm{MgO}$ flow rate is set at two times the molar flow rate of potassium.

The gasifier fluidization medium is steam that is supplied from the steam cycle (Steam System and Power Generation - Area 600). The steam-to-feed ratio is $0.4 \mathrm{lb}$ of steam/lb of bone dry biomass. The gasifier pressure is 23 psia. The olivine circulating flow rate is $27 \mathrm{lb}$ of olivine/lb of bone dry wood. Fresh olivine is added at a rate of $0.01 \%$ of the circulating rate to account for losses. The char combustor is operated with $20 \%$ excess air. 
Both the gasifier and the char combustor temperatures are allowed to "float" and are dictated from the energy balances around the gasifier and combustor. In general, the more char created, the higher the char combustor temperature; but the higher the char combustor temperature, the higher the resulting gasifier temperature, resulting in less char. In this way the gasifier and char combustor temperatures tend to find an equilibrium position. For the design case the resulting gasifier temperature is $1,633^{\circ} \mathrm{F}\left(889^{\circ} \mathrm{C}\right)$ and the char combustor is $1,823^{\circ} \mathrm{F}\left(995^{\circ} \mathrm{C}\right)$. The composition of the outlet gas from the gasifier is shown in Table 3.

Particulate removal from the raw syngas exiting the gasifier is performed using two-stage cyclone separators. Nearly all of the olivine and char ( $99.9 \%$ of both) is separated in the primary gasifier cyclone (S-201) and gravity-fed to the char combustor. A secondary cyclone (S-202) removes $90 \%$ of any residual fines. The char that is formed in the gasifier is burned in the combustor to reheat the olivine. The primary combustor cyclone (S-203) separates the olivine $(99.9 \%)$ from the combustion gases and the olivine is gravity-fed back to the gasifier. Ash and any sand particles that are carried over in the flue gas exiting the combustor are removed in the secondary combustor cyclone (99.9\% separation in S-204) followed by an electrostatic precipitator (S-205) which removes the remaining residual amount of solid particles. The sand and ash mixture from the secondary flue gas cyclone and precipitator are land filled but prior to this the solids are cooled and water is added to the sand/ash stream for conditioning to prevent the mixture from being too dusty to handle. First the ash and sand mixture is cooled to $300^{\circ} \mathrm{F}$ $\left(149^{\circ} \mathrm{C}\right)$ using the water cooled screw conveyor $(\mathrm{M}-201)$ then water is added directly to the mixture until the mixture water content is $10 \mathrm{wt} \%$.

Table 3. Gasifier Operating Parameters, Gas Compositions, and Efficiencies

\begin{tabular}{|c|c|c|}
\hline Gasifier Variable & \multicolumn{2}{|c|}{ Value } \\
\hline Temperature & \multicolumn{2}{|c|}{$1,633^{\circ} \mathrm{F}\left(890^{\circ} \mathrm{C}\right)$} \\
\hline Pressure & \multicolumn{2}{|c|}{23 psia (1.6 bar) } \\
\hline Gasifier outlet gas composition & mol\% (wet) & mol\% (dry) \\
\hline $\mathrm{H}_{2}$ & 15.0 & 25.1 \\
\hline $\mathrm{CO}_{2}$ & 7.4 & 12.4 \\
\hline $\mathrm{CO}$ & 25.1 & 41.9 \\
\hline $\mathrm{H}_{2} \mathrm{O}$ & 40.2 & -- \\
\hline $\mathrm{CH}_{4}$ & 9.0 & 15.1 \\
\hline $\mathrm{C}_{2} \mathrm{H}_{2}$ & 0.3 & 0.4 \\
\hline $\mathrm{C}_{2} \mathrm{H}_{4}$ & 2.5 & 4.1 \\
\hline $\mathrm{C}_{2} \mathrm{H}_{6}$ & 0.1 & 0.2 \\
\hline $\mathrm{C}_{6} \mathrm{H}_{6}$ & 0.1 & 0.1 \\
\hline $\operatorname{tar}\left(\mathrm{C}_{10} \mathrm{H}_{8}\right)$ & 0.1 & 0.2 \\
\hline $\mathrm{NH}_{3}$ & 0.2 & 0.3 \\
\hline $\mathrm{H}_{2} \mathrm{~S}$ & 0.04 & 0.07 \\
\hline $\mathrm{H}_{2}: \mathrm{CO}$ molar ratio & \multicolumn{2}{|c|}{0.60} \\
\hline Gasifier Efficiency & \multicolumn{2}{|c|}{$\begin{array}{l}\text { 76.6\% HHV basis } \\
76.1 \% \text { LHV basis }\end{array}$} \\
\hline
\end{tabular}

Capital costs for the equipment in this section are described in detail in Section 3 of this report. The operating costs for this section are listed in Appendix E and consist of makeup $\mathrm{MgO}$ and olivine, and sand/ash removal. 


\subsection{Gas Cleanup and Conditioning - Area 300}

This section of the process cleans up and conditions the syngas so that the gas can be synthesized into alcohol. The type and the extent of cleanup are dictated by the requirements of the synthesis catalyst:

- The tars in the syngas are reformed to additional $\mathrm{CO}$ and $\mathrm{H}_{2}$.

- Particulates are removed by quenching.

- Acid gases $\left(\mathrm{CO}_{2}\right.$ and $\left.\mathrm{H}_{2} \mathrm{~S}\right)$ are removed.

- The syngas is compressed.

The gas from the secondary gasifier cyclone is sent to the catalytic tar reformer (R-303). In this bubbling fluidized bed reactor the hydrocarbons are converted to $\mathrm{CO}$ and $\mathrm{H}_{2}$ while $\mathrm{NH}_{3}$ is converted to $\mathrm{N}_{2}$ and $\mathrm{H}_{2}$. In the Aspen simulation, the conversion of each compound is set to match targets that are believed to be attainable through near-term research efforts. Table 4 gives the current experimental conversions (for deactivated catalyst) that have been achieved at NREL [32] and the conversions used in the simulation corresponding to the 2012 research targets.

Table 4. Current and Target Design Performance of Tar Reformer

\begin{tabular}{|c|c|c|}
\hline Compound & $\begin{array}{c}\text { Experimental } \\
\text { Conversion to } \mathbf{C O} \text { \& } \mathbf{H}_{\mathbf{2}}\end{array}$ & $\begin{array}{c}\text { Target Conversion to } \\
\mathbf{C O} \text { \& } \mathbf{H}_{\mathbf{2}}\end{array}$ \\
\hline Methane $\left(\mathrm{CH}_{4}\right)$ & $20 \%$ & $80 \%$ \\
\hline Ethane $\left(\mathrm{C}_{2} \mathrm{H}_{6}\right)$ & $90 \%$ & $99 \%$ \\
\hline Ethylene $\left(\mathrm{C}_{2} \mathrm{H}_{4}\right)$ & $50 \%$ & $90 \%$ \\
\hline Tars $\left(\mathrm{C}_{10+}\right)$ & $95 \%$ & $99.9 \%$ \\
\hline Benzene $\left(\mathrm{C}_{6} \mathrm{H}_{6}\right)$ & $70 \%$ & $99 \%$ \\
\hline Ammonia $\left(\mathrm{NH}_{3}\right)^{\dagger}$ & $70 \%$ & $90 \%$ \\
\hline
\end{tabular}

In the Aspen simulation the tar reformer operates isothermally at $1,633^{\circ} \mathrm{F}$. An implicit assumption in this mode of operation is that the energy needed for the endothermic reforming reactions can be transferred into the catalyst bed. Although conceptual reactor designs are readily created for providing the heat of reaction from the fuel combustion area directly into the reformer catalyst bed, in practice this may be a difficult and prohibitively expensive design option requiring internal heat transfer tubes operating at high temperatures. An alternate approach, not used in this study, would be to preheat the process gas upstream of the reformer above the current reformer exit temperature, and operate the reformer adiabatically with a resulting temperature drop across the bed and a lower exit gas temperature. In this configuration, the required inlet and exit gas temperatures would be set by the extent of conversion, the kinetics of the reforming reactions, and the amount of catalyst in the reactor.

The composition of the gas from the tar reformer can be seen in Table 5 .

\footnotetext{
${ }^{\mathrm{f}}$ Converts to $\mathrm{N}_{2}$ and $\mathrm{H}_{2}$.
} 
Table 5. Target Design Tar Reformer Conditions and Outlet Gas Composition

\begin{tabular}{|c|c|c|}
\hline Tar Reformer Variable & \multicolumn{2}{|c|}{ Value } \\
\hline Tar reformer inlet temperature & \multicolumn{2}{|c|}{$1,633^{\circ} \mathrm{F}\left(890^{\circ} \mathrm{C}\right)$} \\
\hline Tar reformer outlet temperature & \multicolumn{2}{|c|}{$1,633^{\circ} \mathrm{F}\left(890^{\circ} \mathrm{C}\right)$} \\
\hline Tar reformer outlet gas composition & mol\% (wet) & mol\% (dry) \\
\hline $\mathrm{H}_{2}$ & 37.4 & 43.0 \\
\hline $\mathrm{CO}_{2}$ & 9.9 & 11.4 \\
\hline $\mathrm{CO}$ & 37.4 & 43.0 \\
\hline $\mathrm{H}_{2} \mathrm{O}$ & 13.0 & --- \\
\hline $\mathrm{CH}_{4}$ & 1.2 & 1.4 \\
\hline $\mathrm{C}_{2} \mathrm{H}_{2}$ & 0.01 & 0.01 \\
\hline $\mathrm{C}_{2} \mathrm{H}_{4}$ & 0.11 & 0.13 \\
\hline $\mathrm{C}_{2} \mathrm{H}_{6}$ & $10.8 \mathrm{ppmv}$ & $12.4 \mathrm{ppmv}$ \\
\hline $\mathrm{C}_{6} \mathrm{H}_{6}$ & $2.7 \mathrm{ppmv}$ & $3.1 \mathrm{ppmv}$ \\
\hline $\operatorname{tar}\left(\mathrm{C}_{10} \mathrm{H}_{8}\right)$ & $0.5 \mathrm{ppmv}$ & $0.6 \mathrm{ppmv}$ \\
\hline $\mathrm{NH}_{3}$ & 0.01 & 0.01 \\
\hline $\mathrm{H}_{2} \mathrm{~S}$ & 0.02 & 0.02 \\
\hline $\mathrm{N}_{2}$ & 0.72 & 0.83 \\
\hline $\mathrm{H}_{2}: \mathrm{CO} \mathrm{molar}_{2}$ ratio & & \\
\hline & & \\
\hline
\end{tabular}

Prior to the quench step, the hot syngas is cooled to $300^{\circ} \mathrm{F}\left(149^{\circ} \mathrm{C}\right)$ with heat exchangers $(\mathrm{H}-$ $301 \mathrm{~A}-\mathrm{C}$ ) that are integrated in the steam cycle (see section Steam System and Power Generation - Area 600). After this direct cooling of the syngas, additional cooling is carried out via water scrubbing (M-302 and M-301), shown in PFD-P800-A302. The scrubber also removes impurities such as particulates, residual ammonia, and any residual tars. The scrubbing system consists of a venturi scrubber (M-302) and quench chamber (M-301). The scrubbing system quench water is a closed recirculation loop with heat rejected to the cooling tower and a continuous blow down rate of approximately 2.3 gallons per minute (gpm) that is sent to a waste water treatment facility. The quench water flow rate is determined by adjusting its circulation rate until its exit temperature from the quench water recirculation cooler $(\mathrm{H}-301)$ is $110^{\circ} \mathrm{F}\left(43^{\circ} \mathrm{C}\right)$. Any solids that settle out in T-301 are sent off-site for treatment as well. For modeling purposes, the water content of the sludge stream was set at $50 \mathrm{wt} \%$.

The quench step cools the syngas to a temperature of $140^{\circ} \mathrm{F}\left(60^{\circ} \mathrm{C}\right)$. The syngas is then compressed using a five-stage centrifugal compressor with interstage cooling as shown in PFDP800-A303. The compressor was modeled such that each section has a polytropic efficiency of $78 \%$ and intercooler outlet temperatures of $140^{\circ} \mathrm{F}\left(60^{\circ} \mathrm{C}\right)$. The interstage coolers are forced air heat exchangers.

Depending on the specific catalysts being used downstream of the tar reformer, varying concentrations of acid gas compounds can be tolerated in the syngas. For example, sulfur concentrations as $\mathrm{H}_{2} \mathrm{~S}$ are required to be below $0.1 \mathrm{ppm}$ for copper based synthesis catalysts. This design is based upon sulfided molybdenum catalysts which actually require up to $100 \mathrm{ppm}$ of $\mathrm{H}_{2} \mathrm{~S}$ in the syngas to maintain catalyst activity. Because the syngas exiting the gasifier contains almost 400 ppmv of $\mathrm{H}_{2} \mathrm{~S}$, some level of sulfur removal will be required by any of the synthesis catalysts currently of interest.

Carbon dioxide is the other acid gas that needs to be removed in the syngas conditioning process. Similar to the sulfur compounds, the acceptable level of $\mathrm{CO}_{2}$ depends on the specific catalyst 
being used in the synthesis reactor to make alcohols. Some synthesis catalysts require low levels of $\mathrm{CO}_{2}$ while others, such as the sulfided molybdenum catalysts can tolerate relatively high $\mathrm{CO}_{2}$ levels compared to the sulfur species. $\mathrm{CO}_{2}$ is a major component of the gasification product, so significant amounts of $\mathrm{CO}_{2}$ may need to be removed upstream of the synthesis reactor.

Since the catalyst selected for this study is a sulfided catalyst that is tolerant of sulfur up to 100 ppmv and $\mathrm{CO}_{2}$ up to $7 \mathrm{~mol} \%$ (see Appendix $\mathrm{J}$ for more detail), a design that can provide for the removal of both sulfur and carbon dioxide was chosen. An amine system capable of selectively removing $\mathrm{CO}_{2}$ and $\mathrm{H}_{2} \mathrm{~S}$ from the main process syngas stream is used. The amine assumed for this study is monoethanol amine (MEA), based on the recommendation by Nexant [33].

The acid gas scrubber was simulated using a simplified model of SEP blocks and specifying the amount of $\mathrm{CO}_{2}$ and $\mathrm{H}_{2} \mathrm{~S}$ needing to be removed to meet design specifications of $50 \mathrm{ppmv}_{2} \mathrm{~S}$ and $5 \mathrm{~mol} \% \mathrm{CO}_{2}$ at the synthesis reactor inlet, including any recycle streams to that unit operation. The amine system heating and cooling duties were calculated using information taken from section 21 of the GPSA Data Handbook [34]. This method gave a heat duty of 2660 Btu per pound of $\mathrm{CO}_{2}$ removed, with a similar magnitude cooling duty provided by forced-air cooling fans. Power requirements for pumping and fans were also calculated using GPSA recommended values. The acid gas scrubber operating values for the base case are given below.

\begin{tabular}{|c|c|}
\hline Acid Gas Removal Parameter & Value \\
\hline Amine Used & Monoethanol amine (MEA) \\
Amine Concentration & $35 \mathrm{wt} \%$ \\
Amine Circ. Rate & $1,945 \mathrm{gpm}$ \\
Amine Temp. @ Absorber & $110^{\circ} \mathrm{F}$ \\
Absorber Pressure & $450 \mathrm{psia}$ \\
Stripper Condenser Temperature & $212^{\circ} \mathrm{F}$ \\
Stripper Reboiler Temperature & $237^{\circ} \mathrm{F}$ \\
Stripper Pressure & $65 \mathrm{psia}$ \\
Stripper Reboiler Duty & $140.1 \mathrm{MMBTU} / \mathrm{hr}$ \\
Stripper Condenser Duty & $93.4 \mathrm{MMBTU} / \mathrm{hr}$ \\
Amine Cooler Duty & $46.7 \mathrm{MMBTU} / \mathrm{hr}$ \\
Heat Duty per Pound $\mathrm{CO}_{2}$ removed & $2,660 \mathrm{Btu} / \mathrm{lb}$ \\
\hline
\end{tabular}

If a highly $\mathrm{CO}_{2}$-tolerant alcohol synthesis catalyst is used, it may become possible to use other syngas conditioning processes or methods to selectively remove $\mathrm{H}_{2} \mathrm{~S}$, with less energy and possibly at a significantly lower capital cost.

The acid gases removed in the amine scrubber are then stripped to regenerate the sorbent and sent through a sulfur removal operation using a liquid phase oxidation process as shown in PFDP800-A305. The combined Amine/ LO-CAT process will remove the sulfur and $\mathrm{CO}_{2}$ to the levels desired for the selected molysulfide catalyst [35]. Although, there are several liquid-phase oxidation processes for $\mathrm{H}_{2} \mathrm{~S}$ removal and conversion available today, the LO-CAT process was selected because of its progress in minimizing catalyst degradation and its environmentallybenign catalyst. LO-CAT is an iron chelate-based process that consists of a venturi precontactor (M-303), liquid-filled absorber (M-304), air-blown oxidizer (R-301), air blower (K-302), solution circulation pump (P-303) and solution cooler (H-305). Elemental sulfur is produced in 
the oxidizer and, since there is such a small amount (1.3 ton/day), it is stockpiled either for eventual disposal or sold as an unconditioned product. The LO-CAT process was modeled to remove the $\mathrm{H}_{2} \mathrm{~S}$ to a concentration of $10 \mathrm{ppmv}$ in the $\mathrm{CO}_{2}$ vent effluent from the amine scrubber. The air flow rate for re-oxidizing the LO-CAT solution was included in the simulation and calculated based on the requirement of 2 moles of $\mathrm{O}_{2}$ per mole of $\mathrm{H}_{2} \mathrm{~S}$. Prior to entering the LOCAT system the gas stream is superheated to $10^{\circ} \mathrm{F}\left(5.6^{\circ} \mathrm{C}\right)$ above its dew point in preheater $(\mathrm{H}-$ $304)$, which in this process is equivalent to $120^{\circ} \mathrm{F}$. This degree of superheating is required for the LO-CAT system. The $\mathrm{CO}_{2}$ from the LO-CAT unit is vented to the atmosphere.

The capital costs for the equipment in this section are described in further detail in the Appendices. The operating costs consist of makeup reforming catalyst, LO-CAT and amine chemical makeup, as well as reforming catalyst disposal cost and WWT. These are described in further detail in Section 3.

\subsection{Alcohol Synthesis - Area 400}

The alcohol synthesis reactor system is the heart of the entire process. Entering this process area, the syngas has been reformed, quenched, compressed and treated to have acid gas concentrations $\left(\mathrm{H}_{2} \mathrm{~S}, \mathrm{CO}_{2}\right)$ reduced. After that, it is further compressed and heated to the synthesis reaction conditions of 1,000 psia and $570^{\circ} \mathrm{F}\left(300^{\circ} \mathrm{C}\right)$. The syngas is converted to the alcohol mixture across a fixed bed catalyst. The product gas is subsequently cooled, allowing the alcohols to condense and separate from the unconverted syngas. The liquid alcohols are then sent to alcohol separation and purification (Area 500). The residual gas stream is recycled back to the tar reformer with a small purge to fuel combustion (5\%).

Research on alcohol synthesis catalysts has waxed and waned over many decades for a variety of reasons. In order to review the status of mixed alcohol technology and how it has developed over the past 20 years, two activities were initiated. First, a literature search was conducted. This search and its findings are described in more detail in Appendix J, along with a discussion on specific terminology, such as "yield", "selectivity", and "conversion". These terms will be used throughout the remainder of this document. Second, an engineering consulting company (Nexant) was hired to document the current state of technology with regards to mixed alcohols production and higher alcohol synthesis. Their results are published in an NREL subcontract [36] report.

Based on the results of this background technology evaluation, a modified Fischer-Tropsch catalyst was used for this process design, specifically a molybdenum-disulfide-based $\left(\mathrm{MoS}_{2}\right)$ catalyst. The former Dow/UCC catalyst was chosen as the basis because of its relatively high ethanol selectivity and because its product slate is a mixture of linear alcohols (as opposed to the branched alcohols that result from modified methanol catalysts). This particular catalyst uses high surface area $\mathrm{MoS}_{2}$ promoted with alkali metal salts (e.g. potassium carbonate) and cobalt $(\mathrm{CoS})$. These promoters shift the product slate from hydrocarbons to alcohols, and can either be supported on alumina or activated carbon, or be used unsupported. 
Table 6 lists several process and syngas conditioning requirements for this synthesis reaction. These include both experimentally verified conditions typical of those found in literature, as well as targeted conditions from the OBP-funded research plan used in the model.

Table 6. Process Conditions for Mixed Alcohols Synthesis

\begin{tabular}{|l|c|c|}
\hline Parameter & $\begin{array}{c}\text { "State of Technology" } \\
\text { Conditions [41] }\end{array}$ & $\begin{array}{c}\text { Target Conditions } \\
\text { Used in Process Design \& } \\
\text { Aspen Model }\end{array}$ \\
\hline Temperature $\left({ }^{\circ} \mathrm{C}\right)$ & $\sim 300$ & 300 \\
\hline Pressure $(\mathrm{psia})$ & $1500-2000$ & 1000 \\
\hline $\mathrm{H}_{2} / \mathrm{CO}$ ratio & $1.0-1.2$ & 1.0 \\
\hline $\mathrm{CO}_{2}$ concentration $(\mathrm{mol} \%)$ & $0 \%-7 \%$ & $5.0 \%$ \\
\hline Sulfur concentration $(\mathrm{ppmv})$ & $50-100$ & 50 \\
\hline
\end{tabular}

Though the synthesis reactor is modeled as operating isothermally, it is recognized that maintaining a constant temperature in a fixed bed reactor system would be difficult, especially since these reactions are highly exothermic. Temperature has a significant impact on the alcohol selectivity and product distribution. High pressures are typically required to ensure the production of alcohols. $\mathrm{MoS}_{2}$ catalysts are efficient Fischer-Tropsch (FT) catalysts at ambient or low pressures. However, significantly raising the pressure (in addition to promoting with alkali) helps to shift the pathways from hydrocarbon production towards alcohol production. However, compression requirements for achieving these pressures can be quite substantial. Thus, targeting a catalyst that achieves optimal performance at lower pressures can potentially provide significant cost savings.

The $\mathrm{CO}_{2}$ concentration requirements for the syngas are less well-known. Herman [37] states that in the first Dow patent application, the presence of larger amounts of $\mathrm{CO}_{2}$ in the synthesis gas retarded the catalyst activity. Further study showed that increasing the $\mathrm{CO}_{2}$ concentration to 30 vol $\%$ decreased the $\mathrm{CO}$ conversion but did not significantly alter the alcohol:hydrocarbon ratio of the product. With $\mathrm{CO}_{2}$ concentrations up to $6.7 \mathrm{vol} \%$, the extent of $\mathrm{CO}$ conversion is not affected; however, higher chain alcohol yield relative to methanol does tend to decrease. This is why $\mathrm{CO}_{2}$ concentrations were reduced to $5 \mathrm{~mol} \%$ in the model using the amine system as part of syngas conditioning. The effect of $\mathrm{CO}_{2}$ concentration on alcohol production will be studied in future laboratory experiments.

One of the benefits of this catalyst is its sulfur tolerance. It must be continuously sulfided to

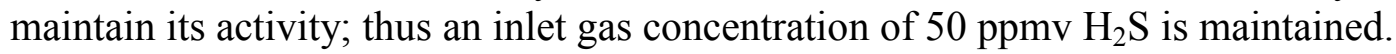
Concentrations above 100 ppmv inhibit the reaction rate and higher alcohol selectivity.

The overall stoichiometric reaction for alcohol synthesis can be summarized as:

$$
n \mathrm{CO}+2 n \mathrm{H}_{2} \rightarrow \mathrm{C}_{n} \mathrm{H}_{2 n+1} \mathrm{OH}+(n-1) \mathrm{H}_{2} \mathrm{O}
$$

Stoichiometry suggests an optimum $\mathrm{H}_{2}: \mathrm{CO}$ ratio of 2.0. However this catalyst maintains significant water-gas shift activity and will generate its own $\mathrm{H}_{2}$ from $\mathrm{CO}$ and $\mathrm{H}_{2} \mathrm{O}$ : 


$$
\mathrm{CO}+\mathrm{H}_{2} \mathrm{O} \rightarrow \mathrm{H}_{2}+\mathrm{CO}_{2}
$$

This shifts the optimal ratio closer to 1.0 and also shifts the primary byproduct from water to $\mathrm{CO}_{2}$. Experiments [38] have been typically conducted using ratios in the range of 1.0 to 1.2.

The compressor (K-410) in this area is a 3-stage steam-driven compressor that takes the syngas from 415 psia to 1000 psia, requiring 9,420 HP (assuming a polytropic efficiency of 78\%). The outlet syngas from the compressor is then mixed with recycled methanol from Alcohol Purification (Area 500), heated to $570^{\circ} \mathrm{F}\left(300^{\circ} \mathrm{C}\right)$, and sent to the reactor. The capital cost for the compressor was developed using Questimate.

The mixed alcohol synthesis reactor is a fixed-bed reactor system that contains the $\mathrm{MoS}_{2}$ catalyst. Because this is a net exothermic reaction system, water is cross exchanged with the reactor to produce steam for the process while helping to maintain a constant reactor temperature. Questimate was used to develop the reactor capital cost.

The purchase price of the catalyst itself was estimated at $\$ 5.25 / \mathrm{lb}$ based on conversations NREL researchers had with CRITERION [39], a petroleum/hydrocarbon catalyst provider. This represents a generalized cost of Molybdenum-based catalyst at around $\$ 5 / \mathrm{lb}$ being sulfided for an additional $\$ 0.25 / \mathrm{lb}$. In addition, NREL was able to speak with Dow catalyst experts [40] who said that in today's market the raw material costs for producing such a catalyst system would run about $\$ 20 / 1 b$. Adding more cost for the catalyst preparation would bring that cost between \$22$40 / 1 b$. However, these costs could go down as demand goes up, and quite substantially if it gets to large enough scale.

In reality, each company developing a process like this will have their own proprietary catalyst and associated formulation. The costs for these catalysts are difficult to predict at the present time since so few providers of mixed alcohols catalyst currently exist (and will likely be negotiated). Nexant also provided information on general catalyst metals price ranges in their report. They reported Molybdenum ranging from $\$ 2-40 / \mathrm{lb}$.

The lifetime of the catalyst was assumed to be 5 years. While existing mixed alcohols catalysts have not been tested for this long, they have operated for over 8,000 hours (roughly 1 year of continuous operating time) with little or no loss in performance.

The reactor was modeled as a simple conversion-specified reactor using a series of alcohol and hydrocarbon production reactions as shown in Table 7. The propane, butane, and pentane+ reactions are set to zero because the catalyst will likely not favor these reactions. The specific conversions of each of the other reactions were set in order to reach catalyst performance targets, see Table 9. Those targets are shown in Table 8 along with values for those parameters typically found in literature. 


\section{Table 7. System of Reactions for Mixed Alcohol Synthesis}

Water-Gas Shift
Methanol
Methane
Ethanol
Ethane
Propanol
Propane
n-Butanol
Butane
Pentanol+
Pentane+

$$
\begin{gathered}
\mathrm{CO}+\mathrm{H}_{2} \mathrm{O} \leftrightarrow \mathrm{H}_{2}+\mathrm{CO}_{2} \\
\mathrm{CO}+2 \mathrm{H}_{2} \rightarrow \mathrm{CH}_{3} \mathrm{OH} \\
\mathrm{CH}_{3} \mathrm{OH}+\mathrm{H}_{2} \rightarrow \mathrm{CH}_{4}+\mathrm{H}_{2} \mathrm{O} \\
\mathrm{CO}+2 \mathrm{H}_{2}+\mathrm{CH}_{3} \mathrm{OH} \rightarrow \mathrm{C}_{2} \mathrm{H}_{5} \mathrm{OH}+\mathrm{H}_{2} \mathrm{O} \\
\mathrm{C}_{2} \mathrm{H}_{5} \mathrm{OH}+\mathrm{H}_{2} \rightarrow \mathrm{C}_{2} \mathrm{H}_{6}+\mathrm{H}_{2} \mathrm{O} \\
\mathrm{CO}+2 \mathrm{H}_{2}+\mathrm{C}_{2} \mathrm{H}_{5} \mathrm{OH} \rightarrow \mathrm{C}_{3} \mathrm{H}_{7} \mathrm{OH}+\mathrm{H}_{2} \mathrm{O} \\
\mathrm{C}_{3} \mathrm{H}_{7} \mathrm{OH}+\mathrm{H}_{2} \rightarrow \mathrm{C}_{3} \mathrm{H}_{8}+\mathrm{H}_{2} \mathrm{O} \\
\mathrm{CO}+2 \mathrm{H}_{2}+\mathrm{C}_{3} \mathrm{H}_{7} \mathrm{OH} \rightarrow \mathrm{C}_{4} \mathrm{H}_{9} \mathrm{OH}+\mathrm{H}_{2} \mathrm{O} \\
\mathrm{C}_{4} \mathrm{H}_{9} \mathrm{OH}+\mathrm{H}_{2} \rightarrow \mathrm{C}_{4} \mathrm{H}_{10}+\mathrm{H}_{2} \mathrm{O} \\
\mathrm{CO}+2 \mathrm{H}_{2}+\mathrm{C}_{4} \mathrm{H}_{9} \mathrm{OH} \rightarrow \mathrm{C}_{5} \mathrm{H}_{11} \mathrm{OH}+\mathrm{H}_{2} \mathrm{O} \\
\mathrm{C}_{5} \mathrm{H}_{11} \mathrm{OH}+\mathrm{H}_{2} \rightarrow \mathrm{C}_{5} \mathrm{H}_{12}+\mathrm{H}_{2} \mathrm{O}
\end{gathered}
$$

Table 8. Mixed Alcohol Reaction Performance Results

\begin{tabular}{|l|c|c|}
\hline \multicolumn{1}{|c|}{ Result } & $\begin{array}{c}\text { "State of Technology" } \\
\text { Value Ranges [37, 41] }\end{array}$ & $\begin{array}{c}\text { Target Results } \\
\text { Used in Process Design \& } \\
\text { Aspen Model }\end{array}$ \\
\hline Total CO Conversion (per-pass) & $10 \%-40 \%$ & $60 \%$ \\
\hline $\begin{array}{l}\text { Total Alcohol Selectivity } \\
\left(\mathrm{CO}_{2} \text {-free basis) }\right.\end{array}$ & $70 \%-80 \%$ & $90 \%$ \\
\hline Gas Hourly Space Velocity $\left(\mathrm{hr}^{-1}\right)$ & $1600-12,000$ & 4000 \\
\hline $\begin{array}{l}\text { Catalyst Alcohol Productivity }(\mathrm{g} / \mathrm{kg}- \\
\text { catalyst/hr })^{\mathrm{g}}\end{array}$ & $150-350$ & 600 \\
\hline
\end{tabular}

The individual target values are less important than the net result of the entire collection. For example, a catalyst system can have a high CO conversion well above $40 \%$, but if most of that $\mathrm{CO}$ is converted to methane or $\mathrm{CO}_{2}$, then the alcohol selectivities would be very low and the entire process economics would suffer. Likewise, if the catalyst had a high CO conversion and selectivity, but had very low productivity, a much larger reactor would have to be built to accommodate the volume of catalyst required. The set of targets shown above are improvements over current literature values, but were chosen as targets believed to be achievable through catalyst research and development. There is precedent for these results from other catalyst systems. For example, FT catalysts are currently capable of CO conversions above $70 \%$ [42]. Also commercial methanol catalysts have productivities over $1000 \mathrm{~g} / \mathrm{kg}$-catalyst $/ \mathrm{hr}$ [37].

The reaction conversions were also set to achieve a certain product distribution of alcohols. The mixed alcohol products described in literature are often high in methanol, but contain a wide distribution of several different alcohols. The product distributions described by Dow and SRI are shown in Table 9 along with the relative product concentrations calculated by the model.

\footnotetext{
${ }^{\mathrm{g}}$ Based on assumed catalyst density of $64 \mathrm{lb} / \mathrm{ft}^{3}, 600 \mathrm{~g} / \mathrm{kg}$-catalyst $/ \mathrm{hr}=615 \mathrm{~g} / \mathrm{L}$-catalyst $/ \mathrm{hr}$.
} 
Table 9. Mixed Alcohol Product Distributions

\begin{tabular}{|l|c|c|c|}
\hline \multicolumn{1}{|c|}{ Alcohol } & $\begin{array}{c}\text { Dow [43] } \\
\text { (wt \%) }\end{array}$ & $\begin{array}{c}\text { SRI [44] } \\
\text { (wt\%) }\end{array}$ & $\begin{array}{c}\text { NREL Model } \\
\text { (wt\%) }^{*}\end{array}$ \\
\hline Methanol & $30-70 \%$ & $30.77 \%$ & $5.01 \%$ \\
\hline Ethanol & $34.5 \%$ & $46.12 \%$ & $70.66 \%$ \\
\hline Propanol & $7.7 \%$ & $13.3 \%$ & $10.07 \%$ \\
\hline Butanol & $1.4 \%$ & $4.14 \%$ & $1.25 \%$ \\
\hline Pentanol + & $1.5 \%$ & $2.04 \%$ & $0.17 \%$ \\
\hline Acetates (C1 \& C2) & $2.5 \%$ & $3.63 \%$ & $10.98 \%$ \\
\hline Others & & & $1.86 \%$ \\
\hline Water & $2.4 \%$ & & $100 \%$ \\
\hline Total & $100 \%$ & $100 \%$ & \\
\hline
\end{tabular}

* Prior to alcohol purification and methanol recycle

The most significant differences between the NREL model product distribution and those shown in literature are with regards to the methanol and ethanol distributions. This is primarily due to the almost complete recycle of methanol within this process. In the alcohol purification section downstream, virtually all methanol is recovered via distillation and recycled back to mix with the compressed syngas. This is done in order to increase the production of ethanol and higher alcohols. This concept has been proposed in literature, but data from testing in an integrated setting has not been seen. In literature, experiments are often conducted on closed or batch systems and do not examine the potential impacts of recycled compounds or other integration issues. However, this catalyst is known to have methanol decomposition functionality which indicates that methanol in the feed will not be detrimental to the reaction. The effects of recycled methanol will be examined experimentally as research progresses.

A kinetic model was used to guide these conversion assumptions to help predict how the catalyst may perform as a result of significant methanol recycle. Very few kinetic models have been developed for this catalyst system [45, 46, 47]. Of these, only Gunturu examined the possibility of methanol recycle. Therefore NREL reproduced this kinetic model using Polymath software. This kinetic model predicted that methanol entering the reactor would largely be converted to ethanol and methane. This model also predicts that maintaining high partial pressures of methanol in the reactor would further reduce the production of alcohols higher than ethanol. More detailed discussion on the kinetic model can be found in Appendix K.

After the reactor, the effluent is cooled to $110^{\circ} \mathrm{F}\left(43^{\circ} \mathrm{C}\right)$ through a series of heat exchangers while maintaining high pressure. First, the reacted syngas is cross exchanged with cooler process streams, lowering the temperature to $200^{\circ} \mathrm{F}\left(93^{\circ} \mathrm{C}\right)$. Air-cooled exchangers then bring the temperature down to $140^{\circ} \mathrm{F}\left(60^{\circ} \mathrm{C}\right)$. The final $30^{\circ} \mathrm{F}\left(17^{\circ} \mathrm{C}\right)$ drop is provided by cooling water. A knock-out drum (S-501) is then used to separate the liquids (primarily alcohols) from the remaining gas, which is comprised of unconverted syngas, $\mathrm{CO}_{2}$, and methane. Aspen Plus contains other physical property packages that model non-ideal liquid systems much better than the Redlich-Kwong-Soave (RKS) equation of state used throughout the model. Therefore, the Non-Random Two-Liquid (NRTL) package was used to model the alcohol condensation.

From here, the liquid crude alcohols are sent to product purification while the residual syngas is superheated to $1500^{\circ} \mathrm{F}\left(816^{\circ} \mathrm{C}\right)$ and sent through an expander to generate additional power for 
the process. The pressure is dropped from 970 to 35 psia prior to being recycled to the tar reformer. A $5 \%$ purge stream is sent to fuel combustion.

Alternate configurations will be discussed later in this report as will the economic sensitivity of certain synthesis parameters. One particular variation would be to recycle the unconverted syngas to the throat of the synthesis reactor instead of to the tar reformer. This would save money on upstream equipment costs because of lower process throughput, but would also lower yields because the $\mathrm{CO}_{2}$ would build up in the recycle loop. The limit to the amount of unconverted syngas that could be recycled to the reactor is less than $50 \%$ because this would cause the $\mathrm{H}_{2}$ : $\mathrm{CO}$ ratio to grow well above 1.2.

Future experiments and analysis will examine the impacts of methanol recycle, and of variations in concentration of $\mathrm{CO}_{2}, \mathrm{CH}_{4}$, and other compounds. Alternate reactor designs will also be examined. For example, FT technology largely has switched to slurry reactors instead of fixedbed reactors because the slurry fluidization achieves better heat and mass transfer properties that allow, in turn, for higher conversions. Such improvements could help to achieve the conversion targets outlined above and reduce the costs of major equipment items.

\subsection{Alcohol Separation - Area $\mathbf{5 0 0}$}

The mixed alcohol stream from Area 400 is sent to Area 500 where it is de-gassed, dried, and separated into three streams: methanol, ethanol, and mixed higher-molecular weight alcohols. The methanol stream is used to back-flush the molecular sieve drying column and then recycled, along with the water removed during back flushing, to the inlet of the alcohol synthesis reactor in Area 400. The ethanol and mixed alcohol streams are cooled and sent to product storage tanks.

Carbon dioxide is readily absorbed in alcohol. Although the majority of the non-condensable gases leaving the synthesis reactor are removed in the separator vessel, S-501, a significant quantity of these gases remains in the alcohol stream, especially at the high system pressure. These gases are removed by depressurizing from 970 to 60 psia. Most of the dissolved gasses separate from the alcohols in the knock-out vessel S-502. This gas stream is made up primarily of carbon dioxide with some small amounts of hydrocarbons and alcohols; it is recycled to the Tar Reformer in Area 300. After being vaporized by cross exchanging with steam to a $20^{\circ} \mathrm{F}$ $\left(11^{\circ} \mathrm{C}\right)$ superheated temperature, the alcohol stream goes to the molecular sieve dehydrator unit operation.

The molecular sieve dehydrator design was based upon previous biochemical ethanol studies [5, 3] and assumed to have similar performance with mixed alcohols. In the biochemical ethanol cases, the molecular sieve is used to dry ethanol after it is distilled to the azeotropic concentration of ethanol and water $(92.5 \mathrm{wt} \%$ ethanol). The adsorbed water is flushed from the molecular sieves with a portion of the dried ethanol and recycled to the rectification column. The water ultimately leaves out the bottom of the distillation column. In this thermochemical process, however, it was determined that drying the entire mixed alcohol stream before any other separation would be preferable. The adsorbed water is desorbed from the molecular sieves with a combination of depressurization and flushing with methanol. This methanol/water mixture is then recycled back to the Alcohol Synthesis section (A400). 
The molecular sieve units require a superheated vapor. The liquid mixed alcohol stream is vaporized, superheated, and then fed to one of two parallel adsorption columns. The adsorption column preferentially removes water and a small amount of the alcohols. While one adsorption bed is adsorbing water, the other is regenerating. The water is desorbed from the bed during regeneration by applying a vacuum and flushing with dry methanol from D-505. This methanol/water mixture is recycled back to the Alcohol Synthesis section (A400). This methanol/water mixture is cooled to $140^{\circ} \mathrm{F}\left(60^{\circ} \mathrm{C}\right)$ using a forced air heat exchanger, and separated from any uncondensed vapor. The gaseous stream is recycled to the Tar Reformer and the condensate is pumped to 1,000 psia in P-514, and mixed with high-pressure syngas from compressor K-410 in Area 400 upstream of the synthesis reactor pre-heater.

The dry mixed alcohol stream leaving the mol sieve dehydrator enters into the first of two distillation columns, D-504. D-504 is a typical distillation column using trays, overhead condenser, and a reboiler. The methanol and ethanol are separated from the incoming stream with $99 \%$ of the incoming ethanol being recovered in the overhead stream along with essentially all incoming methanol. The D-504 bottom stream consists of $99 \%$ of the incoming propanol, $1 \%$ of the incoming ethanol, and all of the butanol and pentanol. The mixed alcohol bottoms is considered a co-product of the plant and is cooled and sent to storage. The methanol/ethanol overhead stream from D-504 goes to a second distillation column, D-505, for further processing.

D-505 separates the methanol from the binary methyl/ethyl alcohol mixture. The ethanol recovery in D-505 is $99 \%$ of the incoming ethanol and has a maximum methanol concentration of 0.5 mole percent to meet product specifications for fuel ethanol. The ethanol, which exits from the bottom of D-505 is cooled before being sent to product storage. The methanol and small quantity of ethanol exiting the overhead of column D-505 is used to flush the mol sieve column during its regeneration step as explained above. Currently, all of the methanol from D-505 is recycled through the mol sieve dehydrator and then to the synthesis reactor in Area 400.

\subsection{Steam System and Power Generation - Area 600}

This process design includes a steam cycle that produces steam by recovering heat from the hot process streams throughout the plant. Steam demands for the process include the gasifier, amine system reboiler, alcohol purification reboilers, and LO-CAT preheater. Of these, only the steam to the gasifier is directly injected into the process; the rest of the plant heat demands are provided by indirect heat exchange of process streams with the steam and have condensate return loops. Power for internal plant loads is produced from the steam cycle using an extraction steam turbine/generator (M-602). Power is also produced from the process expander (K-412), which takes the unconverted syngas from 965 psia to 35 psia before being recycled to the tar reformer. Steam is supplied to the gasifier from the low pressure turbine exhaust stage. The plant energy balance is managed to generate only the amount of electricity required by the plant. The steam system and power generation area is shown in PFD-P800-A601, -A602, and -A603 in Appendix $\mathrm{H}$.

A condensate collection tank (T-601) gathers condensate from the syngas compressors and from the process reboilers along with the steam turbine condensate and make-up water. The total 
condensate stream is heated to the saturation temperature and sent to the deaerator (T-603) to degas any dissolved gases out of the water. The water from the deaerator is first pumped to a pressure of 930 psia and then pre-heated to its saturation (bubble point) temperature using a series of exchangers. The saturated steam is collected in the steam drum (T-604). To prevent solids build up, water must be periodically discharged from the steam drum. The blowdown rate is equal to $2 \%$ of water circulation rate. The saturated steam from the steam drum is superheated with another series of exchangers. The superheated steam temperature and pressure were set as a result of pinch analysis. Superheated steam enters the turbine at $900^{\circ} \mathrm{F}$ and $850 \mathrm{psia}$ and is expanded to a pressure of $175 \mathrm{psia}$. The remaining steam then enters the low pressure turbine and is expanded to a pressure of 65 psia. Here a slipstream of steam is removed and sent to the gasifier and other exchangers. Finally, the steam enters a condensing turbine and is expanded to a pressure of $1.5 \mathrm{psia}$. The steam is condensed in the steam turbine condenser $(\mathrm{H}-601)$ and the condensate re-circulated back to the condensate collection tank.

The integration of the individual heat exchangers can only be seen in the PFDs included in the Appendices. To close the heat balance of the system, the Aspen Plus model increases or decreases the water flowrate through the steam cycle until the heat balance of the system is met.

This process design assumes that the two compressors in this process (K301, K410) are steamdriven. All other drives for pumps, fans, etc are electric motors. Additionally, an allowance of $0.7 \mathrm{MW}$ of excess power is made to total power requirement to account for miscellaneous usage and general electric needs (lights, computers, etc). Table 10 contains the power requirement of the plant broken out into the different plant sections. Because syngas compression is steam driven, it is not a demand on the power system, which makes the total power requirement much less than it would be if compression demands were included. The plant power demands and power production were designed specifically to be nearly equal. Therefore, no excess power is being sold to or purchased from the grid. This plant was designed to be as energy self-sufficient as possible. This was accomplished by burning a portion of the "dirty" unreformed syngas in the fuel combustor (Section 300). While this does have a negative impact on the overall alcohol yields of the process, it does negate the purchase of natural gas or grid power.

Table 10. Plant Power Requirements

\begin{tabular}{|c|c|}
\hline Plant Section & Power Requirement (kW) \\
\hline Feed Handling \& Drying & 742 \\
\hline Gasification & 3,392 \\
\hline Tar Reforming, Cleanup, \& Conditioning & 1,798 \\
\hline Mixed Alcohol Synthesis & 119 \\
\hline Alcohol Separation and Purification & 256 \\
\hline Steam System \& Power Generation & 431 required \\
& 7,994 generated \\
\hline Cooling Water \& Other Utilities & 529 \\
\hline Miscellaneous & 727 \\
\hline Total plant power requirement & 7,994 \\
\hline
\end{tabular}




\subsection{Cooling Water and Other Utilities - Area 700}

The cooling water system is shown on PFD-P800-A701. A mechanical draft cooling tower (M701) provides cooling water to several heat exchangers in the plant. The tower utilizes large fans to force air through circulated water. Heat is transferred from the water to the surrounding air by the transfer of sensible and latent heat. Cooling water is used in the following pieces of equipment:

- the sand/ash cooler (M-201) which cools the sand/ash mixture from the gasifier/combustor

- the quench water recirculation cooler (M-301) which cools the water used in the syngas quench step

- the water-cooled aftercooler (H-303) which follows the syngas compressor and cools the syngas after the last stage of compression

- the LO-CAT absorbent solution cooler (H-305) which cools the regenerated solution that circulates between the oxidizer and absorber vessels

- the reacted syngas cooler (H-414) which cools the gas in order to condense out the liquid alcohols

- the end product finishing coolers (H-591, H-593) for both the higher alcohols co-product and the primary ethanol product

- the blowdown water-cooled cooler (H-603) which cools the blowdown from the steam drum

- the steam turbine condenser (H-601) which condenses the steam exiting the steam turbine

Make-up water for the cooling tower is supplied at $14.7 \mathrm{psia}$ and $60^{\circ} \mathrm{F}\left(16^{\circ} \mathrm{C}\right)$. Water losses include evaporation, drift (water entrained in the cooling tower exhaust air), and tower basin blowdown. Drift losses were estimated to be $0.2 \%$ of the water supply. Evaporation losses and blowdown were calculated based on information and equations in Perry, et al. [27]. The cooling water returns to the process at a supply pressure of 65 psia and temperature is $90^{\circ} \mathrm{F}\left(32^{\circ} \mathrm{C}\right)$. The cooling water return temperature is $110^{\circ} \mathrm{F}\left(43^{\circ} \mathrm{C}\right)$.

An instrument air system is included to provide compressed air for both service and instruments. The instrument air system is shown on PFD-P800-A701. The system consists of an air compressor (K-701), dryer (S-701) and receiver (T-701). The instrument air is delivered at a pressure of 115 psia, a moisture dew point of $-40^{\circ} \mathrm{F}\left(-40^{\circ} \mathrm{C}\right)$, and is oil free.

Other miscellaneous items that are taken into account in the design include:

- a firewater storage tank (T-702) and pump (P-702)

- a diesel tank (T-703) and pump (P-703) to fuel the front loaders

- an olivine truck scale with dump (M-702) and an olivine lock hopper (T-705) as well as an $\mathrm{MgO}$ lock hopper (T-706)

- a hydrazine storage tank (T-707) and pump (P-705) for oxygen scavenging in the cooling water

This equipment is shown on PFD-P800-A702. 


\subsection{Additional Design Information}

Table 11 contains some additional information used in the Aspen Plus model and production design.

Table 11. Utility and Miscellaneous Design Information

\begin{tabular}{|l|l|}
\hline \multicolumn{1}{|c|}{ Item } & \multicolumn{1}{|c|}{ Design Information } \\
\hline Ambient air conditions ${ }^{(1,2, \text { and }}$ & Pressure: 14.7 psia \\
& $\mathrm{T}_{\text {Dry Bulb }: 90^{\circ} \mathrm{F}}$ \\
& $\mathrm{T}_{\text {Wet Bulb: } 80^{\circ} \mathrm{F}}$ \\
& Composition $(\mathrm{mol} \%):$ \\
\hline $\mathrm{N}_{2}: 75.7 \% \quad \mathrm{O}_{2}: 20.3 \% \quad$ Ar: $0.9 \% \quad \mathrm{CO}_{2}: 0.03 \% \quad \mathrm{H}_{2} \mathrm{O}: 3.1 \%$ \\
\hline Pressure drop allowance & $\begin{array}{l}\text { Syngas compressor intercoolers }=2 \quad \mathrm{psi} \\
\text { Heat exchangers and packed beds }=5 \mathrm{psi}\end{array}$ \\
\hline
\end{tabular}

(1) In the GPSA Engineering Data Book [48], see Table 11.4 for typical design values for dry bulb and wet bulb temperature by geography. Selected values would cover summertime conditions for most of lower 48 states.

(2) In Weast [49], see F-172 for composition of dry air. Nitrogen value adjusted slightly to force mole fraction closure using only $\mathrm{N}_{2}, \mathrm{O}_{2}, \mathrm{Ar}$, and $\mathrm{CO}_{2}$ as air components.

(3) In Perry, et al. [27], see psychrometric chart, Figure 12-2, for moisture content of air.

\subsection{Pinch Analysis}

A pinch analysis was performed to analyze the energy network of the biomass gasification to ethanol production process. The pinch technology concept offers a systematic approach to optimum energy integration of the process. First temperature and enthalpy data were gathered for the "hot" process streams (i.e., those that must be cooled), "cold" process streams (i.e., those that must be heated), and utility streams (such as steam, flue gas, and cooling water). The minimum approach temperature was set at $42.6^{\circ} \mathrm{F}$. A temperature versus enthalpy graph (the "composite curve") was constructed for the hot and cold process streams. These two curves are shifted so that they touch at the pinch point. From this shifted graph, a grand composite curve is constructed which plots the enthalpy differences between the hot and cold composite curves as a function of temperature. The composite curve is shown in Figure 7. From this figure the heat exchanger network of the system was determined. 


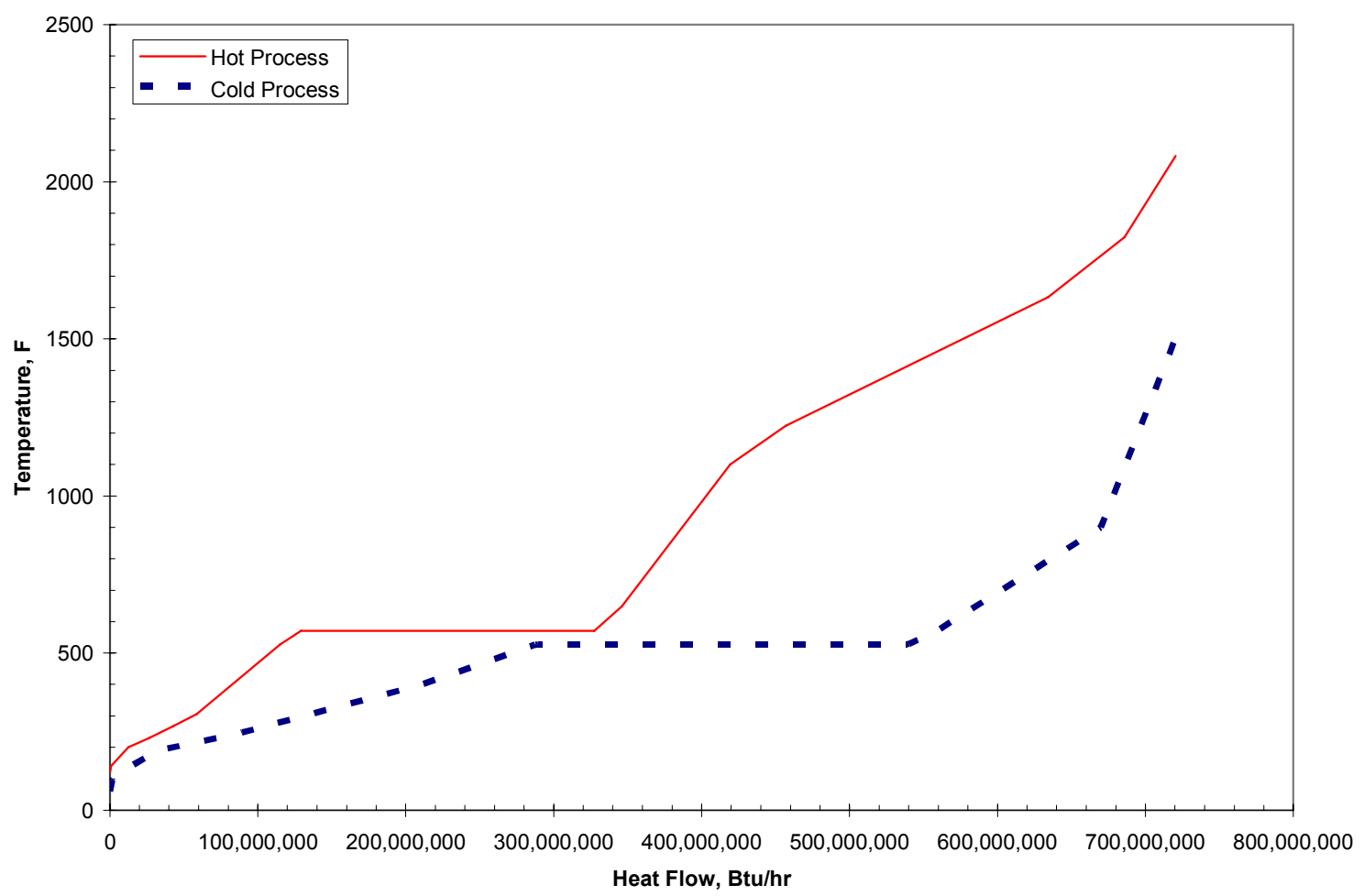

Figure 7. Pinch analysis composite curve

The total heating enthalpy equals the total cooling enthalpy because the Aspen model is designed to adjust the water flowrate through the steam cycle until the heat balance in the system is met. Because no outside utilities were used in this process, all heating and cooling duties are satisfied through process-process interchanges or process-steam interchanges. The minimum vertical distance between the curves is $\Delta T_{\min }$, which is theoretically the smallest approach needed in the exchange network. For this design, the pinch occurs at $\sim H=280,000,000 \mathrm{BTU} / \mathrm{hr}$, and the upper and lower pinch temperatures are $570.0^{\circ} \mathrm{F}$ and $527.4^{\circ} \mathrm{F}$, respectively, giving a $\Delta T_{\min }$ of $42.6^{\circ} \mathrm{F}$.

Design of the heat exchange network for the above the pinch and below pinch regions are done separately. While pinch theory teaches that multiple solutions are possible, this particular solution has the advantage that heat released by the alcohol synthesis reactor is dissipated by raising steam. This is a standard design practice for removing heat from methanol synthesis and other similar reactors. The left-hand side of the composite curve shows the below pinch curves are constrained at the pinch and are also nearly pinched at the very left-hand side in the $\sim 100^{\circ} \mathrm{F}$ range. This makes heat exchanger network design below the pinch more difficult.

\subsection{Energy Balance}

Energy integration is extremely important to the overall economics and efficiency of this process. Therefore a detailed understanding of how and where the energy is utilized and 
recovered is required. Detailed energy balances around the major process areas were derived using data from the Aspen Plus simulation. Comparing the process energy inputs and outputs enables the energy efficiency of the process to be quantified. Also, tracing energy transfer between process areas makes it possible to identify areas of potential improvement to the energy efficiency.

The philosophy of defining the "energy potential" of a stream is somewhat different from what was done for the biochemical ethanol process design report [50]. For that analysis the definition of the energy potential was based upon the higher heating values (HHVs) of each component. This HHV basis is convenient when a process is primarily made up of aqueous streams in the liquid phase. Since liquid water at the standard temperature has a zero HHV, the contribution for any liquid water is very small, especially as compared to any other combustible material also present in the stream. However, the thermochemical ethanol production process differs significantly in that most of the process streams are in the gas phase. To remove the background contributions of the water, the energy potential is based instead upon the lower heating values (LHVs) of each component.

The total energy potential for a stream has other contributions beyond that of the heating value. Other energy contributions are:

- Sensible heat effect - the stream is at a temperature (and pressure) different from that of the standard conditions at which the heating values are defined.

- Latent heat effect - one or more components in the stream are in a different phase from that at which their heating values are defined.

- Non-ideal mixing effect - any heating or cooling due to blending dissimilar components in a mixture.

The procedure for actually calculating the energy potential of a stream is also different from what was done prior. When the biochemical ethanol process was analyzed, the contributions for the HHVs, the sensible heating effects, and the latent heat effects were directly computed and combined. The calculations of the sensible and latent heat effects were done in an approximate manner. For example, the sensible heat effect was estimated from the heat capacity at the stream's temperature, pressure, and composition; it was assumed that this heat capacity remained constant over the temperature range between the stream's temperature and the standard temperature. For the relatively low temperatures of the biochemical ethanol process systems, this assumption makes sense. However, for this thermochemical process design, this assumption is not accurate because of the much larger differences between the process stream temperatures and the standard temperature

The enthalpy values reported by Aspen Plus can actually be adjusted in a fairly simple manner to reflect either an HHV or LHV basis for the energy potential. The enthalpies calculated and reported by Aspen Plus are actually based upon a heat of formation for the energy potential of a stream. So, the reported enthalpies already include the sensible, latent, and non-ideal mixing effects. If certain constants in Aspen's enthalpy expressions could be modified to be based on either the components' HHVs or LHVs instead of the heats of formation then Aspen Plus would report the desired energy potential values. However, since the constants cannot be easily changed, the reported enthalpy values were adjusted instead as part of a spreadsheet calculation. 
The factors used to adjust the reported enthalpies were calculated from the difference between each component's heat of combustion (LHV) and the reported pure component enthalpy at combustion conditions.

This process for thermochemical conversion of cellulosic biomass was designed with the goal of being as energy self-sufficient. Natural gas inputs that could be used to fire the char combustor and fuel combustor have been eliminated. Instead, a slipstream of "dirty" unreformed syngas is used to meet the fuel demand. The downside to this is a decrease in ethanol yield. In addition, the process was designed to require no electricity be purchased from the grid. Instead, the integrated combined heat and power system supplies all steam and electricity needed by the plant.

Consequently no electricity is sold as a co-product either. The only saleable products are the fuel ethanol and a higher molecular weight mixed alcohol co-product.

The major process energy inputs and outlets are listed in Table 12, along with their energy flowrates. Each input and output is also ratioed to the biomass energy entering the system. The biomass is of course the primary energy input, however other energy inputs are required. Air is required for both the fuel combustor as well as the char combustor; however it remains a minor energy input. Some water is used to wet the ash leaving the gasification system, however, the majority of process water is used for boiler feed water makeup and cooling water makeup. A large negative energy flow value is associated with this because it enters the process as a liquid. 
Table 12. Overall Energy Analysis (LHV basis)

\begin{tabular}{|c|c|c|}
\hline & $\begin{array}{c}\text { Energy Flow } \\
\text { (MMBTU/hr, LHV basis) }\end{array}$ & $\begin{array}{l}\text { Ratio to Feedstock } \\
\text { Energy Flow }\end{array}$ \\
\hline \multicolumn{3}{|l|}{ Energy Inlets } \\
\hline Wood Chip Feedstock (wet) & 1269.7 & 1.000 \\
\hline Natural Gas & 0.0 & 0.000 \\
\hline Air & 2.3 & 0.002 \\
\hline Olivine & 0.0 & 0.000 \\
\hline $\mathrm{MgO}$ & 0.0 & 0.000 \\
\hline Water & -133.4 & -0.105 \\
\hline Tar Reforming Catalyst & 0.0 & 0.000 \\
\hline Other & 0.0 & 0.000 \\
\hline Total & 1138.6 & 0.897 \\
\hline \multicolumn{3}{|l|}{ Energy Outlets } \\
\hline Ethanol & 619.1 & 0.488 \\
\hline Higher Alcohols Co-product & 122.1 & 0.096 \\
\hline Cooling Tower Evaporation & 17.0 & 0.013 \\
\hline Flue Gas & 46.2 & 0.036 \\
\hline Sulfur & 0.4 & 0.000 \\
\hline Compressor Heat & 178.3 & 0.140 \\
\hline Heat from Air-cooled Exchangers & 222.0 & 0.175 \\
\hline $\begin{array}{l}\text { Vents to Atmosphere } \\
\text { (including excess } \mathrm{CO}_{2} \text { ) }\end{array}$ & 0.8 & 0.001 \\
\hline Sand and Ash & 16.4 & 0.013 \\
\hline Catalyst Purge & 0.0 & 0.000 \\
\hline Wastewater & -1.2 & -0.001 \\
\hline Other & -82.5 & -0.064 \\
\hline Total & 1138.6 & 0.897 \\
\hline
\end{tabular}

Besides the saleable alcohol products, other important process energy outlets also exist. There are two sources of flue gas: the char combustor and the reformer fuel combustor. Together, they total about $4 \%$ of the energy in the raw biomass. Cooling tower evaporative losses, excess $\mathrm{CO}_{2}$ vent to the atmosphere, wastewater, and ash streams are also minor process energy outlets. However, two of the larger energy outlets come from air-cooled interstage cooling of the compressors, and from several other air-cooled heat exchangers. Together, these two loss categories represent over $30 \%$ of the energy that is not recovered within the process. The "other" category consists primarily of other losses from the cooling tower system (drift and blowdown), but also accounts for energy losses due to ambient heating effects and mechanical work (pump, compressor) efficiency losses.

Some of this lost heat could potentially be recovered by using cooling water instead of air-cooled exchangers. However, this would require additional makeup water, and limiting water usage throughout the process was a primary design consideration. Additional heat integration with process streams could also be examined, however, there comes a point where this becomes too complex and costly for a cost-effective design and practical operation.

Overall, the TC process is approximately $46 \%$ efficient on an LHV basis for moisture-free biomass, as shown in the Appendices. Table 12 shows that approximately $58 \%$ of the energy in the wet raw biomass is recovered in the two alcohol products. Improvements in these energy efficiencies could potentially result in additional cost savings to the process. 


\subsection{Water Issues}

Water is required as a reactant, a fluidizing agent, and a cooling medium in this process. As a reactant, it participates in reforming and water gas shift reactions. Using the BCL gasifier, it also acts as the fluidizing agent in the form of steam. Its cooling uses are outlined in Section 3.8.

Water usage is becoming an increasingly important aspect of plant design, specifically with regards to today's ethanol plants. Most ethanol plants reside in the Midwest where many places are experiencing significant water supply concerns 51 . For several years, significant areas of water stress have been reported during the growing season, while livestock and irrigation operations compete for the available resources.

Today's dry mill ethanol plants have a high degree of water recycle. In fact many plants use what is known as a "zero discharge" design where no process water is discharged to wastewater treatment. The use of centrifuges and evaporators enables this recycle of process water. Therefore, much of the consumptive water demand of an ethanol plant comes from the evaporative losses from the cooling tower and utility systems. Oftentimes well water is used to supply the water demands of the ethanol plants, which draws from the local aquifers that are not readily recharged. This is driven by the need for high quality water in the boiler system. Studies have shown that water usage by today's corn ethanol plants range from 3-7 gallons per gallon of ethanol produced. This means that a $50 \mathrm{MM}$ gal/yr dry mill will use between $150-350 \mathrm{MM}$ gallons/yr of water that is essentially a non-renewable resource. This ratio however has decreased over time from an average of $5.8 \mathrm{gal} / \mathrm{gal}$ in 1998 to $4.2 \mathrm{gal} / \mathrm{gal}$ in 2005 .

Therefore, a primary design consideration for this process was the minimization of fresh water requirements, which therefore meant minimizing the cooling water demands and recycling process water as much as possible. Air-cooling was used in several areas of the process in place of cooling water (e.g. distillation condensers, compressor interstage cooling, etc). However there are some instances where cooling water is required to reach a sufficiently low temperature that air-cooling can not reach.

Table 13 quantifies the particular water demands of this design. Roughly $71 \%$ of the fresh water demand is from cooling tower makeup, with most of the remainder needed as makeup boiler feed water. Some of this water is directly injected into the gasifier, but other system losses (blowdown) also exist. The overall water demand is considerably less than today's ethanol plants. This design requires less than 2 gallons of fresh water for each gallon of ethanol produced. It may be worthwhile for the entire ethanol industry to more thoroughly investigate efficiency gains that are possible within these utility systems.

Table 13. Process Water Demands for Thermochemical Ethanol

\begin{tabular}{|l|r|}
\hline \multicolumn{1}{|c|}{ Fresh Water Demands } & Ib per hour \\
\hline Cooling Tower Makeup & 84,672 \\
\hline Boiler Feed Makeup & 34,176 \\
\hline Sand/ash Wetting & 243 \\
\hline Total & $\mathbf{1 1 9 , 0 9 1}$ \\
\hline & $\mathbf{1 . 9 4}$ \\
\hline $\begin{array}{l}\text { Overall Water Demand (gal water / gal } \\
\text { ethanol) }\end{array}$ & \\
\hline
\end{tabular}




\section{Process Economics}

The total project investment (based on total equipment cost) as well as variable and fixed operating costs is developed first. With these costs, a discounted cash flow analysis was used to determine the production cost of ethanol when the net present value of the project is zero. This section describes the cost areas and the assumptions made to complete the discounted cash flow analysis.

\subsection{Capital Costs}

The following sections discuss the methods and sources for determining the capital cost of each piece of equipment within the plant. A summary of the individual equipment costs can be found in Appendix D.

The capital cost estimates are based as much as possible on the design work done by Spath et al . for the hydrogen design report [9] and Aden et al. for the biochemical conversion design report [3]. The majority of the Spath et al. costs came from literature and Questimate (an equipment capital cost estimating software tool by Aspen Tech), not from vendor quotes. For these estimated costs, the purchased cost of the equipment was calculated and then cost factors were used to determine the installed equipment cost. This method of cost estimation has an expected accuracy of roughly $+30 \%$ to $-10 \%$. The factors used in determining the total installed cost (TIC) of each piece of equipment are shown in Table 14 [52]. The Aden et al. cost estimates came from a variety of sources (including vendor quotes); the installation factors for these estimates may be significantly different from what is in Table 14 .

Table 14. General Cost Factors in Determining Total Installed Equipment Costs

\begin{tabular}{|l|c|}
\hline & \% of TPEC \\
\hline Total Purchased Equipment Cost (TPEC) & 100 \\
\hline Purchased equipment installation & 39 \\
\hline Instrumentation and controls & 26 \\
\hline Piping & 31 \\
\hline Electrical systems & 10 \\
\hline Buildings (including services) & 29 \\
\hline Yard improvements & 12 \\
\hline Total Installed Cost (TIC) & 247 \\
\hline
\end{tabular}

The indirect costs (non-manufacturing fixed-capital investment costs) were also estimated as per Spath et al. using cost factors. The factors are shown in Table 15 [52] and have been put as percentages in terms of total purchased equipment cost, total installed cost (TIC), and total project investment (TPI, the sum of the TIC and the total indirect costs). 
Table 15. Cost Factors for Indirect Costs

\begin{tabular}{|l|c|c|c|}
\hline Indirect Costs & \% of TPEC & \% of TIC & \% of TPI \\
\hline Engineering & 32 & 13 & 9 \\
\hline Construction & 34 & 14 & 10 \\
\hline Legal and contractors fees & 23 & 9 & 7 \\
\hline Project contingency & 7.4 & 3 & 2 \\
\hline Total Indirect Costs & 96.4 & 39 & 28 \\
\hline
\end{tabular}

The biomass handling and drying costs as well as the gasification and gas clean up costs were estimated by Spath et al. using several reports by others that documented detailed design and cost estimates. Some of the reports gave costs for individual pieces of equipment while others lumped the equipment costs into areas. The costs from the reports were amalgamated into:

- feedstock handling and drying.

- gasification and clean up.

Costs from those reports scaled to a 2,000 bone dry tonne/day plant are given in Table 16. Table 17 gives the basic dryer and gasifier design basis for the references. Spath et al. used an average feed handling and drying cost from all of the literature sources and an average gasifier and gas clean up cost for the references using the BCL gasifier.

Table 16. Feed Handling \& Drying and Gasifier \& Gas Clean Up Costs from the Literature Scaled to 2,000 tonne/day plant

\begin{tabular}{|c|c|c|}
\hline Reference & $\begin{array}{c}\text { Scaled Feed } \\
\text { Handling and } \\
\text { Drying Cost \$K } \\
(2002)\end{array}$ & $\begin{array}{c}\text { BCL - Scaled } \\
\text { Gasifier and Gas } \\
\text { Clean Up Cost \$K } \\
(2002)\end{array}$ \\
\hline Breault and Morgan [53] ${ }^{(a)}$ & $\$ 15,048$ & $\$ 15,801$ \\
\hline Dravo Engineering Companies [54] ${ }^{(a)}$ & $\$ 14,848$ & $\$ 15,774$ \\
\hline Weyerhaeuser, et al., [55] $]^{(\mathrm{a})}$ & $\$ 21,241$ & $\$ 24,063$ \\
\hline Stone \& Webster, et al. [56] ${ }^{(a)}$ & $\$ 25,067$ & $-\ldots$ \\
\hline Wan and Malcolm [57 $]^{(\mathrm{a})}$ & $\begin{array}{l}\$ 18,947^{(b)} \\
\$ 14,098^{(c)}\end{array}$ & $\begin{array}{l}\$ 11,289^{(b)} \\
\$ 11,109^{(c)}\end{array}$ \\
\hline Weyerhaeuser [58] ${ }^{(a)}$ & $\$ 13,468$ & $\$ 10,224$ \\
\hline Wright and Feinberg [59] $^{\text {(a) }}$ & $\begin{array}{c}\$ 26,048-\mathrm{BCL} \\
\text { design } \\
\$ 21,942-\mathrm{GTI} \text { design }\end{array}$ & $\begin{array}{l}\$ 12,318 \text { - quench } \\
\$ 26,562-\text { HGCU }^{(d)}\end{array}$ \\
\hline Craig [60] & $\$ 13,680$ & --- \\
\hline AVERAGE & $\$ 18,840$ & $\$ 16,392$ \\
\hline
\end{tabular}

(a) From detailed design and cost estimates

(b) Estimated from a 200 dry ton/day plant design.

(c) Estimated from a 1,000 dry ton/day plant design.

(d) Two separate gas clean up configurations were examined for the BCL gasifier. HGCU = hot gas clean up. 
Table 17. System Design Information for Gasification References

\begin{tabular}{|l|c|c|}
\hline Reference & $\begin{array}{c}\text { Feed Handling and } \\
\text { Drying } \\
\text { Rotary dryer }\end{array}$ & $\begin{array}{c}\text { BCL Gasifier and Gas } \\
\text { Clean Up }\end{array}$ \\
\hline Breault and Morgan [53] & $\begin{array}{c}\text { Cyclones, heat exchange \& } \\
\text { scrubber }\end{array}$ \\
\hline $\begin{array}{l}\text { Dravo Engineering Companies } \\
\text { [54] }\end{array}$ & Rotary drum dryer & $\begin{array}{c}\text { Cyclones, heat exchange \& } \\
\text { scrubber }\end{array}$ \\
\hline Weyerhaeuser, et al. [55] & Steam dryer & $\begin{array}{c}\text { Cyclones, heat exchange, } \\
\text { tar reformer, \& scrubber }\end{array}$ \\
\hline Stone \& Webster, et al. [56] & Flue gas dryer & -- \\
\hline Wan and Malcolm [57] & Flue gas dryer & $\begin{array}{c}\text { Cyclones, heat exchange \& } \\
\text { scrubber }\end{array}$ \\
\hline Weyerhaeuser [58] & Flue gas dryer & $\begin{array}{c}\text { Cyclones, heat exchange \& } \\
\text { scrubber }\end{array}$ \\
\hline Wright and Feinberg [59] & Unclear & $\begin{array}{c}\text { Quench system - details } \\
\text { are not clear } \\
\text { Tar reformer system - } \\
\text { details are not clear }\end{array}$ \\
\hline Craig [60] & & Rotary drum dryer \\
\hline
\end{tabular}

In this report, we have further broken apart the gasification and clean up costs into their respective areas. Based upon the Utrecht report [19] these were split 50/50 between the two areas.

The cost of reactors, heat exchangers, compressors, blowers and pumps were estimated for a "base" size using Questimate and then scaled using material and energy balance results from the Aspen Plus simulation. The reactors were sized based on a gas hourly space velocity (GHSV), where GHSV is measured at standard temperature and pressure, $60^{\circ} \mathrm{F}$ and $1 \mathrm{~atm}$ [61], and a height to diameter ratio of 2 . The GHSV for the mixed alcohol reactor and tar reformer were set at $4,000 / \mathrm{hr}$ and $2475 / \mathrm{hr}$, respectively. These are in agreement with typical values given by Kohl and Nielsen [62]. The heat exchanger costs were mostly developed based on the required surface area as calculated from the heat transfer equation appropriate for a 1-1 shell and tube heat exchanger:

$$
Q=U A(\Delta T)_{l m} \Rightarrow A=\frac{Q}{U(\Delta T)_{l m}}
$$

where $Q$ is the heat duty, $U$ is the heat transfer coefficient, $A$ is the exchanger surface area, and $(\Delta T)_{l m}$ is the log mean temperature difference. The heat transfer coefficients were estimated from literature sources, primarily Perry, et al [27]. However, many of the exchangers used in the pinch analysis are subsequently scaled from their calculated duties. At present, these duties will not change as the process changes, unless the pinch calculations are specifically updated. This is acceptable as long as the total cost of the heat exchange network remains a small fraction of the overall minimum ethanol plant gate price, and as long as plant scale does not change significantly. 
For the various pieces of equipment, the design temperature is determined to be the operating temperature plus $50^{\circ} \mathrm{F}\left(28^{\circ} \mathrm{C}\right)$ [63]. The design pressure is the higher of the operating pressure plus 25 psi or the operating pressure times 1.1 [63].

The following costs were estimated based on the Aden, et al. design report: [3]

- cooling tower.

- plant and instrument air.

- steam turbine/generator/condenser package.

- Deaerator.

- alcohol separation equipment (e.g., the distillation columns and molecular sieve unit).

Appendix $\mathrm{G}$ contains the design parameters and cost references for the various pieces of equipment in the plant.

\subsection{Operating Costs}

There are two kinds of operating costs: variable and fixed costs. The following sections discuss the operating costs including the assumptions and values for these costs.

There are many variable operating costs accounted for in this analysis. The variables, information about them, and costs associated with each variable are shown in Table 18.

Table 18. Variable Operating Costs

\begin{tabular}{|c|c|}
\hline Variable & Information and Operating Cost \\
\hline Tar reformer catalyst & $\begin{array}{l}\text { To determine the amount of catalyst inventory, the tar reformer was } \\
\text { sized for a gas hourly space velocity (GHSV) of } 2,476 / \mathrm{hr} \text { based on } \\
\text { the operation of the tar reformer at NREL's TCPDU where GHSV is } \\
\text { measured at standard temperature and pressure [61]. Initial fill then a } \\
\text { replacement of } 1 \% \text { per day of the total catalyst volume. } \\
\text { Price: } \$ 4.67 / \mathrm{lb}[64]\end{array}$ \\
\hline $\begin{array}{l}\text { Alcohol Synthesis } \\
\text { Catalyst }\end{array}$ & $\begin{array}{l}\text { Initial fill then replaced every } 5 \text { years based on typical catalyst } \\
\text { lifetime. } \\
\text { Catalyst inventory based on GHSV of } 6,000 / \mathrm{hr} \text {. } \\
\text { Price: } \$ 5.25 / \mathrm{lb}[7]\end{array}$ \\
\hline Gasifier bed material & $\begin{array}{l}\text { Synthetic olivine and } \mathrm{MgO} \text {. Delivered to site by truck equipped with } \\
\text { self-contained pneumatic unloading equipment. Disposal by landfill. } \\
\text { Olivine price: } \$ 172.90 / \text { ton [65] } \\
\text { MgO price: } \$ 365 / \text { ton [66] }\end{array}$ \\
\hline Solids disposal cost & Price: $\$ 18 /$ ton [67] \\
\hline Diesel fuel & $\begin{array}{l}\text { Usage: } 10 \text { gallon/hr plant wide use } \\
\text { Price: } \$ 1.00 / \text { gallon [68] }\end{array}$ \\
\hline Chemicals & $\begin{array}{l}\text { Boiler chemicals - Price: } \$ 2.80 / \mathrm{lb}[3] \\
\text { Cooling tower chemicals - Price: } \$ 2.00 / \mathrm{lb}[3] \\
\text { LO-CAT chemicals - Price: } \$ 150 / \text { tonne of sulfur produced [69] }\end{array}$ \\
\hline Waste Water & $\begin{array}{l}\text { The waste water is sent off-site for treatment. } \\
\text { Price: } \$ 2.07 / 100 \mathrm{ft}^{3}[70]\end{array}$ \\
\hline
\end{tabular}


Previous biomass gasification studies have not looked at fixed operating costs (i.e. salaries, overhead, maintenance, etc) in detail, therefore little data were available. As a result, the fixed operating costs for a biochemical ethanol facility given in Aden, et al., 2002 [3] were used as a starting point to develop fixed costs for this thermochemical design.

The fixed operating costs used in this analysis are shown in Table 19 (labor costs) and Table 20 (other fixed costs). They are shown in 2002 U.S. dollars. The following changes in base salaries and number of employees were made compared to those used in the ethanol plant design in Aden, et al., 2002 [3].

- Plant manager salary raised from $\$ 80,000$ to $\$ 110,000$

- Shift supervisor salary raised from $\$ 37,000$ to $\$ 45,000$

- Lab technician salary raised from $\$ 25,000$ to $\$ 35,000$

- Maintenance technician salary raised from $\$ 28,000$ to $\$ 40,000$

- Shift operators salaries raised from $\$ 25,000$ to $\$ 40,000$

- Yard employees salaries raised from $\$ 20,000$ to $\$ 25,000$ and number reduced from 32 to 12.

- General manager position eliminated

- Clerks and secretaries salaries raised from $\$ 20,000$ to $\$ 25,000$ and number reduced from 5 to 3 .

The number of yard employees was changed to reflect a different feedstock and feed handling system compared to Aden, et al., 2002 [3]. Handling baled stover requires more hands-on processing when compared to a wood chip feedstock. Based on a 4-shift system, 3 yard employees were estimated to be needed, mostly to run the front end loaders. The general manager position was eliminated because a plant manager would likely be sufficient for this type of facility. Biomass gasification plants are more likely to be operated by larger companies instead of operating like the dry mill ethanol model of farmer co-ops. Finally, the number of clerks and secretaries was reduced from 5 to 3 . The estimate of three comes from needing 1 to handle the trucks and scales entering and leaving the facility, 1 to handle accounting matters, and 1 to answer phones, do administrative work, etc.

Table 19. Labor Costs

\begin{tabular}{|l|c|c|c|}
\hline \multicolumn{1}{|c|}{ Position } & Salary & Number & Total Cost \\
\hline Plant manager & $\$ 110,000$ & 1 & $\$ 110,000$ \\
\hline Plant engineer & $\$ 65,000$ & 1 & $\$ 65,000$ \\
\hline Maintenance supervisor & $\$ 60,000$ & 1 & $\$ 60,000$ \\
\hline Lab manager & $\$ 50,000$ & 1 & $\$ 50,000$ \\
\hline Shift supervisor & $\$ 45,000$ & 5 & $\$ 225,000$ \\
\hline Lab technician & $\$ 35,000$ & 2 & $\$ 70,000$ \\
\hline Maintenance technician & $\$ 40,000$ & 8 & $\$ 320,000$ \\
\hline Shift operators & $\$ 40,000$ & 20 & $\$ 800,000$ \\
\hline Yard employees & $\$ 25,000$ & 12 & $\$ 300,000$ \\
\hline Clerks \& secretaries & $\$ 25,000$ & 3 & $\$ 75,000$ \\
\hline Total salaries $(2002 \$)$ & & $\$ 2,080,000$ \\
\hline \multicolumn{2}{|r|}{$(2005 \$)$} & & $\$ 2,270,000$ \\
\hline
\end{tabular}


Since the salaries listed above are not fully loaded (i.e. do not include benefits), a general overhead factor was used. This also covers general plant maintenance, plant security, janitorial services, communications, etc. The 2003 PEP yearbook [71] lists the national average loaded labor rate at $\$ 37.66$ per hr. Using the salaries in Table 19 above along with the $60 \%$ general overhead factor from Aden, et al. [3] gave an average loaded labor rate of $\$ 30 \mathrm{per}$ hr. To more closely match the PEP yearbook average, the overhead factor was raised to $95 \%$. The resulting average loaded labor rate was $\$ 36$ per hr.

Table 20. Other Fixed Costs

\begin{tabular}{|l|c|c|}
\hline \multicolumn{1}{|c|}{ Cost Item } & Factor & Cost \\
\hline General overhead & 95\% of total salaries & $\$ 2,155,000$ \\
\hline Maintenance [52] & 2\% of total project investment & $\$ 3,817,000$ \\
\hline Insurance \& taxes [52] & 2\% of total project investment & $\$ 3,817,000$ \\
\hline
\end{tabular}

The updated salaries in Table 19 above were examined against salaries from a free salary estimation tool [72] which uses Bureau of Labor Statistics data and several other sources. Because the biomass analysis does not reflect a specific site in the United States, National Average Salaries for 2003 were used. With such an extensive listing of job titles in the salary estimation tool, a general position such as "clerks and secretaries" could be reflected by multiple job titles. In these instances, care was taken to examine several of the possible job titles that were applicable. A list of the job positions at the production plant and the corresponding job titles in the salary estimation tool [72] is shown in Table 21. Overall, the salaries used in the biomass-tohydrogen production plant design are close to the U.S. national average values given in column 4. 
Table 21. Salary Comparison

\begin{tabular}{|c|c|c|c|c|}
\hline $\begin{array}{c}\text { Job Title in } \\
\text { Biomass Plant }\end{array}$ & $\begin{array}{l}\text { Corresponding Job } \\
\text { Title in Salary } \\
\text { Estimating Tool [72] }\end{array}$ & $\begin{array}{c}\text { Salary Range } \\
\left(17^{\text {th }} \text { to } 67^{\text {th }}\right. \\
\text { percentile })\end{array}$ & $\begin{array}{c}\text { Average } \\
\text { Salary (U.S. } \\
\text { national } \\
\text { average) }\end{array}$ & $\begin{array}{c}\text { Salary used } \\
\text { in Biomass } \\
\text { Plant Design } \\
\text { (see Table 19) }\end{array}$ \\
\hline Plant manager & $\begin{array}{l}\text { Plant manager } \\
\text { (experience) }\end{array}$ & $\begin{array}{l}\$ 81,042- \\
\$ 220,409\end{array}$ & $\$ 106,900$ & $\$ 110,000$ \\
\hline Plant engineer & Plant engineer & $\$ 36,213-\$ 66,542$ & $\$ 58,324$ & $\$ 65,000$ \\
\hline \multirow[t]{3}{*}{$\begin{array}{l}\text { Maintenance } \\
\text { supervisor }\end{array}$} & $\begin{array}{l}\text { Maintenance crew } \\
\text { supervisor }\end{array}$ & $\$ 35,036-\$ 53,099$ & $\$ 45,191$ & \multirow[t]{3}{*}{$\$ 60,000$} \\
\hline & $\begin{array}{l}\text { Supervisor } \\
\text { maintenance }\end{array}$ & $\$ 34,701-\$ 56,097$ & $\$ 47,046$ & \\
\hline & $\begin{array}{l}\text { Supervisor } \\
\text { maintenance \& } \\
\text { custodians }\end{array}$ & $\$ 23,087-\$ 45,374$ & $\$ 39,924$ & \\
\hline Lab manager & Laboratory manager & $\$ 38,697-\$ 70,985$ & $\$ 51,487$ & $\$ 50,000$ \\
\hline Shift supervisor & Supervisor production & $\$ 32,008-\$ 51,745$ & $\$ 43,395$ & $\$ 45,000$ \\
\hline Lab technician & Laboratory technician & $\$ 25,543-\$ 41,005$ & $\$ 34,644$ & $\$ 35,000$ \\
\hline $\begin{array}{l}\text { Maintenance } \\
\text { technician }\end{array}$ & Maintenance worker & $\$ 27,967-\$ 46,754$ & $\$ 39,595$ & $\$ 40,000$ \\
\hline Shift operators & Operator control room & $\$ 33,983-\$ 61,362$ & $\$ 49,243$ & $\$ 40,000$ \\
\hline Yard employees & $\begin{array}{l}\text { Operator front end } \\
\text { loader }\end{array}$ & $\$ 24,805-\$ 39,368$ & $\$ 31,123$ & $\$ 25,000$ \\
\hline \multirow{3}{*}{$\begin{array}{l}\text { Clerks \& } \\
\text { secretaries }\end{array}$} & Administrative clerk & $\$ 19,876-\$ 25,610$ & $\$ 26,157$ & \multirow[t]{3}{*}{$\$ 25,000$} \\
\hline & Secretary & $\$ 20,643-\$ 31,454$ & $\$ 26,534$ & \\
\hline & Clerk general & $\$ 15,984-\$ 25,610$ & $\$ 22,768$ & \\
\hline
\end{tabular}

Overall, Aden, et al. [3] lists fixed operating costs totaling \$7.54MM in \$2000. Using the labor indices, this equates to $\$ 7.85 \mathrm{MM}$ in $\$ 2002$. On the other hand, the mixed alcohols design report has fixed operating costs totaling $\$ 12.06 \mathrm{MM}$ in $\$ 2005$.

\subsection{Value of Higher Alcohol Co-Products}

The alcohol synthesis process will create higher molecular weight alcohols. How this co-product is valued will depend upon its end market. There were two extreme cases envisioned. At the high end, these might be sold into the chemical market. This could command a high value for this coproduct, upwards to $\$ 3.70$ to $\$ 4.20$ per gallon [7]. However, it is unlikely that the market would support more than one or two biomass plants to support these prices. Because of this, the biomass process did not include any detailed separation or clean-up of the separate alcohols. It is envisioned that if this co-product was sold for this purpose, it would be transferred "over the fence" as is and the buyer would take on the costs of separation and clean-up. So, even at the high end, the highest value would be some fraction of the chemical market value.

At the low end, the co-product could command a value for a fuel with minimal ASTM standards on its specifications. This would be priced similar to a residual fuel oil. Historically, this is about $80 \%$ of gasoline price [73]. Using the ethanol minimum plant gate price as a scaled reference gasoline price (adjusted for ethanol's lower heating value), this translates to $\$ 0.85$ per gallon. 
For the baseline case, a middle ground was chosen. It is anticipated that the higher alcohols would make an excellent gasoline additive or gasoline replacement in its own right - engine testing and certification would be required. If this is done, then it should command a price similar to that of gasoline. Again using the ethanol minimum plant gate price as a scaled reference gasoline price and adjusting to n-propanol's heating value (the major constituent of the higher alcohol stream), then its value should be $\$ 1.25$ per gallon. However, since no special efforts were taken in the process design to clean up this stream to meet anticipated specs, its value is discounted to $\$ 1.15$ per gallon.

\subsection{Minimum Ethanol Plant Gate Price}

Once the capital and operating costs were determined, a minimum ethanol selling price (MESP) was determined using a discounted cash flow rate of return analysis. The methodology used is identical to that used in Aden, et al., (2002) [3]. The MESP is the selling price of ethanol that makes the net present value of the process equal to zero with a $10 \%$ discounted cash flow rate of return over a 20 year plant life. The base case economic parameters used in this analysis are given in Table 22. A sensitivity analysis was performed to examine the MESP for different financial scenarios. These are discussed in Section 4.

Table 22. Economic Parameters

\begin{tabular}{|l|c|}
\hline \multicolumn{1}{|c|}{ Assumption } & Value \\
\hline Internal rate of return (after-tax) & $10 \%$ \\
\hline Debt/equity & $0 \% / 100 \%$ \\
\hline Plant life & 20 years \\
\hline General plant depreciation & $200 \%$ DDB \\
\hline General plant recovery period & 7 years \\
\hline Steam plant depreciation & $150 \%$ DDB \\
\hline Steam plant recovery period & 20 years \\
\hline Construction period & 2.5 years \\
$1^{\text {st } 6 \text { months expenditures }}$ & $8 \%$ \\
Next 12 months expenditures & $60 \%$ \\
Last 12 months expenditures & $32 \%$ \\
\hline Start-up time & 6 months \\
Revenues & $50 \%$ \\
Variable costs & $75 \%$ \\
Fixed costs & $100 \%$ \\
\hline Working capital & 6\% of Total Capital Investment \\
\hline Land & (Cost taken as an expense in the $1^{\text {st }}$ \\
& construction year) \\
\hline
\end{tabular}

Note: The depreciation amount was determined using the same method as that documented in Aden, et al. [3] using the IRS Modified Accelerated Cost Recovery System (MACRS). 


\section{Process Economics, Sensitivity Analyses, and Alternate Scenarios}

The cost of ethanol as determined in the previous section was derived using technology that has been developed and demonstrated or is currently being developed as part of the OBP research program. Combined, all process, market, and financial targets in the design represent what must be achieved to obtain the reported $\$ 1.01$ per gallon. A summary of the breakdown of costs are depicted in Figure 8 and further tabulated in Appendix F.

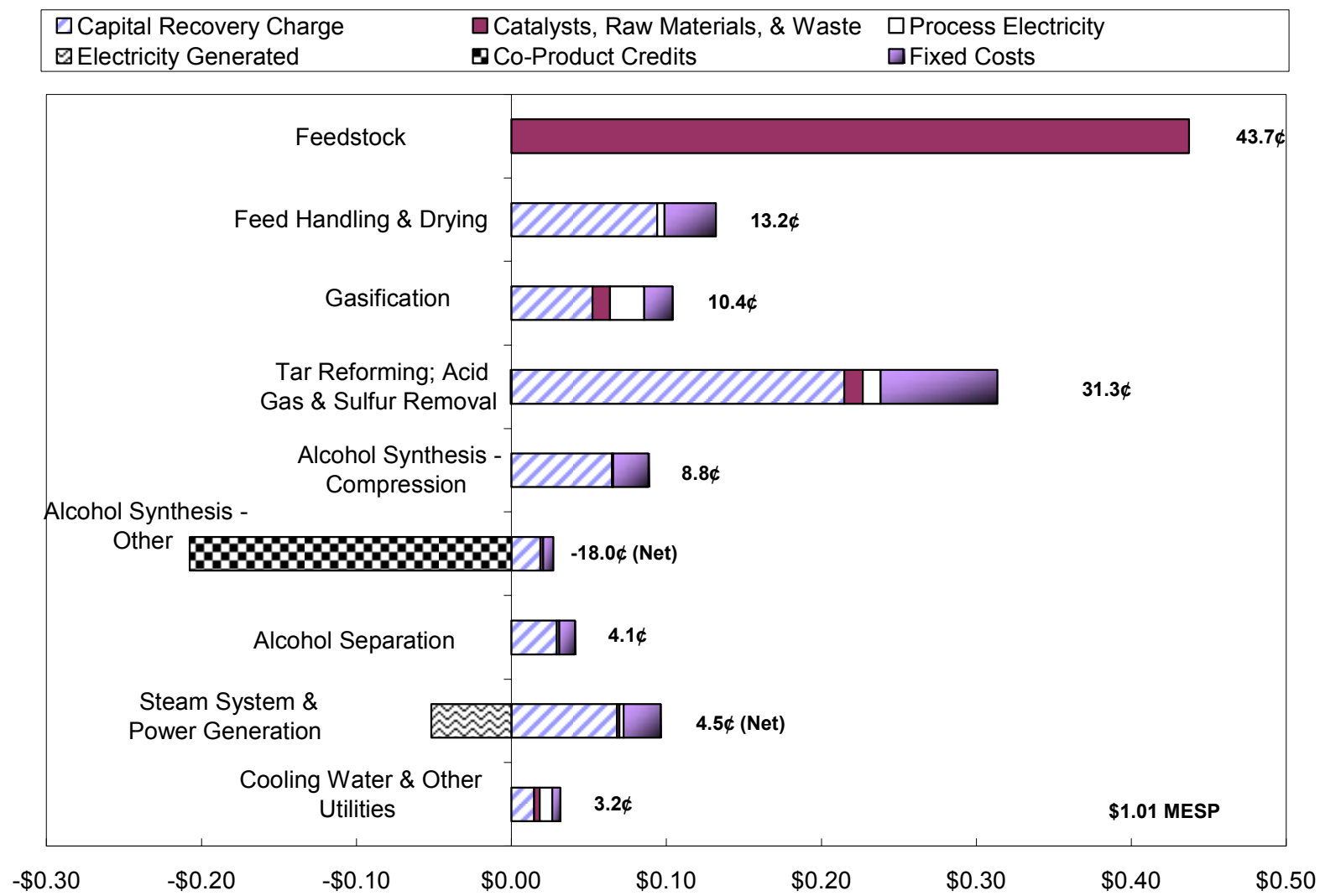

Figure 8. Cost contribution details from each process area

This cost contribution chart appears to show two different co-product credits: alcohols from the Alcohol Synthesis area and electricity from the Steam System \& Power Generation area. However, the process was adjusted so the electricity generated is balanced by the electricity required by all other areas, so there is no net credit for electricity generation.

The cost year chosen for the analysis had a significant effect on the results. As discussed in Section 1.1, capital costs increased significantly after 2003 primarily because of the large increase in steel costs worldwide. Figure 9 depicts how the MESP for this process would change depending on the cost year chosen for the analysis. Notice that between the years 2000 to 2003 the MESP would be much lower, $\$ 0.89$ to $\$ 0.91$ per gallon ethanol, instead of the $\$ 1.01$ determined for 2005 . The values for 2006 are tentative, since all factors necessary for the MESP calculation have not yet been published. 


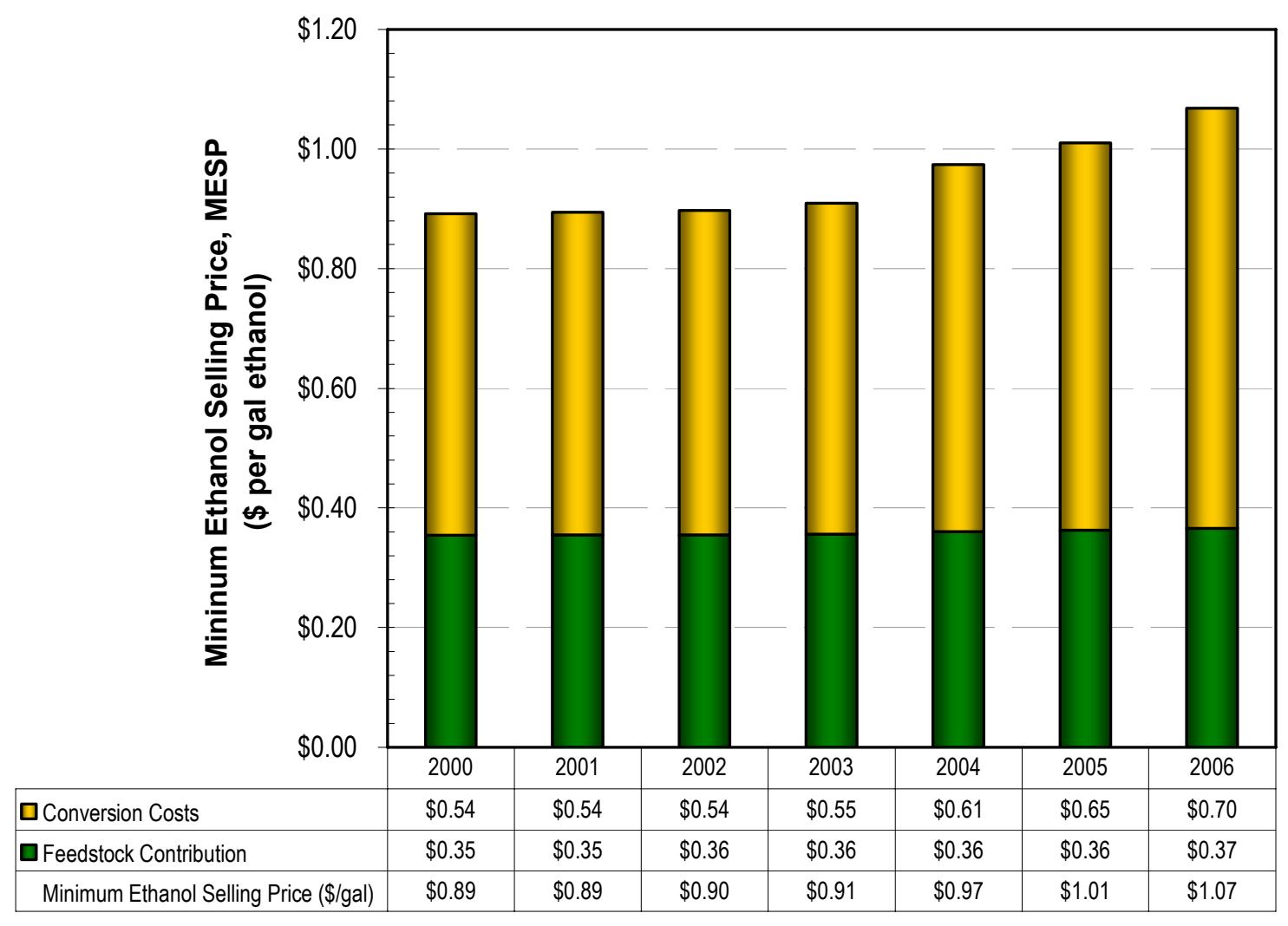

Figure 9. Effect of cost year on MESP ${ }^{h}$

The process costs (as indicated by the MESP) are determined from various assumptions on technology (based upon 2012 research targets), markets (such as the value of the higher alcohol co-products), and various financial assumptions (such as required Return on Investment, ROI). When any research target cannot be obtained, or a market or financial assumption does not hold, then the MESP is affected to varying degrees. In addition, uncertainty about equipment design and installation and construction costs will impact the economics. The key is to understand the impact of those types of parameters that are likely to vary, and how they might be controlled to a definable range. Discussed here are process targets that had been identified a priori as key ones to understand and achieve. (As can be seen from the sensitivity results, many items examined had much less affect on the MESP than had been thought.) In most cases, values used for the sensitivities are picked from current experimental data, to demonstrate the effect of technology advancement (or lack of) on the economic viability of the process.

\footnotetext{
${ }^{\mathrm{h}}$ Note that the relative splits between feedstock and conversion costs have been scaled to attribute some of the costs to the mixed alcohol co-products. So, the feedstock contribution appears to be different than what is depicted in the cost contribution chart for the different areas.
} 
The results for the sensitivity analysis discussed in the following sections are depicted in Figure 10; those sensitivities directly impacted by research programs are shown first. Nearly all of these ranges represent variations of a single variable at a time (e.g., ash content while holding the ratio of the non-ash elements constant). There are a couple exceptions to this:

- The feedstock comparison of corn stover to lignin necessitated varying the ultimate elemental analysis, ash content, and moisture content simultaneously.

- The Combined Tar Reformer Conversions incorporated all of the ranges listed for the methane, benzene, and tar simultaneously.

Note that all items in the chart have values associated with them. If a bar is not readily seen, then the MESP effect over the range listed is insignificant.

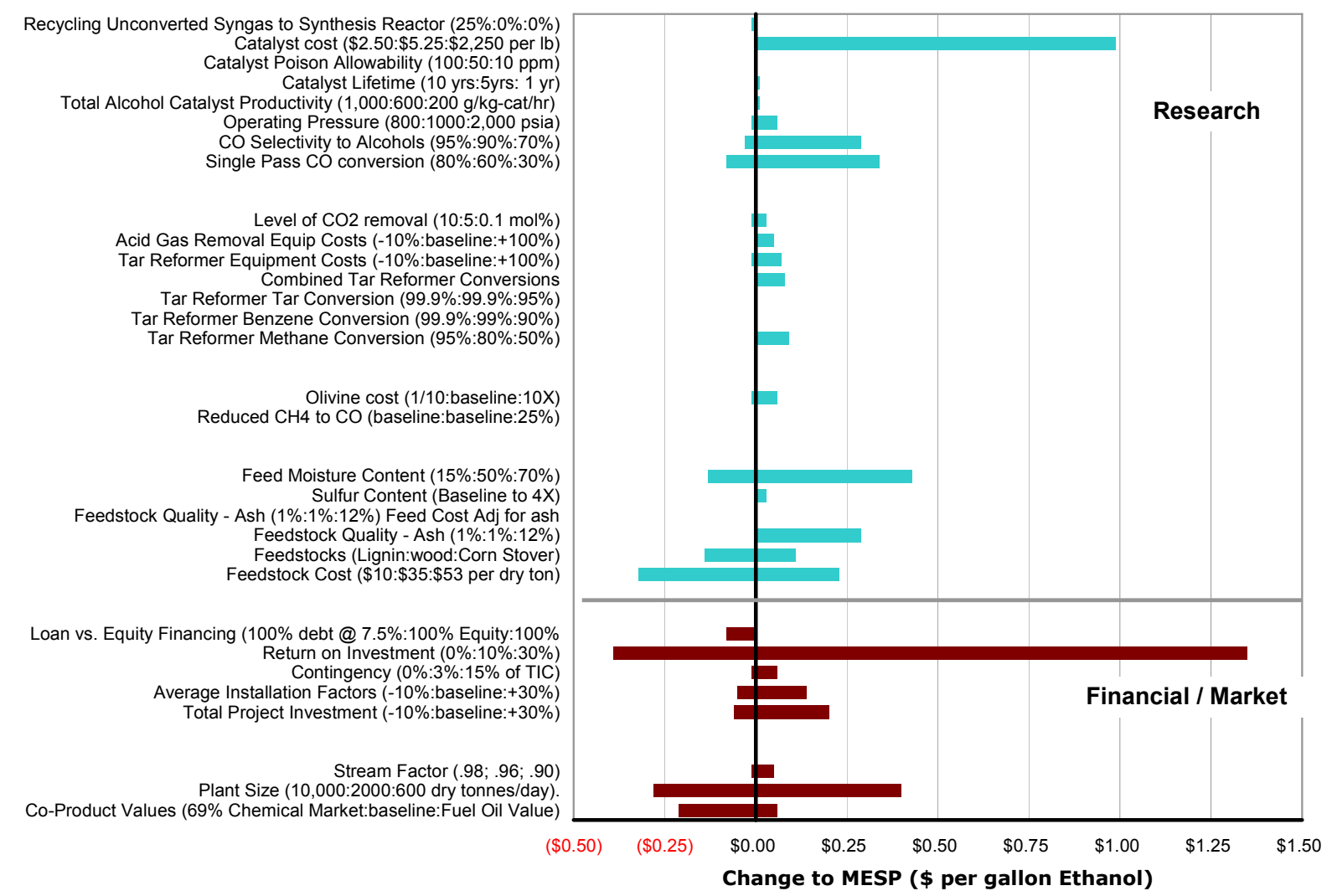

Figure 10. Results of sensitivity analyses

All analyses are discussed further in the following sections.

\subsection{Financial Scenarios}

These parameters have the greatest effect on the MESP but R\&D has the smallest direct effect on them. In particular, the required ROI for the project could more than double the calculated MESP. Successful R\&D and demonstration projects would, at best, ease the ROI requirements of corporations and/or lending institutions and reduce the required MESP toward the baseline case 
in this report. Also, the baseline of $0 \%$ debt financing is not a very realistic scenario, but does represent the conservative endpoint. Many projects of this nature are often financed by some mixture of debt and equity financing. However, the magnitude of this parameter's effect on MESP is quite small in comparison to many of the other financial and market parameters.

A conceptual design like this is normally thought to give accuracy in the capital requirements of $-10 \%$ to $+30 \%$. Using this range for the TPI (Total Project Investment) gives an MESP range of $6 \%$ to $+20 \%$.

\subsection{Feedstocks}

Because this process has been designed for utilization of forest resources there may be little control over the feedstock quality coming to the plant ${ }^{\mathrm{i}}$. The two most important feedstock quality parameters that can most impact the process economics are moisture and ash content.

The high range of the ash content examined here are more indicative of agricultural residues (from fertilizer) or lignin-rich biochemical process residues; forest resources should have ash contents near that of this baseline case (about 1\%). It was originally thought that the cost effects of high ash content could be damped by basing feedstock payments on a dry and ash-free basis, not just a dry basis. However, Figure 11 shows that this is not the case. Increased ash in the feedstock results in larger ash handling equipment and power requirements, especially in the electrostatic precipitator (ESP) used to remove ash fines from the flue gas. These higher power requirements are met by diverting more syngas to the fuel system to generate electricity. Keeping the feedstock cost constant on a moisture and ash free ("maf") basis decreases the MESP for high-ash feeds by reducing the cost per pound of biomass. However, at a constant mass feedrate to the process, there is inherently less carbon available for conversion to alcohols and therefore smaller revenues. The reduced revenues together with increased capital and operating costs result in an overall increase in MESP despite the lower feedstock cost.

The operating costs due to ash disposal may be reduced by finding an alternate use for the ash. One potential use may be as a soil amendment to replace minerals lost from the soil. The ash collected from gasification in this case should be comparable to the minerals removed from the soil during the plant growth. More study would be needed to determine the best and most economic method for using the ash as a soil amendment.

\footnotetext{
${ }^{\mathrm{i}}$ At least less so than using agricultural residues or energy crops that can be bred for specific properties in these lignocellulosic materials.
} 


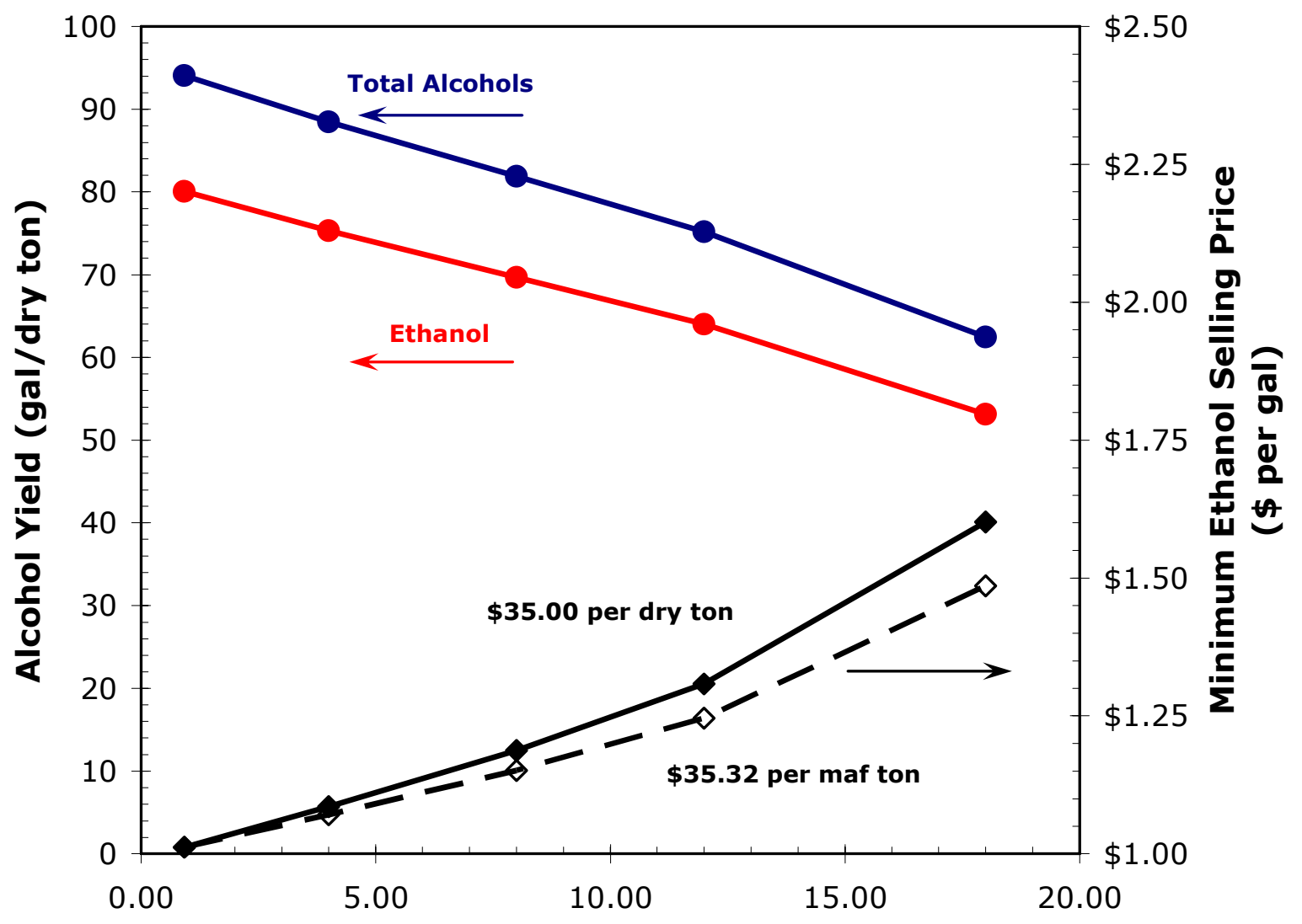

Biomass Ash Content (wt\%)

Figure 11. Sensitivity analysis of biomass ash content

The biomass feed's moisture content is a problem if it is higher than the baseline $50 \%$. This is not envisioned as being very likely except in the case of processing wet ensiled agricultural residues or energy crops; however, these feedstocks are more envisioned to be processed by biochemical means, not thermochemical means. Drier feedstocks will have lower MESPs because of decreased heat requirements to dry the incoming feedstock directly relate to lower raw syngas diversion to heat and power and higher alcohol yields. This is depicted in Figure 12 and Figure 13. As the moisture content increases, the alcohol yield will decrease because more raw syngas must be diverted for heat. Note that very low moisture contents do not give corresponding increased alcohol yields; this is because flue gas is used for the drying and other operating specifications dictate the amount of raw syngas diverted for heat and power, not the feedstock drying. 


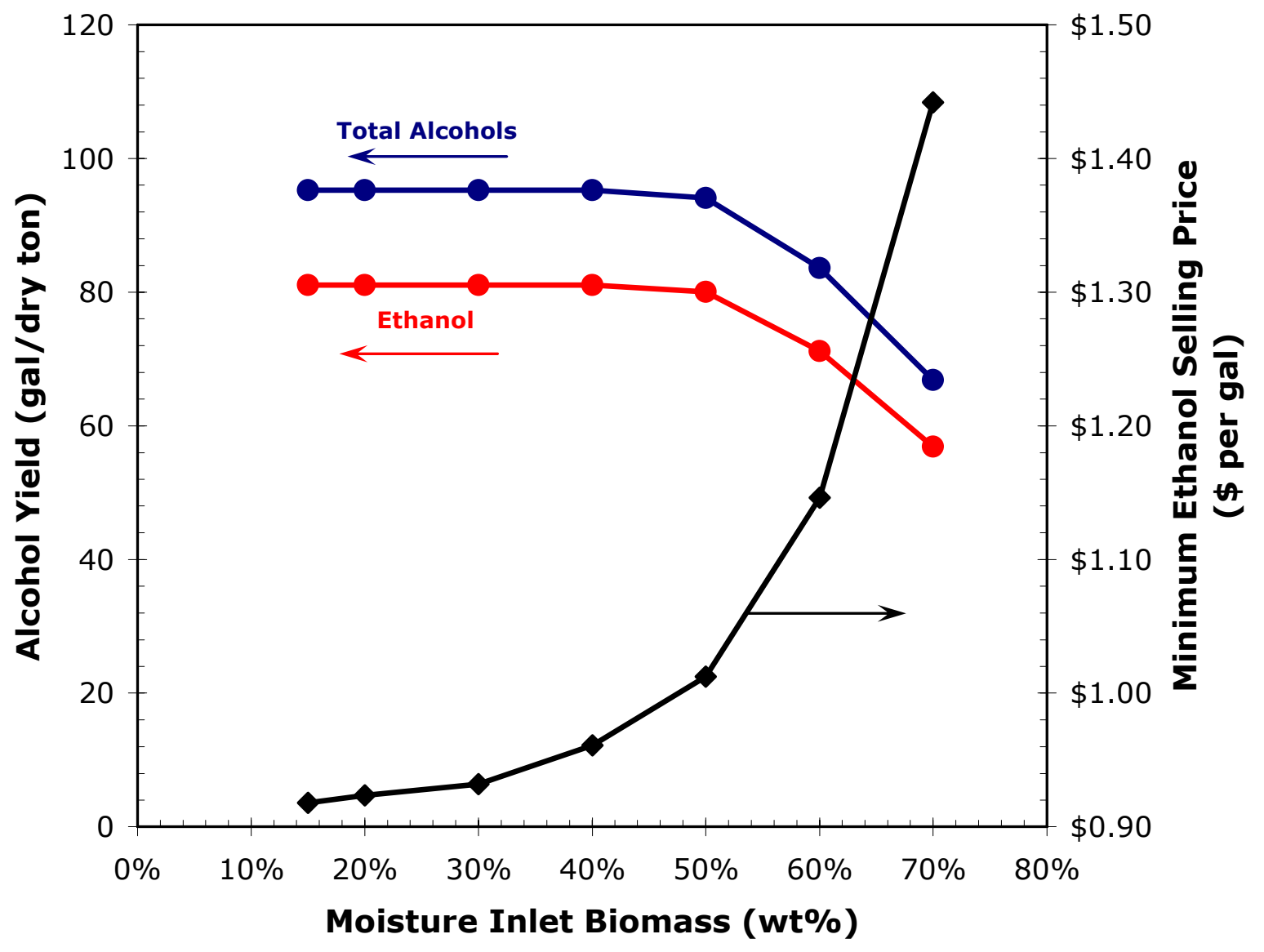

Figure 12. Sensitivity analysis of biomass moisture content 


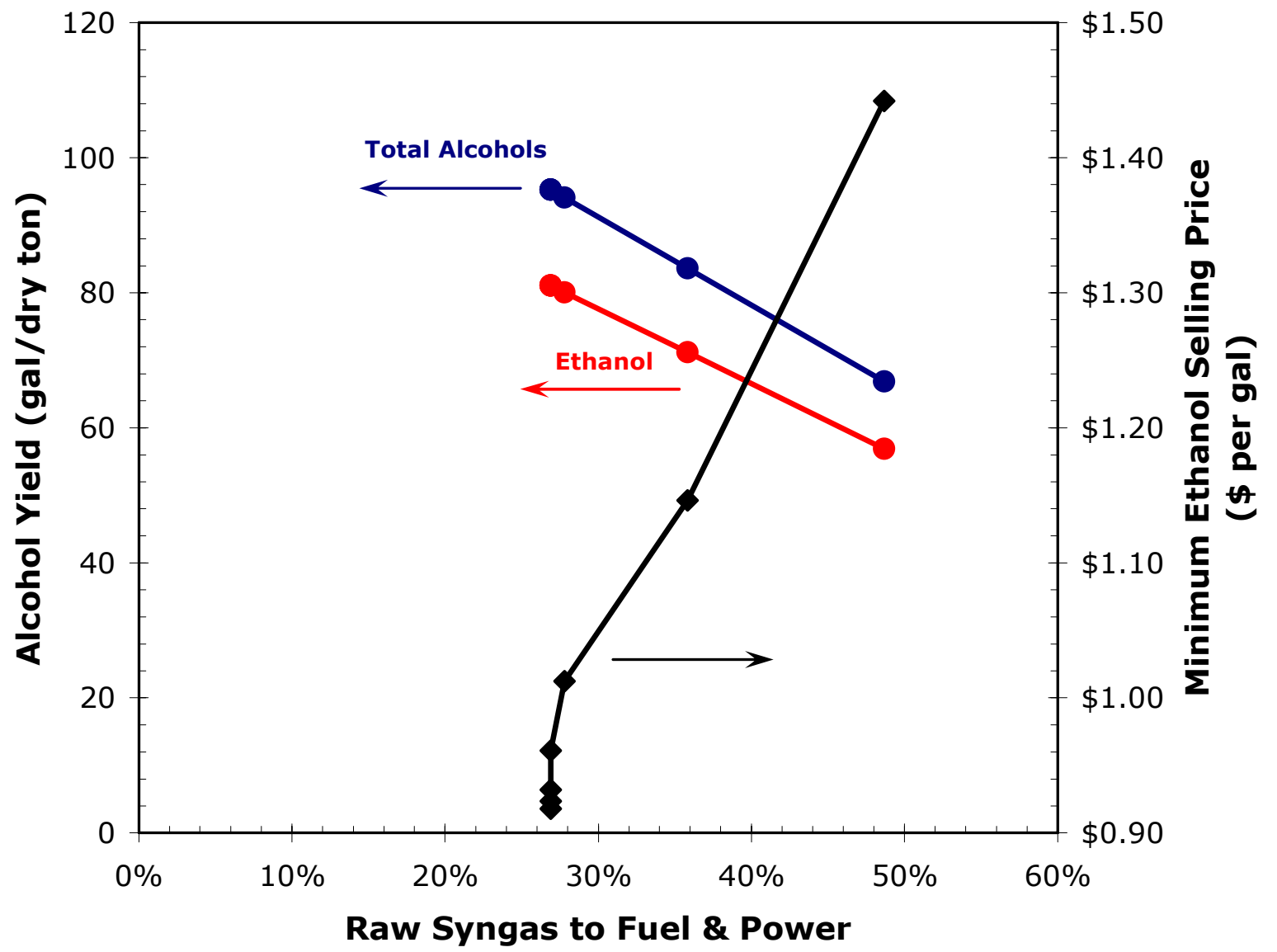

Figure 13. Sensitivity analysis of raw syngas diverted for heat and power due to biomass moisture content

Two combined scenarios were analyzed for two different kinds of feedstocks: corn stover and lignin-rich residues from a biochemical process. The compositions of both are consistent with the Aden et al. design report [3]. Corn stover gives rise to a higher MESP even though its elemental analysis is very similar to wood and its moisture content is very low. The overwhelming effect is due to its higher ash content. Lignin-rich residues have a much lower MESP. Lignin-rich residues also have the virtue of making more electricity than the process needs, so it is exported, even if the raw syngas to the fuel system is minimized while still achieving all other operating specifications. This is a very positive sign that incorporating a thermochemical conversion unit with a biochemical conversion unit and make the heat and power for the entire complex will be cost effective. The feed handling system may have to be different, however, since lignin tends to get very powdery when dried; direct contact with the flue gas for drying would very likely lead to high losses of the feedstock. Drying with indirect contact of the heating medium must be investigated. 


\subsection{Thermal Conversion}

Two gasification scenarios were examined. The first was to explore the impact of increasing the olivine cost which could come about from catalytic modification. Increasing the olivine cost by an order of magnitude could increase the MESP by $6 \%$. This is not significant. The second scenario examined the effect of reducing methane production in the gasifier to reflect a case where the gasifier does not operate within the given correlations. This gave an unexpected result. It was expected that the MESP would decrease when it actually increased a nearly insignificant amount $(0.1 \%)$. There are two reasons for this. One is an artifact of the way in which the decrease was modeled - more $\mathrm{CO}$ was formed and the hydrogen that would have gone to the methane instead went to the char (and was lost for further processing). This required modifications to the operations to keep the $\mathrm{H}_{2}$ :CO ratio to the alcohol synthesis reactor above 1.0 and, in doing so, increased the MESP.

\subsection{Clean-Up \& Conditioning}

These scenarios appeared to have an imperceptible effect on the MESP. However, this is misleading. The scenarios show primarily cost effects due to the material and energy balances. Since the amount of tar is small compared to the amount of $\mathrm{CO}$ and $\mathrm{H} 2$, these effects are small. In reality, Clean-Up and Conditioning is absolutely required for acceptable performance of gas compressors, waste water treatment, and alcohol synthesis catalysts. Excessive tars in the syngas would significantly impact compressors and waste water treatment with severe consequences to equipment and increased operating costs that are not rigorously modeled here. So, not meeting these targets would give poor performance, leading to greater cost effects than reflected by the sensitivity analysis for this area.

\subsection{Fuels Synthesis}

These scenarios show the importance of the R\&D for the synthesis catalysts. Poor performance could increase MESP by $25 \%$ or more. Whether this is due to actual non-target catalyst formulations or due to poor performance in Clean-Up and Conditioning that leads to poor alcohol synthesis catalyst performance, the cost effects are major. The catalyst cost sensitivity range was extremely large, from $\$ 2.50 / \mathrm{lb}$ to over $\$ 2,250 / \mathrm{lb}$. This was done to bracket a variety of potential catalyst systems, not just cobalt moly-sulfide. Exotic metals such as rhodium (Rh) or ruthenium $(\mathrm{Ru})$ can add considerable cost to a catalyst system even at relatively low concentrations. At low catalyst costs, total $\mathrm{CO}$ conversion and alcohol selectivity $\left(\mathrm{CO}_{2}\right.$-free basis) have the largest impact on the overall MESP. The catalyst productivity $(\mathrm{g} / \mathrm{kg} / \mathrm{hr})$ did not show much impact over the sensitivity range chosen. In reality, all of these catalyst performance indicators are tightly linked. It is unlikely that research could change one without affecting the others.

\subsection{Markets}

Crediting the co-product higher alcohols with the lower fuel oil value increases the MESP by about $6 \%$; this is still reasonable to meet the qualitative "cost competitive" target. Of even more significance is that selling these higher alcohols for even $69 \%$ of their chemical market value will lead to a significant reduction of MESP (about 20\%). This shows that the first couple thermochemical conversion plants could get a significant economic advantage in their early life by being able to do this. 


\section{Conclusions}

This analysis shows that biomass-derived ethanol from a thermochemical conversion process has the possibility of being produced in a manner that is "cost competitive with corn-ethanol" by 2012. This thermochemical conversion process would make use of many sub-processes that are currently used commercially (such as acid gas removal) but also requires the successful demonstration of R\&D targets being funded by the DOE's OBP.

This analysis has demonstrated that forest resources can be converted to ethanol in a cost competitive manner allowing greater flexibility in converting biomass resources to achieve stated volume targets by 2030 .

\section{Future Work}

Future R\&D work to develop and demonstrate reforming and synthesis catalysts is inherent in this study. There many other areas of demonstration and process development also required:

- Demonstrate gasifier performance on other feedstocks (agricultural residues such as corn stover, energy crops such as switchgrass, and lignin-rich residues that would be available from a co-located biochemical conversion process). Of particular importance for the lignin-rich residues is the impact on process performance of trace amounts of chemicals used in the biochemical processing that might negatively impact the thermochemical conversion process.

- Compare the relative merits of direct oxygen blown gasifiers to the indirect steam gasifier upon which this study is based.

- Examine the trade-offs of the greater use of water cooling (greater water losses in the cooling tower) vs. air cooling (greater power usage) vs. organic Rankine cycle for cooling and power production.

- Better understand the trade offs between operating conditions in the alcohol synthesis reactor to operating conditions (pressure, temperature, extent of reaction, extent of methanol recycle). A "tuned" kinetics based model would be required for this.

- Explore alternate synthesis reactor configurations (slurry phase vs. fixed bed).

- Understand trade offs between an energy neutral, alcohol production facility to one that could also supply heat and electricity to a co-located biochemical conversion facility.

- Further explore the potential benefits of integrating biochemical and thermochemical technologies. 
- Examine potential for decreased heat integration complexity and increased overall energy efficiency.

- Better understand the kinetics of catalytic tar reforming and deactivation, and the necessary regeneration kinetics to achieve a sustainable tar reforming process.

- Examine the emissions profile from the plant and explore alternate emissions control equipment. 


\section{References}

12006 State of the Union address, January 31, 2006.

http://www.whitehouse.gov/stateoftheunion/2006/

2 http://www.whitehouse.gov/news/releases/2006/01/20060131-6.html

3 Aden, A.; Ruth, M.; Ibsen, K.; Jechura, J.; Neeves, K.; Sheehan, J.; Wallace, B.; Montague, L.; Slayton, A.; Lukas, J. Lignocellulosic Biomass to Ethanol Process Design and Economics Utilizing Co-Current Dilute Acid Prehydrolysis and Enzymatic Hydrolysis for Corn Stover. NREL Report No. TP-510-32438. June 2002. http://www.nrel.gov/docs/fy02osti/32438.pdf

4 CEH Marketing Research Report - Ethyl Alcohol, Chemical Economics Handbook - SRI International, pp 50-51.2002

5 Wooley, R.; Ruth, M.; Sheehan, J.; Ibsen, K. Lignocellulosic Biomass to Ethanol Process Design and Economics Utilizing Co-Current Dilute Acid Prehydrolysis and Enzymatic Hydrolysis Current and Futuristic Scenarios, NREL report TP-580-26157, July 1999. http://devafdc.nrel.gov/pdfs/3957.pdf

6Perlack, R.D.; Wright, L.L.; Turhollow, A.F.; Graham, R.L.; Stokes, B.J.; Erbach, D.C. Biomass as Feedstock for a Bioenergy and Bioproducts Industry: the Technical Feasibility of a Billion-Ton Annual Supply. A joint U.S. Department of Energy and U.S. Department of Agriculture report. DOE/GO-102995-2135 \& ORNL/TM-2005/66. April 2005. http://www1.eere.energy.gov/biomass/pdfs/final billionton vision report2.pdf

7 Aden, A.; Spath, P.; Atherton, B. The Potential of Thermochemical Ethanol Via Mixed Alcohols Production. NREL Milestone Report. September 30, 2005.

http://devafdc.nrel.gov/bcfcdoc/9432.pdf

8 Bain, R.L. The Role of Thermochemical Processing in an Integrated Sugars/Thermochemical Biorefinery: Conceptual Process Technoeconomic Analysis. NREL Technical Memo, February 9, 2005. http://devafdc.nrel.gov/bcfcdoc/8967.pdf

9 Spath, P.; Aden, A.; Eggeman, T.; Ringer, M.; Wallace, B.; Jechura, J. Biomass to Hydrogen Production Detailed Design and Economics Utilizing the Battelle Columbus Laboratory Indirectly-Heated Gasifier. NREL Report No. Number NREL/TP-510-37408. May 30, 2005. http://www.nrel.gov/docs/fy05osti/37408.pdf

10 http://engineering.dartmouth.edu/rbaef/ Final report under development.

11 Larson, E.D.; Jin, H.; Celika, F.E. "Large-Scale Gasification-Based Co-Production of Fuels and Electricity from Switchgrass." Draft manuscript for Biomass \& Bioenergy. March 2006. 
12 E.D. Larson, G.W. McDonald, W. Yang, W.J. Frederick, K. Iisa, T.G. Kreutz, E.W. Malcom, and C.A. Brown, "A Cost-Benefit Assessment of Black Liquor Gasifier/Combined Cycle Technology Integrated into a Kraft Pulp Mill,” Tappi Journal, 83(6): 57-, June 2000.

13 Bain, R. L., K. R. Craig and R. P. Overend (2000). "Gasification for Heat and Power, Methanol, and Hydrogen," Chapter 9.2 of Industrial Uses of Biomass Energy, ed. F. RosilloCalle, et al., Taylor and France, London, UK, ISBN-0-7484-0884-3.

14 Wyman, C.E., R. L. Bain, N.D. Hinman, and D.J. Stevens, (1993) "Ethanol and Methanol from Cellulosic Materials, "Chapter 21 of Renewable Energy: Sources for Fuels and Electricity, ed T.B. Johansson, et al, Island Press.

15 Chem Systems "Assessment of Costs and Benefits of Flexible and Alternative Fuel Use in the U.S. Transportation Sector", by Chem Systems, Tarrytown, NY, for the U.S. Department of Energy, Washington, D.C., Report No. DOE/PE--0093, 46 pp, November 1989.

16 Feldmann, H.F., Paisley, M.A., Appelbaum, H.R., and D.R. Taylor, "Conversion of Forest Residues to a Methane-Rich Gas in a High- Throughput Gasifier", prepared by Battelle Columbus Division, Columbus, Ohio, for the Pacific Northwest Laboratory, Richland, WA, PNL Report no. PNL-6570, May 1988.

17 Wan, E. I. and M. D. Fraser, "Economic Assessment of Advanced Biomass Gasification Systems", by Science Applications International Corporation, McLean, VA, IGT Biomass Conference, New Orleans, LA, Feb 1989.

18 Wyman, C.E., R. L. Bain, N.D. Hinman, and D.J. Stevens, (1993) "Ethanol and Methanol from Cellulosic Materials, "Chapter 21 of Renewable Energy: Sources for Fuels and Electricity, ed T.B. Johansson, et al, Island Press.

19 Hamelinck, C. N. and A. P. C. Faaij (2001). "Future Prospects for Production of Methanol and Hydrogen from Biomass," Utrecht University, Utrecht, the Netherlands, Report No. NWS-E2001-49, ISBN-90-73958-84-9

20 Williams, R. H., E. D. Larson, R. E. Katofsky, and J. Chen (1995). "Methanol and Hydrogen from Biomass for Transportation, with Comparisons to Methanol and Hydrogen from Natural Gas and Coal," PU/CEES Report No. 292, Princeton University, Princeton, NJ, July.

21 Nexant Inc. Equipment Design and Cost Estimation for Small Modular Biomass Systems, Synthesis Gas Cleanup, and Oxygen Separation Equipment, Task 1: Cost Estimates of Small Modular Systems. Subcontract Report NREL/SR-510-39943. May 2006.

http://www.nrel.gov/docs/fy06osti/39943.pdf

22 Nexant Inc. Equipment Design and Cost Estimation for Small Modular Biomass Systems, Synthesis Gas Cleanup, and Oxygen Separation Equipment ,Task 2: Gas Cleanup Design and Cost Estimates - Wood Feedstock. Subcontract Report NREL/SR-510-39945. May 2006. http://www.nrel.gov/docs/fy06osti/39945.pdf 
23 Nexant Inc. Equipment Design and Cost Estimation for Small Modular Biomass Systems, Synthesis Gas Cleanup, and Oxygen Separation Equipment, Task 2.3: Sulfur Primer.

Subcontract Report NREL/SR-510-39946 May 2006.

http://www.nrel.gov/docs/fy06osti/39946.pdf

24 Nexant Inc. Equipment Design and Cost Estimation for Small Modular Biomass Systems, Synthesis Gas Cleanup, and Oxygen Separation Equipment, Task 9: Mixed Alcohols From Syngas - State of Technology. Subcontract Report NREL/SR-510-39947 May 2006. http://www.nrel.gov/docs/fy06osti/39947.pdf

25 Garrett, D.E., Chemical Engineering Economics, Van Nostrand Reinhold, New York, 1989.

26 Peters, M.S.; K.D. Timmerhaus. Plant Design and Economics for Chemical Engineers, $5^{\text {th }}$ Edition, McGraw-Hill, Inc., New York. 2003.

27 Perry, R.H., Green, D.W., Maloney, J.O. Perry’s Chemical Engineers' Handbook, $7^{\text {th }}$ ed., McGraw-Hill. 1997

28 October 2006 values used from http://www.che.com/inc/CEeconomicIndicators.php.

29 Craig, K.R.; Mann, M.K. Cost and Performance Analysis of Biomass-Based Integrated Gasification Combined-Cycle (BIGCC) Power Systems, NREL Report No. NREL/TP-43021657. October 1996. http://www.nrel.gov/docs/legosti/fy97/21657.pdf

30 Foust, T.; et al., A National Laboratory Market and Technology Assessment of the 30x30 Scenario. Draft in progress, 2007, DOE Report.

31 Mann, M.K.; Spath, P.L. Life Cycle Assessment of a Biomass Gasification Combined-Cycle Power System. National Renewable Energy Laboratory, Golden, CO, TP-430-23076. 1997. http:/www.nrel.gov/docs/legosti/fy98/23076.pdf

32 Phillips, S.; Carpenter, D.; Dayton, D.; Feik, C.; French, R.; Ratcliff, M.; Hansen, R.; Deutch, S.; and Michener, B. (2004). Preliminary Report on the Performance of Full Stream Tar Reformer. Internal NREL Milestone report.

33 Nexant Inc. Equipment Design and Cost Estimation for Small Modular Biomass Systems, Synthesis Gas Cleanup, and Oxygen Separation Equipment ,Task 2: Gas Cleanup Design and Cost Estimates - Wood Feedstock. Subcontract Report NREL/SR-510-39945. May 2006. http://www.nrel.gov/docs/fy06osti/39945.pdf

34 Gas Processors Suppliers Association. Engineering Data Book, FPS Version, $12^{\text {th }}$ ed., Tulsa, OK. 2004

35 A Claus unit for reducing sulfur was briefly considered as an alternative to LO-CAT, however the size of the stream and $\mathrm{H}_{2} \mathrm{~S}$ concentration made this a fairly impractical choice. 
36 Nexant, Inc. Equipment Design and Cost Estimation for Small Modular Biomass Systems, Synthesis Gas Cleanup, and Oxygen Separation Equipment. Task 9: Mixed Alcohols from Syngas - State of Technology. NREL/SR-510-39947. Performed by Nexant Inc., San Fransisco, CA. Golden, CO: National Renewable Energy Laboratory, May 2006. http://www.nrel.gov/docs/fy06osti/39947.pdf

37 Herman, R.G. (1991). "Chapter 7 - Classical and Non-classical Routes for Alcohol Synthesis.” New Trends in CO Activation, L. Guczi, ed., Elsevier, New York, pp 265-349.

38 Consult Appendix $\mathrm{J}$ for specific literature experiment.

39 Personal communication between Yves Parent at NREL and CRITERION (Houston, TX) on Friday, April 13, 2006.

40 Email correspondence between David Dayton, NREL, and Mark Jones, Dow Chemical. January 19, 2007.

41 Forzatti, P., Tronconi, E., and Pasquon, I. (1991). "Higher Alcohol Synthesis." Catalysis Reviews - Science and Engineering, 33(1-2), pp109-168.

42 Hamelinck, C.; et al. Production of FT Transportation Fuels from Biomass; Technical Options, Process Analysis, and Optimisation, and Development Potential. Utrecht University, Copernicus Institute. March 2003. ISBN 90-393-3342-4.

43 Quarderer, G.J. "Mixed Alcohols from Synthesis Gas.” Proceedings from the $78^{\text {th }}$ Spring National AIChE Meeting. April 6-10, 1986, New Orleans, LA.

44 Nirula, S. ”Dow / Union Carbide Process for Mixed Alcohols from Syngas" SRI International. March 1986. PEP Review No 85-1-4. Menlo Park, CA.

45 Park, T.; et al.; "Kinetic Analysis of Mixed Alcohol Synthesis from Syngas over K/MoS 2 Catalyst." Ind. Eng. Chem. Res. Vol 36, 1997. pp 5246 - 5257.

46 Gunturu, A.; et al. "A Kinetic Model for the Synthesis of High-Molecular-Weight Alcohols over a Sulfided Co-K-Mo/C Catalyst.” Ind. Eng. Chem. Res. Vol. 37, 1998. pp. 2107 - 2115.

47 Smith, K.; et al. "Kinetic Modeling of Higher Alcohol Synthesis over Alkali-Promoted $\mathrm{Cu} / \mathrm{ZnO}$ and MoS2 Catalysts." Chemical Engineering Science, Vol. 45. 1990. pp. 2639 - 2646.

48 Gas Processors Suppliers Association. Engineering Data Book, FPS Version, $12^{\text {th }}$ ed., Tulsa, OK. 2004

49 Weast, R.C., ed. CRC Handbook of Chemistry and Physics, $62^{\text {nd }}$ ed., CRC Press, Boca Raton, FL. 1981 
50 Aden, et .al. "Lignocellulosic Biomass to Ethanol Process Design and Economics Utilizing Co-Current Dilute Acid Prehydrolysis and Enzymatic Hydrolysis for Corn Stover", NREL/TP510-32438, June 2002.

51 Keeney, D.; et al. "Water Use by Ethanol Plants Potential Challenges". Institute for Agriculture and Trade Policy, Minneapolis, MN. October 2006. http://www.iatp.org/iatp/publications.cfm?accountID=258\&refID=89449

52 Peters, M.S.; K.D. Timmerhaus. Plant Design and Economics for Chemical Engineers, $5^{\text {th }}$ Edition, McGraw-Hill, Inc., New York. 2003.

53 Breault, R.; Morgan, D. Design and Economics of Electricity Production Form An Indirectlyheated Biomass Gasifier. Report TR4533-049-92. Columbus, Ohio: Battelle Columbus Laboratory. 1992.

54 Dravo Engineering Companies. Gasification Capital Cost Estimation. Obtained from Mark Paisley, August, 1994. Battelle Columbus Laboratory. 1987.

55 Weyerhaeuser, Nexant, and Stone \& Webster. Biomass Gasification Combined Cycle. Weyerhaeuser Company, Tacoma, WA . DOE DE-FC36-96GO10173. 2000.

56 Stone \& Webster; Weyerhaeuser; Amoco; and Carolina Power \& Light. New Bern Biomass to Energy Project Phase 1 Feasibility Study. Response to NREL Contract No. LOI No. RCA-313326. NREL Report No. TP-421-7942. June 1995.

57 Wan, E. I. and Malcolm D. F. "Economic Assessment of Advanced Biomass Gasification Systems," in Energy from Biomass and Wastes XIII, Donald L. Klass, ed. Chicago: Institute of Gas Technology, pp.791-827. 1990.

58 Weyerhaeuser. Gasification Capital Cost Estimation. Obtained from Mark Paisley, August, 1994. Battelle Columbus Laboratory. 1992.

59 Wright, J.; Feinberg, D. A Comparison of the Production of Methanol and Ethanol from Biomass. For the International Energy Agency. Contract no. 23218-1-9201/01-SQ. 1993.

60 Craig, K. Electric Power Generation Cost - Version 1.11 spreadsheet from Kevin Craig. July 6, 1994.

61 Fogler, H.S. Elements of Chemical Reaction Engineering. Second Edition. Prentice Hall. Englewood Cliffs, New Jersey. 1992.

62 Kohl, A.L.; Nielsen, R.B. Gas Purification, $5^{\text {th }}$ Edition. Gulf Publishing Company. 1997

63 Walas, S.M. Chemical Process Equipment Selection and Design. Butterworth-Heinemann. 1988. 
64 Leiby, S.M. (1994) Operations for Refinery Hydrogen. SRI Report No. 212. Menlo Park, CA.

65 Jeakel, D. (2004). Price quote from AGSCO for super sacks or bulk.

66 Chemical Marketing Reporter. (2004). August 23-30 issues.

67 Chem Systems. (1994). Biomass to Ethanol Process Evaluation. Prepared for NREL.

Tarrytown, New York.

68 Energy Information Agency (EIA). 2003.

http://www.eia.doe.gov/pub/oil gas/petroleum/data publications/petroleum marketing monthly /current/pdf/pmmtab16.pdf.

69 Graubard, D. Personal correspondence. Gas Technology Products LLC. Schaumburg, IL. 2004

70 East Bay municipal utility district. 2004.

http://www.ebmud.com/wastewater/industrial_\& commercial permits \& fees/wastewater_rates /default.htm\#non-residential\%20rates

71 SRI International. (2003). PEP Yearbook International. Volume 1E. United States. Menlo Park, CA.

72 Baker, Thomsen Associates Insurance Services Inc. (BTA), Salary Expert ePro®), www.salaryexpert.com, 2004.

73 Based on historical wholesale prices found on the Energy Information Agency web site, http://www.eia.doe.gov/oil_gas/petroleum/info glance/petroleum.html 
Appendix A

\section{List of Acronyms}




\begin{tabular}{|c|c|c|c|}
\hline ASME & $\begin{array}{l}\text { American Society of Mechanical } \\
\text { Engineers }\end{array}$ & MTBE & Methyl-tertiary-butyl Ether \\
\hline BCL & Battelle Columbus Laboratory & MW & Megawatts \\
\hline BFW & Boiler Feed Water & NREL & National Renewable Energy Laboratory \\
\hline bpd & Barrels per Day & NRTL & $\begin{array}{l}\text { Non-Random Two Liquid activity } \\
\text { coefficient method }\end{array}$ \\
\hline BTU & British Thermal Unit & OBP & Office of the Biomass Program \\
\hline CFM & Cubic Feet per Minute & PFD & Process flow diagram \\
\hline $\mathrm{CH}_{4}$ & Methane & PEFI & Power Energy Fuels, Inc. \\
\hline CIP & Clean-in-place & PNNL & Pacific Northwest National Laboratory \\
\hline $\mathrm{CO}$ & Carbon Monoxide & PPMV & Parts per million by volume \\
\hline Co & Cobalt & psia & Pounds per square inch (absolute) \\
\hline $\mathrm{CO}_{2}$ & Carbon Dioxide & RKS-BM & $\begin{array}{l}\text { Redlich-Kwong-Soave equation of state } \\
\text { with Boston-Mathius modifications }\end{array}$ \\
\hline DCFROR & $\begin{array}{l}\text { Discounted Cash Flow Rate of } \\
\text { Return }\end{array}$ & SEHT & $\begin{array}{l}\text { Snamprogetti, Enichem and Haldor } \\
\text { Topsoe }\end{array}$ \\
\hline DOE & US. Department of Energy & SMR & Steam Methane Reformer \\
\hline EIA & $\begin{array}{l}\text { Energy Information } \\
\text { Administration }\end{array}$ & TC EtOH & Thermochemical Ethanol \\
\hline EtOH & Ethanol & tpd & Short Tons per Day \\
\hline FT & Fischer-Tropsch & TPI & Total Project Investment \\
\hline FY & Fiscal Year & UCC & Union Carbide Corp. \\
\hline GHSV & Gas Hourly Space Velocity & WGS & Water Gas Shift \\
\hline GJ & GigaJoule & WRI & Western Research Institute \\
\hline gpm & Gallons per minute & WWT & Wastewater Treatment \\
\hline $\mathbf{H}_{2}$ & Hydrogen & & \\
\hline HAS & Higher Alcohol Synthesis & & \\
\hline HHV & Higher Heating Value & & \\
\hline IFP & Institut Francais du Petrole & & \\
\hline IRR & Internal Rate of Return & & \\
\hline kWh & Kilowatt-hour & & \\
\hline LHV & Lower Heating Value & & \\
\hline MA & Mixed Alcohols & & \\
\hline MASP & Minimum alcohols selling price & & \\
\hline МeOH & Methanol & & \\
\hline MESP & Minimum ethanol selling price & & \\
\hline $\mathbf{M o S}_{2}$ & Molybdenum disulfide & & \\
\hline
\end{tabular}




\section{Appendix B}

\section{OBP Thermochemical Platform Research Targets}




\section{Background/Introduction}

Thermochemical conversion technology options include both gasification and pyrolysis. Thermochemical conversion is envisioned to be important in enabling lignocellulosic biorefineries and to maximize biomass resource utilization for the production of biofuels. Moving forward, the role of thermochemical conversion is to provide a technology option for improving the economic viability of the developing bioenergy industry by converting the fraction of the biomass resources that are not amenable to biochemical conversion technologies into liquid transportation fuels. The thermochemical route to ethanol is synergistic with the biochemical conversion route. A thermochemical process can more easily convert lowcarbohydrate or "non-fermentable" biomass materials such as forest and wood residues to alcohol fuels, which adds technology robustness to efforts to achieve the $30 \mathrm{x} 30$ goal (Foust, et al., 2006). This Appendix describes the R\&D needed to achieve the market target production price in 2012 for a stand-alone biomass gasification/mixed alcohol process. Future advanced technology scenarios rely on considerable biofuel yield enhancements achieved by combining biochemical and thermochemical conversion technologies into an integrated biorefinery that implements mixed alcohol production from gasification of lignin-rich bioconversion residues to maximize the liquid fuel yield per delivered ton of biomass.

Biomass gasification can convert a heterogeneous supply of biomass feedstock into a consistent gaseous intermediate that can then be reliably converted to liquid fuels. The biomass gasification product gas ("synthesis gas" or simply "syngas") has a low to medium energy content (depending on the gasifying agent) and consists mainly of $\mathrm{CO}, \mathrm{H}_{2}, \mathrm{CO}_{2}, \mathrm{H}_{2} \mathrm{O}, \mathrm{N}_{2}$, and hydrocarbons. Minor components of the syngas include tars, sulfur and nitrogen oxides, alkali metals, and particulates. These minor components of the syngas potentially threaten the successful application of downstream syngas conversion steps.

Commercially available and near-commercial syngas conversion processes were evaluated on technological, environmental, and economic bases (Spath and Dayton, 2003). This design report provides the basis for identifying promising, cost-effective fuel synthesis technologies that maximize the impact of biomass gasification for transforming biomass resources into clean, affordable, and domestically produced biofuels. For the purpose of this report the precommercial mixed alcohols synthesis process implementing an alkali promoted $\mathrm{MoS}_{2}$ catalyst, a variant of Fischer-Tropsch synthesis, was selected as the conversion technology of choice because high yields of ethanol are possible with targeted R\&D technology advancements. The $\mathrm{MoS}_{2}$ catalyst is also tolerant of low levels of sulfur gases that are common catalyst poisons. The proposed mixed alcohol process does not produce ethanol with $100 \%$ selectivity. Production of higher normal alcohols (e.g., n-propanol, n-butanol, and n-pentanol) is unavoidable. Fortunately, these by-product higher alcohols have value as commodity chemicals, fuel additives, or potentially fuels in their own right.

The schedule for meeting specific research goals for improved tar reforming and mixed alcohol synthesis catalyst performance was accelerated by the President's Advanced Energy Initiative to achieve cost-competitive cellulosic ethanol by 2012. This design report provides a rigorous engineering analysis to provide a baseline technology scenario for doing this. The conceptual process design and ethanol production cost estimate quantify the benefits of meeting the R\&D 
goals for tar reforming and improved mixed alcohol catalyst performance helps establish technical R\&D targets that need to be overcome by a concerted and directed core research effort.

\section{Process Description}

Figure 1 shows a block process flow diagram of the cost-competitive target process and the major technical barriers that need to be addressed to accomplish this target case. The feedstock interface addresses the main biomass fuel properties that impact the long-term technical and economic success of a thermochemical conversion process: moisture content, fixed carbon and volatiles content, impurity (sulfur, nitrogen, chlorine) concentrations, and ash content. High moisture and ash contents reduce the usable fraction of delivered biomass fuels proportionally. Therefore, maximum system efficiencies should be possible with dry, low ash biomass fuels.

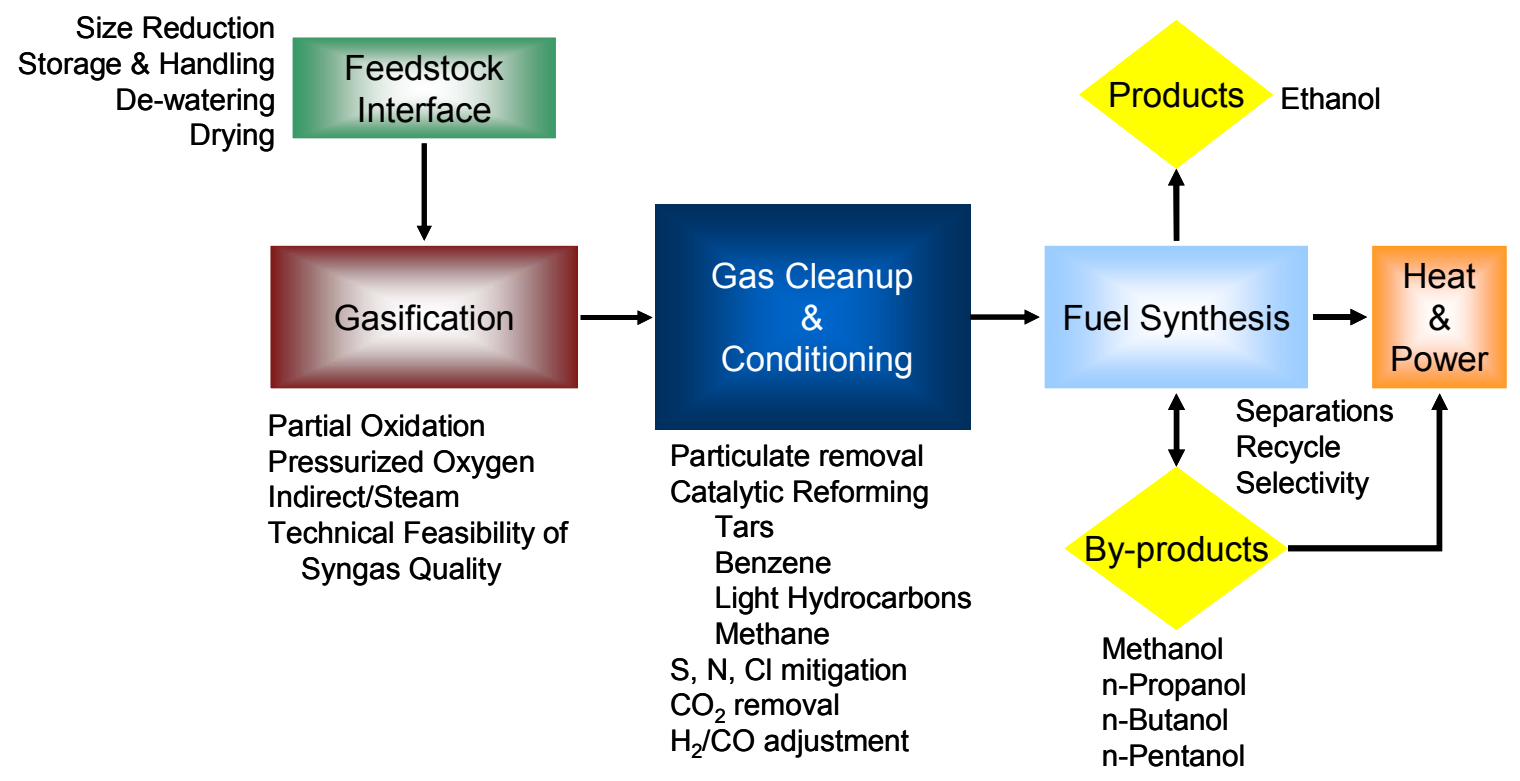

Figure 1. Process flow diagram with research barriers for cost-competitive thermochemical ethanol production

Biomass gasification is a complex thermochemical process that begins with the thermal decomposition of a lignocellulosic fuel followed by partial oxidation of the fuel with a gasifying agent, usually air, oxygen, or steam to yield a raw syngas. The raw gas composition and quality are dependent on a wide range of factors including feedstock composition, type of gasification reactor, gasification agents, stoichiometry, temperature, pressure, and the presence or lack of catalysts.

Gas cleanup is a general term for removing the unwanted impurities from biomass gasification product gas and generally involves an integrated, multi-step approach that depends on the end use of the product gas. This entails removing or eliminating tars, acid gas removal, ammonia scrubbing, alkali metal capture, and particulate removal. Gas conditioning refers to final modifications to the gas composition that makes it suitable for use in a fuel synthesis process. Typical gas conditioning steps include sulfur polishing to remove trace levels of remaining $\mathrm{H}_{2} \mathrm{~S}$ and water-gas shift to adjust the final $\mathrm{H}_{2}$ : $\mathrm{CO}$ ratio for optimized fuel synthesis. 
Comprehensive cleanup and conditioning of the raw biomass gasification product gas yields a "clean" syngas comprised of essentially $\mathrm{CO}$ and $\mathrm{H}_{2}$, in a given ratio that can converted to a mixed alcohol product. Separation of ethanol from this product yields a methanol-rich stream that can be recycled with unconverted syngas to improve process yield. The higher alcohol-rich stream yields by-product chemical alcohols. The fuel synthesis step is exothermic so heat recovery is essential to maximize process efficiency.

\section{R\&D Needs To Achieve the 2012 Technical Target for Thermochemical Ethanol}

Essential R\&D activities from 2007 through 2011 to overcome identified technical barrier areas to meet the established 2012 technical target for thermochemical ethanol production are outlined in Table 1. The rigorous engineering analysis of the thermochemical ethanol process conducted in this study will help to validate the feasibility of these technical targets and provide focus for the technical barriers that provide the largest economic benefit. These R\&D activities include fundamental kinetic measurements, micro-activity catalyst testing, bench-scale thermochemical conversion studies, pilot-scale validation of tar reforming catalyst performance, mixed alcohol catalyst development, and pilot-scale demonstration of integrated biomass gasification mixed alcohol synthesis. Process data collected in the integrated pilot-scale testing will provide the basis for process optimization and cost estimates that will guide deployment of the technology. 
Table 1. Thermochemical Ethanol (Gasification/Mixed Alcohols) R\&D Targets to meet the 2012 Cost-Competitive Thermochemical Ethanol Cost Target

\begin{tabular}{|c|c|c|c|c|c|c|c|}
\hline R\&D Area & Current & 2007 & 2008 & 2009 & 2010 & 2011 & 2012 \\
\hline $\begin{array}{l}\text { Feedstock } \\
\text { Interface }\end{array}$ & $\begin{array}{l}\$ 30 / \text { dry ton wood chips } 50 \% \\
\text { moisture dried to } 12 \%-2000 \\
\text { tpd plant }\end{array}$ & & & & & $\begin{array}{l}\$ 30 / \text { dry ton biorefinery } \\
\text { residues based on } \$ 45 / \text { dry ton } \\
\text { corn stover. } 50 \% \text { moisture } \\
\text { dried to } 12 \%-2000 \text { tpd plant }\end{array}$ & \\
\hline $\begin{array}{l}\text { Thermochemical } \\
\text { Conversion - } \\
\text { Gasification }\end{array}$ & $\begin{array}{l}\text { Wood chips (model) - Indirect } \\
\text { (atm) gasification - } 78 \% \\
\text { syngas efficiency: } \\
\\
\mathrm{H}_{2} / \mathrm{CO}=1.0-1.5 \\
\mathrm{CH}_{4} \leq 15 \mathrm{vol} \% \\
\mathrm{Tars} \leq 30 \mathrm{~g} / \mathrm{Nm}^{3} \\
\text { benzene } \leq 1 \mathrm{vol} \% \\
\mathrm{H}_{2} \mathrm{~S}=50-600 \mathrm{ppm} \\
\mathrm{NH}_{3} \text { and } \mathrm{HCl} \text { to be } \\
\text { determined }\end{array}$ & $\begin{array}{l}\text { Biorefinery residues - Indirect } \\
\text { (atm) gasification : corn } \\
\text { stover; switchgrass; wheat } \\
\text { straw; lignin - } 78 \% \text { syngas } \\
\text { efficiency: } \\
\mathrm{H}_{2} / \mathrm{CO}=1.0-1.5 \\
\mathrm{CH}_{4} \leq 15 \mathrm{vol} \% \\
\text { Tars } \leq 30 \mathrm{~g} / \mathrm{Nm}^{3} \text {; benzene } \leq \\
1 \mathrm{vol} \% \\
\mathrm{H}_{2} \mathrm{~S}=50-600 \mathrm{ppm} \\
\mathrm{NH}_{3} \text { and } \mathrm{HCl} \text { to be } \\
\text { determined }\end{array}$ & $\begin{array}{l}\text { Demonstrate biomass } \\
\text { gasification for } \\
\$ 6.88 / \text { MMBtu syngas cost } \\
\text { based on } 2007\end{array}$ & $\begin{array}{l}\text { Indirect (atm) gasification }- \\
78 \% \text { syngas efficiency: } \\
\\
\mathrm{H}_{2} / \mathrm{CO}=1.0-1.5 \\
\mathrm{CH}_{4} \leq 8 \mathrm{vol} \% \\
\mathrm{Tars} \leq 10 \mathrm{~g} / \mathrm{Nm}^{3} ; \text { benzene } \leq \\
0.1 \text { vol } \% ; \mathrm{H}_{2} \mathrm{~S} \leq 20 \mathrm{ppm} ; \\
\mathrm{NH}_{3} \text { and } \mathrm{HCl} \text { to be } \\
\text { determined }\end{array}$ & $\begin{array}{l}\begin{array}{l}\text { Demonstrate biomass } \\
\text { gasification for } \\
\$ 5.25 / \mathrm{MMBtu} \text { syngas cost }\end{array}\end{array}$ & 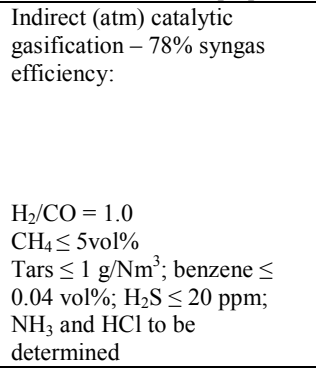 & \\
\hline $\begin{array}{l}\text { Cleanup and } \\
\text { Conditioning }\end{array}$ & $\begin{array}{l}\text { Cyclone particulate removal } \\
\mathrm{H}_{2} \mathrm{~S} \geq 50 \text { ppm (based on } \\
\text { feedstock) with no } \mathrm{S} \text { removal } \\
\text { Tar Reformer Efficiency } \\
\mathrm{CH}_{4} \geq 20 \% \\
\text { Benzene } \geq 70 \% \\
\text { heavy tars } \geq 95 \% \\
\text { ( } 79 \% \mathrm{CH}_{4} \text { conversion in } \\
\text { separate } \mathrm{SMR} \text { ) }\end{array}$ & $\begin{array}{l}\text { Sorbent injection to maintain } \\
\mathrm{H}_{2} \mathrm{~S} \text { levels } \leq 50 \text { ppm for } \\
\text { syngas from biomass to } \\
\text { reduce sulfur deactivation of } \\
\text { tar reforming catalysts. }\end{array}$ & $\begin{array}{l}\text { Tar Reformer Efficiency } \\
\\
\mathrm{CH}_{4} \geq 50 \% \\
\text { Benzene } \geq 90 \% \\
\text { heavy tars } \geq 97 \% \\
\text { (79\% } \mathrm{CH}_{4} \text { conversion in } \\
\text { separate SMR) }\end{array}$ & $\begin{array}{l}\text { Improve tar reforming } \\
\text { catalyst performance - } \\
\text { Regen/TOS ratio } \leq 600\end{array}$ & $\begin{array}{l}\text { Tar Reformer Efficiency } \\
\\
\mathrm{CH}_{4} \geq 80 \% \\
\text { Benzene } \geq 99 \% \\
\text { heavy tars } \geq 99.9 \% \\
\text { Eliminate SMR; highest } \\
\text { activity re-gained by } \\
\text { regenerating deactivated } \\
\text { catalyst }\end{array}$ & $\begin{array}{l}\text { Improve tar reforming } \\
\text { catalyst performance - } \\
\text { Regen/TOS ratio } \leq 250\end{array}$ & $\begin{array}{l}\text { Integrated operations for } \\
\text { syngas cleanup and } \\
\text { conditioning target } \\
\text { composition for fuel; } \\
\text { synthesis: } \\
\mathrm{CH}_{4} \leq 3 \mathrm{vol} \% \\
\text { Benzene } \leq 10 \mathrm{ppm} \\
\text { Heavy tars } \leq 0.1 \mathrm{~g} / \mathrm{Nm}^{3} \\
\\
\mathrm{H}_{2} \mathrm{~S} \leq 1 \mathrm{ppm} \\
\mathrm{NH}_{3} \leq 10 \mathrm{ppm} \\
\mathrm{HCl} \leq 10 \mathrm{ppb}\end{array}$ \\
\hline $\begin{array}{l}\text { Catalytic Fuels } \\
\text { Synthesis } \\
\text { (Mixed } \\
\text { Alcohols) }\end{array}$ & $\begin{array}{l}\mathrm{H}_{2} / \mathrm{CO}=1.2 \\
\text { Pressure } \leq 2000 \mathrm{psia} \\
\text { Productivity }=100-400 \\
\text { gMA } / \mathrm{kg}(\mathrm{cat}) / \mathrm{hr} \\
\text { EtOH Selectivity } \geq 70 \%\left(\mathrm{CO}_{2}-\right. \\
\text { free })\end{array}$ & $\begin{array}{l}\mathrm{H}_{2} / \mathrm{CO} \leq 1.2 \\
\text { Pressure } \leq 2000 \text { psia } \\
\text { Productivity } \geq 150 \\
\text { gMA } / \mathrm{kg}(\mathrm{cat}) / \mathrm{hr} \\
\text { EtOH Selectivity } \geq 70 \%\left(\mathrm{CO}_{2^{-}}\right. \\
\text {free })\end{array}$ & $\begin{array}{l}\text { Demonstrate } 500 \text { hours } \\
\text { catalyst lifetime at } 2007 \\
\text { performance with bottled } \\
\text { syngas for mixed alcohol } \\
\text { catalyst cost of } \leq \$ 0.50 / \mathrm{gal} \\
\text { EtOH }\end{array}$ & $\begin{array}{l}\mathrm{H}_{2} / \mathrm{CO} \leq 1.0 \\
\text { Pressure } \leq 1500 \mathrm{psia} \\
\text { Productivity } \geq 300 \\
\mathrm{gMA} / \mathrm{kg} \text { (cat)/hr } \\
\text { EtOH Selectivity } \geq 75 \% \\
\left(\mathrm{CO}_{2} \text {-free) }\right.\end{array}$ & $\begin{array}{l}\text { Demonstrate } 500 \text { hours } \\
\text { catalyst lifetime at } 2009 \\
\text { performance. with biomass } \\
\text { syngas for mixed alcohol } \\
\text { catalyst cost of } \leq \$ 0.22 / \text { gal } \\
\text { EtOH }\end{array}$ & $\begin{array}{l}\mathrm{H}_{2} / \mathrm{CO} \leq 1.0 \\
\text { Pressure } \leq 1000 \mathrm{psia} \\
\text { Productivity } \geq 600 \\
\mathrm{gMA} / \mathrm{kg}(\mathrm{cat}) / \mathrm{hr} \\
\text { EtOH Selectivity } \geq 80 \%\left(\mathrm{CO}_{2^{-}}\right. \\
\text {free) }\end{array}$ & $\begin{array}{l}\text { Demonstrate } 1000 \text { hours } \\
\text { catalyst lifetime at } 2009 \\
\text { performance. with biomass } \\
\text { syngas }\end{array}$ \\
\hline $\begin{array}{l}\text { Integration and } \\
\text { Modeling }\end{array}$ & $\begin{array}{l}\text { Research state-of-technology } \\
-56 \text { gal/dry ton EtOH } \\
\$ 2.02 / \text { gal minimum EtOH } \\
\text { selling price (higher alcohols } \\
\text { sold at } 85 \% \text { of market value) } \\
\text { at } \$ 2.71 / \text { gal installed capital } \\
\text { costs. }\end{array}$ & $\begin{array}{l}\text { Biomass Gasification/Mixed } \\
\text { Alcohol Design Report - } \\
\text { Establishes a cost and quality } \\
\text { baseline for technology } \\
\text { improvements for } \$ 1.07 / \mathrm{gal} \\
\text { thermochemical ethanol by } \\
2012 \text { from indirect biomass } \\
\text { gasification through a clean } \\
\text { syngas intermediate. }\end{array}$ & $\begin{array}{l}\text { Improved hydrocarbon } \\
\text { conversion efficiency } \\
\text { yields- } 56 \text { gal/dry ton EtOH } \\
\$ 1.73 / \text { gal minimum EtOH } \\
\text { selling price (higher } \\
\text { alcohols priced as gasoline } \\
\text { on an energy adjusted basis } \\
-\$ 1.15 / \text { gal) at } \$ 2.69 / \text { gal } \\
\text { installed capital costs. }\end{array}$ & $\begin{array}{l}\text { Validated } \$ 1.73 / \text { gal EtOH } \\
\text { for integrated Cleanup \& } \\
\text { Conditioning + Mixed } \\
\text { Alcohol synthesis }\end{array}$ & $\begin{array}{l}\text { Demonstrate feasibility of } \\
\text { system }(8000 \mathrm{hr} \text { on stream } \\
\text { with } \leq 10 \% \text { catalyst losses } \\
\text { per year) based on } \\
\text { regenerating fluidizable tar } \\
\text { reforming catalyst to } \\
\text { eliminate SMR }\end{array}$ & $\begin{array}{l}\text { Validated \$1.35/gal EtOH for } \\
\text { integrated Cleanup \& } \\
\text { Condtioning + Mixed Alcohol } \\
\text { synthesis }\end{array}$ & $\begin{array}{l}\text { Demonstrate mixed alcohol } \\
\text { yields of } 89 \text { gal/ton ( } 76 \\
\text { gal/dry ton EtOH) via } \\
\text { indirect biomass } \\
\text { gasification at pilot-scale } \\
\text { for "\$1.07" minimum } \\
\text { ETOH selling price (higher } \\
\text { alcohols priced as gasoline } \\
\text { on an energy adjusted basis } \\
\text { - } \$ 1.15 / \text { gal). Total installed } \\
\text { capital costs are } \\
\$ 2.31 / \text { annual gallon of } \\
\text { ethanol. }\end{array}$ \\
\hline
\end{tabular}




\section{Feedstock Interface}

Feedstock handling, processing, and feeding specifically related to the thermochemical conversion process will need to be addressed. Because the $30 \times 30$ scenario envisions mixed alcohol conversion for low-grade or "non-fermentable" feedstocks, refinements in dry biomass feeder systems for use with gasification will be required to meet cost targets. These refinements should reduce upfront feed processing requirements to yield biomass feedstocks at $\$ 35$ per ton delivered to the thermochemical process. Additional challenges will be associated with feeding the delivered biomass into developing pressurized biomass gasification systems. In all cases, demonstrating biomass feed systems beyond the pilot-scale will be necessary but this is not a significant component of the proposed research portfolio.

\section{Fundamental Gasification Studies R\&D Needs}

The thermochemical mixed alcohol synthesis conversion route is envisioned initially for forest thinnings and other predominately woody feedstocks and residues. Hence, gasification studies will need to be performed to determine how feedstock composition affects syngas composition and quality and syngas efficiency. The gasifier technology chosen for the basis of this analysis is the Battelle Columbus Laboratory indirectly heated gasifier. Other gasifier technologies are under development that could prove more promising. These technologies will need to be tracked to ascertain their applicability to the mixed alcohol synthesis process.

\section{Tar Cleanup and Conditioning $R \& D$ Needs}

Previous techno-economic analyses (Aden and Spath, 2005) have shown that achieving the research goals for cleanup and conditioning of biomass-derived syngas to remove chemical contaminants such as tar, ammonia, chlorine, sulfur, alkali metals, and particulates has the greatest impact on reducing the cost of mixed alcohol synthesis. To date, gas cleanup and conditioning technologies and systems are unproven in integrated biorefinery applications. The goal of this research is to eliminate the tar removal and disposal via water quench, which is problematic both from efficiency and waste disposal perspectives, and develop a consolidated tar and light hydrocarbon reforming case.

The current lab-scale demonstration results and target conversions for various impurities measured in biomass-derived syngas are listed in Table 2 for the year 2005 "current" state of technology case and the year 2012 "goal" case. The goal case conversions were selected to yield an economically viable clean syngas that is suitable for use in a catalytic fuel synthesis process without further hydrocarbon conversion steps. 


Table 2. Tar Reformer Performance - \% Conversion
\begin{tabular}{|c|c|c|}
\hline Compound & $\begin{array}{c}\text { Current } \\
(\mathbf{2 0 0 5})\end{array}$ & $\begin{array}{c}\text { Goal } \\
\mathbf{( 2 0 1 2 )}\end{array}$ \\
\hline Methane $\left(\mathrm{CH}_{4}\right)$ & $20 \%$ & $80 \%$ \\
\hline Ethane $\left(\mathrm{C}_{2} \mathrm{H}_{6}\right)$ & $90 \%$ & $99 \%$ \\
\hline Ethylene $\left(\mathrm{C}_{2} \mathrm{H}_{4}\right)$ & $50 \%$ & $90 \%$ \\
\hline Tars $\left(\mathrm{C}_{10}+\right)$ & $95 \%$ & $99.9 \%$ \\
\hline Benzene $\left(\mathrm{C}_{6} \mathrm{H}_{6}\right)$ & $70 \%$ & $99 \%$ \\
\hline Ammonia $\left(\mathrm{NH}_{3}\right)$ & $70 \%$ & $90 \%$ \\
\hline
\end{tabular}

The research target will be met when tar and light hydrocarbons are sufficiently converted to additional syngas, technically validating the elimination of a downstream steam methane reforming unit operation to separately reform methane from the other light hydrocarbons. Specific research to generate the required chemical and engineering data to design and successfully demonstrate a regenerating tar reforming reactor for long-term, reliable gas cleanup and conditioning includes:

- Performing tar deactivation/regeneration cycle tests to determine activity profiles to maintain the required long-term tar reforming catalyst activity

- Performing fundamental catalyst studies to determine deactivation kinetics and mechanisms by probing catalyst surfaces to uncover molecular-level details

- Determining optimized catalyst formulations and materials at the pilot scale to demonstrate catalyst performance and lifetimes as a function of process conditions and feedstock

Although consolidated tar and light hydrocarbon reforming tests performed with Ni-based catalysts have demonstrated the technical feasibility of this gas cleanup and conditioning strategy, alternative catalyst formulations can be developed to optimize reforming catalyst activity and lifetime in addition to expanded functionality. Specific further improvements that could be realized in catalyst functionality are:

- Further process intensification is possible by designing catalysts with higher tolerances for sulfur and chlorine poisons.

- Further reductions in gas cleanup costs could be realized by lowering or eliminating the sulfur and chlorine removal cost prior to reforming.

- Optimizing the water gas shift activity of reforming catalysts could reduce or eliminate the need for an additional downstream shift reactor.

\section{Mixed Alcohol Synthesis R\&D Needs}

The ability to produce mixed alcohols from syngas has been known since the beginning of the last century; however, the commercial success of mixed alcohol synthesis has been limited by poor selectivity and low product yields. Single-pass yields are on the order of $10 \%$ syngas conversion (38.5\% CO conversion) to alcohols, with methanol typically being the most abundant alcohol produced (Wender 1996; Herman 2000). For mixed alcohol synthesis to become an 
economical commercial process, there is a need for improved catalysts that increase the productivity and selectivity to higher alcohols (Fierro 1993).

Improvements in mixed alcohol synthesis catalysts could potentially increase alcohol yields and selectivity of ethanol production from clean syngas and improve the overall economics of the process through better heat integration and control and fewer syngas recycling loops. Specific research targets to achieve the cost-competitive 2012 target case are:

- Develop improved mixed alcohol catalysts that will increase the single-pass CO conversion from $38.5 \%$ to $50 \%$ and potentially higher and improve the CO selectivity to alcohols from $80 \%$ to $90 \%$.

- Develop improved mixed alcohol catalysts with higher activity that will require a lower operating pressure (1,000 psia compared with 2,000 psia) to significantly lower process operating costs. This combination of lower syngas pressure for alcohol synthesis and less unconverted syngas to recompress and recycle has the added benefit of lowering the energy requirement for the improved synthesis loop.

- Alternative mixed alcohol synthesis reactors and catalysts should be explored. Greatly improved temperature control of the exothermic synthesis reaction has been demonstrated to significantly improve yields and product selectivity. Precise temperature control reactor designs need to be developed for the mixed alcohol synthesis reaction to improve the yields and the economics of the process.

\section{Integration/Demonstration}

As is the case for any sophisticated conversion process, combining the individual unit operations into a complete, integrated systematic process is a significant challenge. Individual pilot-scale operations to demonstrate the required performance of the unit operations as well as complete integrated pilot development runs will be required to demonstrate the cost-competitive technology. A specific challenge will be to continue to demonstrate process intensification and higher yields at pilot scale to reduce capital costs.

Achieving the technical target for the accelerated path to thermochemical ethanol requires meeting the specific research targets as outlined above. Missing or delaying any of these targets forfeits the 2012 target and jeopardizes the deployment of technologies in time to meet the 30x30 goal. The cost implications of missing, hitting or exceeding a target or set of targets are easily determined with process uncertainty analysis that will be performed and detailed in the upcoming Mixed Alcohol Design Report due in January 2007. Combinations of sensitivity analysis can provide several ways to achieve the same cost-competitive target, which reduces the overall risk of the process. Quantifying the relative cost savings for process improvements allows work to be directed to the most cost effective R\&D to achieve the 2012 technical target for thermochemical ethanol production. 


\section{References}

Aden, A., Spath,. P.L. (2005) Milestone Completion Report "The Potential of Thermochemical Ethanol Via Mixed Alcohols Production.” September 2005.

http://devafdc.nrel.gov/bcfcdoc/9432.doc

Bizzari, S.N.; Gubler, R.; Kishi, A. (2002). "Oxo Chemicals.” Chemical Economics Handbook, SRI International, Menlo Park, CA. Report number 682.7000

Foust, T.D.; Wooley, R.; Sheehan, J.; Wallace, R.; Ibsen, K.; Dayton, D.; Himmel, M.; Ashworth, J.; McCormick, R.; Melendez, M.; Hess, J.R.; Kenney, K.; Wang, M.; Snyder, S.; Werpy, T. A National Laboratory Market and Technology Assessment of the 30X30 Scenario. Draft NREL Report. December 2006.

Fierro, J. L. G. (1993). "Catalysis in C1 chemistry: future and prospect." Catalysis Letters 22(12): 67-91.

Herman, R. G. (2000). "Advances in catalytic synthesis and utilization of higher alcohols." Catalysis Today 55(3): 233-245.

Wender, I. (1996). "Reactions of synthesis gas." Fuel Processing Technology 48(3): 189-297.

Spath, P.L. and Dayton, D. C. "Preliminary Screening -- Technical and Economic Assessment of Synthesis Gas to Fuels and Chemicals with Emphasis on the Potential for Biomass-Derived Syngas.” 160 pp.; NREL Report No. TP-510-34929. 2003 


\section{Appendix C}

NREL Biorefinery Design Database Description and Summary 
NREL's Process Engineering Team has developed a database of primary information on all of the equipment in the benchmark model. This database contains information about the cost, reference year, scaling factor, scaling characteristic, design information and back-up cost referencing. The information is stored in a secure database and can be directly linked to the economic portion of the model. In addition to having all of the cost information used by the model, it has the ability to store documents pertaining to the piece of equipment. These include sizing and costing calculations and vendor information when available.

The following summarizes the important fields of information contained in the database. A partial listing of the information is attached for each piece of equipment. Additional information from the database is contained in the equipment cost listing in Appendix D.

Equipment Number: ${ }^{\mathrm{AB}}$

Equipment Name: ${ }^{\mathrm{AB}}$ Associated PFD:

Equipment Category: ${ }^{\mathrm{A}}$ Equipment Type: ${ }^{\mathrm{A}}$

Equipment Description: ${ }^{\mathrm{A}}$

Number Required: ${ }^{\mathrm{B}}$

Number Spares: ${ }^{B}$

Scaling Stream: ${ }^{\mathrm{B}}$

Base Cost: ${ }^{\mathrm{B}}$

Cost Basis: ${ }^{\mathrm{A}}$

Cost Year: ${ }^{\text {B }}$

Base for Scaling: ${ }^{\mathrm{B}}$

Base Type:

Base Units:

Installation Factor: ${ }^{\mathrm{B}}$

Installation Factor Basis:

Scale Factor Exponent: ${ }^{B}$

Scale Factor Basis:

Material of Construction: ${ }^{A}$

Notes:

Document:

Design Date:

Modified Date:
Unique identifier, the first letter indicates the equipment type and the first number represents the process area, e.g., P-301 is a pump in Area 300

Descriptive name of the piece of equipment

PFD number on which the piece of equipment appears, e.g., PFD-P800-A101

Code indicating the general type of equipment, e.g., PUMP

Code indicating the specific type of equipment, e.g., CENTRIFUGAL for a pump

Short description of the size or characteristics of the piece of equipment, e.g., $20 \mathrm{gpm}, 82 \mathrm{ft}$ head for a pump

Number of duplicate pieces of equipment needed

Number of on-line spares

Stream number or other characteristic variable from the ASPEN model by which the equipment cost will be scaled

Equipment cost

Source of the equipment cost, e.g., ICARUS or VENDOR

Year for which the cost estimate is based

Value of the scaling stream or variable used to obtain the base cost of the equipment

Type of variable used for scaling, e.g., FLOW, DUTY, etc.

Units of the scaling stream or variable, e.g., KG/HR, CAL/S

Value of the installation factor. Installed Cost $=$ Base Cost $\mathrm{x}$ Installation

Factor

Source of the installation factor value, e.g., ICARUS, VENDOR

Value of the exponential scaling equation

Source of the scaling exponent value, e.g., GARRETT, VENDOR

Material of Construction

Any other important information about the design or cost

Complete, multi-page document containing design calculations, vendor

literature and quotations and any other important information. This is stored as an electronic document and can be pages from a spreadsheet other electronic sources or scanned information from vendors.

Original date for the design of this piece of equipment

The system automatically marks the date in this field whenever any field is changed

\footnotetext{
${ }^{A}$ These fields are listed for all pieces of equipment in this Appendix.
}

${ }^{\mathrm{B}}$ These fields are part of the equipment cost listing in Appendix D. 


\begin{tabular}{|c|c|c|c|c|c|c|}
\hline \multicolumn{2}{|c|}{ EQUIPMENT_NUEQUIPMENT_NAME } & \multicolumn{2}{|c|}{ EQUIPMENT_CATEGOEQUIPMENT_TYPE } & \multirow[t]{2}{*}{ EQUIPMENT_DESCRIPTION } & \multicolumn{2}{|c|}{ MATERIAL_CONSCOST_BASIS } \\
\hline \multicolumn{2}{|c|}{ PFD-P800-A101-2 } & & & & & \\
\hline C-101 & Hopper Feeder & CONVEYOR & $\begin{array}{l}\text { VIBRATING- } \\
\text { FEEDER }\end{array}$ & Included in overall cost for feed handling \& drying taken from several literature sources & cs & LITERATURE \\
\hline C-102 & Screener Feeder Conveyor & CONVEYOR & BELT & Included in overall cost for feed handling \& drying taken from several literature sources & cs & LITERATURE \\
\hline C-103 & Radial Stacker Conveyor & CONVEYOR & BELT & Included in overall cost for feed handling \& drying taken from several literature sources & cs & LITERATURE \\
\hline C-104 & Dryer Feed Screw Conveyor & CONVEYOR & SCREW & Included in overall cost for feed handling \& drying taken from several literature sources & cs & LITERATURE \\
\hline C-105 & Gasifier Feed Screw Conveyor & CONVEYOR & SCREW & Included in overall cost for feed handling \& drying taken from several literature sources & $3165 s$ & LITERATURE \\
\hline $\mathrm{H}-286 \mathrm{~B}$ & Flue Gas Cooler/Steam Generator \#1 & HEATX & SHELL-TUBE & duty $=155 \mathrm{MMBtu} / \mathrm{hr} ; \mathrm{LMTD}=733 \mathrm{~F} ; \mathrm{U}=150 \mathrm{Btu} / \mathrm{hr}-\mathrm{ft}^{\wedge} 2-\mathrm{F} ;$ area $=1,410 \mathrm{ft} \mathrm{ft}^{2} 2$ fixed tube sheet & CS/INCL & QUESTIMATE \\
\hline $\mathrm{H}-286 \mathrm{C}$ & Flue Gas Cooler /Boiler Water Preheater \#1 & HEATX & SHELL-TUBE & duty $=20 \mathrm{MMBtu} / \mathrm{hr} ; \mathrm{LMTD}=244 \mathrm{~F} ; \mathrm{U}=100 \mathrm{Btu} / \mathrm{hr}-\mathrm{ft}^{\wedge} 2-\mathrm{F} ;$ area $=823 \mathrm{ft}{ }^{\wedge} 2 ;$ fixed TS & CS/A214 & QUESTIMATE \\
\hline $\mathrm{H}-311 \mathrm{~B}$ & Flue Gas Cooler / Steam Generator \#3 & HEATX & SHELL-TUBE & duty $=47.9 \mathrm{MMBtu} / \mathrm{hr} ; \mathrm{LMTD}=457 ;$ area $=698 \mathrm{sq} \mathrm{ft} ; \mathrm{U}=150 \mathrm{Btu} / \mathrm{hr}-\mathrm{ft}^{\wedge} 2-\mathrm{F} ;$ fixed TS & $\mathrm{CS} / 316 \mathrm{~S}$ & ICARUS \\
\hline K-101 & Flue Gas Blower & FAN & CENTRIFUGAL & Included in overall cost for feed handling \& drying taken from several literature sources & SS304 & LITERATURE \\
\hline M-101 & Hydraulic Truck Dump with Scale & SCALE & TRUCK-SCALE & Included in overall cost for feed handling \& drying taken from several literature sources & & LITERATURE \\
\hline M-102 & Hammermill & SIZE-REDUCTION & & Included in overall cost for feed handling \& drying taken from several literature sources & cs & LITERATURE \\
\hline M-103 & Front End Loaders & VEHICLE & LOADER & Included in overall cost for feed handling \& drying taken from several literature sources & cs & LITERATURE \\
\hline M-104 & Rotary Biomass Dryer & DRYER & ROTARY-DRUM & Included in overall cost for feed handling \& drying taken from several literature sources & cs & LITERATURE \\
\hline S-101 & Magnetic Head Pulley & SEPARATOR & MAGNET & Included in overall cost for feed handling \& drying taken from several literature sources & cs & LITERATURE \\
\hline S-102 & Screener & SEPARATOR & SCREEN & Included in overall cost for feed handling \& drying taken from several literature sources & cs & LITERATURE \\
\hline S-103 & Dryer Air Cyclone & SEPARATOR & GAS CYCLONE & Included in overall cost for feed handling \& drying taken from several literature sources & cs & LITERATURE \\
\hline S-104 & Dryer Air Baghouse Filter & SEPARATOR & FABRIC-FILTER & Included in overall cost for feed handling \& drying taken from several literature sources & & LITERATURE \\
\hline T-101 & Dump Hopper & TANK & LIVE-BTM-BIN & Included in overall cost for feed handling \& drying taken from several literature sources & cs & LITERATURE \\
\hline T-102 & Hammermill Surge Bin & TANK & LIVE-BTM-BIN & Included in overall cost for feed handling \& drying taken from several literature sources & cs & LITERATURE \\
\hline T-103 & Dryer Feed Bin & TANK & LIVE-BTM-BIN & Included in overall cost for feed handling \& drying taken from several literature sources & cs & LITERATURE \\
\hline $\mathrm{T}-104$ & Dried Biomass Hopper & TANK & VERTICAL-VESSEL & Included in overall cost for feed handling \& drying taken from several literature sources & cs & LITERATURE \\
\hline \multicolumn{2}{|c|}{ PFD-P800-A201 } & & & & & \\
\hline $\mathrm{C}-201$ & Sand/ash Conditioner/Conveyor & CONVEYOR & SCREW & Included in overall cost for gasification \& gas clean up taken from several literature sources & cs & LITERATURE \\
\hline K-202 & Combustion Air Blower & FAN & CENTRIFUGAL & Included in overall cost for gasification \& gas clean up taken from several literature sources & cs & LITERATURE \\
\hline M-201 & Sand/ash Cooler & MISCELLANEOUS & MISCELLANEOUS & Included in overall cost for gasification \& gas clean up taken from several literature sources & & LITERATURE \\
\hline R-201 & Indirectly-heated Biomass Gasifier & REACTOR & VERTICAL-VESSEL & Included in overall cost for gasification \& gas clean up taken from several literature sources & CS w/refractory & LITERATURE \\
\hline $\mathrm{R}-202$ & Char Combustor & REACTOR & VERTICAL-VESSEL & Included in overall cost for gasification \& gas clean up taken from several literature sources & CS w/refractory & LITERATURE \\
\hline S-201 & Primary Gasifier Cyclone & SEPARATOR & GAS CYCLONE & Included in overall cost for gasification \& gas clean up taken from several literature sources & CS w/refractory & LITERATURE \\
\hline S-202 & Secondary Gasifier Cyclone & SEPARATOR & GAS CYCLONE & Included in overall cost for gasification \& gas clean up taken from several literature sources & CS w/refractory & LITERATURE \\
\hline S-203 & Primary Combustor Cyclone & SEPARATOR & GAS CYCLONE & Included in overall cost for gasification \& gas clean up taken from several literature sources & CS w/refractory & LITERATURE \\
\hline S-204 & Secondary Combustor Cyclone & SEPARATOR & GAS CYCLONE & Included in overall cost for gasification \& gas clean up taken from several literature sources & CS w/refractory & LITERATURE \\
\hline S-205 & Electrostatic Precipitator & SEPARATOR & MISCELLANEOUS & Included in overall cost for gasification \& gas clean up taken from several literature sources & cs & LITERATURE \\
\hline $\mathrm{T}-201$ & Sand/ash Bin & TANK & $\begin{array}{l}\text { FLAT-BTM- } \\
\text { STORAGE }\end{array}$ & Included in overall cost for gasification \& gas clean up taken from several literature sources & cs & LITERATURE \\
\hline
\end{tabular}




\begin{tabular}{|c|c|c|c|c|c|c|}
\hline \multicolumn{2}{|c|}{ EQUIPMENT_NUIEQUIPMENT_NAME } & \multicolumn{2}{|c|}{ EQUIPMENT_CATEGOEQUIPMENT_TYPE } & \multirow[t]{2}{*}{ EQUIPMENT_DESCRIPTION } & \multicolumn{2}{|c|}{ MATERIAL_CONSCOST_BASIS } \\
\hline \multicolumn{6}{|c|}{ PFD-P800-A301-5 } & \\
\hline $\mathrm{H}-301$ & Quench Water Recirculation Cooler & HEATX & SHELL-TUBE & Included in overall cost for gasification \& gas clean up taken from several literature sources & Cs & LITERATURE \\
\hline $\mathrm{H}-301 \mathrm{~A}$ & Post-tar Reformer Cooler / Steam Generator \#2 & HEATX & SHELL-TUBE & duty $=47.9 \mathrm{MMBtu} / \mathrm{hr} ; \mathrm{LMTD}=457 ;$ area $=698 \mathrm{sq} \mathrm{ft} ; \mathrm{U}=150 \mathrm{Btu} / \mathrm{hr}-\mathrm{ft}^{\wedge} 2-\mathrm{F} ;$ fixed TS & $\mathrm{CS} / 316 \mathrm{~s}$ & ICARUS \\
\hline $\mathrm{H}-301 \mathrm{~B}$ & Reformer Flue Gas Cooler/Steam superheater & HEATX & SHELL-TUBE & duty $=94 \mathrm{MMBtu} / \mathrm{hr} ; \mathrm{LMTD}=217 \mathrm{~F} ; \mathrm{U}=150 \mathrm{Btu} / \mathrm{hr}-\mathrm{ft}^{\wedge} 2-\mathrm{F} ;$ area $=2,900 \mathrm{ft} \wedge 2$; fixed TS & CS/INCL & QUESTIMATE \\
\hline $\mathrm{H}-301 \mathrm{C}$ & $\# 1$ & HEATX & SHELL-TUBE & duty $=40.0 \mathrm{MMBtu} / \mathrm{hr} ; \mathrm{LMTD}=? ? \mathrm{~F} ; \mathrm{U}=90 \mathrm{Btu} / \mathrm{hr}-\mathrm{ft}^{\wedge} 2-\mathrm{F} ;$ surface area $=1,552 \mathrm{f \textrm {ft } ^ { \wedge } 2}$ & A214 & QUESTIMATE \\
\hline $\mathrm{H}-302$ & Syngas Compressor Intercoolers & HEATX & $\begin{array}{l}\text { AIR-COOLED } \\
\text { EXCHANGER }\end{array}$ & Cost of intercoolers included in cost for syngas compressor, K-301 & CS & ICARUS \\
\hline $\mathrm{H}-303$ & Water-cooled Aftercooler & HEATX & SHELL-TUBE & duty $=2.9 \mathrm{MMBtu} / \mathrm{hr} ; \mathrm{LMTD}=25 \mathrm{~F} ; \mathrm{U}=150 \mathrm{Btu} / \mathrm{hr}-\mathrm{ft}^{\wedge} 2-\mathrm{F} ;$ surface area $=794 \mathrm{ft}^{\wedge} 2 ;$ fixed TS & SS304CS/A214 & QUESTIMATE \\
\hline $\mathrm{H}-304$ & LO-CAT Preheater & HEATX & SHELL-TUBE & duty $=0.8 \mathrm{MMBtu} / \mathrm{hr} ; \mathrm{LMTD}=87 \mathrm{~F} ; \mathrm{U}=90 \mathrm{Btu} / \mathrm{hr}-\mathrm{ft}^{\wedge} 2-\mathrm{F} ;$ surface area $=98 \mathrm{ft} 2$; fixed TS & A285C/CA443 & QUESTIMATE \\
\hline $\mathrm{H}-305$ & LO-CAT Absorbent Solution Cooler & HEATX & SHELL-TUBE & Included in LO-CAT system cost & 304SS & VENDOR \\
\hline H-315D1 & Recycle Syngas Cooler / Steam Generator \#4 & HEATX & SHELL-TUBE & duty $=1.37 \mathrm{MMBtu} / \mathrm{hr} ; \mathrm{LMTD}=1,220 \mathrm{~F} ; \mathrm{U}=150 \mathrm{Btu} / \mathrm{hr}-\mathrm{ft}^{\wedge} 2-\mathrm{F} ;$ area $=7 \mathrm{ft} 2$; fixed TS & $\mathrm{CS} / \mathrm{INCL}$ & QUESTIMATE \\
\hline H-315D2 & Recycle Syngas cooler \#2 / Air preheat\#1 & HEATX & SHELL-TUBE & duty $=0.8 \mathrm{MMBtu} / \mathrm{hr} ; \mathrm{LMTD}=87 \mathrm{~F} ; \mathrm{U}=90 \mathrm{Btu} / \mathrm{hr}-\mathrm{ft}^{\wedge} 2-\mathrm{F} ;$ surface area $=98 \mathrm{ft} 2 ;$ fixed TS & A285C/CA443 & QUESTIMATE \\
\hline $\mathrm{K}-301$ & Syngas Compressor & COMPRESSOR & CENTRIFUGAL & $\begin{array}{l}\text { gas flow rate }=70,000 \mathrm{CFM} ; 6 \text { impellers; design outlet pressure }=465 \mathrm{psi} ; 30,000 \mathrm{HP} \text {; intercoolers, } \\
\text { aftercooler, \& K.O.s included }\end{array}$ & A285C & QUESTIMATE \\
\hline $\mathrm{K}-302$ & LO-CAT Feed Air Blower & FAN & CENTRIFUGAL & Included in LO-CAT system cost & Cs & VENDOR \\
\hline K-305 & Regenerator Combustion Air Blower & FAN & CENTRIFUGAL & gas flow rate $($ actual $)=70133$ CFM; & SS304 & QUESTIMATE \\
\hline M-301 & Syngas Quench Chamber & MISCELLANEOUS & & Included in overall cost for gasification \& gas clean up taken from several literature sources & cs & LITERATURE \\
\hline M-302 & Syngas Venturi Scrubber & MISCELLANEOUS & & Included in overall cost for gasification \& gas clean up taken from several literature sources & Cs & LITERATURE \\
\hline M-303 & LO-CAT Venturi Precontactor & MISCELLANEOUS & & Included in LO-CAT system cost & $304 S s$ & VENDOR \\
\hline M-304 & LO-CAT Liquid-filled Absorber & COLUMN & ABSORBER & Included in LO-CAT system cost & $304 S s$ & VENDOR \\
\hline P-301 & Sludge Pump & PUMP & CENTRIFUGAL & 1.4 GPM; 0.053 brake HP; design pressure $=60$ psia & cs & QUESTIMATE \\
\hline $\mathrm{P}-302$ & Quench Water Recirculation Pump & PUMP & CENTRIFUGAL & Included in the cost of the gasification \& gas clean up system & cs & LITERATURE \\
\hline P-303 & LO-CAT Absorbent Solution Circulating Pump & PUMP & CENTRIFUGAL & Included in LO-CAT system cost & $304 S S$ & VENDOR \\
\hline R-301A & Tar Reformer Catalyst Regenerator & REACTOR & VERTICAL-VESSEL & Taken from literature source & CS w/refractory & LITERATURE \\
\hline R-303 & Tar Reformer & REACTOR & VERTICAL-VESSEL & Included in overall cost for gasification \& gas clean up taken from several literature sources & CS w/refractory & LITERATURE \\
\hline R-304 & LO-CAT Oxidizer Vessel & REACTOR & VERTICAL-VESSEL & Included in LO-CAT system cost & $304 S s$ & VENDOR \\
\hline S-301 & Pre-compressor Knock-out & SEPARATOR & KNOCK-OUT DRUM & $18 \mathrm{ft}$ diameter; $36 \mathrm{ft}$ height; design pres $=40$ psia; design temp $=197 \mathrm{~F}$ & cs & QUESTIMATE \\
\hline S-302 & Syngas Compressor Interstage Knock-outs & SEPARATOR & KNOCK-OUT DRUM & Cost of intercoolers K.O.s included in cost for syngas compressor, K-301 & CS & ICARUS \\
\hline $\mathrm{S}-303$ & Post-compressor Knock-out & SEPARATOR & KNOCK-OUT DRUM & $7 \mathrm{ft}$. diameter; $14 \mathrm{ft}$ height; design pres $=506 \mathrm{psia}$; design temp $=160 \mathrm{~F}$ & CS & QUESTIMATE \\
\hline S-306 & Tar Reformer Cyclone & SEPARATOR & GAS CYCLONE & Included in the cost of the tar reformer catalyst renegerator, R-204 & Cs & LITERATURE \\
\hline S-307 & Catalyst Regenerator Cyclone & SEPARATOR & GAS CYCLONE & Included in the cost of the tar reformer catalyst renegerator, R-204 & cs & LITERATURE \\
\hline S-310 & L.P. Amine System & COLUMN & ABSORBER & & & OTHER \\
\hline $\mathrm{T}-301$ & Sludge Settling Tank & SEPARATOR & CLARIFIER & $3 \mathrm{ft}$ diameter; $7 \mathrm{ft}$ height; 431 gal volume; & SS304 & QUESTIMATE \\
\hline $\mathrm{T}-302$ & Quench Water Recirculation Tank & TANK & $\begin{array}{l}\text { HORIZONTAL- } \\
\text { VESSEL }\end{array}$ & Included in overall cost for gasification \& gas clean up taken from several literature sources & CS & LITERATURE \\
\hline
\end{tabular}




\begin{tabular}{|c|c|c|c|c|c|c|}
\hline \multicolumn{2}{|c|}{ EQUIPMENT_NUEQUIPMENT_NAME } & \multicolumn{2}{|c|}{ EQUIPMENT_CATEGOEQUIPMENT_TYPE } & \multirow[t]{2}{*}{ EQUIPMENT_DESCRIPTION } & \multicolumn{2}{|c|}{ MATERIAL_CONSCOST_BASIS } \\
\hline \multicolumn{6}{|c|}{ PFD-P800-A401-2 } & \\
\hline $\mathrm{H}-410 \mathrm{~B}$ & Flue Gas Cool / syngas rxn preheat & HEATX & SHELL-TUBE & duty $=0.8 \mathrm{MMBtu} / \mathrm{hr} ; \mathrm{LMTD}=87 \mathrm{~F} ; \mathrm{U}=90 \mathrm{Btu} / \mathrm{hr}-\mathrm{ft}^{\wedge} 2-\mathrm{F} ;$ surface area $=98 \mathrm{ft} \mathrm{ft}^{\wedge}$; fixed TS & A285C/CA443 & QUESTIMATE \\
\hline $\mathrm{H}-411 \mathrm{~A}$ & Air preheat \#3 / post Reactor Syngas cooling \#1 & HEATX & SHELL-TUBE & duty $=0.8 \mathrm{MMBtu} / \mathrm{hr} ; \mathrm{LMTD}=87 \mathrm{~F} ; \mathrm{U}=90 \mathrm{Btu} / \mathrm{hr}-\mathrm{ft}^{\wedge} 2-\mathrm{F} ;$ surface area $=98 \mathrm{ft} 2$; fixed TS & A285C/CA443 & QUESTIMATE \\
\hline $\mathrm{H}-411 \mathrm{~B}$ & $\# 1$ & HEATX & SHELL-TUBE & duty $=20 \mathrm{MMBtu} / \mathrm{hr} ; \mathrm{LMTD}=244 \mathrm{~F} ; \mathrm{U}=100 \mathrm{Btu} / \mathrm{hr}-\mathrm{ft}^{\wedge} 2-\mathrm{F} ;$ area $=823 \mathrm{ft}{ }^{\wedge} 2 ;$ fixed TS & CS/A214 & QUESTIMATE \\
\hline $\mathrm{H}-411 \mathrm{C}$ & Post Synthesis cooler \#3/Makeup Water heater & HEATX & SHELL-TUBE & duty $=20 \mathrm{MMBtu} / \mathrm{hr} ; \mathrm{LMTD}=244 \mathrm{~F} ; \mathrm{U}=100 \mathrm{Btu} / \mathrm{hr}-\mathrm{ft}^{\wedge} 2-\mathrm{F} ;$ area $=823 \mathrm{ft}{ }^{\wedge} 2 ;$ fixed TS & CS/A214 & QUESTIMATE \\
\hline H-411D & Post Synthesis cooler \#4 / syngas recycle heat \#1 & HEATX & SHELL-TUBE & duty $=0.8 \mathrm{MMBtu} / \mathrm{hr} ; \mathrm{LMTD}=87 \mathrm{~F} ; \mathrm{U}=90 \mathrm{Btu} / \mathrm{hr}-\mathrm{ft}^{\wedge} 2-\mathrm{F} ;$ surface area $=98 \mathrm{ft} \mathrm{ft}^{\wedge} 2$;ixed TS & A285C/CA443 & QUESTIMATE \\
\hline H-411E & Post Synthesis Cooler \#5/Mol Sieve preheater \#2 & HEATX & SHELL-TUBE & duty $=20 \mathrm{MMBtu} / \mathrm{hr} ; \mathrm{LMTD}=244 \mathrm{~F} ; \mathrm{U}=100 \mathrm{Btu} / \mathrm{hr}-\mathrm{ft}^{\wedge} 2-\mathrm{F} ;$ area $=823 \mathrm{ft} 22$; fixed TS & CS/A214 & QUESTIMATE \\
\hline $\mathrm{H}-412$ & Post Mixed Alcohol Cooler & HEATX & SHELL-TUBE & duty $=76.5 \mathrm{MMBtu} / \mathrm{hr} ; \mathrm{LMTD}=? ? \mathrm{~F} ; \mathrm{U}=100 \mathrm{Btu} / \mathrm{hr}-\mathrm{ft}^{\wedge} 2-\mathrm{F} ;$ surface area $=4,763 \mathrm{ft}^{\wedge} 2$ & A214 & QUESTIMATE \\
\hline $\mathrm{H}-413$ & Mixed Alcohol first Condenser (air cooled) & HEATX & $\begin{array}{l}\text { AIR-COOLED } \\
\text { EXCHANGER }\end{array}$ & & & \\
\hline $\mathrm{H}-414$ & Mixed Alcohol Condenser & HEATX & SHELL-TUBE & duty $=78 \mathrm{MMBtu} / \mathrm{hr} ; \mathrm{LMTD}=41 \mathrm{~F} ; \mathrm{U}=150 \mathrm{Btu} / \mathrm{hr}-\mathrm{ft}^{\wedge} 2-\mathrm{F} ;$ surface area $=12,462 \mathrm{ft}^{\wedge} 2$ & A214 & QUESTIMATE \\
\hline $\mathrm{H}-416 \mathrm{~B}$ & Recycle Syngas Heat \#2 / Flue gas Cool & HEATX & SHELL-TUBE & duty $=40.0 \mathrm{MMBtu} / \mathrm{hr} ; \mathrm{LMTD}=? ? \mathrm{~F} ; \mathrm{U}=90 \mathrm{Btu} / \mathrm{hr}-\mathrm{ft}^{\wedge} 2-\mathrm{F} ;$ surface area $=1,552 \mathrm{ft} \wedge 2$ & A214 & QUESTIMATE \\
\hline \begin{tabular}{|l|l}
$\mathrm{K}-410$ \\
$\mathrm{~K}-412$
\end{tabular} & $\begin{array}{l}\text { Mixed Alcohol Gas Compressor } \\
\text { Purge Gas Expander }\end{array}$ & $\begin{array}{l}\text { COMPRESSOR } \\
\text { COMPRESSOR }\end{array}$ & $\begin{array}{l}\text { CENTRIFUGAL } \\
\text { CENTRIFUGAL }\end{array}$ & $\begin{array}{l}\text { gas flow rate }=2,481 \text { CFM; } 4 \text { impellers; design outlet pressure }=700 \mathrm{psi} ; 10,617 \mathrm{HP} \text {; intercoolers, } \\
\text { aftercooler, \& K.O.s included } \\
\text { gas flow rate = } 144 \text { CFM; design outlet pressure }=25 \mathrm{psi} ; 2740 \mathrm{HP}\end{array}$ & $\mid \mathrm{A} 285 \mathrm{C}$ & $\begin{array}{l}\text { QUESTIMATE } \\
\text { QUESTIMATE }\end{array}$ \\
\hline R-410 & Mixed Alcohol Reactor & REACTOR & VERTICAL-VESSEL & Fixed Bed Synthesis Reactor with MoS2-based catalyst. Sized from hourly space velocity of 3000 & CS w/refractory & QUESTIMATE \\
\hline S-501 & Mixed Alcohols Condensation Knock-out & SEPARATOR & KNOCK-OUT DRUM & $H / D=2 ; 5 \mathrm{ft} \mathrm{diam} ; 9 \mathrm{ft}$ height; operating pressure $=1993$ psia; operating temperature $=110 \mathrm{~F}$ & A-515 & QUESTIMATE \\
\hline \multicolumn{7}{|c|}{ PFD-P800-A501-2 } \\
\hline D-504 & Ethanol/Propanol Splitter & COLUMN & DISTILLATION & & & \\
\hline D-505 & Methanol/Ethanol Splitter & COLUMN & DISTILLATION & & & \\
\hline $\mathrm{H}-503 \mathrm{~A}$ & Syngas Cooler \#4 / Mol Sieve preheater \#1 & HEATX & SHELL-TUBE & duty $=20 \mathrm{MMBtu} / \mathrm{hr} ;$ LMTD $=244 \mathrm{~F} ; \mathrm{U}=100 \mathrm{Btu} / \mathrm{hr}-\mathrm{ft}^{\wedge} 2-\mathrm{F} ;$ area $=823 \mathrm{ft}{ }^{\wedge} 2 ;$ fixed TS & CS/A214 & QUESTIMATE \\
\hline $\mathrm{H}-503 \mathrm{~B}$ & Mol Sieve Superheater / reformed syngas cool \#5 & HEATX & SHELL-TUBE & duty $=0.8 \mathrm{MMBtu} / \mathrm{hr} ; \mathrm{LMTD}=87 \mathrm{~F} ; \mathrm{U}=90 \mathrm{Btu} / \mathrm{hr}-\mathrm{ft}^{\wedge} 2-\mathrm{F} ;$ surface area $=98 \mathrm{ft} 2$; fixed TS & A285C/CA443 & QUESTIMATE \\
\hline $\mathrm{H}-504 \mathrm{C}$ & D-504 condenser (air cooled) & HEATX & EXCHANGER & & & \\
\hline $\mathrm{H}-504 \mathrm{R}$ & Ethanol/Propanol Splitter Reboiler & HEATX & SHELL-TUBE & & & \\
\hline $\mathrm{H}-505 \mathrm{C}$ & D-505 condenser (air cooled) & HEATX & $\begin{array}{l}\text { AIR-COOLED } \\
\text { EXCHANGER }\end{array}$ & & & \\
\hline $\mathrm{H}-505 \mathrm{R}$ & Methanol/Ethanol Splitter Reboiler & HEATX & SHELL-TUBE & & & \\
\hline $\mathrm{H}-513$ & Mol Sieve Flush Condenser (air cooled) & HEATX & $\begin{array}{l}\text { AIR-COOLED } \\
\text { EXCHANGER }\end{array}$ & & & \\
\hline $\mathrm{H}-590$ & MA Product Cooler / Mol Sieve preheater \#3 & HEATX & SHELL-TUBE & duty $=3 \mathrm{MMBtu} / \mathrm{hr} ; \mathrm{LMTD}=236 \mathrm{~F} ; \mathrm{U}=600 \mathrm{Btu} / \mathrm{hr}-\mathrm{ft}^{\wedge} 2-\mathrm{F} ;$ area $=20 \mathrm{ft} 2$; pre-engineered U-tube & A285C/CA443 & QUESTIMATE \\
\hline $\mathrm{H}-591$ & Higher Alcohol Product Finishing cooler & HEATX & SHELL-TUBE & Included in overall cost for gasification \& gas clean up taken from several literature sources & & LITERATURE \\
\hline $\mathrm{H}-592$ & ETHANOL Product Cooler / Mol Sieve preheater \#4 & HEATX & SHELL-TUBE & duty $=3 \mathrm{MMBtu} / \mathrm{hr} ; \mathrm{LMTD}=236 \mathrm{~F} ; \mathrm{U}=600 \mathrm{Btu} / \mathrm{hr}-\mathrm{ft}^{\wedge} 2-\mathrm{F} ;$ area $=20 \mathrm{ft} \mathrm{ft}^{2} 2$ pre-engineered U-tube & A285C/CA443 & QUESTIMATE \\
\hline $\mathrm{H}-593$ & ETHANOL Product Finishing cooler & HEATX & SHELL-TUBE & Included in overall cost for gasification \& gas clean up taken from several literature sources & CS & LITERATURE \\
\hline P-504B & Ethanol/Propanol Splitter Bottoms Pump & PUMP & CENTRIFUGAL & & & \\
\hline P-504R & Ethanol/Propanol Splitter Reflux Pump & PUMP & CENTRIFUGAL & & & \\
\hline $\mathrm{P}-505 \mathrm{~B}$ & Methanol/Ethanol Splitter Bottoms Pump & PUMP & CENTRIFUGAL & & & \\
\hline $\mathrm{P}-505 \mathrm{R}$ & Methanol/Ethanol Splitter Reflux Pump & PUMP & CENTRIFUGAL & & & \\
\hline S-502 & Methanol Separation Column & COLUMN & DISTILLATION & 13.5' dia, 32 Actual Trays, Nutter V-Grid Trays & SS304 & ICARUS \\
\hline S-503 & Molecular Sieve (9 pieces) & MISCELLANEOUS & PACKAGE & Superheater, twin mole sieve columns, product cooler, condenser, pumps, vacuum source. & SS & VENDOR \\
\hline T-504 & Ethanol/Propanol Splitter Reflux Drum & TANK & KNOCK-OUT DRUM & & & \\
\hline T-505 & Methanol/Ethanol Splitter Reflux Drum & TANK & KNOCK-OUT DRUM & & & \\
\hline $\mathrm{T}-590$ & Mixed Alcohol Product Storage Tank & TANK & $\begin{array}{l}\text { FLAT-BTM- } \\
\text { STORAGE }\end{array}$ & & & \\
\hline $\mathrm{T}-592$ & Ethanol Product Storage Tank & TANK & $\begin{array}{l}\text { FLAT-BTM- } \\
\text { STORAGE } \\
\end{array}$ & & & \\
\hline
\end{tabular}




\begin{tabular}{|c|c|c|c|c|c|c|}
\hline \multicolumn{2}{|c|}{ EQUIPMENT_NUEQUIPMENT_NAME } & \multicolumn{2}{|c|}{ EQUIPMENT_CATEGOEQUIPMENT_TYPE } & \multirow[t]{2}{*}{ EQUIPMENT_DESCRIPTION } & \multicolumn{2}{|c|}{ MATERIAL_CONSCOST_BASIS } \\
\hline & \\
\hline H-601 & Steam Turbine Condenser & HEATX & SHELL-TUBE & $\begin{array}{l}\text { Included in the cost of the steam trubine/generator (M-602); condenser steam flow rate }=342,283 \\
\mathrm{lb} / \mathrm{hr}\end{array}$ & & $\begin{array}{l}\text { ADEN, ET. AL. } \\
2002\end{array}$ \\
\hline $\mathrm{H}-602$ & Blowdown Cooler / Deaerator Water Preheater & HEATX & SHELL-TUBE & duty $=3 \mathrm{MMBtu} / \mathrm{hr} ; \mathrm{LMTD}=236 \mathrm{~F} ; \mathrm{U}=600 \mathrm{Btu} / \mathrm{hr}-\mathrm{ft}^{\wedge} 2-\mathrm{F} ;$ area $=20 \mathrm{ft} \mathrm{f}^{\wedge} ;$ pre-engineered U-tube & A285C/CA443 & QUESTIMATE \\
\hline $\mathrm{H}-603$ & Blowdown Water-cooled Cooler & HEATX & SHELL-TUBE & duty $=0.6 \mathrm{MMBtu} / \mathrm{hr} ; \mathrm{LMTD}=47 \mathrm{~F} ; \mathrm{U}=225 \mathrm{Btu} / \mathrm{hr}-\mathrm{ft}^{\wedge} 2-\mathrm{F} ;$ area $=60 \mathrm{ft} 2$; fixed TS & A214 & QUESTIMATE \\
\hline M-601 & Hot Process Water Softener System & MISCELLANEOUS & PACKAGE & scaled cost to $700 \mathrm{gpm}$ flow, 24 " dia softener. Includes filters, chemical feeders, piping, valves & & RICHARDSON \\
\hline M-602 & Extraction Steam Turbine/Generator & GENERATOR & STEAM-TURBINE & $25.6 \mathrm{MW}$ generated; $34,308 \mathrm{HP}$ & & VENDOR \\
\hline M-603 & Startup Boiler & MISCELLANEOUS & PACKAGE & $\begin{array}{l}\text { Assume need steam requirement equal to } 1 / 2 \text { of steam requirement for gasifier at full rate steam } \\
\text { rate }=36,560 \mathrm{lb} / \mathrm{hr}\end{array}$ & cs & QUESTIMATE \\
\hline P-601 & Collection Pump & PUMP & CENTRIFUGAL & 513 GPM; 4 brake HP; outlet pressure $=25$ psia & cs & QUESTIMATE \\
\hline P-602 & Condensate Pump & PUMP & CENTRIFUGAL & 190 GPM; 4 brake HP; outlet pressure $=25$ psia & SS304 & QUESTIMATE \\
\hline$P-603$ & Deaerator Feed Pump & PUMP & CENTRIFUGAL & 702 GPM; 14 brake HP; outlet pressure $=40$ psia & cs & QUESTIMATE \\
\hline P-604 & Boiler Feed Water Pump & PUMP & CENTRIFUGAL & 730 GPM; 759 brake HP; outlet pressure = 1,345 psia & cs & QUESTIMATE \\
\hline S-601 & Blowdown Flash Drum & TANK & $\begin{array}{l}\text { HORIZONTAL- } \\
\text { VESSEL }\end{array}$ & $\mathrm{H} / \mathrm{D}=2$; residence time $=5 \mathrm{~min} ; 2 \mathrm{ft}$ diameter; $4 \mathrm{ft}$ height; op press $=1,280 \mathrm{psi} ; \mathrm{op} \mathrm{temp}=575 \mathrm{~F}$ & cs & QUESTIMATE \\
\hline T-601 & Condensate Collection Tank & TANK & $\begin{array}{l}\text { HORIZONTAL- } \\
\text { VESSEL }\end{array}$ & residence time $=10$ minutes; $H / D=2 ; 8 \mathrm{ft}$ diameter; $17 \mathrm{ft} \mathrm{height}$ & cs & QUESTIMATE \\
\hline $\mathrm{T}-602$ & Condensate Surge Drum & TANK & $\begin{array}{l}\text { HORIZONTAL- } \\
\text { VESSEL }\end{array}$ & residence time $=10$ minutes; $H / D=2 ; 9 \mathrm{ft}$ diameter; $17 \mathrm{ft} \mathrm{height}$ & cs & QUESTIMATE \\
\hline T-603 & Deaerator & TANK & $\begin{array}{l}\text { HORIZONTAL- } \\
\text { VESSEL }\end{array}$ & liquid flow rate $=348,266 \mathrm{lb} / \mathrm{hr} ; 150 \mathrm{psig}$ design pressure; $10 \mathrm{~min}$ residence time & CS;SS316 & VENDOR \\
\hline $\mathrm{T}-604$ & Steam Drum & TANK & $\begin{array}{l}\text { HORIZONTAL- } \\
\text { VESSEL }\end{array}$ & 424 gal, $4.5^{\prime} \times 4^{\prime}$ dia, 15 psig & cs & ICARUS \\
\hline \multicolumn{7}{|c|}{ PFD-P800-A701-2 } \\
\hline K-701 & Plant Air Compressor & COMPRESSOR & RECIPROCATING & $450 \mathrm{cfm}, 125$ psig outlet & cs & ICARUS \\
\hline M-701 & Cooling Tower System & COOLING-TOWER & INDUCED-DRAFT & approx $16,500 \mathrm{gpm}, 140 \mathrm{MMBtu} / \mathrm{hr}$ & FIBERGLASS & DELTA-T98 \\
\hline M-702 & Hydraulic Truck Dump with Scale & SCALE & TRUCK-SCALE & Hydraulic Truck Dumper with Scale & cs & VENDOR \\
\hline M-703 & Flue Gas Stack & MISCELLANEOUS & MISCELLANEOUS & 42 inch diameter; $250 \mathrm{deg} \mathrm{F}$ & A515 & QUESTIMATE \\
\hline P-701 & Cooling Water Pump & PUMP & CENTRIFUGAL & 16,188 GPM; 659 brake HP; outlet pressure 75 psi & cs & QUESTIMATE \\
\hline P-702 & Firewater Pump & PUMP & CENTRIFUGAL & $2,500 \mathrm{gpm}, 50 \mathrm{ft}$ head & cs & ICARUS \\
\hline P-703 & Diesel Pump & PUMP & CENTRIFUGAL & $30 \mathrm{gpm}, 150 \mathrm{ft}$ head & cs & ICARUS \\
\hline P-704 & Ammonia Pump & PUMP & CENTRIFUGAL & $8.5 \mathrm{gpm}, 22 \mathrm{ft}$ head & cs & ICARUS \\
\hline P-705 & Hydrazine Pump & PUMP & CENTRIFUGAL & $5 \mathrm{gpm}, 75 \mathrm{ft}$ head & cs & DELTA-T98 \\
\hline S-701 & Instrument Air Dryer & DRYER & PACKAGE & 400 SCFM Air Dryer, -40 F Dewpoint & cs & RICHARDSON \\
\hline T-701 & Plant Air Receiver & TANK & $\begin{array}{l}\text { HORIZONTAL- } \\
\text { VESSEL }\end{array}$ & 900 gal., 200 psig & cs & ICARUS \\
\hline T-702 & Firewater Storage Tank & TANK & $\begin{array}{l}\text { FLAT-BTM- } \\
\text { STORAGE }\end{array}$ & 600,000 gal, 4 hr res time, $51^{\prime}$ dia $\times 40^{\prime}$ high, atmospheric & A285C & ICARUS \\
\hline T-703 & Diesel Storage Tank & TANK & $\begin{array}{l}\text { FLAT-BTM- } \\
\text { STORAGE }\end{array}$ & $10,667 \mathrm{gal}, 120 \mathrm{hr}$ res time, $90 \% \mathrm{wv}, 10^{\prime}$ dia $\times 18.2^{\prime}$ high, atmospheric & A285C & ICARUS \\
\hline T-704 & Ammonia Storage Tank & TANK & $\begin{array}{l}\text { HORIZONTAL- } \\
\text { STORAGE }\end{array}$ & Included in the cost of the feed handling step. & A515 & ICARUS \\
\hline T-705 & Olivine Lock Hopper & TANK & VERTICAL-VESSEL & Included in the cost of the feed handling step. & cS & DELTA-T98 \\
\hline T-706 & MgO Lock Hopper & TANK & VERTICAL-VESSEL & $20^{\prime} \times 20^{\prime}$ Bin, Tapering to $3^{\prime} \times 3^{\prime}$ at Bottom. Capacity $6,345 \mathrm{cf}$, two truck loads. & cs & DELTA-T98 \\
\hline T-707 & Hydrazine Storage Tank & TANK & VERTICAL-VESSEL & 260 gal, 4.9' x 3'dia., 10psig & SS316 & ICARUS \\
\hline
\end{tabular}




\section{Appendix D}

\section{Individual Equipment Cost Summary}




\begin{tabular}{|c|c|c|c|c|c|c|c|c|c|c|c|c|}
\hline $\begin{array}{l}\text { Equipment } \\
\text { Number }\end{array}$ & $\begin{array}{l}\text { Number } \\
\text { Required }\end{array}$ & $\begin{array}{c}\text { Number } \\
\text { Spares }\end{array}$ & Equipment Name & Size Ratio & $\begin{array}{c}\text { Original Equip Cost (per } \\
\text { unit) }\end{array}$ & Base Year & \begin{tabular}{|c|}
$\begin{array}{c}\text { Total Original Equip Cost } \\
\text { (Req'd \& Spare) in Base } \\
\text { Year }\end{array}$ \\
\end{tabular} & $\begin{array}{c}\text { Scaling } \\
\text { Exponent }\end{array}$ & \begin{tabular}{|r|}
$\begin{array}{r}\text { Scaled Cost in Base } \\
\text { Year } \mid\end{array}$ \\
\end{tabular} & Installation Factor & $\begin{array}{l}\text { Installed Cost in Base } \\
\text { Year }\end{array}$ & Installed Cost in $2005 \$$ \\
\hline $\mathrm{C}-101$ & 4 & & Hopper Feeder & 1.00 & so & 2002 & so & 0.75 & \$0 & 2.47 & \$0 & \$o \\
\hline C-102 & 2 & & Screener Feeder Conveyor & 1.00 & \$0 & 2002 & so & 0.75 & so & 2.47 & \$0 & \$o \\
\hline C-103 & 2 & & Radial Stacker Conveyor & 1.00 & \$0 & 2002 & so & 0.75 & so & 2.47 & \$o & $\$ 0$ \\
\hline C-104 & 2 & & Dryer Feed Screw Conveyor & 1.00 & so & 2002 & \$o & 0.75 & so & 2.47 & \$o & $\$ 0$ \\
\hline$c-105$ & 2 & & Gasifier Feed Screw Conveyor & 0.93 & \$0 & 2002 & so & 0.75 & \$o & 2.47 & $\$ 0$ & $\$ 0$ \\
\hline $\mathrm{H}-286 \mathrm{~B}$ & 1 & & Flue Gas Cooler/Steam Generator \#1 & 0.60 & $\$ 347,989$ & 2002 & $\$ 347,989$ & 0.6 & $\$ 256,890$ & 2.47 & $\$ 634,519$ & $\$ 750,965$ \\
\hline $\mathrm{H}-286 \mathrm{C}$ & 1 & & Flue Gas Cooler /Boiler Water Preheater \#1 & 0.03 & $\$ 20,989$ & 2002 & $\$ 20,989$ & 0.6 & $\$ 2,637$ & 2.47 & $\$ 6,512$ & $\$ 7,708$ \\
\hline $\mathrm{H}-311 \mathrm{~B}$ & 1 & & Flue Gas Cooler / Steam Generator \#3 & 0.69 & $\$ 69,089$ & 2002 & $\$ 69,089$ & 0.65 & $\$ 54,035$ & 2.47 & $\$ 133,465$ & $\$ 157,959$ \\
\hline M-101 & 4 & & Hydraulic Truck Dump with Scale & 1.00 & \$0 & 2002 & \$o & 0.75 & so & 2.47 & \$0 & $\$ 0$ \\
\hline M-102 & 2 & & Hammermill & 1.00 & \$0 & 2002 & so & 0.75 & so & 2.47 & $\$ 0$ & \$o \\
\hline M-103 & 3 & & Front End Loaders & 1.00 & \$0 & 2002 & so & 0.75 & \$o & 2.47 & $\$ 0$ & \$o \\
\hline M-104 & 2 & & Rotary Biomass Dryer & 1.00 & $\$ 3,813,728$ & 2002 & $\$ 7,627,455$ & 0.75 & $\$ 7,627,450$ & 2.47 & $\$ 18,839,801$ & $\$ 22,297,257$ \\
\hline$s-101$ & 2 & & Magnetic Head Pulley & 1.00 & \$o & 2002 & so & 0.75 & so & 2.47 & $\$ 0$ & \$o \\
\hline$s-102$ & 2 & & Screener & 1.00 & \$o & 2002 & \$o & 0.75 & \$o & 2.47 & \$o & $\$ 0$ \\
\hline$s-103$ & 2 & & Dryer Air Cyclone & 1.56 & \$0 & 2002 & \$o & 0.75 & \$o & 2.47 & $\$ 0$ & $\$ 0$ \\
\hline$s-104$ & 2 & & Dryer Air Baghouse Filter & 0.93 & \$0 & 2002 & so & 0.75 & so & 2.47 & \$0 & $\$ 0$ \\
\hline$T-101$ & 4 & & Dump Hopper & 1.00 & \$o & 2002 & \$0 & 0.75 & \$o & 2.47 & \$o & $\$ 0$ \\
\hline$T-103$ & 2 & & Dryer Feed Bin & 1.00 & so & 2002 & so & 0.75 & so & 2.47 & so & so \\
\hline$T-104$ & 2 & & Dried Biomass Hopper & 0.93 & \$o & 2002 & \$0 & 0.75 & \$o & 2.47 & $\$ 0$ & $\$ 0$ \\
\hline A100 & & & & & & Subtotal & $\$ 8,065,522$ & & $\$ \$ \$, 941,011$ & 2.47 & $\$ 19,614,298$ & $\$ 23,213,888$ \\
\hline & & & & & & & & & & & & \\
\hline$c-201$ & 1 & & Sand/ash Conditioner/Conveyor & 0.33 & \$o & 2002 & so & 0.65 & so & 2.47 & $\$ 0$ & $\$ 0$ \\
\hline $\mathrm{K}-202$ & 2 & & Combustion Air Blower & 0.97 & \$0 & 2002 & so & 0.65 & so & 2.47 & \$0 & \$o \\
\hline M-201 & 2 & & Sand/ash Cooler & 0.33 & \$0 & 2002 & so & 0.65 & so & 2.47 & \$0 & $\$ 0$ \\
\hline R-201 & 2 & & Indirectly-heated Biomass Gasifier & 1.00 & $\$ 2,212,201$ & 2002 & $\$ 4,424,402$ & 0.65 & $\$ 4,418,389$ & 2.47 & $\$ 10,913,421$ & $\$ 12,916,238$ \\
\hline$R-202$ & 2 & & Char Combustor & 1.00 & \$0 & 2002 & \$o & 0.65 & \$o & 2.47 & so & so \\
\hline$s-201$ & 2 & & Primary Gasifier Cyclone & 1.00 & \$0 & 2002 & so & 0.65 & so & 2.47 & \$0 & $\$ 0$ \\
\hline$s-202$ & 2 & & Secondary Gasifier Cyclone & 0.97 & \$o & 2002 & so & 0.65 & so & 2.47 & so & \$o \\
\hline S-203 & 2 & & Primary Combustor Cyclone & 1.00 & \$0 & 2002 & so & 0.65 & \$0 & 2.47 & $\$ 0$ & $\$ 0$ \\
\hline s-204 & 2 & & Secondary Combustor Cyclone & 0.95 & $\$ 0$ & 2002 & \$0 & 0.65 & \$0 & 2.47 & \$o & $\$ 0$ \\
\hline$s-205$ & 2 & & Electrostatic Precipitator & 0.96 & \$0 & 2002 & \$o & 0.65 & so & 2.47 & \$o & so \\
\hline $\mathrm{T}-201$ & 1 & & Sandlash Bin & 0.33 & so & 2002 & so & 0.65 & so 0 & 2.47 & so & \$o \\
\hline & & & & & & & & & & & & \\
\hline A200 & & & & & & Subtotal & 年 & & 年 $\$ 4,418,389$ & 2.47 & $\begin{array}{l}\$ 10,913,421 \\
\end{array}$ & $\begin{array}{l}12,916,238 \\
\end{array}$ \\
\hline
\end{tabular}




\begin{tabular}{|c|c|c|c|c|c|c|c|c|c|c|c|c|}
\hline $\mathrm{H}-301$ & 1 & & Quench Water Recirculation Cooler & 1.57 & $\$ 0$ & 2002 & so & 0.44 & $\$ 0$ & 2.47 & $\$ 0$ & $\$ 0$ \\
\hline H-301A & 1 & & Post-tar Reformer Cooler / Steam Generator \#2 & 1.66 & $\$ 69,089$ & 2002 & $\$ 69,089$ & 0.65 & $\$ 96,054$ & 2.47 & $\$ 237,253$ & $\$ 280,793$ \\
\hline $\mathrm{H}-301 \mathrm{~B}$ & 1 & & Reformer Flue Gas Cooler/Steam superheater & 1.00 & $\$ 196,589$ & 2002 & $\$ 196,589$ & 0.6 & $\$ 196,056$ & 2.47 & $\$ 484,259$ & $\$ 573,129$ \\
\hline $\mathrm{H}-301 \mathrm{C}$ & 1 & & Reformed Syngas cooler / Synthesis Reactor Preheat\#1 & 0.32 & $\$ 144,006$ & 2002 & $\$ 144,006$ & 0.44 & $\$ 87,219$ & 2.47 & $\$ 215,431$ & $\$ 254,966$ \\
\hline $\mathrm{H}-302$ & 5 & & Syngas Compressor Intercoolers & 1.57 & \$0 & 2002 & \$o & 0.65 & so & 2.47 & $\$ 0$ & so \\
\hline $\mathrm{H}-303$ & 1 & & Water-cooled Aftercooler & 1.81 & $\$ 20,889$ & 2002 & $\$ 20,889$ & 0.44 & $\$ 27,111$ & 2.47 & $\$ 66,965$ & $\$ 79,254$ \\
\hline $\mathrm{H}-304$ & 1 & & LO-CAT Preheater & 0.15 & $\$ 4,743$ & 2002 & $\$ 4,743$ & 0.6 & $\$ 1,539$ & 2.47 & $\$ 3,800$ & $\$ 4,498$ \\
\hline $\mathrm{H}-305$ & 1 & & LO-CAT Absorbent Solution Cooler & 0.29 & \$0 & 2002 & \$o & 0.44 & \$o & 2.47 & $\$ 0$ & so \\
\hline H-315D1 & 1 & & Recycle Syngas Cooler / Steam Generator \#4 & 4.20 & $\$ 26,143$ & 2002 & $\$ 26,143$ & 0.6 & $\$ 61,841$ & 2.47 & $\$ 152,746$ & $\$ 180,778$ \\
\hline $\mathrm{H}-315 \mathrm{D} 2$ & 1 & & Recycle Syngas cooler \#2 / Air preheat \#1 & 4.08 & $\$ 4,743$ & 2002 & $\$ 4,743$ & 0.6 & $\$ 11,020$ & 2.47 & $\$ 27,219$ & $\$ 32,214$ \\
\hline K-301 & 1 & & Syngas Compressor & 1.73 & $\$ 3,896,834$ & 2002 & $\$ 3,896,834$ & 0.8 & $\$ 6,036,915$ & 2.47 & $\$ 14,911,181$ & $\$ 17,647,662$ \\
\hline K-302 & 1 & & LO-CAT Feed Air Blower & 0.73 & $\$ 0$ & 2002 & so & 0.65 & \$o & 2.47 & $\$ 0$ & so \\
\hline K-305 & 1 & & Regenerator Combustion Air Blower & 0.94 & $\$ 35,020$ & 2002 & $\$ 35,020$ & 0.59 & $\$ 33,806$ & 2.47 & $\$ 83,500$ & $\$ 98,824$ \\
\hline M-301 & 1 & & Syngas Quench Chamber & 1.57 & \$0 & 2002 & $\$ 0$ & 0.65 & so & 2.47 & $\$ 0$ & so \\
\hline M-302 & 1 & & Syngas Venturi Scrubber & 1.57 & \$o & 2002 & \$o & 0.65 & so & 2.47 & \$0 & $\$$ \\
\hline M-303 & 1 & & LO-CAT Venturi Precontactor & 0.73 & $\$ 0$ & 2002 & so & 0.65 & $\$ 0$ & 2.47 & $\$ 0$ & $\$ 0$ \\
\hline M-304 & 1 & & LO-CAT Liquid-filled Absorber & 0.29 & \$0 & 2002 & so & 0.65 & so & 2.47 & $\$ 0$ & so \\
\hline$P-301$ & 1 & 1 & Sludge Pump & 0.08 & $\$ 3,911$ & 2002 & $\$ 7,822$ & 0.33 & $\$ 3,351$ & 2.47 & $\$ 8,277$ & $\$ 9,795$ \\
\hline P-302 & 1 & 1 & Quench Water Recirculation Pump & 0.99 & \$0 & 2002 & \$o & 0.65 & so & 2.47 & \$o & $\$ 0 \mid$ \\
\hline$R-303$ & 1 & & Tar Reformer & 1.57 & $\$ 2,212,201$ & 2002 & $\$ 2,212,201$ & 0.65 & $\$ 2,965,912$ & 2.47 & $\$ 7,325,802$ & $\$ 8,670,224$ \\
\hline$R-304$ & 1 & & LO-CAT Oxidizer Vessel & 0.73 & $\$ 1,000,000$ & 2002 & $\$ 1,000,000$ & 0.65 & $\$ 813,486$ & 2.47 & $\$ 2,009,311$ & $\$ 2,378,057$ \\
\hline$s-301$ & 1 & & Pre-compressor Knock-out & 1.73 & $\$ 157,277$ & 2002 & $\$ 157,277$ & 0.6 & $\$ 218,395$ & 2.47 & $\$ 539,436$ & $\$ 638,432$ \\
\hline$S-302$ & 4 & & Syngas Compressor Interstage Knock-outs & 1.73 & \$0 & 2002 & so & 0.6 & \$0 & 2.47 & $\$ 0$ & $\$ 0$ \\
\hline s-303 & 1 & & Post-compressor Knock-out & 1.86 & $\$ 40,244$ & 2002 & $\$ 40,244$ & 0.6 & $\$ 58,421$ & 2.47 & $\$ 144,300$ & $\$ 170,781$ \\
\hline s-306 & 1 & & Tar Reformer Cyclone & 1.57 & \$0 & 2002 & so & 0.65 & so & 2.47 & $\$ 0$ & sol \\
\hline S-307 & 1 & & Catalyst Regenerator Cyclone & 1.62 & \$0 & 2002 & so & 0.65 & $\$ 0$ & 2.47 & $\$ 0$ & $\$ 0$ \\
\hline$s-310$ & 1 & & L.P. Amine System & 1.26 & $\$ 3,485,685$ & 2002 & $\$ 3,485,685$ & 0.75 & $\$ 4,155,524$ & 2.47 & $\$ 10,264,143$ & $\$ 12,147,805$ \\
\hline $\mathrm{T}-301$ & 1 & & Sludge Settling Tank & 0.00 & $\$ 11,677$ & 2002 & $\$ 11,677$ & 0.6 & $\$ 260$ & 2.47 & $\$ 641$ & $\$ 759$ \\
\hline$T-302$ & 1 & & Quench Water Recirculation Tank & 1.57 & \$o & 2002 & so & 0.65 & so & 2.47 & $\$ 0$ & \$o \\
\hline & & & & & & & & & & & & \\
\hline A300 & & & & & & Subtotal & $\$ 13,742,341$ & & $\$ 18,091,903$ & 2.47 & $\$ 44,687,000$ & $\$ 52,887,900$ \\
\hline
\end{tabular}




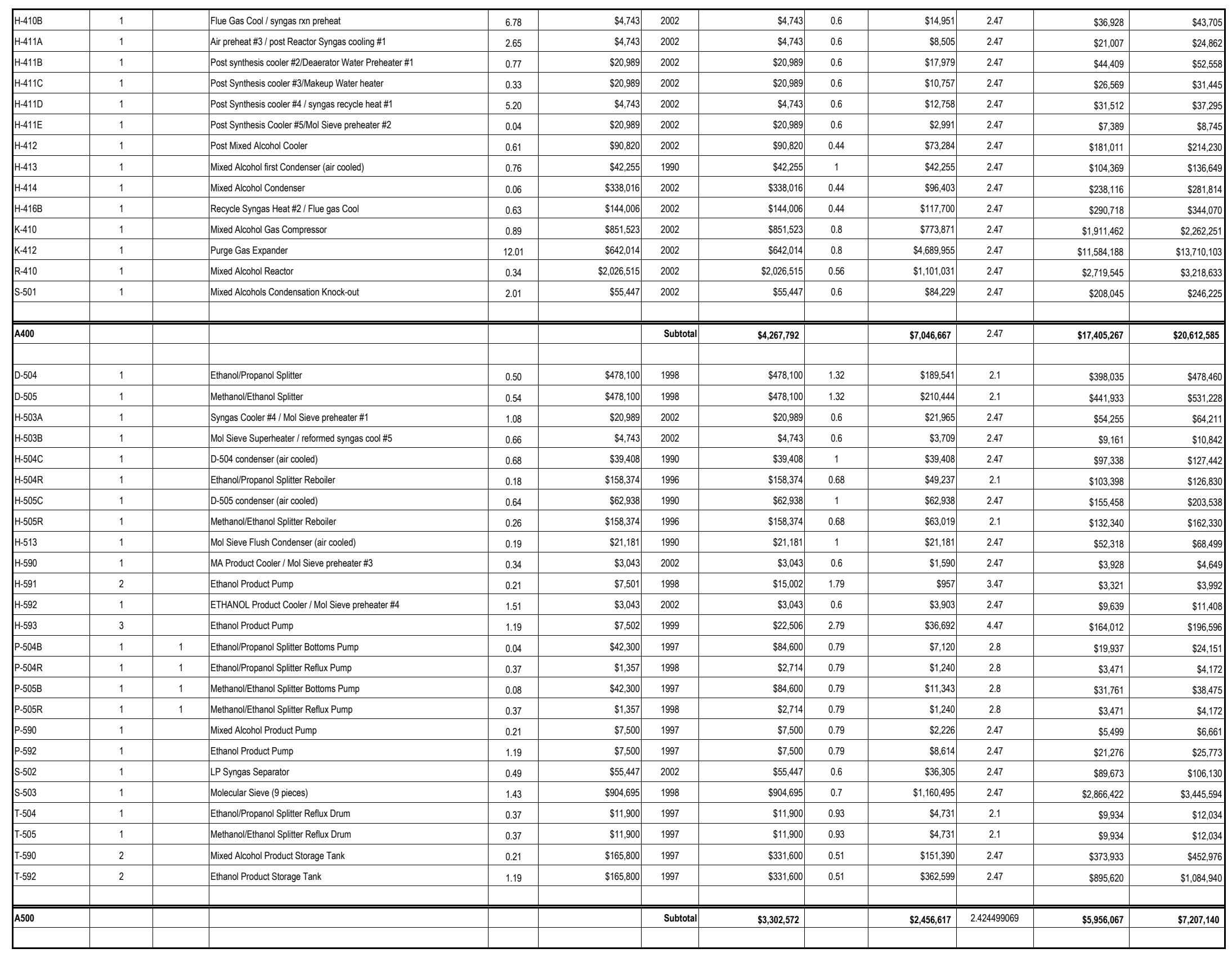




\begin{tabular}{|c|c|c|c|c|c|c|c|c|c|c|c|c|}
\hline H-601 & 1 & & Steam Turbine Condenser & 0.87 & $\$ 0$ & 2002 & $\$ 0$ & 0.71 & $\$ 0$ & 2.47 & $\$ 0$ & $\$ 0$ \\
\hline H-602 & 1 & & Blowdown Cooler / Deaerator Water Preheater & 0.00 & $\$ 3,043$ & 2002 & $\$ 3,043$ & 0.6 & $\$ 0$ & 2.47 & \$o & $\$ 0$ \\
\hline $\mathrm{H}-603$ & 1 & & Blowdown Water-cooled Cooler & 4.90 & $\$ 16,143$ & 2002 & $\$ 16,143$ & 0.44 & $\$ 32,485$ & 2.47 & $\$ 80,237$ & 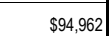 \\
\hline M-601 & 1 & & Hot Process Water Softener System & 1.00 & $\$ 1,031,023$ & 1999 & $\$ 1,031,023$ & 0.82 & $\$ 1,028,430$ & 2.47 & $\$ 2,540,222$ & $\$ 3,044,885$ \\
\hline M-602 & 1 & & Extraction Steam Turbine/Generator & 1.00 & $\$ 4,045,870$ & 2002 & $\$ 4,045,870$ & 0.71 & $\$ 4,037,059$ & 2.47 & $\$ 9,971,535$ & $\$ 11,801,498$ \\
\hline$M-603$ & 1 & & Startup Boiler & 1.00 & $\$ 198,351$ & 2002 & $\$ 198,351$ & 0.6 & $\$ 198,351$ & 2.47 & $\$ 489,927$ & $\$ 579,837$ \\
\hline P-601 & 1 & 1 & Collection Pump & 0.13 & $\$ 7,015$ & 2002 & $\$ 14,030$ & 0.33 & $\$ 7,226$ & 2.47 & $\$ 17,847$ & $\$ 21,122$ \\
\hline $\mathrm{P}-602$ & 1 & 1 & Condensate Pump & 0.87 & $\$ 5,437$ & 2002 & $\$ 10,874$ & 0.33 & $\$ 10,366$ & 2.47 & $\$ 25,605$ & $\$ 30,304$ \\
\hline $\mathrm{P}-603$ & 1 & 1 & Deaerator Feed Pump & 1.00 & $\$ 8,679$ & 2002 & $\$ 17,358$ & 0.33 & $\$ 17,340$ & 2.47 & $\$ 42,831$ & $\$ 50,691$ \\
\hline P-604 & 1 & 1 & Boiler Feed Water Pump & 1.00 & $\$ 95,660$ & 2002 & $\$ 191,320$ & 0.33 & $\$ 191,126$ & 2.47 & $\$ 472,082$ & $\$ 558,718$ \\
\hline$s-601$ & 1 & & Blowdown Flash Drum & 1.00 & $\$ 14,977$ & 2002 & $\$ 14,977$ & 0.6 & $\$ 14,950$ & 2.47 & $\$ 36,926$ & $\$ 43,703$ \\
\hline$T-601$ & 1 & & Condensate Collection Tank & 1.00 & $\$ 24,493$ & 2002 & $\$ 24,493$ & 0.6 & $\$ 24,448$ & 2.47 & $\$ 60,386$ & $\$ 71,468$ \\
\hline$T-602$ & 1 & & Condensate Surge Drum & 1.00 & $\$ 28,572$ & 2002 & $\$ 28,572$ & 0.6 & $\$ 28,519$ & 2.47 & $\$ 70,443$ & $\$ 83,371$ \\
\hline$T-603$ & 1 & & Deaerator & 1.00 & $\$ 130,721$ & 2002 & $\$ 130,721$ & 0.72 & $\$ 130,432$ & 2.47 & $\$ 322,168$ & $\$ 381,292$ \\
\hline$T-604$ & 1 & & Steam Drum & 1.00 & $\$ 9,200$ & 1997 & $\$ 9,200$ & 0.72 & $\$ 9,180$ & 2.47 & $\$ 22,674$ & $\$ 27,467$ \\
\hline A600 & & & & & & \begin{tabular}{l|l|} 
Subtotal \\
\end{tabular} & \begin{tabular}{l|l|}
$\$ 5,735,975$ \\
\end{tabular} & & $\begin{array}{l}5,729,912 \\
\end{array}$ & 2.47 & $\$ 14,152,883$ & $\$ 16,789,318$ \\
\hline & & & & & & & & & & & & \\
\hline K-701 & 2 & 1 & Plant Air Compressor & 1.00 & $\$ 32,376$ & 2002 & $\$ 97,129$ & 0.34 & $\$ 97,129$ & 2.47 & $\$ 239,908$ & $\$ 283,936$ \\
\hline M-702 & 1 & & Hydraulic Truck Dump with Scale & 1.00 & $\$ 80,000$ & 1998 & $\$ 80,000$ & 0.6 & $\$ 80,000$ & 2.47 & $\$ 197,600$ & $\$ 237,526$ \\
\hline M-703 & 1 & & Flue Gas Stack & 0.31 & $\$ 51,581$ & 2002 & $\$ 51,581$ & 1 & $\$ 15,917$ & 2.47 & $\$ 39,315$ & $\$ 46,530$ \\
\hline P-701 & 1 & 1 & Cooling Water Pump & 0.66 & $\$ 158,540$ & 2002 & $\$ 317,080$ & 0.33 & $\$ 276,264$ & 2.47 & $\$ 682,373$ & $\$ 807,601$ \\
\hline P-702 & 1 & 1 & Firewater Pump & 1.00 & $\$ 18,400$ & 1997 & $\$ 36,800$ & 0.79 & $\$ 36,800$ & 2.47 & $\$ 90,896$ & $\$ 110,110$ \\
\hline P-703 & 1 & 1 & Diesel Pump & 1.00 & $\$ 6,100$ & 1997 & $\$ 12,200$ & 0.79 & $\$ 12,200$ & 2.47 & $\$ 30,134$ & $\$ 36,504$ \\
\hline P-704 & 1 & 1 & Ammonia Pump & 1.00 & $\$ 5,000$ & 1997 & $\$ 10,000$ & 0.79 & $\$ 10,000$ & 2.47 & $\$ 24,700$ & $\$ 29,921$ \\
\hline P-705 & 1 & & Hydrazine Pump & 1.00 & $\$ 5,500$ & 1997 & $\$ 5,500$ & 0.79 & $\$ 5,500$ & 2.47 & $\$ 13,585$ & $\$ 16,457$ \\
\hline S-701 & 1 & 1 & Instrument Air Dryer & 1.00 & $\$ 8,349$ & 2002 & $\$ 16,698$ & 0.6 & $\$ \$ 16,698$ & 2.47 & $\$ 41,244$ & $\$ 48,813$ \\
\hline$T-701$ & 1 & & Plant Air Receiver & 1.00 & $\$ 7,003$ & 2002 & $\$ 7,003$ & 0.72 & $\$ 7,003$ & 2.47 & $\$ 17,297$ & $\$ 20,472$ \\
\hline T-702 & 1 & & Firewater Storage Tank & 1.00 & $\$ 16,100$ & 1997 & $\$ 16,100$ & 0.51 & $\$ 166,100$ & 2.47 & $\$ 410,267$ & $\$ 496,991$ \\
\hline T-703 & 1 & & Diesel Storage Tank & 1.00 & $\$ 14,400$ & 1997 & $\$ 14,400$ & 0.51 & $\$ 14,400$ & 2.47 & $\$ 35,568$ & $\$ 43,086$ \\
\hline$T-704$ & 1 & & Ammonia Storage Tank & 1.00 & $\$ 287,300$ & 1997 & $\$ 287,300$ & 0.72 & $\$ 287,300$ & 2.47 & $\$ 709,631$ & $\$ 859,635$ \\
\hline $\mathrm{T}-705$ & 1 & & Olivine Lock Hopper & 1.00 & \$0 & 1998 & \$0 & 0.71 & $\$ 0$ & 2.47 & $\$ 0$ & $\$ 0$ \\
\hline $\mathrm{T}-706$ & 1 & & MgO Lock Hopper & 1.00 & $\$ 0$ & 1998 & so & 0.71 & $\$ 0$ & 2.47 & \$0 & $\$ 0$ \\
\hline $\mathrm{T}-707$ & 1 & & Hydrazine Storage Tank & 1.00 & $\$ 12,400$ & 1997 & $\$ 12,400$ & 0.93 & $\$ 12,400$ & 2.47 & $\$ 30,628$ & $\$ 37,102$ \\
\hline & & & & & & & & & & & & \\
\hline \multirow[t]{2}{*}{ A700 } & & & & & & Subbtotal & \begin{tabular}{|l|}
$\$ 1,381,507$ \\
\end{tabular} & & \begin{tabular}{l|l|}
$\$ 1,230,719$ \\
\end{tabular} & 2.47 & $\$ 33,039,875$ & $\$ 33,601,800$ \\
\hline & & & & & & & & & & & & \\
\hline
\end{tabular}




\section{Appendix F \\ Discounted Cash Flow Rate of Return Summary}




\begin{tabular}{|c|c|c|c|c|c|c|c|c|c|c|c|c|c|}
\hline & & & & & & & 3 & 4 & 5 & 6 & 7 & & \\
\hline $\begin{array}{l}\text { YYar } \\
\text { Fixed Capital Investment } \\
\text { Working capital }\end{array}$ & & $\$ 18,603,984$ & $\$ 114,503,967$ & $\begin{array}{l}\$ 61,068,782 \\
\$ \$, 551,997\end{array}$ & & & & & & & & & \\
\hline Loan Payment & & & & & $\$ 0$ & so & so & s0 & $\$ 0$ & so & $\$ 0$ & $\$ 0$ & \\
\hline Loan Interest Payment & & $\$ 0$ & $\$ 0$ & $\$ 0$ & $\$ 0$ & so & $\$ 0$ & $\$ 0$ & $\$ 0$ & so & $\$ 0$ & $\$ 0$ & $\$ 0$ \\
\hline Loan Principal & & $\$ 0$ & $\$ 0$ & $\$ 0$ & $\$ 0$ & so & So & $\$ 0$ & 50 & $\$ 0$ & 80 & $\$ 0$ & \\
\hline \begin{tabular}{|l|} 
Ethanol Sales \\
By-Product Credit \\
\end{tabular} & & & & & $\begin{array}{r}\$ 46,938,097 \\
\$ 9633280\end{array}$ & 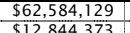 & \begin{tabular}{|l|}
$\$ 62,584,129$ \\
$\$ 12844,373$
\end{tabular} & \begin{tabular}{|l|l|}
$\$ 662,584,129$ \\
12844,373
\end{tabular} & $\begin{array}{l}\$ 62,584,129 \\
\$ 12844,373\end{array}$ & $\begin{array}{l}\$ 62,584,129 \\
\$ 12844,373\end{array}$ & $\begin{array}{l}\$ 62,584,129 \\
\$ 12844373\end{array}$ & $\begin{array}{l}\$ 62,584,129 \\
\$ 12844,373\end{array}$ & $\begin{array}{l}562,584,129 \\
51284,373\end{array}$ \\
\hline $\begin{array}{l}\text { By-Product Credit } \\
\text { Total Annual Sales }\end{array}$ & & & & & $\begin{array}{r}\$ 9,63,280 \\
\$ 56,571,377\end{array}$ & $\begin{array}{l}\$ 12,844,373 \\
\$ 75,428,503\end{array}$ & $\begin{array}{l}\$ 12,844,373 \\
\$ 75,428,503\end{array}$ & $\begin{array}{l}\$ 12,844,373 \\
\$ 75,428,503\end{array}$ & $\begin{array}{l}\$ 12,844,373 \\
\$ 75,428,503\end{array}$ & $\begin{array}{l}\$ 12,844,373 \\
\$ 75,428,503\end{array}$ & $\begin{array}{l}\$ 12,844,373 \\
\$ 75,428,503\end{array}$ & $\begin{array}{l}\$ 12,844,373 \\
\$ 75,428,503\end{array}$ & $\begin{array}{l}\$ 12,844,373 \\
\$ 85,428,503\end{array}$ \\
\hline Annual Manufacturing Cost & & & & & & & & & & & & & \\
\hline Raw Materials & & & & & $\$ 23,647,650$ & $\$ 27,025,885$ & $\$ 27,025,885$ & $\$ 27,025,885$ & $\$ 27,025,885$ & $\$ 27,025,885$ & $\$ 27,025,885$ & $\$ 27,025,885$ & $\$ 27,025,885$ \\
\hline Tar reforming catalysts & & & & & $\$ 808,613$ & & & & 20,003 & $2 z, 003$ & 025,003 & 023,005 & \\
\hline Steam reforming catalysts & & & & & $\$ 0$ & & & & & $\begin{array}{l}\$ 0 \\
\$ 0\end{array}$ & & & \\
\hline \begin{tabular}{|l}
$\mathrm{Zn}$ \\
Mixed Alcohol catalysts
\end{tabular} & & & & & $\$ 542,966$ & $\$ 0$ & so & so & so & $\$ 542,966$ & so & so & so \\
\hline Baghouse Bags & & & & & $\$ 415,430$ & & & & & $\$ 415,430$ & & & \\
\hline \begin{tabular}{|l|l} 
Oth \\
\end{tabular} & & & & & $\$ 1,531,320$ & $\$ 1,732,166$ & $\$ 1,732,166$ & $\$ 1,732,166$ & $\$ 1,732,166$ & $\$ 1,732,166$ & $\$ 1,732,166$ & $\$ 1,732,166$ & $\$ 1,732,166$ \\
\hline \begin{tabular}{|l} 
Fixed Operating Costs \\
Total Product Cost
\end{tabular} & & & & & $\begin{array}{l}\$ 12,059,682 \\
\$ 39,056,661\end{array}$ & $\begin{array}{l}\$ 12,059,682 \\
\$ 0,817,733\end{array}$ & $\begin{array}{l}\$ 12,059,682 \\
\$ 40,817,733\end{array}$ & $\begin{array}{l}\$ 12,059,682 \\
\$ \$ 0,817,733\end{array}$ & $\begin{array}{l}\$ 12,059,682 \\
\$ 40,817,733\end{array}$ & $\begin{array}{l}\$ 12,059,682 \\
\$ 47,776,129\end{array}$ & $\begin{array}{l}\$ 12,059,682 \\
\$ 40,877,733\end{array}$ & $\begin{array}{l}\$ 12,059,682 \\
\$ 48,17,733\end{array}$ & $\begin{array}{l}\$ 12,059,682 \\
\$ 40,87,733\end{array}$ \\
\hline Annual Depreciation & & & & & & & & & & & & & \\
\hline Genera & & & & & & 527180054 & & & & & & & \\
\hline DDB & & & & & $\$ 38,064,676$ & $\$ 27,189,054$ & $\$ 19,420,753$ & $\$ 13,871,967$ & $\$ 9,908,548$ & $\$ 7,077,534$ & $\$ 5,055,381$ & & \\
\hline $\begin{array}{l}\text { SL } \\
\text { Rem }\end{array}$ & & & & & $\begin{array}{l}\$ 19,032,338 \\
\$ 95,161690\end{array}$ & $\begin{array}{l}\$ 15,860,282 \\
\$ 67972636\end{array}$ & $\begin{array}{l}\$ 13,594,527 \\
\$ 48551883\end{array}$ & $\begin{array}{l}\$ 12,137,971 \\
\$ 34679916\end{array}$ & $\begin{array}{l}\$ 11,559,972 \\
\$ 24771369\end{array}$ & $\$ 11,559,972$ & $\begin{array}{l}\$ 11,559,972 \\
\$ \$ 1,63853\end{array}$ & & \\
\hline \begin{tabular}{|l} 
Remanining value \\
Actual \\
\end{tabular} & & & & & $\$ 38,064,676$ & $\$ \$ 27,189,054$ & \begin{tabular}{|l|l}
$\$ 40,531,005$ \\
$\$ 19,420,753$
\end{tabular} & $\begin{array}{l}\$ \$ 3,01,871,967 \\
\$ 13,967\end{array}$ & $\$ 11,559,972$ & $\$ 11,559,972$ & $\$ 111,559,4972$ & & \\
\hline \begin{tabular}{|l} 
Steam Plant \\
\end{tabular} & & & & & & & & & & & & & \\
\hline \begin{tabular}{|l} 
DDB \\
$S L$
\end{tabular} & & & & & $\begin{array}{l}\$ 4,321,018 \\
8800679\end{array}$ & $\frac{\$ 3,996,942}{\$ 2804872}$ & $\begin{array}{l}\$ 3,697,171 \\
\$ 2738645\end{array}$ & \begin{tabular}{|l|l|l|}
$\$ 3,419,883$ \\
$\$ 2682,62$
\end{tabular} & $\begin{array}{l}\$ 3,163,392 \\
\$ 8636160\end{array}$ & $\$ 2,926,138$ & \begin{tabular}{|l|l|}
$2,706,677$ \\
$\$ 257788$
\end{tabular} & $\begin{array}{l}\$ 2,503,677 \\
\$ 557873\end{array}$ & $\begin{array}{l}\$ 2,315,901 \\
8567873\end{array}$ \\
\hline $\begin{array}{l}\text { SL } \\
\text { Remaining Value }\end{array}$ & & & & & $\begin{array}{r}\$ 2,80,0679 \\
\$ 53,292,560\end{array}$ & $\begin{array}{r}\$ 2,804,872 \\
\$ 49,295,618\end{array}$ & $\begin{array}{r}\$ 2,7388,645 \\
\$ 45,598,446\end{array}$ & $\begin{array}{r}\$ 2,682,262 \\
\$ 42,178,563\end{array}$ & $\begin{array}{r}\$ 2,636,160 \\
\$ 39,015,171\end{array}$ & $\begin{array}{r}\$ 2,661,011 \\
\$ 36,089,033\end{array}$ & $\begin{array}{r}\$ 2,577,788 \\
\$ 33,382,355\end{array}$ & $\begin{array}{r}\$ 2,567,883 \\
\$ 30,878,679\end{array}$ & $\begin{array}{r}\$ 2,567,873 \\
\$ 28,562,778\end{array}$ \\
\hline$A C$ & & & & & $\$ 4,321,018$ & 53 & $\$ 3$, & $\$$ & $\$ 3,163,392$ & $\$ 2,926,138$ & $\$ 2,706,677$ & $\$ 2,567,873$ & $\$ 2,567,873$ \\
\hline \begin{tabular}{|l|} 
Net Revenue \\
Lcses
\end{tabular} & & & & & $(\$ 24,819,978)$ & , & $\$ 11,4$ & 31 & $\$ 19,887,405$ & $\$ 19,166,264$ & $\$ 20,344,120$ & $\$ 32,042,896$ & $\$ 32,042,896$ \\
\hline $\begin{array}{l}\text { Losses Forward } \\
\end{array}$ & & & & & $(\$ 24.819978)$ & $\begin{array}{l}(\$ 22,819,978) \\
(\$ 29,8)\end{array}$ & $(\$ 21,395,205)$ & $\begin{array}{l}(99,902,360) \\
9505\end{array}$ & so & $\$ 0$ & 50 & 50 & $\$ 0$ \\
\hline $\begin{array}{l}\text { axabole Income } \\
\text { Income Tax }\end{array}$ & & & & & $(\$<4,819,9 / 8)$ & $\frac{(\$ 21,395,205)}{\$ 0}$ & $\frac{(\$ 9,902,360)}{\$ 0}$ & $\begin{array}{r}\$ 7,416,559 \\
\$ 2,892,458 \\
\end{array}$ & $\begin{array}{r}\$ 19,887,405 \\
77,756,088\end{array}$ & $\begin{array}{r}\$ 19,166,264 \\
\$ 77,474,843\end{array}$ & $\frac{\$ 20,344,120}{\$ 7,934,207}$ & $\frac{\$ 32,042,896}{\$ 12,496,729}$ & $\begin{array}{ll}532,042,896 \\
852,496729\end{array}$ \\
\hline$\frac{1 m}{A n n}$ & & & & & 65,716 & & & & $\frac{\$ 1,150,000}{\$ 26,854,681}$ & & & & \\
\hline Discount & & 1.21 & 1.1 & & $\begin{array}{l}0.909090909 \\
0.90909\end{array}$ & 0.826 & 0.751314801 & 0.683013455 & $\begin{array}{l}\$ 20,034,001 \\
0.620921323\end{array}$ & 0.56447393 & 0.513158118 & $\begin{array}{r}\$ 2,114,040 \\
0.46650738\end{array}$ & 0.424097618 \\
\hline a Present Value & $\$ 217,657,607$ & & & & $\$ 15,968,833$ & $\$ 28,603,942$ & $\$ 26,003,583$ & $\$ 21,664,033$ & $\$ 16,674,644$ & $\$ 14,776,534$ & $\$ 13,689,295$ & $\$ 10,316,363$ & $\$ 9,378,512$ \\
\hline \begin{tabular}{|l|} 
Total Capital Investment + Interest \\
Net resernt Worth
\end{tabular} & & $\$ 22,510,821.23$ & $\$ 125,954,363.41$ & $\$ 70,610,779.49$ & & & & & & & & & \\
\hline
\end{tabular}




\begin{tabular}{|c|c|c|c|c|c|c|c|c|c|c|c|}
\hline \begin{tabular}{|l} 
DCFROR Worksheet \\
Year \\
\end{tabular} & 10 & 11 & 12 & 13 & 14 & 15 & 16 & 17 & 18 & 19 & \\
\hline \begin{tabular}{|l} 
Fel Caped Capital Investment \\
Wixkring Capital
\end{tabular} & & & & & & & & & & & $\begin{array}{r}20 \\
(59,541,997)\end{array}$ \\
\hline $\mid$\begin{tabular}{|l} 
Working Capital \\
Loan Payment
\end{tabular} & so & $\$ 0$ & so & 50 & $\$ 0$ & 50 & so & so & $\$ 0$ & 50 & \\
\hline Loan Interest Payment & & & & & & & & & & & \\
\hline Loan Principal & so & so & so & so & $\$ 0$ & so & so & 80 & so & $\$ 0$ & $\begin{array}{l}\text { so } \\
\text { so }\end{array}$ \\
\hline $\begin{array}{l}\text { Ethanol Sales } \\
\end{array}$ & $\$ \$ 62,584,129$ & $\$ 62,584,129$ & $\$ 62,584,129$ & $\$ 62,584,129$ & $\$ 562,584,129$ & $562,584,129$ & $\$ 62.584 .129$ & $\$ 62.584 .129$ & $\$ 62.584 .129$ & 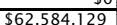 & $\begin{array}{r}\$ 62,584,129 \\
\$(1)\end{array}$ \\
\hline By-Product Credit & $\$ 12,844,373$ & $\$ 12,844,373$ & $\$ 12,842,373$ & $\$ 12,842,373$ & $\$ \$ 12,844,373$ & $\$ \$ 12,844,373$ & $\$ \$ 12,844,373$ & $\$ 12,844,373$ & $\$ 12,844,373$ & $\$ 12,844,373$ & $\$ 12,844,373$ \\
\hline 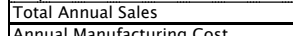 & $\$ 75,428,503$ & $\$ 75,428,503$ & $\$ 75,428,503$ & & & & & & & & \\
\hline Raw M & $\$ 27,025,885$ & $\$ 27,025,885$ & $\$ 27,025,885$ & $\$ 27,025,885$ & $\$ 27,025,885$ & $\$ 27,025,885$ & $\$ 27,025,885$ & $\$ 27,025,885$ & $\$ 27,025,885$ & $\$ 27,025,885$ & $\$ 27,025,885$ \\
\hline $\begin{array}{l}\text { Tar reforming catallysts } \\
\text { Steam reforming catatysts }\end{array}$ & & & & & & & 50 & & & & \\
\hline $\begin{array}{l}\text { Steam reforming catalysts } \\
\text { ZnO }\end{array}$ & & $\$ 0$ & & & & & $\$ 0$ & & & & \\
\hline Mixed Alcohol catalysts & so & $\$ 542,966$ & $\$ 0$ & so & so & $\$ 0$ & $\$ 542,966$ & so & so & so & $\$ 0$ \\
\hline Baghou & & $\$ 415,430$ & & & & & $\$ 415,430$ & & & & \\
\hline Other V & $\begin{array}{r}\$ 1,732,166 \\
\$ 1259682\end{array}$ & $\$ 1,732,166$ & $\begin{array}{r}\$ 1,732,166 \\
\$ 1,050682\end{array}$ & $\$ 1,732,166$ & $\$ 1,732,166$ & $\begin{array}{r}\$ 1,732,166 \\
\$ \$ 1,050682\end{array}$ & $\begin{array}{r}\$ 1,732,166 \\
\$ 12059682\end{array}$ & $\begin{array}{r}\$ 1,732,166 \\
\$ 1259682\end{array}$ & $\begin{array}{r}\$ 1,732,166 \\
\$ 1355962\end{array}$ & $\begin{array}{l}\$ 1,732,166 \\
\$ 1209682\end{array}$ & $\begin{array}{r}\$ 1,732,166 \\
\$ 1059682\end{array}$ \\
\hline $\begin{array}{l}\text { Fixed Operating C } \\
\text { Total Product Cost }\end{array}$ & $\begin{array}{l}\$ 12,059,682 \\
\$ 40,817,733\end{array}$ & $\begin{array}{r}\$ 12,059,682 \\
\$ 41,776,129\end{array}$ & $\begin{array}{l}\$ 1,2099,682 \\
\$ 40,817,733\end{array}$ & $\begin{array}{l}\$ 1,2059,682 \\
\$ 40,817,733\end{array}$ & $\begin{array}{l}\$ 2,059,682 \\
\$ 40,817,733 \\
\end{array}$ & $\begin{array}{l}\$ \$ 2,059,682 \\
\$ 40,817,733\end{array}$ & $\begin{array}{r}\$ 12,059,682 \\
\$ 41,776,129\end{array}$ & $\begin{array}{l}\$ 12,0599,682 \\
\$ 40,817,733 \\
\end{array}$ & $\begin{array}{l}\$ 1,2059,682 \\
\$ 40,817,733\end{array}$ & $\begin{array}{l}\$ 12,059,682 \\
\$ 40,817,733\end{array}$ & $\begin{array}{l}\$ 12,059,682 \\
\$ 40,817,733 \\
\end{array}$ \\
\hline $\begin{array}{l}\text { Annual Depreciation } \\
\end{array}$ & & & & & & & & & & & \\
\hline General Plant & & & & & & & & & & & \\
\hline SI & & & & & & & & & & & \\
\hline $\begin{array}{l}\text { SL } \\
\text { Remaining Value }\end{array}$ & & & & & & & & & & & \\
\hline Actual & & & & & & & & & & & \\
\hline Steam & & & & & & & & & & & \\
\hline DDE & $\$ 2,142,208$ & $\$ 1,981,543$ & 2,927 & 5,457 & $\$ 1,568,298$ & $\$ 1,450,676$ & $\$ 1,341,875$ & $\$ 1,241,234$ & $\$ 1,148,142$ & $\$ 1,062,031$ & $\$ 982,379$ \\
\hline $\begin{array}{l}\text { Lemaining Value } \\
\text { Re }\end{array}$ & $\begin{array}{r}\$ 2,56 /, 883 \\
\$ 26,420,570\end{array}$ & $\begin{array}{r}\$ 2,56 /, 883 \\
\$ 24,439,027\end{array}$ & $\begin{array}{r}\$ 2,56,8,8 / 3 \\
\$ 22,606,100\end{array}$ & $\begin{array}{r}\$ 2,56,8 / 8 \\
\$ 20,910,642\end{array}$ & $\begin{array}{r}\$ 2,36 /, 873 \\
\$ 19,342,344\end{array}$ & $\begin{array}{r}\$ 2,56 /, 8 / 3 \\
\$ 17,891,668\end{array}$ & $\begin{array}{r}\$ 2,567,873 \\
\$ 16,549,793\end{array}$ & $\begin{array}{r}\$ 2,367,, 873 \\
\$ 15,308,559\end{array}$ & $\begin{array}{r}\$ 2,567,8 / 3 \\
\$ 14,160,417\end{array}$ & $\begin{array}{r}\$ 2,56,8 / 3 \\
\$ 13,098,386\end{array}$ & $\begin{array}{r}\$ 2,567,873 \\
\$ 12,116,007\end{array}$ \\
\hline Actual & $\$ 2,567,873$ & $\$ 2,567,873$ & $\$ 2,567,873$ & $\$ 2,567,873$ & $\$ 2,567,8 / 3$ & $\$ 2,567,873$ & $\$ 2,567,873$ & $\$ 2,567,873$ & $\$ 2,567,873$ & $\$ 2,567,873$ & $\$ 2,567,873$ \\
\hline \begin{tabular}{|l} 
Net Revenue \\
Losses Forwa
\end{tabular} & $\$ 32,042,896$ & $\$ 31,084,500$ & $\$ 32,042,896$ & $\$ 32,042,896$ & $\$ 32,042,896$ & $\$ 32,042,896$ & $\$ 31,084,500$ & $\$ 32,042,896$ & $\$ 32,042,896$ & $\$ 32,042,896$ & $\$ 32,042,896$ \\
\hline Taxable & $\$ 32,042,896$ & $\$ 31,084,500$ & 896 & & 2,896 & 896 & 500 & 96 & 96 & & , 042,896 \\
\hline Income & $\$ 12$, & $\frac{22,955}{22}$ & & & $\$ 12,496,729$ & $\$ 12,496,729$ & 2,955 & & $\$ 12,496,729$ & & 729 \\
\hline$\overline{A n}$ & $\$ 22,114,040$ & $\$ 21,529,419$ & & & $\$ 22,114,040$ & & & & & & $\$ 22,114,040$ \\
\hline Dis & 0.385543289 & 0.350493899 & 0.31 & & 0 & & 0.217629136 & 0.1 & & & 0.148643628 \\
\hline Annual Present & $\$ 8,525,920$ & $\$ 7,545,930$ & $\$ 7,046,215$ & $\$ 6,405,650$ & $\$ 5,823,318$ & $\$ 5,293,925$ & $\$ 4,685,429$ & $\$ 4,375,145$ & $\$ 3,977,404$ & $\$ 3,615,822$ & $\$ 3,287,111$ \\
\hline Total Ca & & & & & & & & & & & \\
\hline
\end{tabular}




\title{
Ethanol from Mixed Alcohols Production Process Engineering Analysis
}

2012 Market Target Case

2,000 Dry Metric Tonnes Biomass per Day

BCL Gasifier, Tar Reformer, Sulfur Removal, MoS2 Catalyst, Fuel Purification, Steam-Power Cycle

All Values in $2005 \$$

Minimum Ethanol Selling Price (\$/gal) $\$ 1.01$

\author{
EtOH Production at Operating Capacity (MM Gal / year) 61.8 \\ EtOH Product Yield (gal / Dry US Ton Feedstock) 80.1 \\ Mixed Alcohols Production at Operating Capacity (MM Gal / year) 72.6 \\ Mixed Alcohols Product Yield (gal / Dry US Ton Feedstock) 94.1 \\ Delivered Feedstock Cost \$/Dry US Ton \$35 \\ Internal Rate of Return (After-Tax) 10\% \\ Equity Percent of Total Investment 100\%
}

\begin{tabular}{|c|c|}
\hline \multicolumn{2}{|l|}{ Capital Costs } \\
\hline Feed Handling \& Drying & $\$ 23,200,000$ \\
\hline Gasification & $\$ 12,900,000$ \\
\hline Tar Reforming \& Quench & $\$ 38,400,000$ \\
\hline Acid Gas \& Sulfur Removal & $\$ 14,500,000$ \\
\hline Alcohol Synthesis - Compression & $\$ 16,000,000$ \\
\hline Alcohol Synthesis - Other & $\$ 4,600,000$ \\
\hline Alcohol Separation & $\$ 7,200,000$ \\
\hline Steam System \& Power Generation & $\$ 16,800,000$ \\
\hline Cooling Water \& Other Utilities & $\$ 3,600,000$ \\
\hline Total Installed Equipment Cost & $\$ 137,200,000$ \\
\hline Indirect Costs & $53,600,000$ \\
\hline (\% of TPI) & $28.1 \%$ \\
\hline Project Contingency & $4,100,000$ \\
\hline Total Project Investment (TPI) & $\$ 190,800,000$ \\
\hline Installed Equipment Cost per Annual Gallon & $\$ 2.22$ \\
\hline Total Project Investment per Annual Gallon & $\$ 3.09$ \\
\hline Loan Rate & $\mathrm{N} / \mathrm{A}$ \\
\hline Term (years) & $\mathrm{N} / \mathrm{A}$ \\
\hline Capital Charge Factor & 0.180 \\
\hline Maximum Yields based on carbon content & \\
\hline Theoretical Ethanol Production (MM gal/yr) & 158.9 \\
\hline Theoretical Ethanol Yield (gal/dry ton) & 205.8 \\
\hline Current Ethanol Yield (Actual/Theoretical) & $39 \%$ \\
\hline Gasifier Efficiency - HHV \% & 76.6 \\
\hline Gasifier Efficiency - LHV \% & 76.1 \\
\hline Overall Plant Efficiency - HHV \% & 47.4 \\
\hline Overall Plant Efficiency - LHV \% & 45.8 \\
\hline Plant Hours per year & 8406 \\
\hline$\%$ & $96.0 \%$ \\
\hline
\end{tabular}

\begin{tabular}{lr}
\multicolumn{2}{c}{ Operating Costs (cents/gal product) } \\
\hline Feedstock & 43.7 \\
Natural Gas & 0.0 \\
Catalysts & 0.3 \\
Olivine & 0.7 \\
Other Raw Materials & 1.6 \\
Waste Disposal & 0.4 \\
Electricity & 0.0 \\
Fixed Costs & 19.5 \\
Co-product credits & -20.7 \\
Capital Depreciation & 15.4 \\
Average Income Tax & 11.8 \\
Average Return on Investment & 28.5
\end{tabular}

\begin{tabular}{|c|c|}
\hline \multicolumn{2}{|l|}{ Operating Costs $(\$ / y r)$} \\
\hline Feedstock & $\$ 27,000,000$ \\
\hline Natural Gas & $\$ 0$ \\
\hline Catalysts & $\$ 200,000$ \\
\hline Olivine & $\$ 400,000$ \\
\hline Other Raw Matl. Costs & $\$ 300,000$ \\
\hline Waste Disposal & $\$ 300,000$ \\
\hline Electricity & $\$ 0$ \\
\hline Fixed Costs & $\$ 12,100,000$ \\
\hline Co-product credits @ $@ 1.15$ per gal & $-\$ 12,800,000$ \\
\hline Capital Depreciation & $\$ 9,500,000$ \\
\hline Average Income Tax & $\$ 7,300,000$ \\
\hline Average Return on Investment & $\$ 17,600,000$ \\
\hline Total Plant Electricity Usage (KW) & 7,994 \\
\hline Electricity Produced Onsite (KW) & 7,998 \\
\hline Electricity Purchased from Grid (KW) & 0 \\
\hline Electricity Sold to Grid (KW) & 4 \\
\hline Steam Plant + Turboexpander Power Generated (hp) & 66,451 \\
\hline Used for Main Compressors (hp) & 55,168 \\
\hline Used for Electricity Generation (hp) & 11,283 \\
\hline Plant Electricity Use (KWh/gal product) & 1.5 \\
\hline Gasification \& Reforming Steam Use (lb/gal) & 9.9 \\
\hline
\end{tabular}




\section{Appendix G}

Process Parameters \& Operation Summary 


\section{Energy Efficiencies}

Gasifier Efficiency - HHV \%

Gasifier Efficiency - LHV \%

Overall Plant Efficiency - HHV \%

Overall Plant Efficiency - LHV \%

\section{Dryer}

Temperature $\left({ }^{\circ} \mathrm{F}\right)$

Moisture Content (wt\%)

Outlet:

Temperature $\left({ }^{\circ} \mathrm{F}\right)$

Moisture Content (wt\%)

Inlet Flue Gas $\left({ }^{\circ} \mathrm{F}\right)$

Outlet Flue Gas $\left({ }^{\circ} \mathrm{F}\right)$

Dew Point Flue Gas $\left({ }^{\circ} \mathrm{F}\right)$

Difference

\section{Gasifier}

Temperature $\left({ }^{\circ} \mathrm{F}\right)$

Pressure (psia)

H2:CO Molar Ratio After Gasifier

Methane (vol\%)

Benzene (vol\%)

$\operatorname{Tar}(\mathrm{wt} \%)$

$\operatorname{Tar}\left(\mathrm{g} / \mathrm{Nm}^{3}\right)$

Char (wt\%)

H2S (ppm)

Residual Heat (MBtu/hr)

\section{Char Combustor}

Temperature $\left({ }^{\circ} \mathrm{F}\right)$

Pressure (psia)

Ratio Actual:Minimum air for combustion

Residual Heat (MBtu/hr)

\section{Syngas Usage}

To Reformer (lb/hr)

To Char Combustor (lb/hr)

To Fuel System (lb/hr)

\section{Fuel System}

\section{Additional fuel (lb/hr)}

Raw Syngas (lb/hr)

Unconverted Syngas (lb/hr)

Into Reformer $\left({ }^{\circ} \mathrm{F}\right)$

Out of Reformer $\left({ }^{\circ} \mathrm{F}\right)$
Tar Reformer

76.6 Inlet Molar Flow (MMscf/hr)

76.1 Space Velocity $\left(\mathrm{hr}^{-1}\right)$

47.4 Reactor Volume $\left(\mathrm{ft}^{3}\right)$

45.8 Inlet:

Temperature $\left({ }^{\circ} \mathrm{F}\right)$

Carbon as $\mathrm{CO}(\mathrm{mol} \%)$

Carbon as tar (ppmv)

$60.0 \quad$ H2:CO Ratio (mole)

Reformer Conversions:

$\mathrm{CO} 2 \rightarrow \mathrm{CO}$

Methane $\rightarrow>\mathrm{CO}$

Ethane $-\rightarrow \mathrm{CO}$

Ethylene $-\rightarrow \mathrm{CO}$

Benzene $-->\mathrm{CO}$

Tar $-\rightarrow \mathrm{CO}$

Ammonia - $\rightarrow \mathrm{CO}$

1,633 Outlet:

23.0 Temperature $\left({ }^{\circ} \mathrm{F}\right)$

0.60 Carbon as $\mathrm{CO}$ (mol\%)

$0.07 \% \quad$ H2. CO Ratio (mole)

$0.91 \%$ Methane (vol\%)

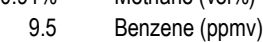

2.7\% Tars (ppmv)

413 Tars $\left(\mathrm{g} / \mathrm{Nm}^{3}\right)$

$0 \quad \mathrm{H} 2 \mathrm{~S}(\mathrm{ppm})$

$\mathrm{NH} 3$ (ppm)

1,823 Quench

21.4 Benzene (ppmv)

1.20 Tars (ppmv)

0.0 Tars $\left(\mathrm{g} / \mathrm{Nm}^{3}\right)$

H2S (ppm)

$\mathrm{NH} 3(\mathrm{ppm})$

168,120

0 Acid Gas Removal

64,703 Inlet:

$$
\mathrm{CO} 2(\mathrm{~mol} / \mathrm{hr})
$$

$\mathrm{CO} 2$ (mol\%)

$\begin{array}{rr}0 & \mathrm{H} 2 \mathrm{~S}(\mathrm{~mol} / \mathrm{hr}) \\ & \end{array}$

64,703 H2S (ppmv)

10,739 Outlet:

$\mathrm{CO} 2(\mathrm{~mol} / \mathrm{hr})$

$1,780 \quad$ Fraction $\mathrm{CO} 2$ removed

$\mathrm{H} 2 \mathrm{~S}(\mathrm{~mol} / \mathrm{hr})$

H2S (ppmv)

Fraction $\mathrm{H} 2 \mathrm{~S}$ removed

\section{Alcohol Synthesis}

Syngas from Conditioning

2,476 Recycled from initial flash tank

2,705 Recycled from MolSieve Flush Total

1,086

$49.0 \%$

5,758 Conditioned Syngas H2:CO Ratio

0.87 Recycled Gas H2:CO Ratio

At Reactor Inlet

$32.5 \% \quad$ Temperature $\left({ }^{\circ} \mathrm{F}\right)$

$80.0 \%$ Pressure (psia)

$\begin{array}{ll}99.0 \% & \text { H2:CO Molar Ratio } \\ 90.0 \% & \text { CO2 (mol \%) }\end{array}$

$99.0 \% \quad$ Methane (mol\%)

$99.9 \% \quad \mathrm{H} 2 \mathrm{O}(\mathrm{wt} \%)$

$90.0 \%$

Inlet Molar Flow (MMscf/hr)

Space Velocity $\left(\mathrm{hr}^{-1}\right)$

1,633 Reactor Volume ( $\left.\mathrm{ft}^{3}\right)$

$75.7 \%$

43 CO Conversion - Overall

Co Conversion - Singlepass

Conversion To:

$\mathrm{CO} 2$

Methane

Ethane

Methanol

Ethanol

Propano

Butanol

Pentanol +

Total

Selectivity (CO2 Free)

Alcohols

Hydrocarbons

At Reactor Outlet

2,041 Temperature $\left({ }^{\circ} \mathrm{F}\right)$

$11.4 \% \quad$ Pressure (psia)

$\mathrm{CO} 2(\mathrm{~mol} \%)$

Methane (mol\%)

$\mathrm{H} 2 \mathrm{O}$ (wt\%)

$5.1 \% \quad$ Total Alcohol Productivity $(\mathrm{kg} / \mathrm{kg} / \mathrm{hr})$

Total Ethanol Productivity $(\mathrm{kg} / \mathrm{kg} / \mathrm{hr})$
Alcohol Synthesis

279,888 Relative Alcohol Distribution After Reactor

215 Methanol

$8.5 \%$

$5,026 \quad$ Ethanol

285,128 Propano

Butanol

Pentanol +

1.06 Flash Separator

Temperature $\left({ }^{\circ} \mathrm{F}\right)$

Pressure (psia)

1 Relative Alcohol Distribution After Flash Tank

Methanol

Ethanol

Propano

Butanol

Pentanol +

Vapor Losses From Flash Tank

Methanol

Ethanol

$59.5 \% \quad$ Propano

Butanol

Pentanol +

Cleaned Gas Recycled to Reactor

\section{Residual Syngas}

Recycled to synthesis reactors (lb/hr)

To Tar Reformers (lb/hr)

To Reformer for Process (lb/hr)

10,739

204,048

\section{Overall Water Demand}

$\mathrm{gal} / \mathrm{gal}$ etoh

$90.1 \%$ gal/gal total alcohols 


\section{Appendix $\mathrm{H}$}

\section{Process Flow Diagrams (PFDs)}




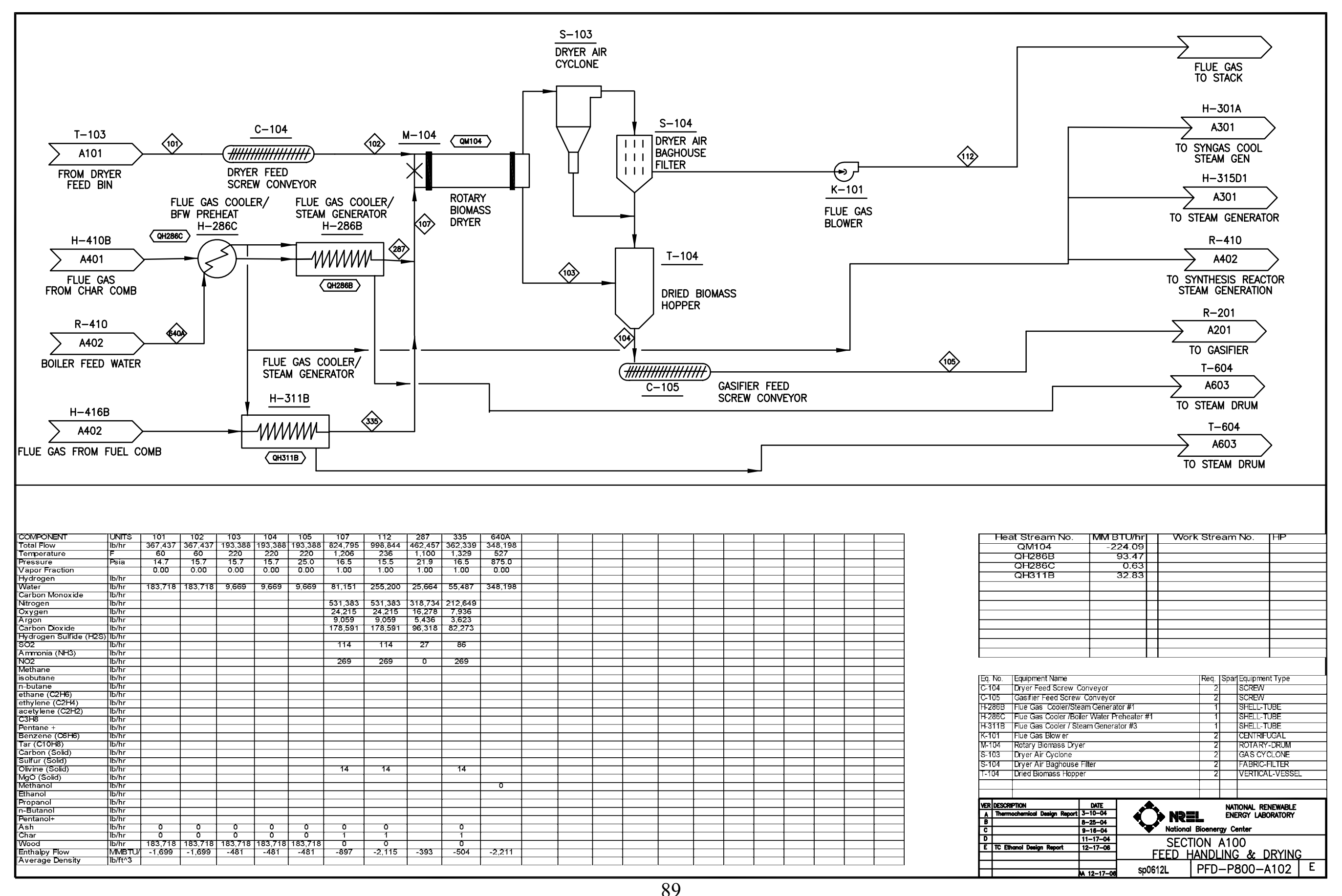




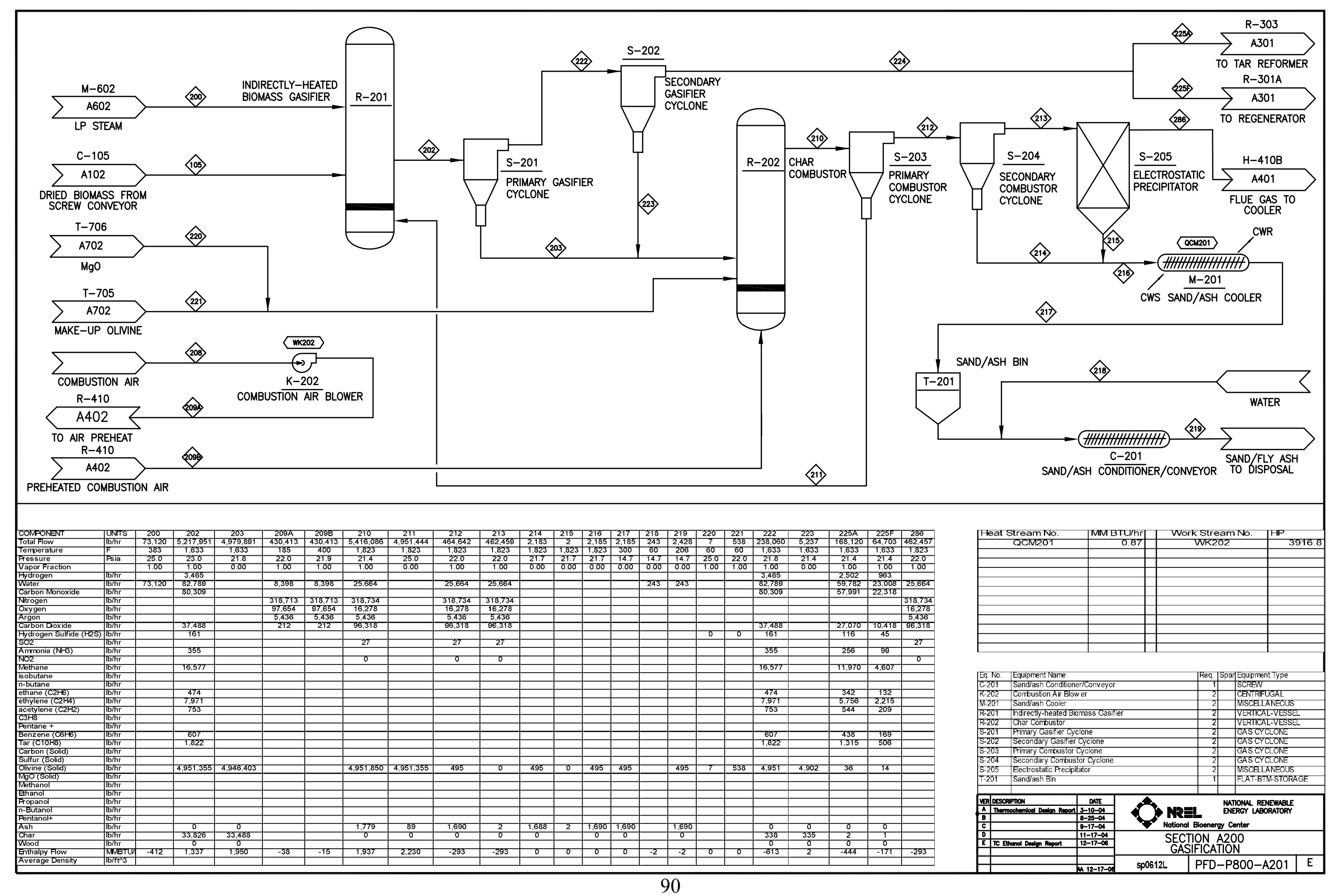




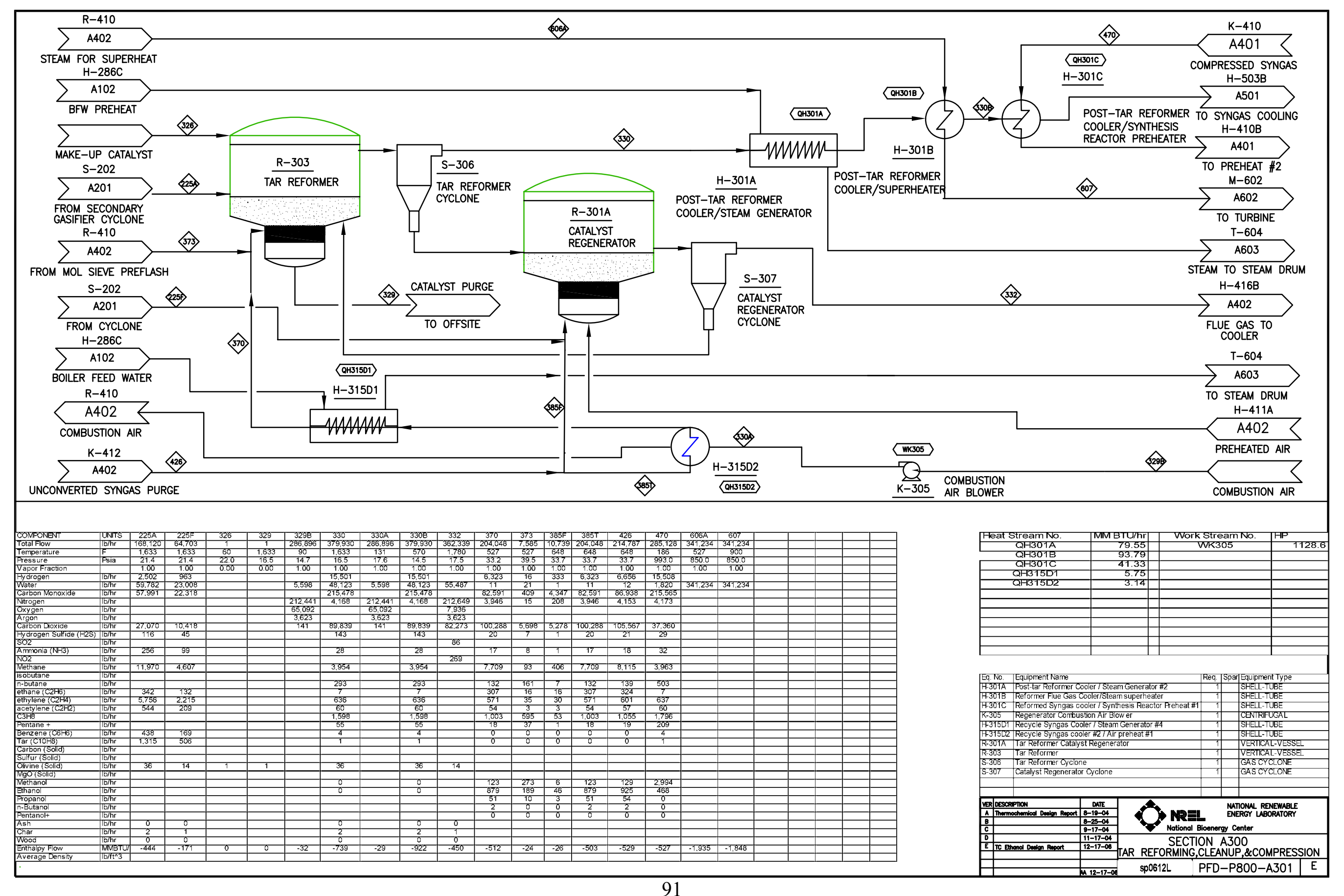




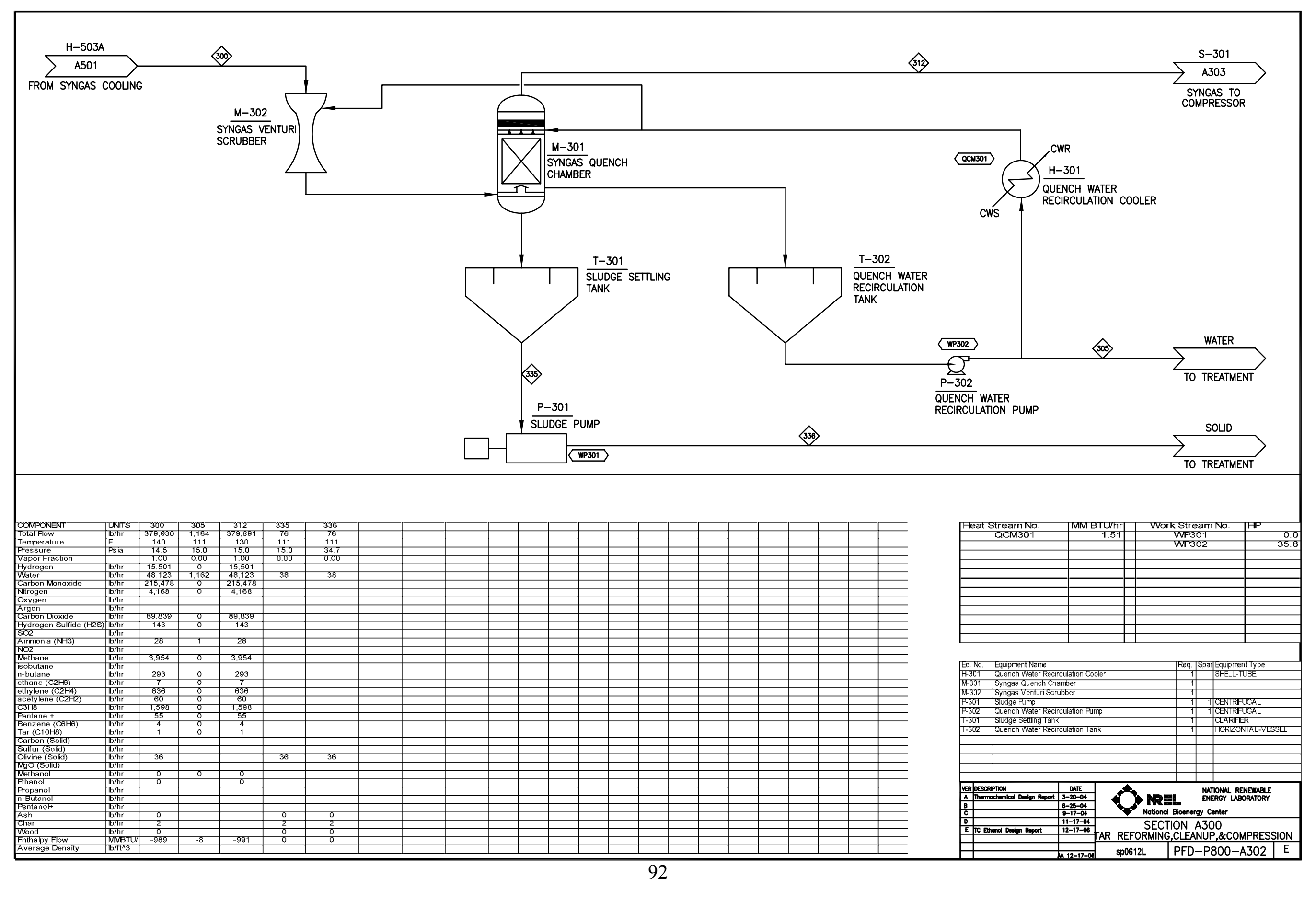




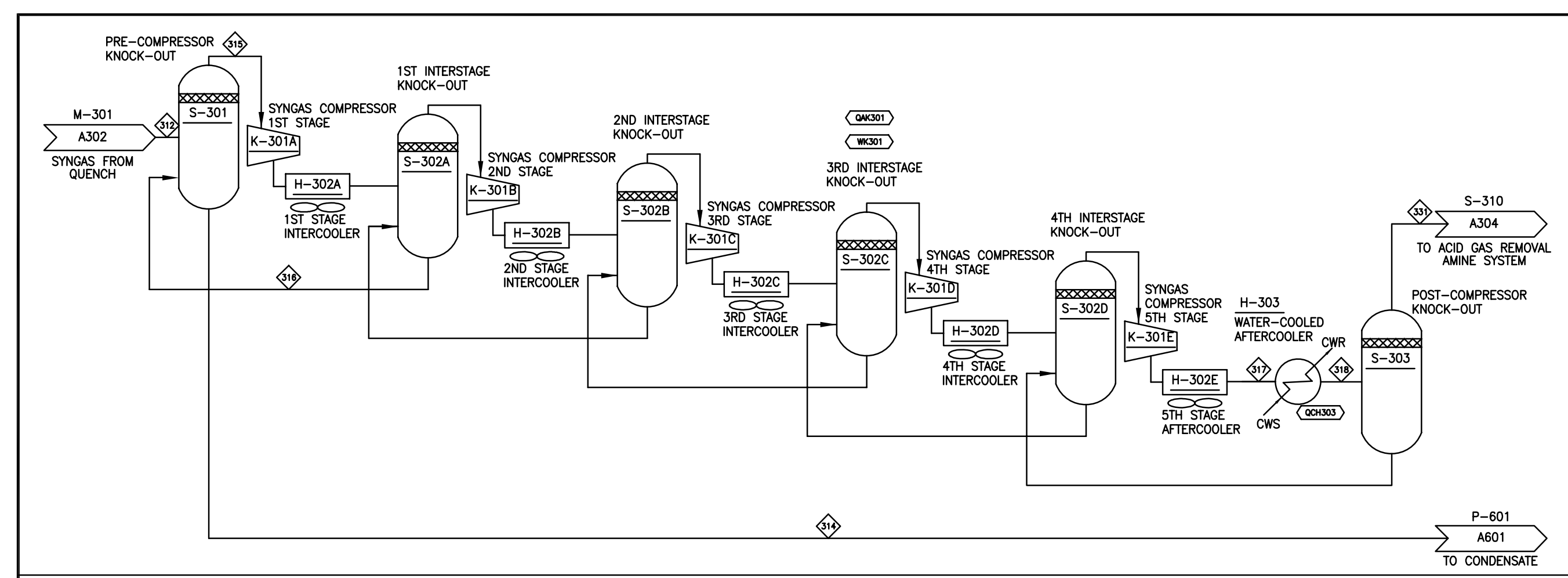

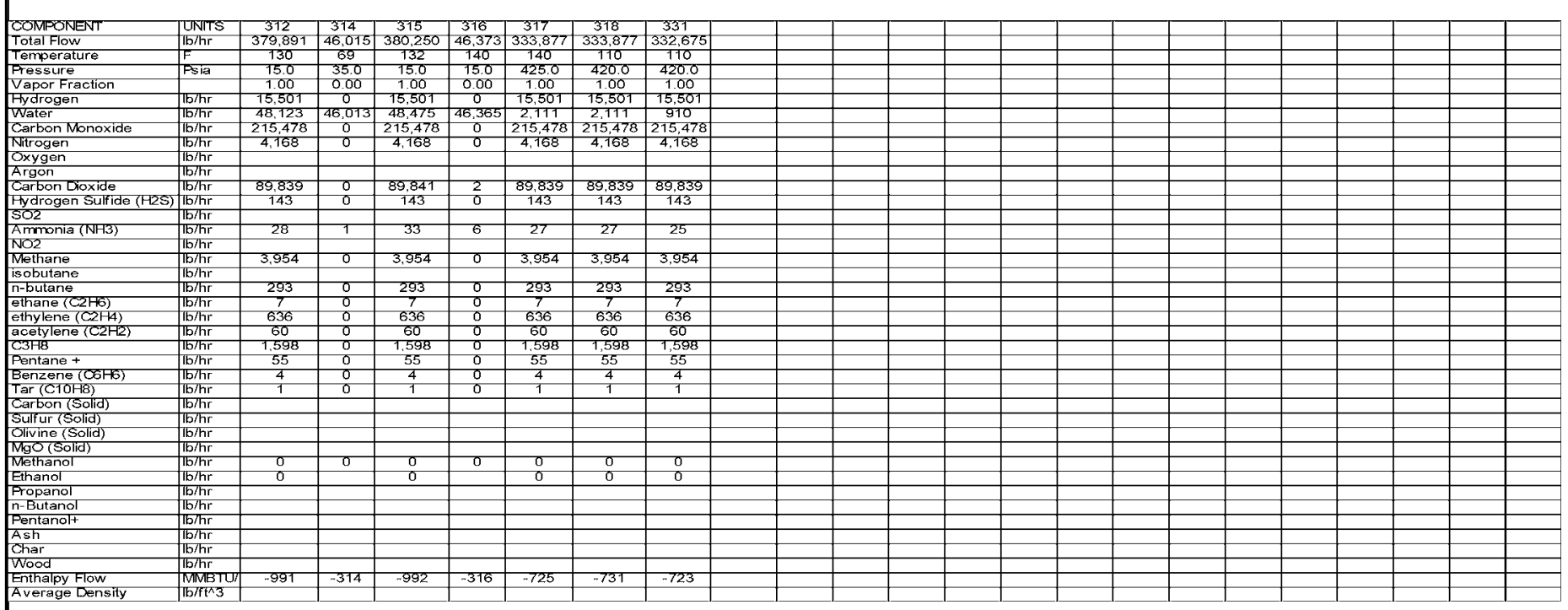
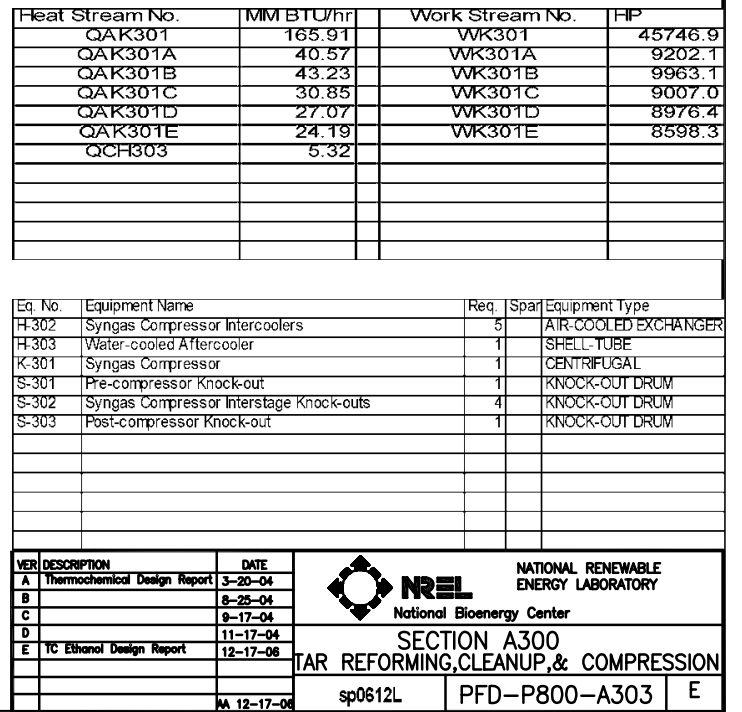

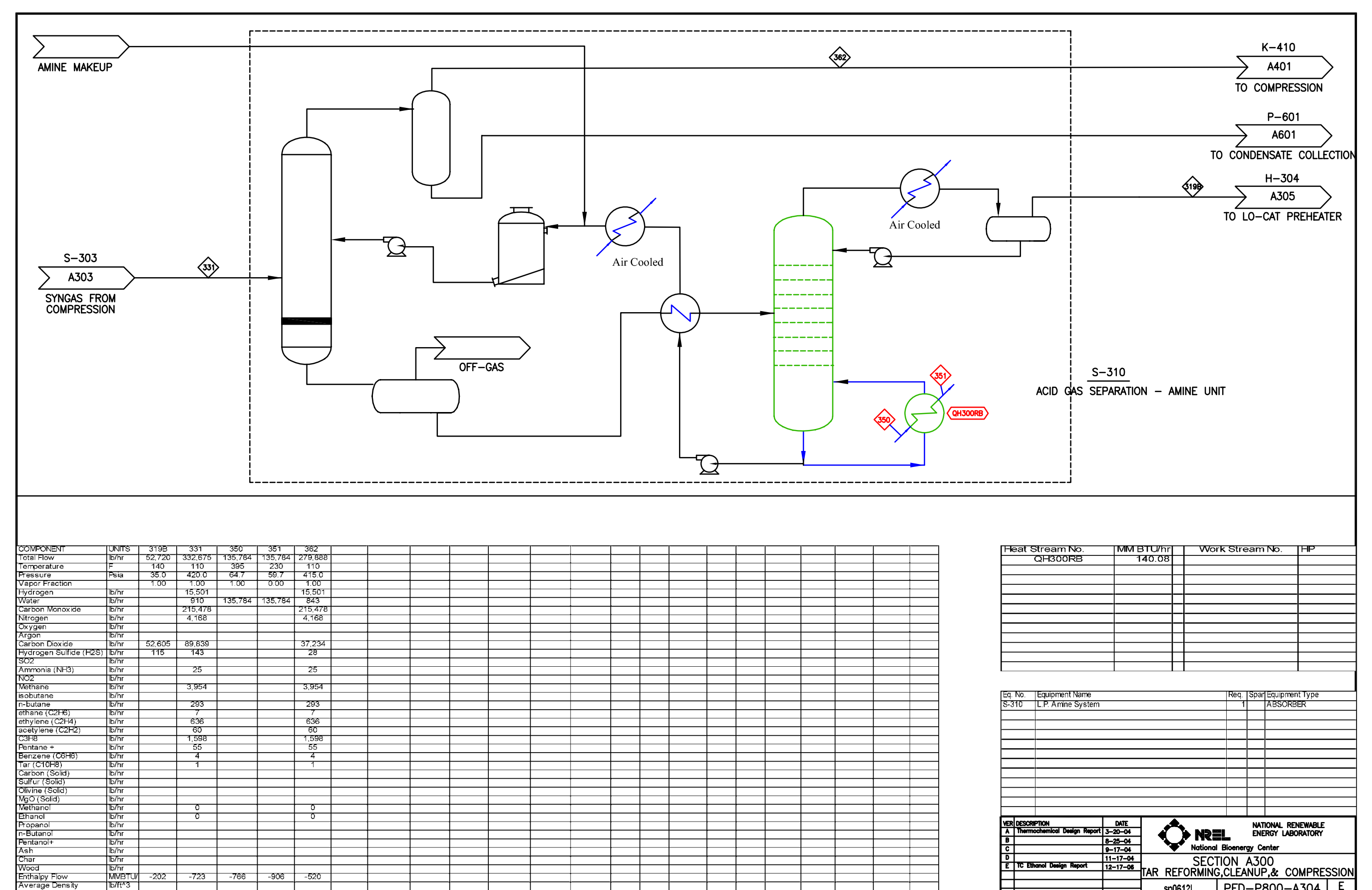
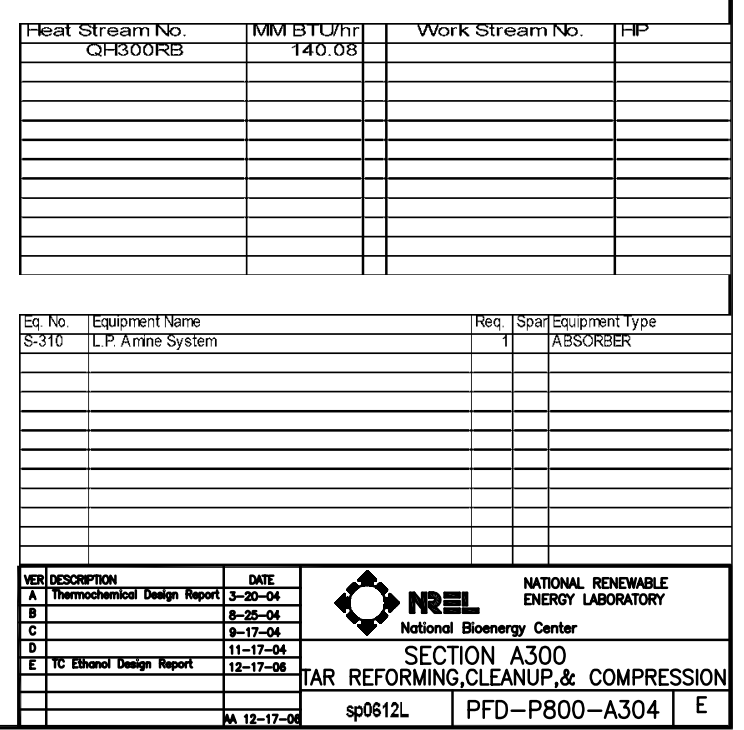

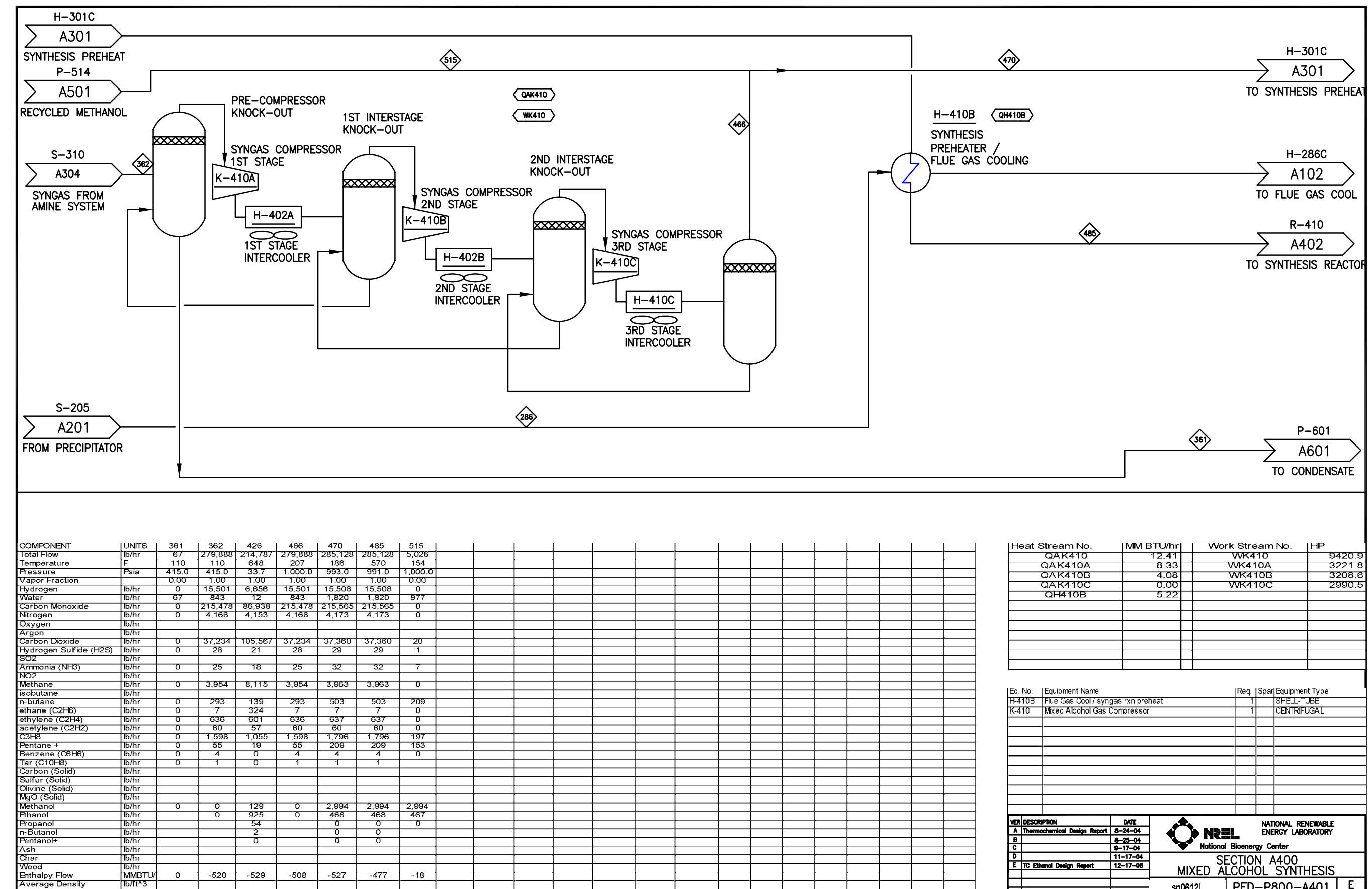
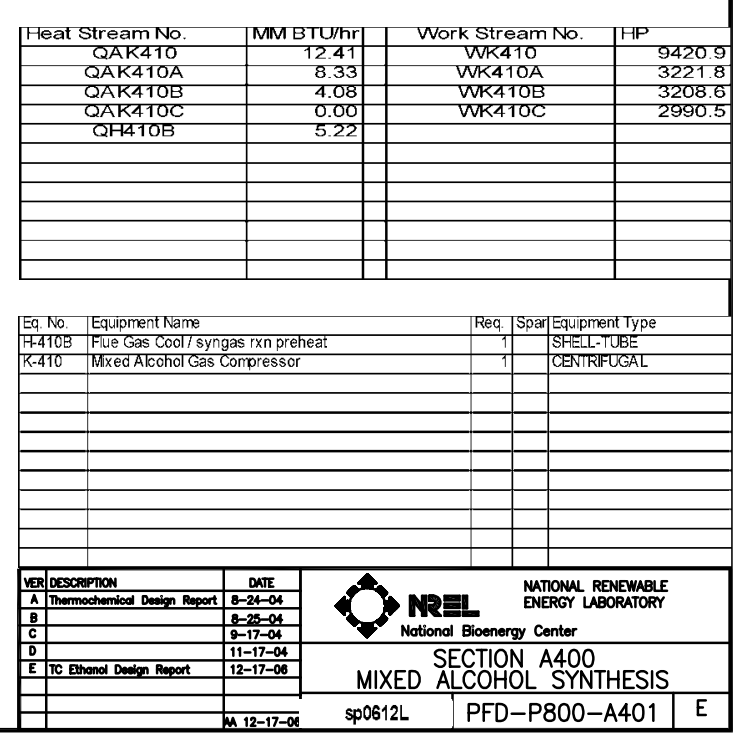


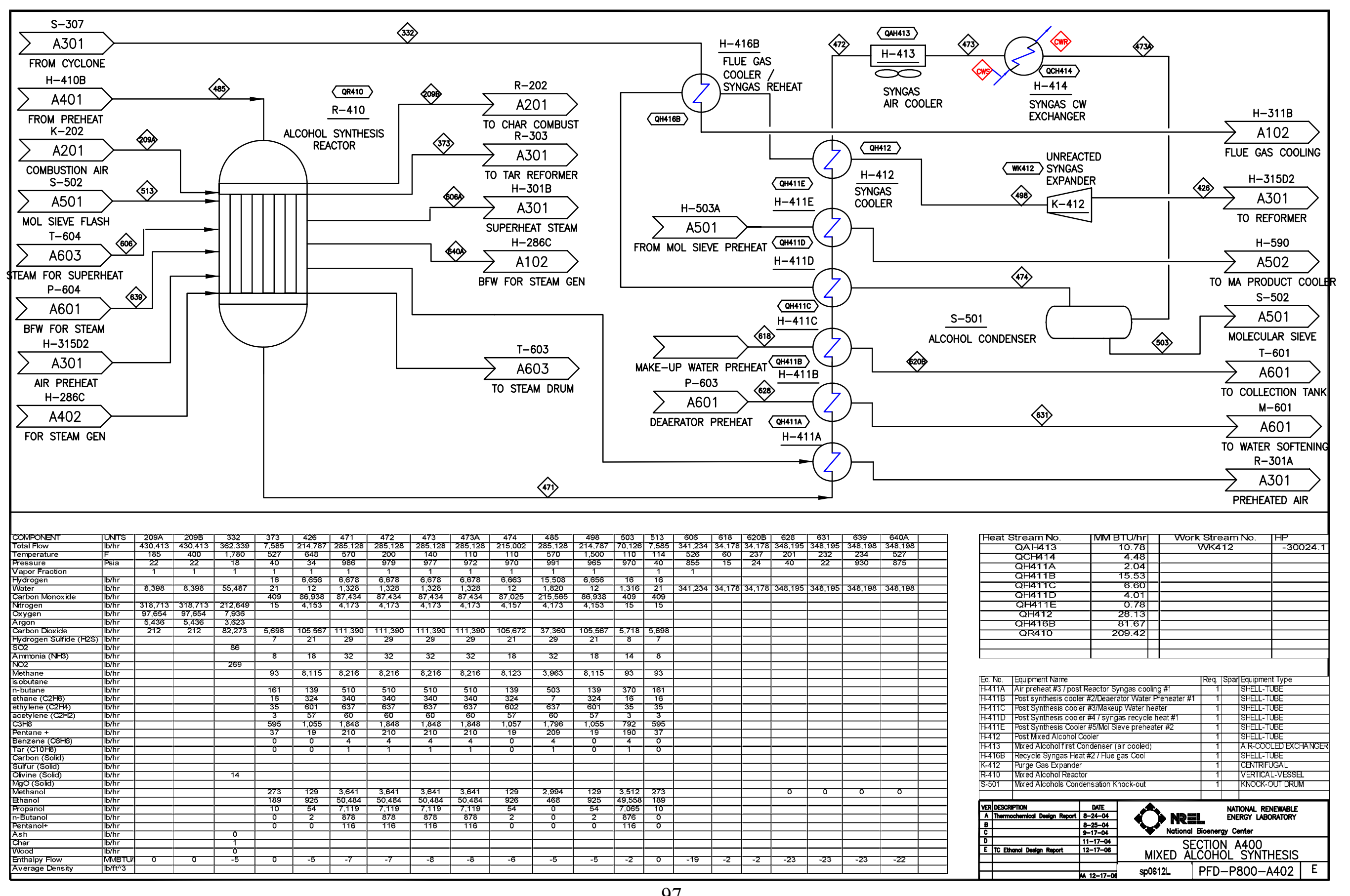




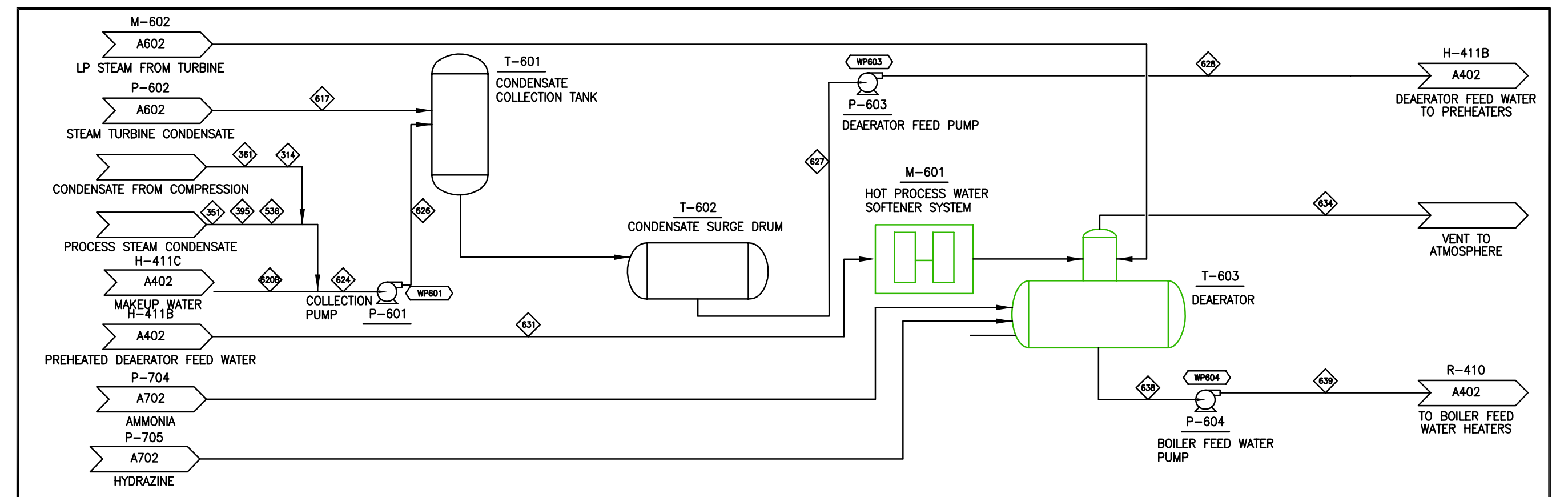

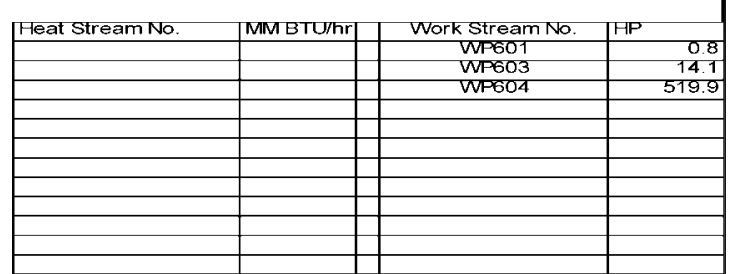
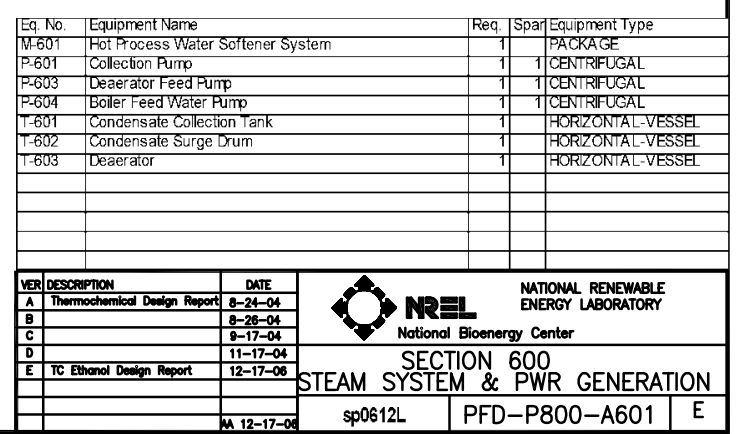


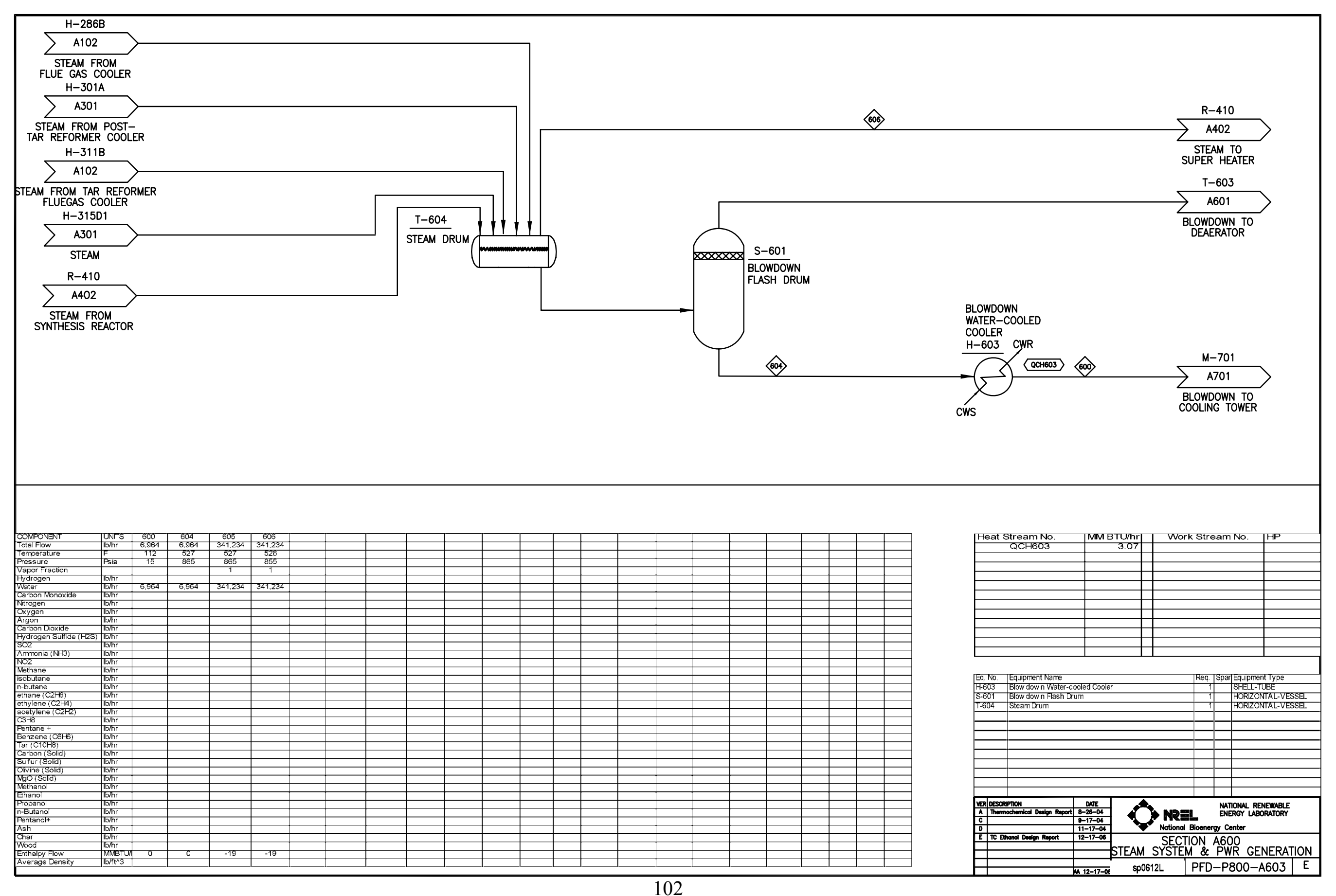




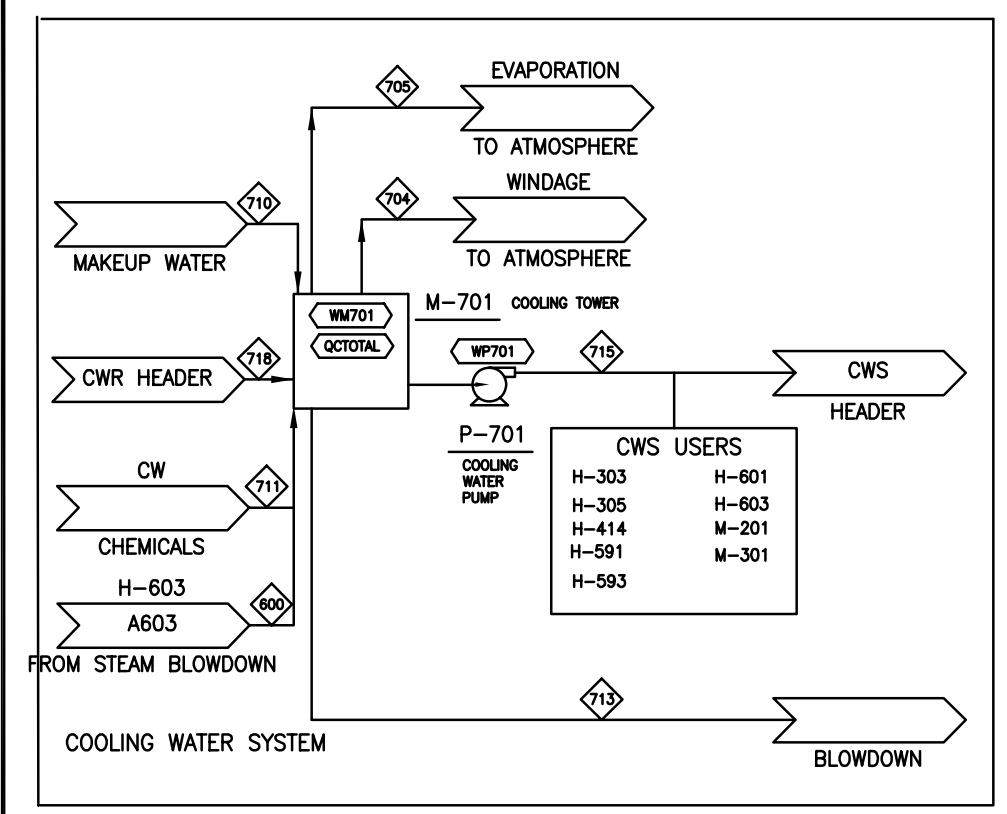

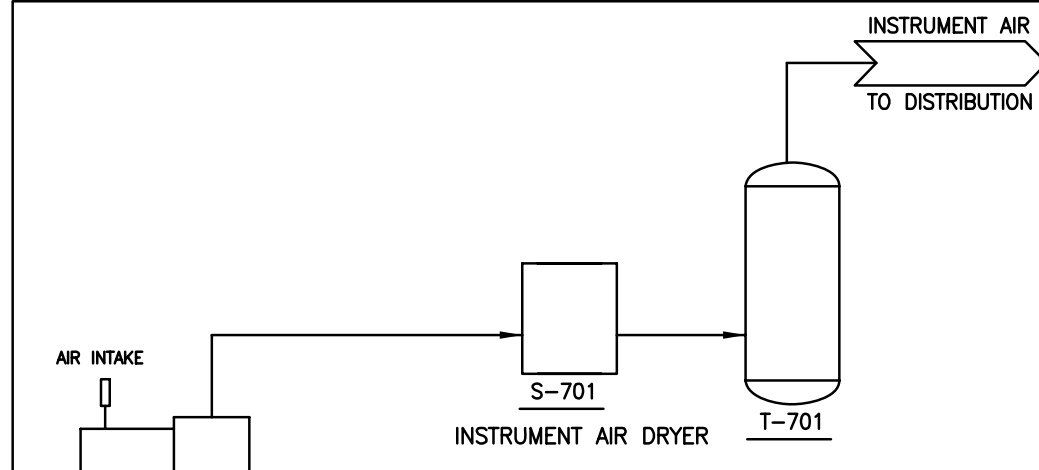

INSTRUMENT AIR RECEIVER

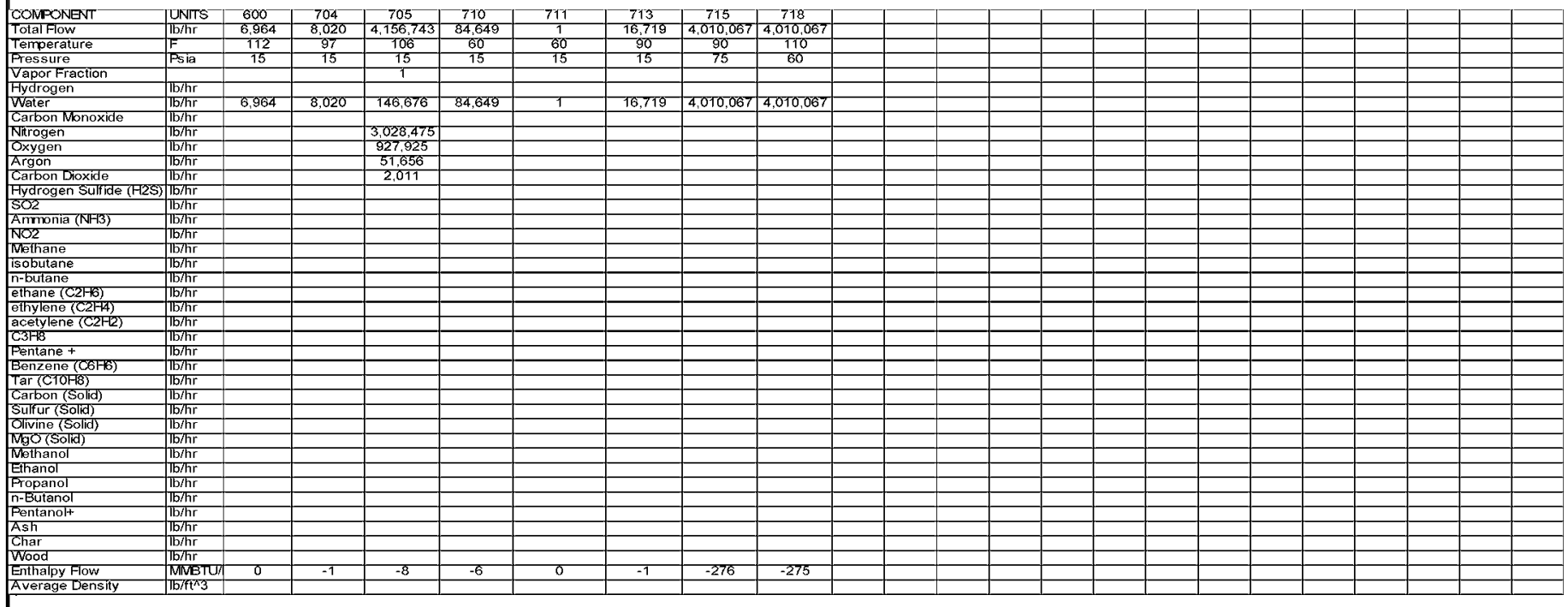

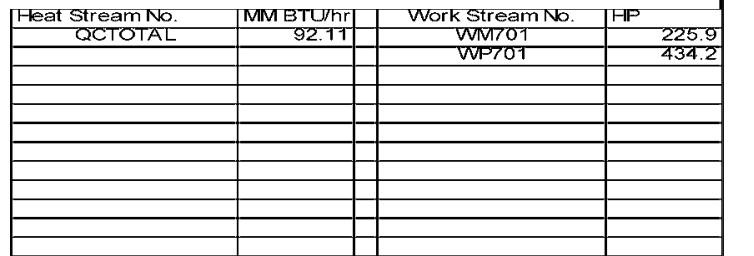
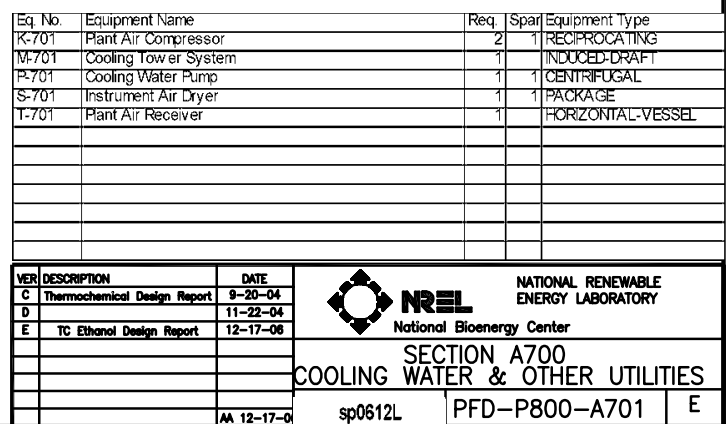


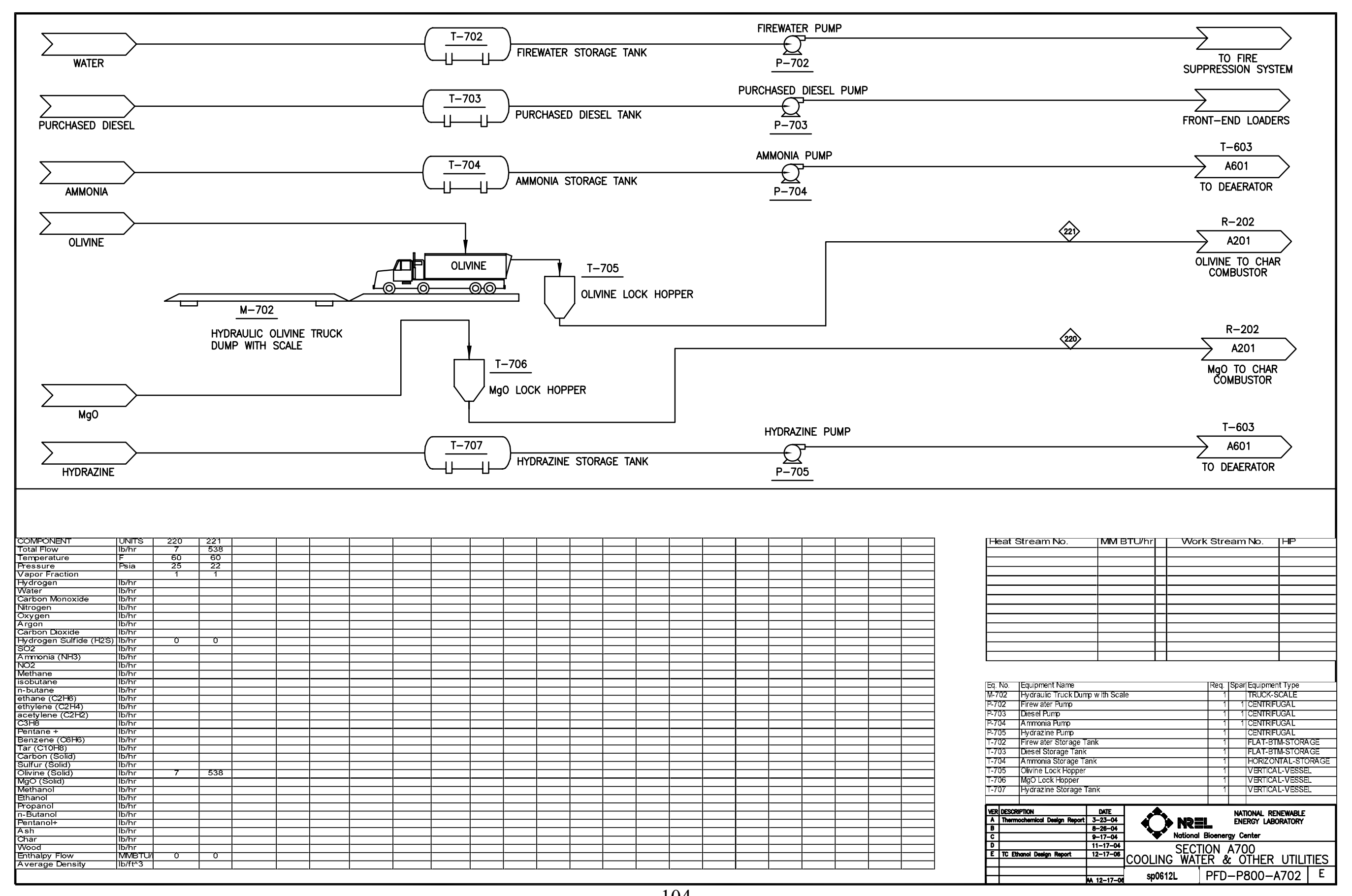




\section{Appendix I}

Syngas and Char Correlations 
The gasifier was modeled using correlations based on data from the Battelle Columbus Laboratory (BCL) 9 tonne/day test facility. The data and original correlations for the gasifier can be found in Bain (1992). The experimental runs were performed for several different wood types including Red Oak, Birch, Maple, and Pine chips, sawdust, and other hard and soft wood chips. The original pilot plant data for these runs can be found in Feldmann, et al, (1988). The temperature range for the data is 1,280 to $1,857^{\circ} \mathrm{F}$ and the pressure range is 2.4 to $14.4 \mathrm{psig}$; the majority of the data are in the range of 1,500 to $1,672^{\circ} \mathrm{F}$.

The BCL test facility's gas production data was correlated to gasifier temperature with a quadratic function in the form:

$$
X=a+b T+c T^{2}
$$

where the temperature, $T$, in units of ${ }^{\circ} \mathrm{F}$. The coefficients $a, b$, and $c$, as well as the units for the correlated variable are shown in Table 3. Even thought there is a correlation for the char formation, it is not used; instead the amount and elemental analysis for the char is determined by mass differences between the produced syngas and the converted biomass.

Table 3. Gasifier Correlation

\begin{tabular}{|c|c|c|c|c|}
\hline Variable & $a$ & $b$ & $c$ & Units \\
\hline Dry Syngas & 28.993 & -0.043325 & 0.000020966 & scf gas/lb maf wood \\
\hline $\mathrm{CO}$ & 133.46 & -0.1029 & 0.000028792 & mol\% dry gas \\
\hline $\mathrm{CO}_{2}$ & -9.5251 & 0.037889 & -0.000014927 & mol\% dry gas \\
\hline $\mathrm{CH}_{4}$ & -13.82 & 0.044179 & -0.000016167 & mol\% dry gas \\
\hline $\mathrm{C}_{2} \mathrm{H}_{4}$ & -38.258 & 0.058435 & -0.000019868 & mol\% dry gas \\
\hline $\mathrm{C}_{2} \mathrm{H}_{6}$ & 11.114 & -0.011667 & 0.000003064 & $\mathrm{~mol} \%$ dry gas \\
\hline $\mathrm{H}_{2}$ & 17.996 & -0.026448 & 0.00001893 & mol\% dry gas \\
\hline $\mathrm{C}_{2} \mathrm{H}_{2}$ & -4.3114 & 0.0054499 & -0.000001561 & mol\% dry gas \\
\hline Tar & 0.045494 & -0.000019759 & & lb/lb dry wood \\
\hline
\end{tabular}

The following general procedure is used for the gasifier production:

- A gasifier temperature $T$ is assumed.

- The mass and molar amounts of carbon, hydrogen, oxygen, sulfur, nitrogen, and ash (as a pseudo-element) are determined from the biomass's ultimate analysis.

- The amount of syngas and its composition is determined from the gasifier correlations.

- The amount of carbon in the syngas and tar is determined. Residual carbon is parsed in the char.

- The amount of oxygen in the syngas is determined. A minimum amount of oxygen is required to be parsed to the char ( $4 \%$ of biomass oxygen). If there is a deficit of oxygen, then the associated water is decomposed to make sure that this amount of oxygen is parsed to the char; if there is excess oxygen, then it is parsed to the char without decomposing hydrogen.

- A set amount of sulfur is parsed to the char (8.3\%). All remaining sulfur is set as $\mathrm{H}_{2} \mathrm{~S}$ in the syngas.

\footnotetext{
${ }^{\mathrm{a}} \mathrm{Scf}=$ standard cubic feet. The standard conditons are $1 \mathrm{~atm}$ pressure and $60^{\circ} \mathrm{F}$ temperature.
} 
- A set amount of nitrogen is parsed to the char (6.6\%). All remaining nitrogen is set as $\mathrm{NH}_{3}$ in the syngas.

- The amount of hydrogen in the syngas (including tar, $\mathrm{H}_{2} \mathrm{~S}, \mathrm{NH}_{3}$, and decomposed water) is determined. All remaining hydrogen is parsed to the char.

- All ash is parsed to the char.

- The heat of formation of the char is estimated from the resulting ultimate analysis from this elemental material balance.

- The gasifier temperature is adjusted so the there is no net heat for an adiabatic reaction.

The syngas amount and composition will be dependent upon the biomass composition and the gasifier temperature. As an example, the resulting syngas composition for the woody biomass used in this design report can be seen in Figure 2. Note from this figure that the amount of char decreases with increasing temperature and that the water does not start to decompose until high temperatures (here at $1650^{\circ} \mathrm{F}$ and higher).

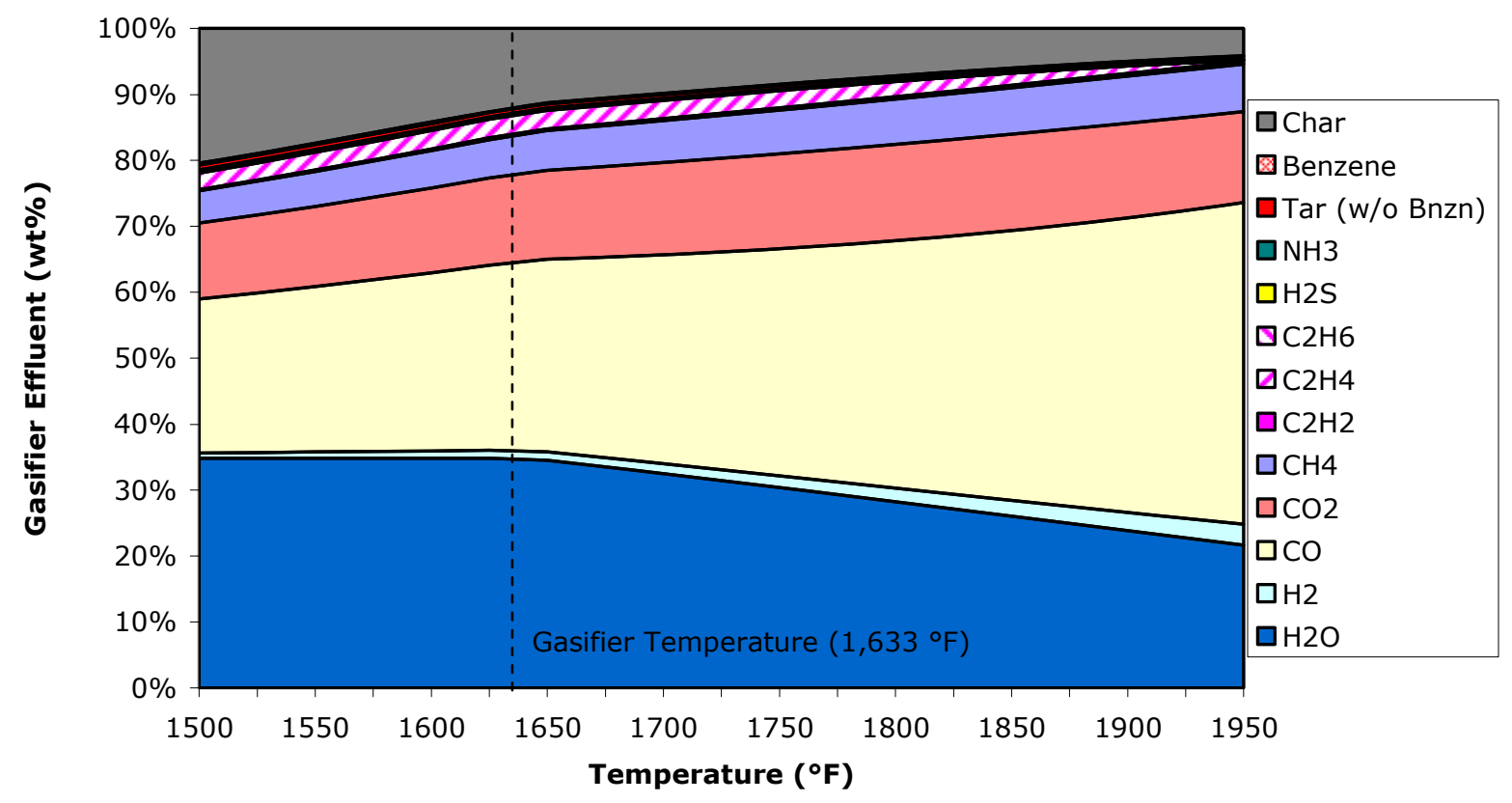

Figure 2. Syngas Composition for Woody Biomass Used in Design Report

\section{References}

Bain, R. (January 14, 1992). Material and Energy Balances for Methanol from Biomass Using Biomass Gasifiers.

Feldmann, H. F.; Paisley, M. A.; Applebaus, H.R.; Taylor, D.R. (July 1988). Conversion of Forest Residues to A Medium-Rich Gas in a High-Throughput Gasifier. 


\section{Appendix J}

\section{Alcohol Synthesis Catalyst References}


A literature search was conducted to review existing mixed alcohol technology and how it has developed over the past 20 years. This appendix provides a list of literature reviewed, including authors and journal names, as well as brief descriptions of the information contained within each source. The literature sources examined include a mixture of experimental results and state of technology summarizations. Together, over 40 different sources were used. Some generalizations garnered from this search are summarized below.

The term "mixed alcohols" refers to a mixture of $\mathrm{C} 1-\mathrm{C} 8$ alcohols, with preference towards the higher alcohols (C2-C6). Mixed alcohols catalysts are typically categorized into several groups based on their composition and/or derivation. Common to all of these catalysts is the addition of alkali metals which shift the product slate towards alcohol production. Spath, et al., categorized the catalysts into five groupings based on the work of Herman (Herman, 1991):

- Modified high pressure methanol catalysts.

- Modified low pressure methanol catalysts.

- Modified Fischer-Tropsch (FT) catalysts.

- Alkali-doped sulfides (modified methanation).

- Other, which includes alternate catalysts, such as Rhodium based catalysts, which are not specifically used for mixed alcohols but have been developed for more selective alcohols synthesis.

Others (Smith, et al., 1992) (Forzatti, et al., 1991) group them simply into three categories:

- Modified methanol catalysts.

- Modified Fischer-Tropsch catalysts.

- Others.

This helps to eliminate confusion that can arise when, for example, molybdenum-based sulfide catalysts are promoted with cobalt or other similar FT elements, thus representing both alkalidoped sulfides and modified-FT groupings.

Since the 1920s scientists have known how to produce mixtures of methanol and other alcohols by reacting syngas over certain catalysts. They observed that when methanol catalysts (Zinc or Copper based) were promoted with alkali ( $\mathrm{Na}, \mathrm{K}$, etc.), and certain reaction conditions were met (temperature, pressure) a mixture of methanol and higher alcohols resulted. At the same time, Fischer and Tropsch observed that hydrocarbon synthesis catalysts produced linear alcohols as byproducts. From this they were able to develop the "Synthol" process for producing higher alcohols. Some development continued, but it wasn't until the 1970s oil embargo that significant interest re-appeared, and researchers renewed efforts to produce higher alcohols for liquid fuels applications. As petroleum prices dropped research declined until the mid-to-late 1980s when interest was driven by environmental aspects, specifically oxygenated fuel and octane enhancement.

In 1990, the Clean Air Act mandated the seasonal use of oxygenated compounds in gasoline in specific regions of the U.S. Soon after, methyl-tertiary-butyl ether (MTBE) became the oxygenate of choice because refiners could cost-effectively produce it using existing products. Since then only a few researchers have been active in the field of higher alcohol synthesis. Some research in the 90s focused on mixed alcohols as a product of coal gasification. Other work continued in Europe, especially by Snamprogetti. Within the past 5 years, however, a desire to 
find alternatives for petroleum based fuels, and the increasing popularity of ethanol fuels, has again brought this research area to life.

Three particular terms require definition before the discussion proceeds. Please refer back to these as needed. Within literature, data can often be confusing if these terms aren't well understood or defined.

Productivity - the amount of product generated, either all alcohols or a specific alcohol, per unit time for a certain weight of catalyst loaded. Units are typically g-product $/ \mathrm{kg}$ catalyst / hr. Typical productivities for mixed alcohol production can range from below 150 to near $400 \mathrm{~g} / \mathrm{kg} / \mathrm{hr}$. In comparison, methanol synthesis productivities can often be over $1000 \mathrm{~g} / \mathrm{kg} / \mathrm{hr}$, or $1 \mathrm{~kg} / \mathrm{kg} / \mathrm{hr}$. Less commonly, productivity refers to concentrations of liquid product per unit of time, $\mathrm{g} / \mathrm{L} / \mathrm{hr}$. This is often referred to as "Yield".

Conversion - usually the amount of carbon monoxide $(\mathrm{CO}$, molar basis) converted to all products. Typically found by: $\left(\mathrm{CO}_{\text {initial }}-\mathrm{CO}_{\text {final }}\right) / \mathrm{CO}_{\text {initial }}$

Sometimes researchers present conversions exclusive of $\mathrm{CO}_{2}$ produced but not often. Typical single-pass conversions for mixed alcohols range from 10\% - 40\%.

Selectivity - selectivities are typically presented on a \%-molar basis. Selectivity refers to the fraction of $\mathrm{CO}$ converted to a specific product. For example, if a reaction achieves a $20 \%$ conversion of $\mathrm{CO}$, and $75 \%$ of that $\mathrm{CO}$ (or $15 \%$ of the total $\mathrm{CO}$ ) is converted to alcohols, then the total alcohols selectivity is said to be $75 \%$. Selectivities are sometimes shown on a $\mathrm{CO}_{2}$-exclusive basis.

Yield-see Productivity.

The overall stoichiometric reaction for higher alcohol synthesis (HAS) can be summarized as:

$$
n \mathrm{CO}+2 n \mathrm{H}_{2} \rightarrow \mathrm{C}_{n} \mathrm{H}_{2 n+1} \mathrm{OH}+(n-1) \mathrm{H}_{2} \mathrm{O}
$$

The value of " $n$ " typically ranges from 1 to 8 . The stoichiometry suggests an optimum $\mathrm{H}_{2} / \mathrm{CO}$ ratio of 2 , however many of these catalysts also display significant water-gas shift activity. This shifts the optimal ratio closer to 1.0 and also shifts the primary byproduct from water to carbon dioxide $\left(\mathrm{CO}_{2}\right)$. The overall reaction is exothermic; therefore, maintaining constant reaction temperature is an important design consideration. The reactions become more exothermic for greater values of " $n$ ". Secondary reactions and other side products will depend on which catalyst system is used. Different kinetic pathways exist for each catalyst system.

\section{Catalysts}

\section{Modified Methanol Catalysts}

The term "modified" methanol catalyst refers to the addition of an alkali promoter and other active elements to a methanol catalyst to shift the product slate from methanol to higher 
branched primary alcohols. High temperature methanol catalysts typically contain Zinc (Zn) Chromium oxides (or manganese chromium oxides), while lower temperature methanol catalysts use Copper $(\mathrm{Cu})$ as the active component. The reaction yields primary branched alcohols, among which 2-methyl-1-propanol (isobutanol) is a main (and thermodynamically favored) component. Aldehydes, esters, ketones, and ethers are also formed, along with large amounts of $\mathrm{CO}_{2}$.

Typical high pressure and low pressure reaction conditions (as provided by Nexant) are listed in Table 4. In general there is a trade-off between maximizing $\mathrm{CO}$ conversion and maximizing the higher alcohol selectivity and yield.

Table 4. "Typical” Modified Methanol Catalyst Conditions

\begin{tabular}{|c|c|c|c|c|c|c|}
\hline & $\begin{array}{c}\mathbf{H}_{2} / \mathbf{C O} \\
\text { ratio }\end{array}$ & $\begin{array}{c}\text { Temperature } \\
\left({ }^{\circ} \mathbf{F}\right)\end{array}$ & $\begin{array}{c}\text { Pressure } \\
\text { (psia) }\end{array}$ & $\begin{array}{c}\mathbf{C O} \\
\text { conversion } \\
\text { (per pass) }\end{array}$ & $\begin{array}{c}\text { Total } \\
\text { Alcohol } \\
\text { Yield } \\
\text { (g/kg/hr) }\end{array}$ & $\begin{array}{c}\mathbf{C}_{\mathbf{2}}+\mathbf{O H} \\
\text { Selectivity }\end{array}$ \\
\hline High Pressure & 1 & 572 to 800 & 1,810 to 3,625 & 5 to $20 \%$ & 203 & \\
\hline Low Pressure* & 1.0 to 1.2 & 482 to 752 & 725 to 1,450 & 20 to $60 \%$ & & $41.9 \mathrm{wt} \%$ \\
\hline
\end{tabular}

* Lurgi: Octamix

Snamprogetti (also referred to as SEHT - Snamprogetti, Enichem and Haldor Topsoe) and Lurgi were two of the leading technology developers of modified methanol catalysis in the 1980s and 1990s. SEHT had a MAS (Metanolo piu Alcoli Superiori - methanol plus higher alcohols) process and Lurgi developed what they called OCTAMIX, each developing pilot scale plants and data. The latest information available to NREL shows each process technology is no longer available. One technology developer still involved in this area is the Standard Alcohol Company of America. They have a bench-scale process to produce a mixed alcohols product known as Envirolene $^{\mathrm{TM}}$. Envirolene is composed of methanol through octanol, with approximately $50 \%$ of the product as ethanol. The process uses a modified high pressure methanol catalyst, and the company is currently seeking funding for a pilot plant.

The proposed kinetic pathway for modified methanol catalysts to branched alcohols is through a base-catalyzed aldol condensation reaction. Carbon chain growth schemes have been developed that describe the product distribution relatively accurately. This is shown in Figure 3. 


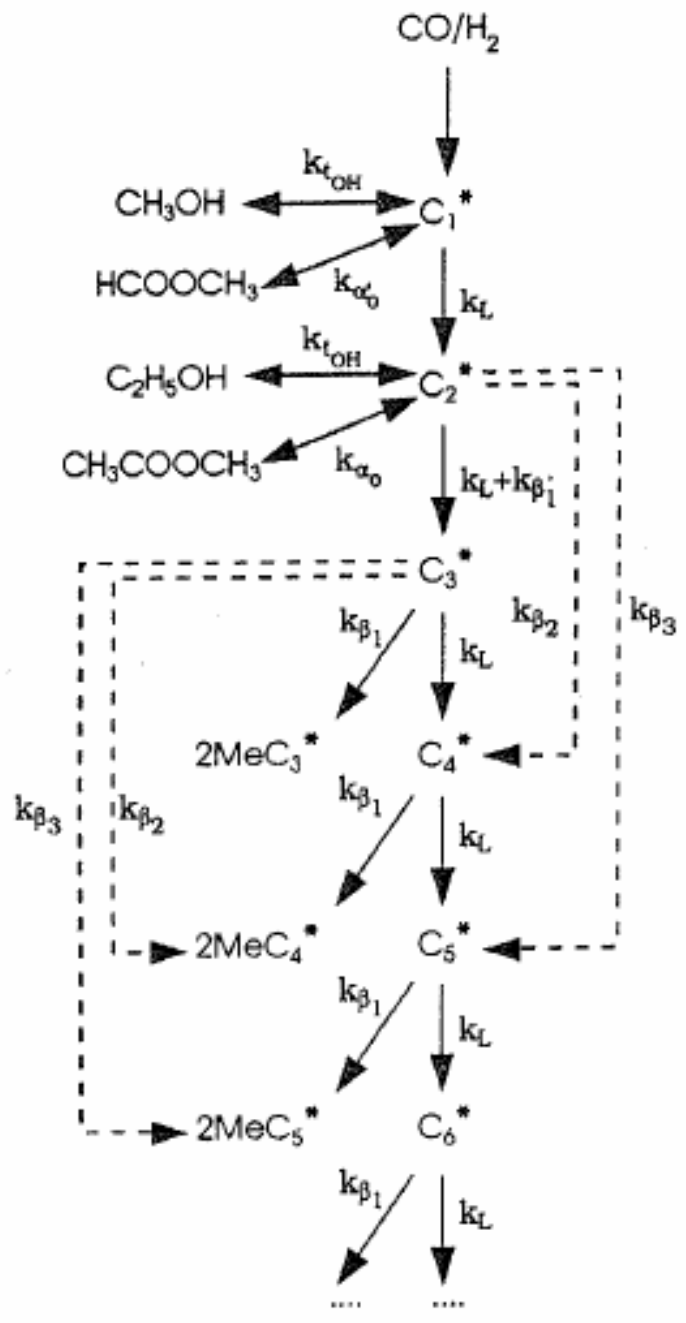

Figure 3. Reaction Network of Smith, et.al., 1991 for the Methanol - Higher Alcohol Synthesis over Cu/ZnO-based

\section{Modified Fischer-Tropsch Catalysts}

Modified Fischer-Tropsch catalysts, on the other hand, are FT catalysts that are alkali-promoted. The two most common FT active elements are Iron ( $\mathrm{Fe})$ and Cobalt (Co), but Nickel (Ni) is considered to have FT activity also. The addition of the alkali promoter helps to shift the product slate from hydrocarbons to linear alcohols, although hydrocarbons remain a significant byproduct. Typical reaction conditions are $220-350^{\circ} \mathrm{C}\left(430-660^{\circ} \mathrm{F}\right)$ and 5-20 $\mathrm{MPa}(725-$ $2,900 \mathrm{psia}$ ). One commonly-researched catalyst system is a $\mathrm{MoS}_{2}$-based system that is alkali and/or Cobalt-promoted. This has the tendency to increase ethanol and other higher alcohols selectivity. $\mathrm{CO}_{2}$ is still a substantial byproduct due to water-gas shift (WGS) activity of the catalysts. Other potential byproducts include aldehydes, esters, carboxylic acids, and ketones.

The primary technology developers for these catalysts were Dow/Union Carbide (UCC) and Institut Francais du Petrole (IFP). Dow and UCC jointly developed a sulfided mixed alcohol catalyst based on molybdenum $\left(\mathrm{MoS}_{2}\right)$. Sulfided catalysts have the advantage of being sulfurtolerant (up to $100 \mathrm{ppm}$ ) which has the potential to reduce upstream cleanup costs. IFP, in 
conjunction with Idemitsu Kosan (Japan), developed a process based on $\mathrm{Cu}-\mathrm{Co}$ and $\mathrm{Cu}-\mathrm{Ni}$ catalyst systems. Dow built a 2-ton-per-day (TPD) demonstration plant in 1990 and IFP built a 20 barrel-per-day (BPD) pilot plant in Japan. The latest information available to NREL indicates that Dow is no longer pursuing the commercial development of their mixed alcohol process and IFP has not continued their work since building the pilot plant, and they have no commercial interest in pursuing a mixed alcohols process.

Technology developers that remain active in this area are Power Energy Fuels Inc. (PEFI), Western Research Institute (WRI), and Pearson Technologies. PEFI continues to develop the Ecalene $^{\mathrm{TM}}$ technology and process, which is a modification of Dow's Sygmal process using polysulfite catalyst. According to Nexant, progress has not moved beyond the bench scale and a planned 500 gallon/day pilot plant is no longer being pursued. However, 2-3 other pilot plants are under funding consideration using various biomass resources. WRI had worked with PEFI in the past, however currently they are not, but are conducting their own bench-scale experiments, particularly reactor and catalyst testing. Pearson Technologies has developed a 30-ton-per-day biomass gasification and alcohols conversion facility in Aberdeen, MS. A project is under development by the Worldwide Energy Group and the State of Hawaii to demonstrate gasification of sugarcane bagasse and production of ethanol using the Pearson technology on the island of Kauai. Sasol (South Africa) is a world leader in FT fuels and chemicals production as well as technology development. They currently produce a mixture of alcohols within their overall process. However, these are not used for fuels. According to Sasol's website, oxygenates in the aqueous stream from their Sasol Advanced Synthol (SAS) process are separated and purified to produce alcohols, acetic acid, and ketones.

Due to the severe process conditions of higher alcohol synthesis, it would be expected that catalyst life would not be significantly long ${ }^{\mathrm{b}}$ (Nexant, 2005). As a benchmark, it could be helpful to recognize that the catalyst life for the typical Fe-Co Fischer-Tropsch catalyst can be longer than 5 years. Information on catalyst life is not abundant because most research into HAS is bench scale and not commercial. The majority of information on catalyst life comes from the earlier commercialization attempts. Dow and UCC, for example, found their catalyst operated for over 8 months continuously with little to no process performance degradation.

The proposed kinetics for modified FT catalysts follow different pathways than for modified methanol kinetics. Linear alcohols are formed from a classic $\mathrm{CO}$ insertion route for chain growth (C-C bond formation) with termination to alcohols and hydrocarbons. This is shown in Figure 4. More complex kinetic models have reaction networks that account for the simultaneous formation of alcohols, hydrocarbons, and esters.

\footnotetext{
${ }^{\mathrm{b}}$ Meaning, 1 year or less.
} 


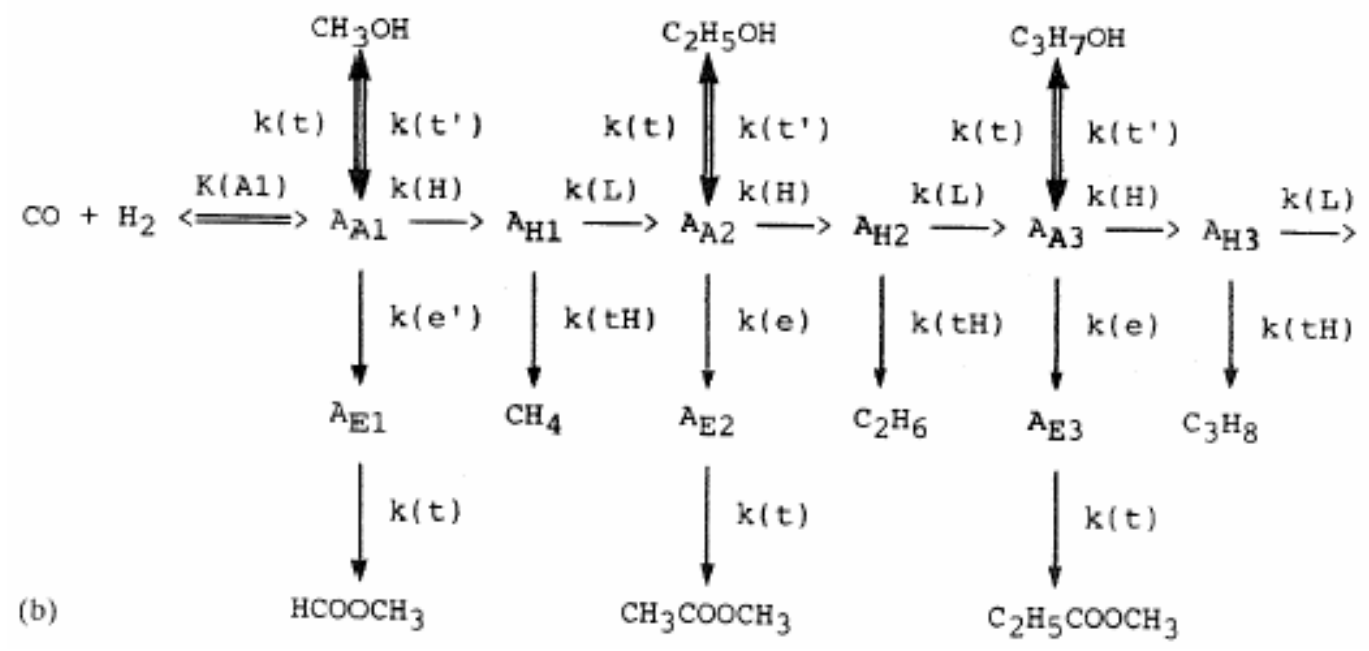

Figure 4. Kinetic Analysis of HAS with Fischer-Tropsch Mechanism

\section{Other Catalysts}

Some research has been conducted on alternative reaction systems for mixed alcohols synthesis. This includes more exotic catalytic elements (Ruthenium (Ru), Rhodium (Rh), Palladium (Pd)) as well as synthesis under supercritical conditions. Rh-based catalysts have been primarily developed for selective ethanol synthesis or other oxygenates. One downfall for these catalysts is their low catalytic activity which results in the need for high catalyst loadings and more drastic reaction conditions. Coupling this with their high cost and limited availability creates limited commercialization potential of these processes. For all Group VIII metal catalysts, CO conversion to hydrocarbons will be a significant side reaction. It has been observed that the selectivity to oxygenates of Rh-based catalysts is highly dependent on the support, promoter, and metal precursor used.

\section{Basis for Catalyst Selection}

Because the focus of this report is thermochemical production of ethanol, a moly-sulfide-based $\left(\mathrm{MoS}_{2}\right)$ system promoted with cobalt and alkali metal salts was chosen as the catalyst system because of its ability to produce linear alcohols (as opposed to branched) and its potential for higher ethanol selectivities. This is a form of original Dow/UCC technology. 


\begin{tabular}{|c|c|c|c|c|c|c|}
\hline Doc \# & Title & Date & Author(s) & Company/University Affiliation & Journal/Conference & Synopsis \\
\hline \multirow[t]{3}{*}{9542} & $\begin{array}{l}\text { Synthesis of } \mathrm{Higher} \text { Alcohols from } \\
\text { Syngas over } \mathrm{Cu}-\mathrm{Co}_{2} \mathrm{O}_{3} / \mathrm{ZnO}, \mathrm{Al}_{2} \mathrm{O}_{3} \\
\text { Catalyst }\end{array}$ & 2005 & $\begin{array}{l}\text { Mahdavi, V.; M.H. Peyrovi, } \\
\text { et.al. }\end{array}$ & $\begin{array}{l}\text { Shahid Beheshti University, Tehran Iran; } \\
\text { National Iranian Oil Company, } \\
\text { Petroleum Research Institute }\end{array}$ & Applied Catalysis, Elsevier & $\begin{array}{l}\text { Fixed bed flow reactor; changes in } \\
\text { activity and selectivity resulting } \\
\text { from feed and operating } \\
\text { conditions; alcohols selectivity } \\
\text { greater than } 80 \%\end{array}$ \\
\hline & $\begin{array}{l}\text { Mixed Alcohols from Syngas: State of } \\
\text { Technology Final Report }\end{array}$ & 2005 & Nexant & 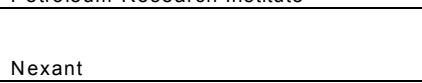 & Subcontract to NREL/DOE & $\begin{array}{l}\text { State of technology of mixed } \\
\text { alcohols and recommendations for } \\
\text { areas of focus for research }\end{array}$ \\
\hline & $\begin{array}{l}\text { Gridley Ethanol Demonstration Project } \\
\text { Utilizing Biomass Gasification } \\
\text { Technology: Pilot Plant Gasifier and } \\
\text { Syngas Conversion Testing } \\
\end{array}$ & 2005 & TSS Consultants & City of Gridley, CA & $\begin{array}{l}\text { NREL Subcontract Report SR- } \\
510-37581\end{array}$ & $\begin{array}{l}\text { Pearson Technologies Pilot } \\
\text { Gasifier; Rice Straw into Ethanol } \\
\text { thermochemically; use PSA to } \\
\text { remove CO22 from system; Not } \\
\text { much data, this is a publicly } \\
\text { available report, supposedly there } \\
\text { is a more detailed proprietary } \\
\text { report }\end{array}$ \\
\hline N/A & Production of Mixed Alcohol Fuels & 2004 & Lucero, Andrew J. & Western Research Institute & DOE workshop on BLG & $\begin{array}{l}\text { Update on efforts to use PEFI's } \\
\text { modified MoS } 2 \text { catalyst; } \\
\text { compression costs dominate op } \\
\text { costs; temp selection is critical; } \\
\text { target alcohol composition given; } \\
\text { Single-pass CO conversions up to } \\
20 \% \text { to alcohols }\end{array}$ \\
\hline 11631 & $\begin{array}{l}\text { Solvent Effects on Higher Alcohols } \\
\text { Synthesis Under Supercritical } \\
\text { Conditions: a Thermodynamic } \\
\text { Consideration }\end{array}$ & 2004 & Qin, Zhangfeng; et.al. & $\begin{array}{l}\text { Institute of Coal Chemistry, Chinese } \\
\text { Academy of Sciences }\end{array}$ & $\begin{array}{l}\text { Fuel Processing Technology, } \\
\text { Elsevier }\end{array}$ & $\begin{array}{l}\text { Supercritical HAS, used redlich- } \\
\text { kwong soave; used various } \\
\text { solvents; low ethanol; nice chart of } \\
\text { equilibrium constants, standard } \\
\text { ethalpies, entropies, and gibbs } \\
\text { free energies }\end{array}$ \\
\hline \multirow[t]{2}{*}{9543} & $\begin{array}{l}\text { Higher-Alcohols Biorefinery: } \\
\text { Improvement of Catalyst for Ethanol } \\
\text { Conversion }\end{array}$ & 2004 & Olson, Edwin S.; et.al. & EERC, North Dakota & Applied Biochem \& Biotech & $\begin{array}{l}\text { React methanol (from gasification) } \\
\text { with ethanol (from biochem) to } \\
\text { yield primarily C4 (C3+) alcohols } \\
\text { (Guerbet rxn) }\end{array}$ \\
\hline & \begin{tabular}{|l|} 
Preliminary Screening - Technical and \\
Economic Assessment of Synthesis \\
Gas to Fuels and Chemicals with \\
Emphasis on the Potential for Biomass- \\
derived Syngas
\end{tabular} & 2003 & Spath, P.L.; Dayton, D.C & $\begin{array}{l}\text { National Re } \\
\text { (NREL) }\end{array}$ & Report TP-510-34929 & $\begin{array}{l}\text { overview of potential for syngas } \\
\text { conversion to fuels and chemicals; } \\
\text { includes hydrogen, ammonia, } \\
\text { methanol, DME, mixed alcohols, } \\
\text { oxosynthesis, MTG, isosynthesis, } \\
\text { ethanol ferm entation, etc. Very } \\
\text { good report }\end{array}$ \\
\hline 11635 & $\begin{array}{l}\text { Palladium-based Catalysts for the } \\
\text { Synthesis of Alcohols }\end{array}$ & 2003 & $\begin{array}{l}\text { M. Josefina Perez-Zurita; } \\
\text { Cifarelli, M.; et.al. }\end{array}$ & Universidad Central de Venezuela & $\begin{array}{l}\text { Journal of Molecular Catalysis, } \\
\text { Elsevier }\end{array}$ & $\begin{array}{l}\text { Catalyst analysis from XRD; high } \\
\text { methane and methanol } \\
\text { selectivities }\end{array}$ \\
\hline 9527 & $\begin{array}{l}\text { Synthesis of Higher Alcohols in a Slurry } \\
\text { Reactor with CS-prom oted Zinc } \\
\text { Chromite Catalyst in } \\
\text { Decahydronaphthalene }\end{array}$ & 2003 & Xiaolei Sun, G.W. Roberts & (2) & ysis, Elsevier & $\begin{array}{l}\text { Continuous Slurry Reactor; Cs } \\
\text { shifts products away from } \mathrm{MeOH}, \\
\text { towards Higher Alcohols }\end{array}$ \\
\hline 9535 & $\begin{array}{l}\text { Fuel from the Synthesis Gas - the Role } \\
\text { of Process Engineering }\end{array}$ & 2003 & Stelmachowski, Marek, et.al. & Technical University of Lodz, Poland & Applied Energy, Elsevier & $\begin{array}{l}\text { MeOH, FT, and HAS, synthesis, } \\
\text { slurry phase reactor; simulation }\end{array}$ \\
\hline N/A & $\begin{array}{l}\text { Alcohol Synthesis over Pre-Reduced } \\
\text { Activated Carbon-supported } \\
\text { Molybdenum-Based Catalysts } \\
\end{array}$ & 2003 & $\begin{array}{l}\text { Dadyburjor, D.B., Li, Xianguo; } \\
\text { et.al. }\end{array}$ & $\begin{array}{l}\text { West Virginia University; Ocean } \\
\text { University of China }\end{array}$ & Molecules & $\begin{array}{l}\text { formation of alcohols at expense } \\
\text { of } C O \text { conversion; prereduced } \\
\text { rather than sulfided; getting lots of } \\
\text { HCs }\end{array}$ \\
\hline $\mathrm{N} / \mathrm{A}$ & $\begin{array}{l}\text { Co-Production of Fuel Alcohols \& } \\
\text { Electricity via Refinery Coke Gasification }\end{array}$ & 200 & $\begin{array}{l}\text { Ravikumar, Ravi; and } \\
\text { Shepard, Paul }\end{array}$ & Fluor & Gasification Technologies Conf & $\begin{array}{l}\text { Use of Power Energy Fuels Inc's } \\
\text { Ecalene process for mixed } \\
\text { alcohols synthesis in refinery } \\
\text { application (Pet Coke); modeling } \\
\text { and economic analysis }\end{array}$ \\
\hline
\end{tabular}




\begin{tabular}{|c|c|c|c|c|c|c|}
\hline 9519 & $\begin{array}{l}\text { The Influence of Clay on } \mathrm{K}_{2} \mathrm{CO}_{3} / \mathrm{Co} \text { - } \\
\text { MoS } \mathrm{Catalyst} \text { in the Production of } \\
\text { Higher Alcohol Fuel }\end{array}$ & 2002 & $\begin{array}{l}\text { Iranm ahboob, Jam shid; Hill, } \\
\text { Donald }\end{array}$ & Uconn, Mississippi State & $\begin{array}{l}\text { Fuel Processing Technology, } \\
\text { Elsevier }\end{array}$ & $\begin{array}{l}\text { Clay had significant impact on } \\
\text { HAS when K2CO3 present; } \\
\text { oxygenates selectivity of } 70 \% \text {; } \\
\text { testing of feed conditions }\end{array}$ \\
\hline 9536 & $\begin{array}{l}\text { Alcohol Synthesis from Syngas over } \\
\mathrm{K}_{2} \mathrm{CO}_{3} / \mathrm{CoS} / \mathrm{MoS}_{2} \text { on Activated Carbon }\end{array}$ & 2002 & $\begin{array}{l}\text { Iranmahboob, Jam shid; Hill, } \\
\text { Donald }\end{array}$ & Uconn, Mississippi State & Catalysis Letters & $\begin{array}{l}\text { Experimentation; Effects of Temp, } \\
\text { H2:CO, GHSV tested; fixed bed; } \\
\text { active chem icals on carbon } \\
\text { decreased surface area } \\
\text { dram atically }\end{array}$ \\
\hline 9528 & $\begin{array}{l}\text { Advances in Catalytic Synthesis and } \\
\text { Utilization of Higher Alcohols }\end{array}$ & 2000 & Herman, R.G. & Lehigh Univ. & Catalysis Today, Elsevier & $\begin{array}{l}\text { focus on oxygenates, particularly } \\
\text { isobutanol; slurry phase bed and } \\
\text { Double Bed designs; some } \\
\text { literature results and op conditions } \\
\text { reported; injection of EtOH may } \\
\text { promote HAS }\end{array}$ \\
\hline & $\begin{array}{l}\text { The Economical Production of Alcohol } \\
\text { Fuels from Coal-derived Synthesis Gas: } \\
\text { Final Report, October } 1991 \text { - March } \\
1998\end{array}$ & 1999 & & West Virginia University & $\begin{array}{l}\text { Submitted to National Energy } \\
\text { Technology Lab (NETL), } \\
\text { Contract \#DE-AC22-91PC } 91034 \text { - } \\
25\end{array}$ & $\begin{array}{l}7 \text { years of research on mixed } \\
\text { alcohols from MoS2 catalystsl; } \\
\text { extensive work; higher alcohol } \\
\text { selectivity }>40 \% \text {; productivity at } \\
-200 \mathrm{~g} / \mathrm{kg} / \mathrm{h} \text {; hydrocarbon selectivity } \\
<20 \% \text {; Use Coal feedstock }\end{array}$ \\
\hline 9545 & $\begin{array}{l}\text { Synthesis of Higher Alcohols - } \\
\text { Enancement by the Addition of } \\
\text { Mnthanol or Ethanol to the Syngas }\end{array}$ & 1999 & Lachowska, M. & Polish Academ y of Sciences & React.Kinet.Catal.Lett Elsevier & $\begin{array}{l}\text { Increase in C } 3+\text { alcohols using } \\
\text { modified methanol catalyst }\end{array}$ \\
\hline $\mathrm{N} / \mathrm{A}$ & $\begin{array}{l}\text { Formation of Ethanol and Higher } \\
\text { Alcohols from Syngas }\end{array}$ & 1999 & $\begin{array}{l}\text { Iranmahboob, Jam shid; } \\
\text { Donald Hill }\end{array}$ & Mississippi State University & $\begin{array}{l}\text { Mississippi State University, } \\
\text { Thesis Report }\end{array}$ & $\begin{array}{l}\text { Talk of biomass; MoS2; Ph. D. } \\
\text { Thesis; unsupported (K2CO3/Co- } \\
\text { MoS2), and supported on Clay. } \\
\text { Mention of methanol rem oval and } \\
\text { adsorption for kinetic driving force }\end{array}$ \\
\hline 9515 & $\begin{array}{l}\text { Selective Synthesis of Mixed Alcohols } \\
\text { Catalyzed by Dissolved Base-activated } \\
\text { Highly Dispersed Slurried Iron }\end{array}$ & 1999 & Mahajan, D. et.al. & Brookhaven National Laboratory & Fuel (Elsevier) & $\begin{array}{l}\text { UItrafine catalyst system, lower } \\
\text { temps }(250 \mathrm{C}) \text { and pres }(<6 \mathrm{MPa}) ; \\
\text { up to } 95 \% \text { selectivity (c1-c4 } \\
\text { alcohols); and } 80 \% \text { CO } \\
\text { Conversion; nanom eter iron oxides } \\
\text { "NANOCAT"; synthesis remains a } \\
\text { problem }\end{array}$ \\
\hline 9538 & $\begin{array}{l}\text { Synthesis of Short Chain Alcohols over } \\
\text { a Cs-promoted } \mathrm{Cu} / \mathrm{ZnO} / \mathrm{Cr}_{2} \mathrm{O}_{3} \text { catalyst }\end{array}$ & 1998 & $\begin{array}{l}\text { Majocchi, L.; Forzatti, Pio; } \\
\text { et.al. }\end{array}$ & $\begin{array}{l}\text { Politecnico di Milano; Snamprogetti } \\
\text { SpA }\end{array}$ & Applied Catalysis, Elsevier & $\begin{array}{l}\text { Effect of Temp, CO:H2 ratio, } \\
\text { GHSV. Temp is key to Alcohol } \\
\text { Productivity, 290 - } 315 \mathrm{C} \text { are best } \\
\text { for C2-C3; HC's minimized }\end{array}$ \\
\hline 9511 & $\begin{array}{l}\text { Higher Alcohols from Synthesis Gas } \\
\text { Using Carbon-Supported Doped } \\
\text { Molybdenum-Based Catalysts } \\
\end{array}$ & 1998 & $\begin{array}{l}\text { Xianguo Li; Dadyburjor, Dady } \\
\text { B.et.al. }\end{array}$ & West Virginia University & Ind. Eng. Chem. Res. (ACS) & $\begin{array}{l}\text { Studied catalyst prep parameters } \\
\text { and reaction conditions; catalyst } \\
\text { promoted } \mathrm{w} / \mathrm{K} \text { and/or Co }\end{array}$ \\
\hline 9537 & $\begin{array}{l}\text { A Kinetic Model for the Synthesis of } \\
\text { High-Molecular-W eight Alcohols over a } \\
\text { Sulfided Co-K-Mo/C Catalyst }\end{array}$ & 1998 & $\begin{array}{l}\text { Gunturu, A.K.; Dadyburjor, } \\
\text { D.B., et.al }\end{array}$ & West Virginia University & Ind. Eng. Chem. Res. (ACS) & $\begin{array}{l}\text { Kinetics, recycle reactor, temps } \\
\text { and feed variables explored; } \\
\text { includes rate expressions }\end{array}$ \\
\hline 9529 & $\begin{array}{l}\text { Development of a Process for Higher } \\
\text { Alcohol Production via Synthesis Gas }\end{array}$ & 1998 & Beretta, A.; Tronconi, E. et.al. & Politecnico di Milano; Snam progetti SpA & Ind. Eng. Chem. Res. (ACS) & $\begin{array}{l}\text { High-tem } p \text { catalyst; single-stage } \\
\text { adiabatic pilot scale reactor, } \\
\text { Kinetics developed; targeting } \\
\text { oxygenates, ethanol low; } \\
\text { simulation of multi-stage adiabatic } \\
\text { reactor }\end{array}$ \\
\hline 9530 & $\begin{array}{l}\mathrm{High} \mathrm{Temperature} \mathrm{Calcined} \mathrm{K-} \\
\mathrm{MoO}_{3} / \text { gamma- } \mathrm{Al}_{2} \mathrm{O}_{3} \text { Catalysts for Mixed } \\
\text { Alcohols Synthesis from Syngas: Effects } \\
\text { of Mo Loadings }\end{array}$ & 1998 & $\begin{array}{l}\text { Bian, Guo-zhu, et.al. (Univ. of } \\
\text { S\&T, China) }\end{array}$ & $\begin{array}{l}\text { University of Sci \& Tech, China; Univ of } \\
\text { Tokyo }\end{array}$ & Applied Catalysis, Elsevier & $\begin{array}{l}\text { total yields of mixed alcohols } \\
\text { decreased but selectivity increased } \\
\text { from } 3-50 \% ; m \text { ainly linear } \mathrm{C} 1-\mathrm{C} 4, \\
\text { small amt iso-C4 }\end{array}$ \\
\hline 9514 & $\begin{array}{l}\text { Kinetic Analysis of Mixed Alcohol } \\
\text { Synthesis from Syngas over K/MoS } \\
\text { Catalyst }\end{array}$ & 1997 & Park, T.Y.; Nam, In-sik, et.al. & $\begin{array}{l}\text { Pohang Univ. of Sci. \& Tech (Postech), } \\
\text { Korea }\end{array}$ & Ind. Eng. Chem Res. (ACS) & $\begin{array}{l}\text { K2CO3-promoted-MOS2; } \\
\text { mechanistic kinetics models; } \\
\text { mixed alcohol formation } \\
\text { maxim ized around } 320 \mathrm{C}\end{array}$ \\
\hline 9518 & $\begin{array}{l}\text { Synthesis of Mixed Alcohols from } \mathrm{CO}_{2} \\
\text { contained syngas on supported } \mathrm{MoS}_{2} \\
\text { catalysts }\end{array}$ & 1997 & Gang, Lu, et.al. & East China University of Sci \& Tech & Applied Catalysis, Elsevier & $\begin{array}{l}\text { CO2 in feed inhibits higher } \\
\text { alcools s p product distribution } \\
\text { strongly influenced by } \mathrm{CO} 2 \text { and } \\
\mathrm{H} 2 \mathrm{O} \text { in feed; high } \mathrm{H} 2 \mathrm{CO} \text { ratio } \\
\text { used; } 0-100 \text { ppm H2S }\end{array}$ \\
\hline
\end{tabular}




\begin{tabular}{|c|c|c|c|c|c|c|}
\hline 9524 & $\begin{array}{l}\text { Development of a Mechanistic Kinetic } \\
\text { Model of the Higher Alcohol Synthesis } \\
\text { over a Cs-doped Zn/Cr/O Catalyst - 1) } \\
\text { Model Derivation and Data Fitting }\end{array}$ & 1996 & Beretta, A.; Forzatti, Pio, et.al. & Politecnico di Milano; Snamprogetti SpA & Ind. Eng. Chem. Res. (ACS) & $\begin{array}{l}\text { Kinetics model; goal is branched } \\
\text { alcohols, not linear because of } \\
\text { better octane properties }\end{array}$ \\
\hline 9525 & $\begin{array}{l}\text { A Kinetic Model for the Methanol-Higher } \\
\text { Alcohol Synthesis from } \mathrm{CO} / \mathrm{CO}_{2} / \mathrm{H}_{2} \text { over } \\
\text { Cu/ZnO-based Catalysts Including } \\
\text { Simultaneous Formation of Methyl } \\
\text { Esters and Hydrocarbons }\end{array}$ & 1994 & $\begin{array}{l}\text { Breman, B.B.; Beenackers, } \\
\text { A.C.C.M.; et.al. }\end{array}$ & $\begin{array}{l}\text { University of Groningen, The } \\
\text { Netherlands }\end{array}$ & $\begin{array}{l}\text { Chemical Engineering Science, } \\
\text { Pergamon }\end{array}$ & $\begin{array}{l}\text { Overview of past work on modified } \\
\text { methanol catalysts and Kinetics; } \\
\text { methanol primary product; claims } \\
\text { to be most accurate kinetics } \\
\text { models to date; substantial HC's } \\
\text { produced as unwanted byprod. }\end{array}$ \\
\hline 9526 & $\begin{array}{l}\text { Thermodynam ics of Higher Alcohol } \\
\text { Synthesis }\end{array}$ & 1993 & $\begin{array}{l}\text { Mawson, S.; Roberts, G.W.; } \\
\text { et.al. }\end{array}$ & North Carolina State & Energy \& Fuels & $\begin{array}{l}\text { Aspen Plus simulation using } \\
\text { RGIBBS; C4 alcohols are } \\
\text { dominant product, especially as } \\
\text { isobutyl; conversions }>90 \% ; \\
\text { Thermodynamics }\end{array}$ \\
\hline 11636 & $\begin{array}{l}\text { SiO2-supported Biometallic Ruthenium } \\
\text { Cluster-derived Catalysts for Selectivity } \\
\text { and Activity Control in CO } \\
\text { Hydrogenation Toward C1-C5 Alcohols }\end{array}$ & 1992 & Xiao, F.; Ichikawa, M.; et.al. & Hokkaido University & $\begin{array}{l}\text { Journal of Molecular Catalysis, } \\
\text { Elsevier }\end{array}$ & Ruthenium Catalyst; \\
\hline 9517 & $\begin{array}{l}\text { The Thermodynamics of Higher Alcohol } \\
\text { Synthesis }\end{array}$ & 1992 & Roberts, G.W., et.al. & North Carolina State & $\begin{array}{l}\text { Sym posium on NG upgrading II, } \\
\text { Division of Petroleum Chem, } \\
\text { Inc., ACS }\end{array}$ & $\begin{array}{l}\text { Basically same info as presented } \\
\text { in } 1993 \text {, }\end{array}$ \\
\hline 9523 & $\begin{array}{l}\text { An Overview of the Higher Alcohol } \\
\text { Synthesis }\end{array}$ & 1992 & Smith, K.; Klier, K. & Univ. British Columbia; Lehigh & $\begin{array}{l}\text { Symposium on NG upgrading II, } \\
\text { Division of Petroleum Chem, } \\
\text { inc., ACS }\end{array}$ & $\begin{array}{l}\text { Good brief review on catalyst } \\
\text { choices and Operating Conditions } \\
\text { at that time, including } \mathrm{Rh} / \mathrm{SiO} 2 ; \\
\text { target for octane seemed to be } \\
70: 30 \mathrm{c} 2+/ \mathrm{c} 1 \text { (required for gasoline } \\
\text { blending?) }\end{array}$ \\
\hline 9521 & $\begin{array}{l}\text { Non-Stoichiometric Spinel-type } \\
\text { Catalysts for the Synthesis of Methanol } \\
\text { and Higher Alcohols }\end{array}$ & 1992 & Trifiro, F., et.al. & $\begin{array}{l}\text { Dipartimento di Chimica Industriale e dei } \\
\text { materiali, Bologna, Italy }\end{array}$ & $\begin{array}{l}\text { Symposium on Octane and } \\
\text { Cetane Enhancement } \\
\text { Processes for Reduced- } \\
\text { i emissions Motor Fuels, Division } \\
\text { of Petroleum Chemistry, ACS }\end{array}$ & $\begin{array}{l}\text { Non-stoichiometric spinel-type } \\
\text { solid oxides; again shows } \\
\text { propensity of K to shift towards } \\
\text { higher alcohols }\end{array}$ \\
\hline 11632 & $\begin{array}{l}\text { The Conversion of Synthesis Gas to } \\
\text { Higher Oxygenated Fuel on Rh-based } \\
\text { Catalysts: Effect of Chemical Additives }\end{array}$ & 1991 & $\begin{array}{l}\text { Balakos, M.W., Chaung, S. S. } \\
\text { C, }\end{array}$ & University of Akron & $\begin{array}{l}\text { Fuel Science and Technology } \\
\text { International }\end{array}$ & $\begin{array}{l}\text { Rhodium catalyst, high selectivities } \\
\text { to } \mathrm{CH} 4 \& \text { C } 2+\text { Oxygenates }\end{array}$ \\
\hline 9522 & Higher Alcohol Synthesis & 1991 & Forzatti, Pio, et.al. & $\begin{array}{l}\text { Politecnico di Milano; Snamprogetti } \\
\text { SpA }\end{array}$ & Catal. Rev. - Sci. Eng & $\begin{array}{l}\text { Extensive writeup (book chapter?) } \\
\text { on status of HAS catalysts; } \\
\text { includes kinetics and } \\
\text { thermodynamics; and commercial } \\
\text { designs from Lurgi, IFP, } \\
\text { Snamprogetti } \\
\end{array}$ \\
\hline & $\begin{array}{l}\text { Production of Oxygenates from } \\
\text { Synthesis Gas: A Technology Review } \\
\text { for US Dept of Energy for Design of } \\
\text { Generic Coal conversion Facilities }\end{array}$ & 1991 & $\begin{array}{l}\text { Pittsburgh Energy Technology } \\
\text { Center }\end{array}$ & M.W. Kellogg Company & Contract \#DE-AC22-91PC89854 & $\begin{array}{l}\text { Oxygenates overview, including } \\
\text { mixed alcohols; discuss dow } \\
\text { technology as } 85 \% \text { selectivity and } \\
\text { CO perpass conversion of } 20- \\
25 \% \text {; effect of catalyst additives } \\
\end{array}$ \\
\hline & $\begin{array}{l}\text { Classical and Non-classical Routes for } \\
\text { Alcohol Synthesis }\end{array}$ & 1991 & Herman, R.G. & Lehigh University & $\begin{array}{l}\text { Book Chapter, New Trends in } \\
\text { co Activation, L. Guczi, Ed. } \\
\text { Elsevier }\end{array}$ & $\begin{array}{l}\text { Impressive summary of state of } \\
\text { mixed alcohols technology. } \\
\text { Includes detailed kinetics work and } \\
\text { experimental results to date }\end{array}$ \\
\hline 9539 & $\begin{array}{l}\text { Catalytic Conversion of Synthesis Gas } \\
\text { to Methanol and Other Oxygenated } \\
\text { Products }\end{array}$ & 1991 & Stiles, Alvin, et.al. & University of Delaware & Ind. Eng. Chem. Res.; ACS & $\begin{array}{l}\text { Experiments, bench-scale, high } \\
\text { aldehyde production based on } \\
\text { conditions; benchmark established } \\
\text { on pure methanol; alkaline earth \& } \\
\text { cobalt additives }\end{array}$ \\
\hline 9531 & $\begin{array}{l}\text { Kinetic Modelling of Higher Alcohol } \\
\text { Synthesis over Alkali-promoted Cu/Zno } \\
\text { and } \mathrm{MoS}_{2} \text { Catalysts }\end{array}$ & 1990 & Smith, K. Herman, R.; Klier, K. & Lehigh University & Chemical Engineering Science & $\begin{array}{l}\text { Kinetics of both modified FT \& } \\
\text { modified MeOH; different reaction } \\
\text { pathways for each }\end{array}$ \\
\hline
\end{tabular}




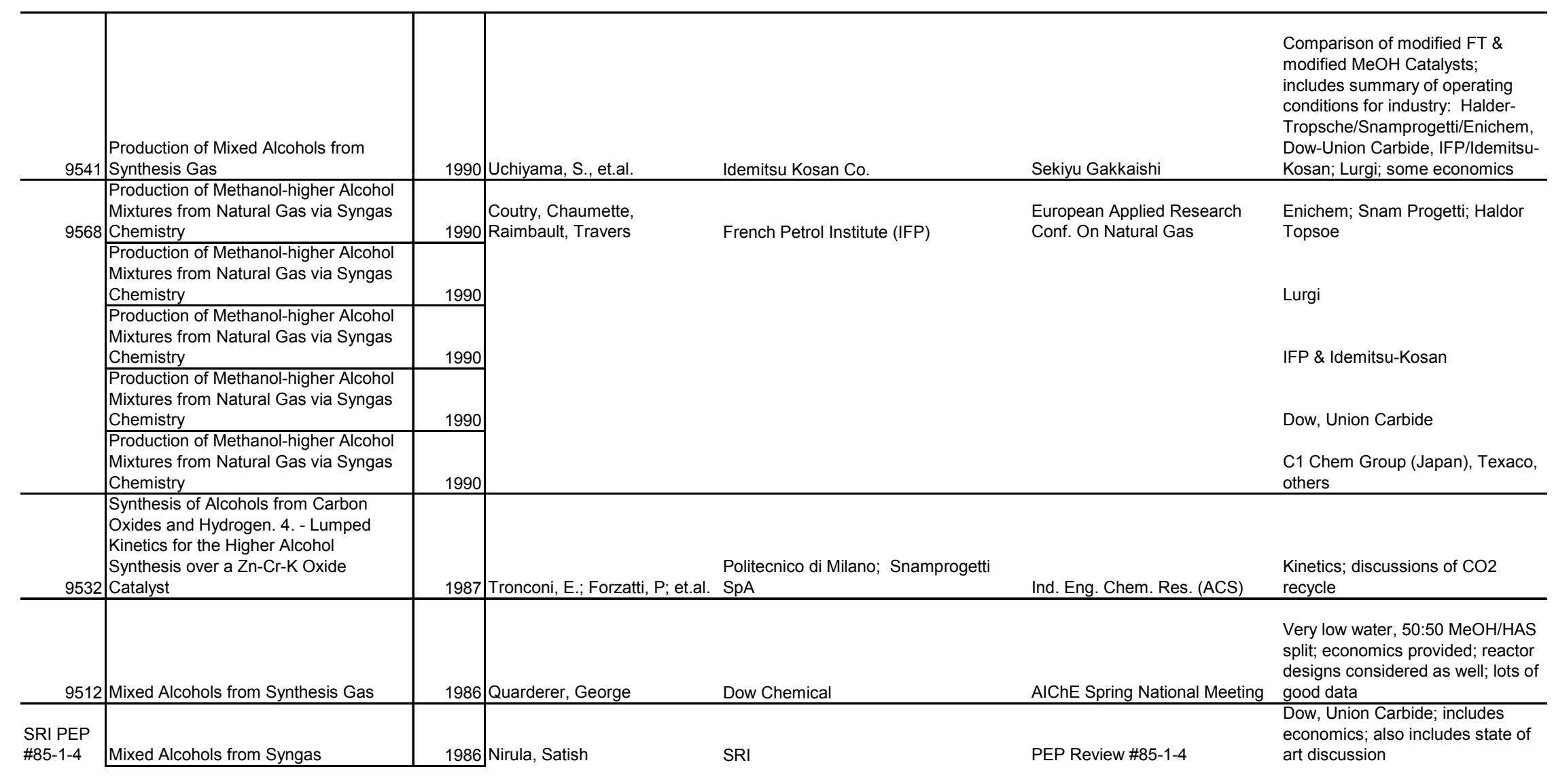




\section{Appendix K}

Alcohol Synthesis Kinetics 
A more rigorous method for modeling the production of alcohols or other products via synthesis is to use kinetics-based reactions to represent the multiple reactions that occur. Used with the appropriate reactor type, a good kinetics-based model can more accurately predict the effect of varying inlet conditions to the synthesis reactor, especially when unconverted syngas or unwanted co-products (i.e., methanol, hydrocarbons) are recycled to the reactor inlet.

Two major barriers to using kinetics-based models are 1) the need for high-quality experimental data to determine the many parameters required for accurate predictions - assuming that a suitable model can be found for the system of equations - and 2) even with data suitable for estimating model parameters, the resulting model is only truly representative of the catalyst used in the experiments over the range of operating conditions explored. Using the model outside the range of operating conditions introduces increased uncertainty the more removed the estimate is from the experimental conditions used to develop the model. Catalyst performance is very sensitive to many factors that can arise during their production. Two seemingly identical catalysts based on chemical formulation can vary greatly in performance because of preparation techniques and catalyst support characteristics (surface area, crystal structure).

Heterogeneous catalysts such as those used in most synthesis work today, are very sensitive to a number of factors including supports, amounts and types of added promoters or inhibitors that help tune the catalyst to promote desired reactions while inhibiting undesirable reactions. An "optimum" catalyst is usually a compromise of competing and interacting promoters, inhibitors, and supports to give a catalyst with the "best" cumulative properties. When precious metals are used, economics also become a major factor in determining the catalyst formulation.

Very little published data exist for the $\mathrm{MoS}_{2}$-based catalysts that are suitable for developing a reasonable model of the alcohol synthesis together with the very important competing reactions that reduce the desired product yields. Gunturu (Gunturu, et al., 1998; Gunturu, 1997; Gunturu, et al., 1999) published relevant data from thesis work done at the University of West Virginia. The data were used to develop a system of Langmuir-Hinshelwood type reactions to describe a five-reaction lumped kinetic scheme. Recently, researchers in Italy, using the same data, generated a model using the same reaction scheme but with slightly different equations and parameters. The procedure for estimating the parameters is not discussed here, but can be found in detail in Larson, et al. (Larson, et al., 2006) and are presented here in Table 1. 
Table 1. Kinetic parameter estimates from Larson, et al. Blank cells do not have values for the corresponding rate equation parameter and rate equation.

\begin{tabular}{|c|c|c|c|c|}
\hline Parameter & Methanol & Ethanol & Propanol & Hydrocarbons \\
\hline $\mathrm{A}_{\mathrm{m}}, \mathrm{A}_{\mathrm{e}}, \mathrm{A}_{\mathrm{p}}, \mathrm{A}_{\mathrm{h}}$ & 14.6233 & 3.0518 & 0.2148 & 9.3856 \\
\hline $\mathrm{E}_{\mathrm{m}}, \mathrm{E}_{\mathrm{e}}, \mathrm{E}_{\mathrm{p}}, \mathrm{E}_{\mathrm{h}}$ & 143.472 & 24.986 & 89.3328 & 95.416 \\
\hline $\mathrm{n}_{\mathrm{m}}, \mathrm{n}_{\mathrm{e}}, \mathrm{n}_{\mathrm{p}}, \mathrm{n}_{\mathrm{h}}$ & 3 & 1 & 1 & 1 \\
\hline $\mathrm{K}_{1}$ & $7.6393 \mathrm{E}-9$ & & & \\
\hline $\mathrm{K}_{2}$ & 0.6785 & & & \\
\hline $\mathrm{K}_{3}$ & 0.9987 & & & \\
\hline $\mathrm{K}_{\mathrm{e}}$ & & 0.7367 & & \\
\hline $\mathrm{K}_{\mathrm{p}}$ & & & 0.6086 & \\
\hline $\mathrm{K}_{\mathrm{h}}$ & & & & 1.2472 \\
\hline $\mathrm{K}_{\mathrm{z}}$ & 0.8359 & & & \\
\hline
\end{tabular}

The rate equations were created using the typical Langmuir-Hinshelwood kinetic approach found in most catalyst kinetics textbooks. Equation 1 is the gross rate of methanol production. It is the only rate equation in the set that has a reverse reaction component and therefore an equilibrium value. Chemical equilibrium is reached when the partial pressure of methanol is sufficiently high to cause the reverse reaction rate, the dissociation of methanol to $\mathrm{CO}$ and $\mathrm{H}_{2}$, plus the consumption rate of methanol to other products, to equal the forward reaction rate of $\mathrm{CO}$ and $\mathrm{H}_{2}$ to make methanol. Given sufficient time in an active catalyst bed, the methanol concentration will reach an equilibrium state. The equilibrium value will include the effects of methanol being consumed to make ethanol or methane as described by equations 4 and 6 , respectively.

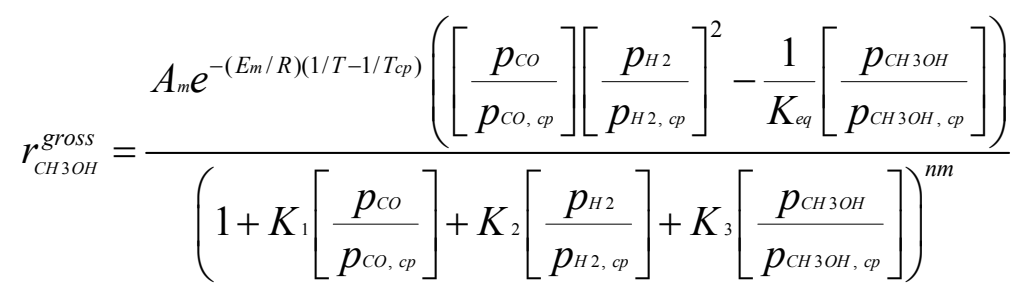

where

and

$$
\begin{gathered}
K_{c p}=\frac{p_{с н з о н, c p}}{p_{c o, c p}\left(p_{H 2, c p}\right)^{2}} \\
K_{e q}=\frac{K_{a}}{K_{2} K_{c p}}
\end{gathered}
$$




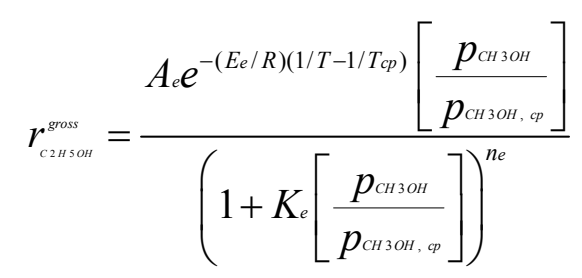

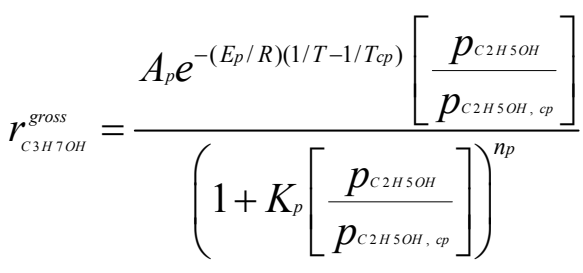

$$
r_{H C}^{\text {gross }}=\frac{A_{h} e^{-(E h / R)\left(1 / T-1 / T_{c p)}\right)}\left[\frac{p_{\text {СH } 3 О \mathrm{H}}}{p_{\mathrm{CH} 3 \mathrm{OH}, c p}}\right]}{\left(1+K_{h}\left[\frac{p_{\text {СH } 3 \mathrm{OH}}}{p_{\mathrm{CH} 3 \mathrm{OH}, \mathrm{cp}}}\right]\right)^{n h}}
$$

The other rate equations describe presumed irreversible reactions of methanol to ethanol, ethanol to propanol, and methanol to methane. Ethanol can react further with $\mathrm{H}_{2}$ and $\mathrm{CO}$ to make propanol. Implicit in this set of equations is the simplifying assumption that any products generated other than methanol, ethanol or propanol produce methane even though in higher molecular weight hydrocarbons are observed experimentally. Small amounts of butanol and pentanol, both expected and experimentally observed, have been ignored in the analysis since $\mathrm{CO}$ conversions were low resulting in minimal production of increasingly higher alcohols.

Using the rate equations above, plus a rate equation for the water-gas-shift reaction, a system of differential equations and initial conditions can be easily written for a plug flow reactor, as in this report, or for a Continuous Stirred Tank Reactor (CSTR). The solution of the system of ordinary differential equations was programmed into the commercially available equation solver, PolyMath, to evaluate the kinetics over a range of conditions.

Examples of the results given by the model are shown in Figure 1 and Figure 2. In the first case the methanol rate reaches a constant value quickly meaning it is consumed at the same rate it is produced. In the second case methanol was "added" to the reactor inlet to make $1 \mathrm{~mol} \%$ concentration. $\mathrm{CO}$ and $\mathrm{H}_{2}$ inlet flow was reduced equally to keep molar inlet flow the constant. The methanol has a negative rate of production initially and then reaches a constant flow rate at a value slightly below $2000 \mathrm{lb} / \mathrm{hr}$. The ethanol flow rate is significantly higher than the case with no methanol added to the feed. 
Mass Flows vs CO Conversion

Temp = 570K; Pressure $=68 \mathrm{~atm}$

$\mathrm{FH} 2=25000 \mathrm{Kmol} / \mathrm{hr} ; \mathrm{FCO}=25000 \mathrm{Kmol} / \mathrm{hr} ; \mathrm{Fmeoh}=0 \mathrm{Kmol} / \mathrm{hr}$

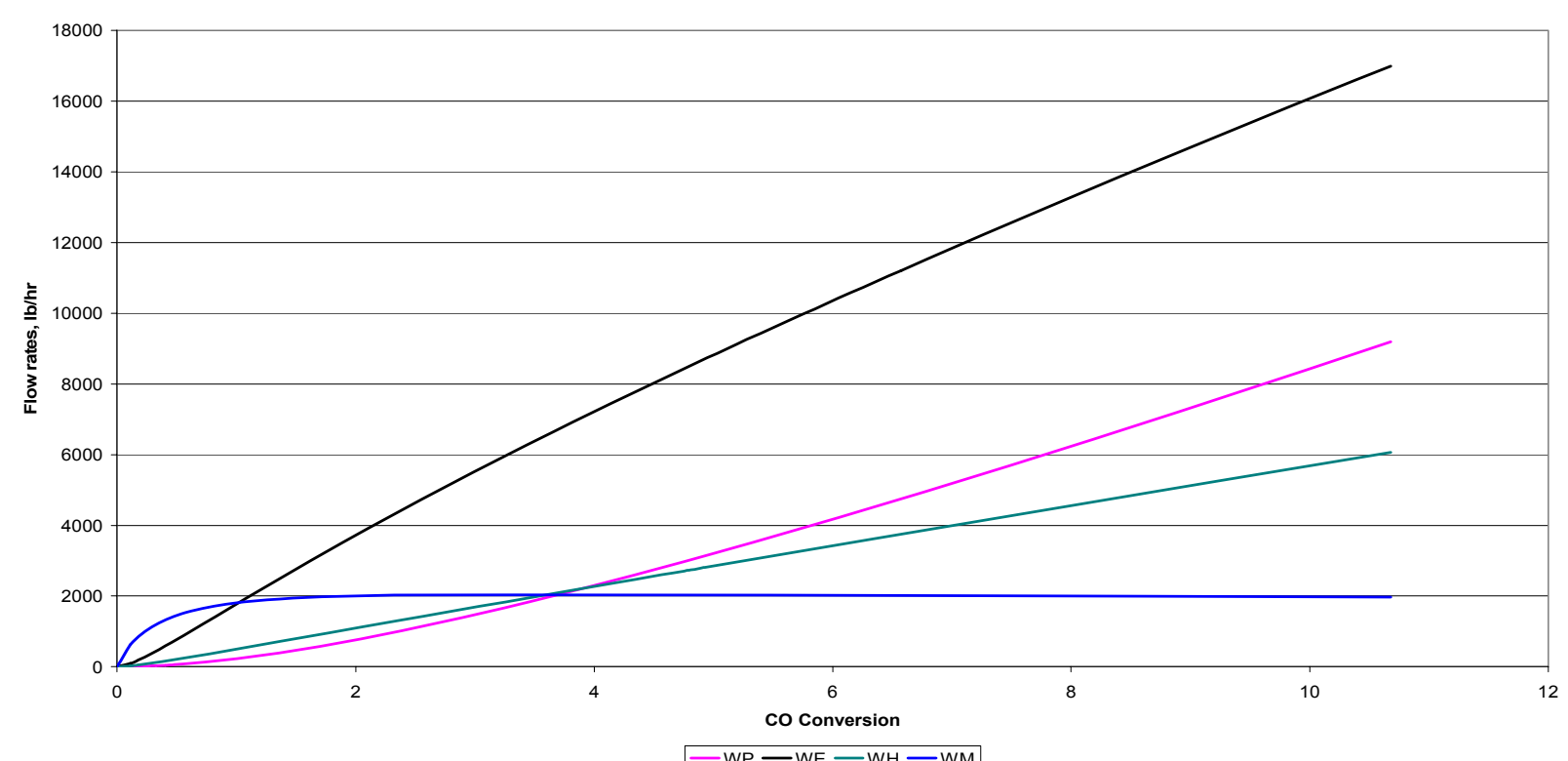

Figure 1. Mass Flow Rates of the Synthesis Reactions vs. CO Conversion in a Isothermal, Plug-Flow Reactor at a WHSV of 1000 L-kgcat $^{-1}-\mathrm{hr}^{-1}$

Mass Flows vs CO Conversion

Temp $=570 \mathrm{~K} ;$ Pressure $=68 \mathrm{~atm}$

$\mathrm{FH} 2=24750 \mathrm{Kmol} / \mathrm{hr} ; \mathrm{FCO}=24750 \mathrm{Kmol} / \mathrm{hr} ; \mathrm{Fmeoh}=500 \mathrm{Kmol} / \mathrm{hr}$

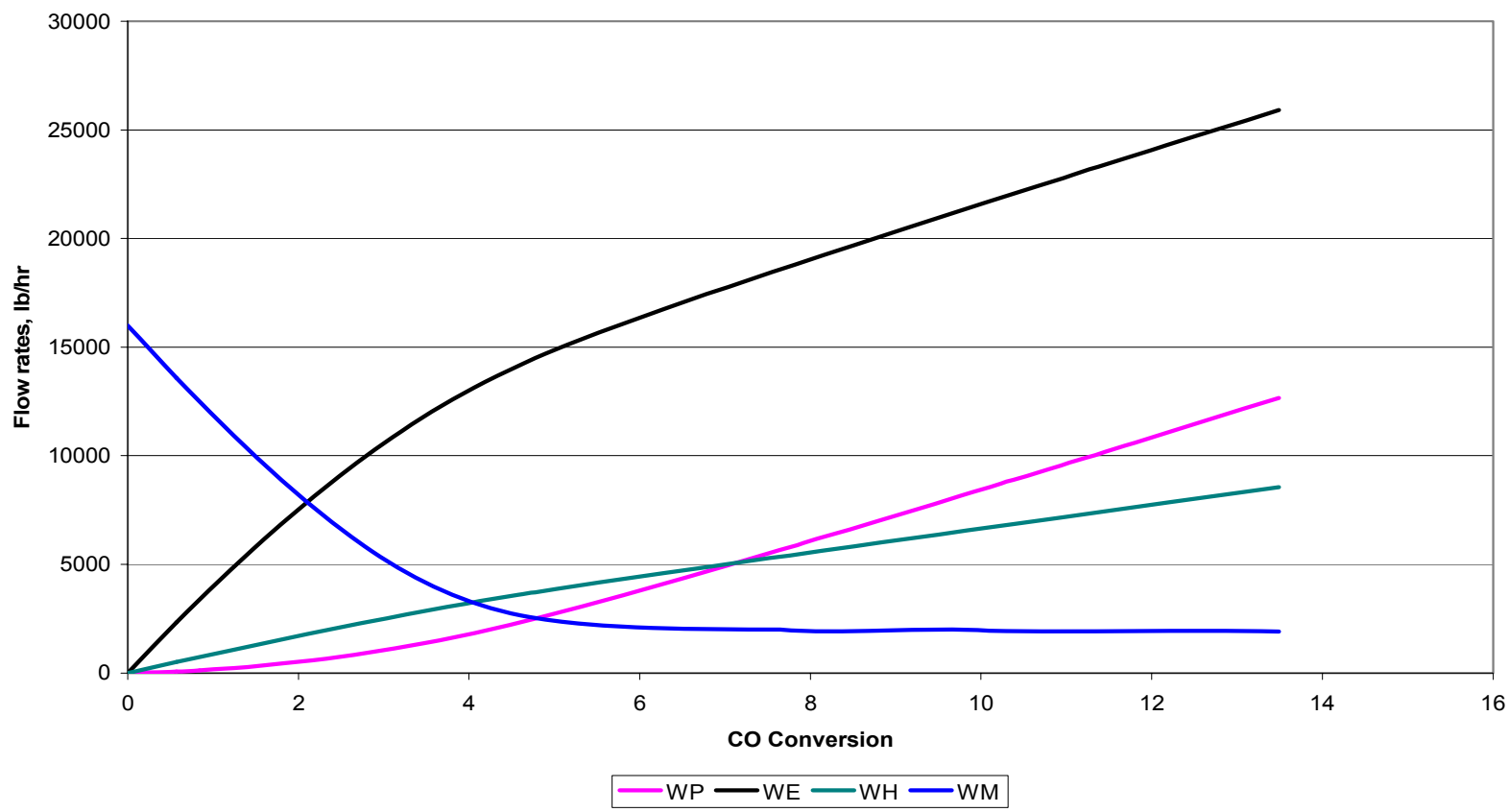

Figure 2. Mass Flow Rates of the Synthesis Reactions vs. CO Conversion in a Isothermal, Plug-Flow Reactor at a WHSV of 1000 L-kgcat $^{-1}-\mathrm{hr}^{-1}$ 
For the catalyst used to develop this model, the $\mathrm{CO}$ conversion is relatively low at $570 \mathrm{~K}$ and 68 atm pressure. With no methanol recycle to the reactor, the CO conversion is $10.7 \%$ with an ethanol yield of $17000 \mathrm{lb} / \mathrm{hr}$. Adding methanol to the reactor inlet increases the CO conversion to $13.5 \%$ with an ethanol yield of $25,900 \mathrm{lb} / \mathrm{hr}$. Adding methanol to the synthesis reactor appears to improve the catalyst performance for making ethanol. However, there is insufficient methanol exiting the reactor to meet the inlet demands. At this temperature and pressure, a lower inlet methanol concentration is needed to be sustainable in a process without modifying the process to produce more methanol.

Values of $\mathrm{CO}$ conversion and product rates at the reactor outlet for a plug flow reactor at 68 , with and without methanol added to the inlet, are given in Error! Reference source not found. for the kinetic model. The first column is for no methanol added to the inlet stream. The second column has $1 \mathrm{~mol} \%$ methanol in the inlet. The GHSV is approximately $1000 \mathrm{~L}-\mathrm{kgcat}^{-1}-\mathrm{hr}^{-1}$ for all cases shown, which is significantly less than the experimental condition at which the kinetic parameters were estimated for the kinetic models.

Table 2. Results From the Kinetic Model at 68 atm Pressure

\begin{tabular}{|c|c|c|}
\hline & MeOH @ inlet $=\mathbf{0} \mathbf{~ K m o l} / \mathbf{h r}$ & $\mathbf{M e O H} @$ inlet $=\mathbf{5 0 0} \mathbf{~ K m o l} / \mathbf{h r}$ \\
\hline $570 \mathrm{~K}$ & $\mathrm{XCO}=5.67$ & $\mathrm{XCO}=6.38$ \\
& $\mathrm{MeOH}=2023$ & $\mathrm{MeOH}=1974$ \\
& $\mathrm{CH}_{4}=3237$ & $\mathrm{CH}_{4}=5770$ \\
& $\mathrm{EtOH}=9861$ & $\mathrm{EtOH}=19600$ \\
$610 \mathrm{~K}$ & $\mathrm{PrOH}=3851$ & $\mathrm{PCH}=6543$ \\
& $\mathrm{XCO}=27.08$ & $\mathrm{MeOH}=4197$ \\
& $\mathrm{MeOH}=4282$ & $\mathrm{CH}=28800$ \\
& $\mathrm{CH}_{4}=26400$ & $\mathrm{EtOH}=28300$ \\
& $\mathrm{EtOH}=25600$ & $\mathrm{PrOH}=23800$ \\
\hline
\end{tabular}

At $570 \mathrm{~K}$, adding methanol to the inlet gas causes the rates of ethanol and propanol production to increase significantly with little change in the $\mathrm{CO}$ conversion. The methanol equilibrium rate is approximately $2000 \mathrm{Kmol} / \mathrm{hr}$ at this temperature. Increasing the temperature to $610 \mathrm{~K}$ greatly increases the conversion of $\mathrm{CO}$ and of the product yields. However, the methane production has increased relative to higher alcohols. The effect of adding methanol at $610 \mathrm{~K}$ is less pronounced than at $570 \mathrm{~K}$. The $\mathrm{CO}$ conversion decreases slightly and the alcohol yields are only slightly increased. The methanol equilibrium rate has increased at $610 \mathrm{~K}$ to approximately $4200 \mathrm{Kmol} / \mathrm{hr}$. In the "methanol added" cases shown, there is insufficient methanol exiting the reactor to supply the inlet after separating the methanol from the other alcohols. A sustainable level would be reached using a lower methanol concentration at the inlet. Higher conversion can also be achieved by decreasing the GHSV although this will require a larger reactor and more catalyst. The optimum combination involves economics to determine when it is infeasible to increase the capital and catalyst costs to increase production.

The effect of adding methanol on the ethanol yield suggests that other configurations may be more effectively used to maximize ethanol production. Since the methanol production at the 
reactor exit is limited by chemical equilibrium, the amount of methanol that can be recycled to the reactor is also limited. Instead of recycling only methanol produced from a mixed alcohol catalyst, it may be possible to economically split the main syngas flow with one portion going to a methanol synthesis reactor to make methanol and the remaining fraction going to the mixed alcohol reactor where the methanol is added to the syngas before entering the reactor. It could also be possible to do the reaction in series with the total syngas going through a methanol synthesis catalyst first followed the mixed alcohol catalyst. The methanol catalyst section would need to be sized to give only partial conversion to methanol, contrary to the way these reactors are typically operated when methanol is the desired end product. These alternate designs would require other factors to be considered, such as lower sulfur and $\mathrm{CO}_{2}$ concentrations for methanol synthesis relative to the mixed alcohol catalyst used.

As more data become available, the kinetic model can be updated to include different catalysts and expanded operation ranges, especially in regards to the amount of methanol and $\mathrm{CO}_{2}$ that can be fed to the reactor without adversely affecting product selectivity and $\mathrm{CO}$ conversion.

\section{References}

Gunturu, A.; et.al. "A Kinetic Model for the Synthesis of High-Molecular-Weight Alcohols over a Sulfided Co-K-Mo/C Catalyst." Ind. Eng. Chem. Res. Vol. 37, 1998. pp. 2107 - 2115.

Gunturu, A.K., Kugler, E.L., Cropley, J.B., Dadyburjor, D.B., "A Kinetic Model for the Synthesis of High-Molecular-Weight Alcohols over a Sulfided Co-K-Mo/C Catalyst", Chapter 5 in "The Economical Production of Alcohol Fuels from Coal-Derived Synthesis Gas", Final Report, Contract \# DE-AC22-91PC91034-25, West Virginia University Research Corporation on behalf of West Virginia University, March 1999.

Gunturu, A.K., "Higher-Alcohol Synthesis from Carbon Monoxide and Hydrogen: Kinetic Studies Over MoS2-Based Catalysts", M.S. Thesis in Chemical Engineering, West Virginia University, Morgantown, West Virginia, 1997.

Larson, E.D., Consonni, S., Katofsky, R.E., Iisa, K. Frederick, J., “A Cost-Benefit Assessment of Gasification-Based Biorefining in the Kraft Pulp and Paper Industry, Volume 2, Detailed Biorefinery Design and Performance Simulation", Final Report under contract DE-FC2604NT42260 with the U.S. Department of Energy and with cost-sharing by the American Forest and Paper Association, December 2006. 


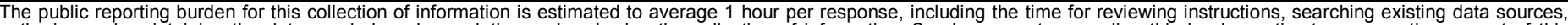

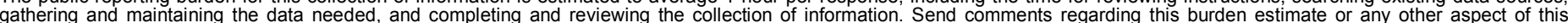

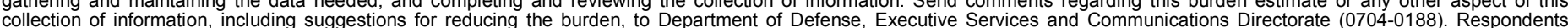

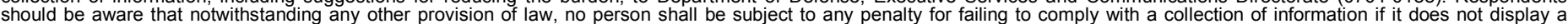

should be aware that notwithstanding

PLEASE DO NOT RETURN YOUR FORM TO THE ABOVE ORGANIZATION.

\begin{tabular}{l|l|l|l} 
1. REPORT DATE $(D D-M M-Y Y Y Y)$ & 2. REPORT TYPE & 3. DATES COVERED (FrOm - TO)
\end{tabular}

April 2007

Technical Report

4. TITLE AND SUBTITLE

Thermochemical Ethanol via Indirect Gasification and Mixed Alcohol

Synthesis of Lignocellulosic Biomass

5a. CONTRACT NUMBER

DE-AC36-99-G010337

5b. GRANT NUMBER

5c. PROGRAM ELEMENT NUMBER

6. AUTHOR(S)

S. Phillips, A. Aden, J. Jechura, D. Dayton, and T. Eggeman

5d. PROJECT NUMBER

NREL/TP-510-41168

5e. TASK NUMBER

BB07.3710

5f. WORK UNIT NUMBER

7. PERFORMING ORGANIZATION NAME(S) AND ADDRESS(ES)

National Renewable Energy Laboratory

1617 Cole Blvd.

8. PERFORMING ORGANIZATION REPORT NUMBER

Golden, CO 80401-3393

NREL/TP-510-41168

9. SPONSORING/MONITORING AGENCY NAME(S) AND ADDRESS(ES)

10. SPONSOR/MONITOR'S ACRONYM(S)

NREL

11. SPONSORING/MONITORING AGENCY REPORT NUMBER

12. DISTRIBUTION AVAILABILITY STATEMENT

National Technical Information Service

U.S. Department of Commerce

5285 Port Royal Road

Springfield, VA 22161

13. SUPPLEMENTARY NOTES

14. ABSTRACT (Maximum 200 Words)

This process design and technoeconomic evaluation addresses the conversion of biomass to ethanol via

thermochemical pathways that are expected to be demonstrated at the pilot level by 2012 .

15. SUBJECT TERMS

process design; thermochemical; pilot; cellulosic; ethanol

\begin{tabular}{|c|c|c|}
\hline 6. SECURIT & CLASSIFICATI & N OF: \\
\hline $\begin{array}{l}\text { a. REPORT } \\
\text { Unclassified }\end{array}$ & $\begin{array}{l}\text { b. ABSTRACT } \\
\text { Unclassified }\end{array}$ & $\begin{array}{l}\text { c. THIS PAGE } \\
\text { Unclassified }\end{array}$ \\
\hline
\end{tabular}

\begin{tabular}{|c|c|}
\hline $\begin{array}{l}\text { 17. LIMITATION } \\
\text { OF ABSTRACT }\end{array}$ & $\begin{array}{l}\text { 18. NUMBER } \\
\text { OF PAGES }\end{array}$ \\
\hline UL & \\
\hline
\end{tabular}

19a. NAME OF RESPONSIBLE PERSON

19b. TELEPHONE NUMBER (Include area code) 